\title{
A FRAMEWORK FOR REDUCING GREENHOUSE GAS (GHG) EMISSIONS THROUGH CARBON PRICING FOR OFFSHORE OUTSOURCING
}

by

\begin{abstract}
Amulya Gurtu
Master of Business Administration - University of Western Ontario, Canada, 2007

Master of Technology - Barkatullah (formerly Bhopal) University, India, 1995
\end{abstract}

A dissertation presented to Ryerson University in partial fulfillment of the requirements for the degree of Doctor of Philosophy in the Program of Mechanical \& Industrial Engineering

Toronto, Ontario, Canada, 2014

(C) Amulya Gurtu 2014 


\section{AUTHOR'S DECLARATION}

I hereby declare that I am the sole author of this dissertation. This is a true copy of the dissertation, including any required final revisions, as accepted by my examiners.

I authorize Ryerson University to lend this dissertation to other institutions or individuals for the purpose of scholarly research.

I further authorize Ryerson University to reproduce this dissertation by photocopying or by other means, in total or in part, at the request of other institutions or individuals for the purpose of scholarly research.

I understand that my dissertation may be made electronically available to the public. 
Dissertation title : A framework for reducing greenhouse gas (GHG) emissions through carbon pricing for offshore outsourcing

Degree (Year) : Doctor of Philosophy in Mechanical and Industrial Engineering (2014)

Name : Amulya Gurtu

Graduate program : Mechanical and Industrial Engineering

University $\quad$ : Ryerson University, Toronto, Canada

\section{ABSTRACT}

Reducing supply chain costs is a primary concern of every organization. Organizations have implemented offshore outsourcing as an effective strategy towards reducing supply chain costs. However, neither government nor corporate organizations have sufficiently taken into account the effects of this strategy on global greenhouse gas (GHG) emissions.

The purpose of this research is to analyze the impact of offshore outsourcing on global GHG emissions, and the effect of changes in fuel prices in addition to a carbon price on additional emissions on supply chain costs. The purpose is supported by five key objectives. The objectives are addressed through a systematic methodology. The analysis is supported by a literature review, and the development and testing of mathematical models. Finally, a framework to reduce global GHG emissions through a carbon price on differential emissions from manufacturing and additional emissions from international transportation is proposed.

The findings suggest that offshore outsourcing has increased global emissions. The fuel prices are increasing at a rate higher than the overall rate. A carbon price on excess emissions due to outsourcing coupled with increasing fuel prices impacts supply chain costs adversely and leads to bigger lot-sizes. As an illustration at the national level, the framework showed that emissions for the USA increased by about 20\% for every year between 2007 and 2010. As another example from a corporate organization, the net profit (profit after tax) for Wal-Mart was reduced by about 19\% for 2006 due to a carbon price on manufacturing emissions alone. 
The suggested framework is a major contribution for quantifying the extent of changes in the emissions due to offshore outsourcing and the value of these emissions at a prevailing rate of carbon tax in North America. It is intended to provide a basis for reducing emissions and costs from global supply chains. The proposed framework provides a level playing field to manufacturers in different countries using different technologies, provides incentives to organizations for manufacturing in locations where net emissions are low, helps national governments determine how they can generate revenue for dealing with emissions, and, most importantly, aids in reducing overall global GHG emissions. 


\section{ACKNOWLEDGEMENTS}

I am grateful to Dr. C. Searcy and Dr. M.Y. Jaber for supporting my work enthusiastically, sharing their knowledge, and guiding me throughout the program.

I am also thankful to the program director, Dr. A. Ghasempoor for providing support, and to the members of my internal defense committee Dr. S. Zolfaghari and Dr. V. Quan, for providing valuable inputs to my research. Thanks also to the Reyrson MIE administrative staff for their support.

My gratitude goes to Neeta Gurtu, my better half, for wholeheartedly supporting me in this endeavor; and special acknowledgements goes to my daughters Apoorva and Akanksha, who were catalysts to me completing this program. 

Dedicated to my father

G. K. Gurtu 



\section{CONTENTS}

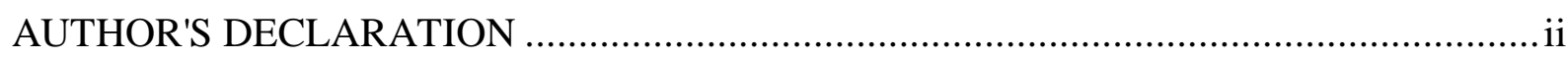

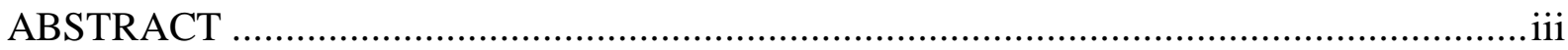

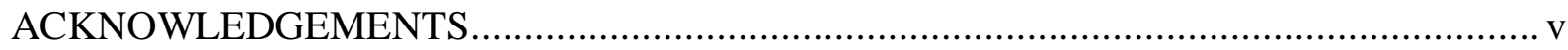

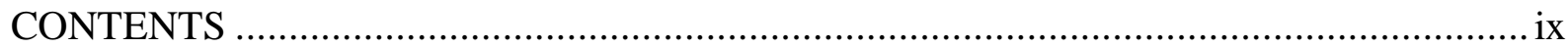

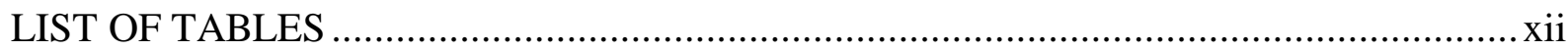

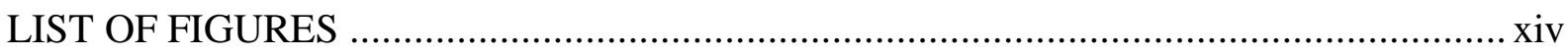

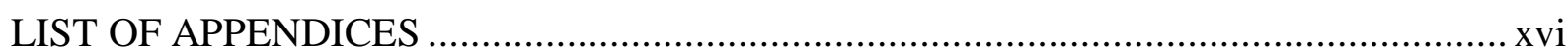

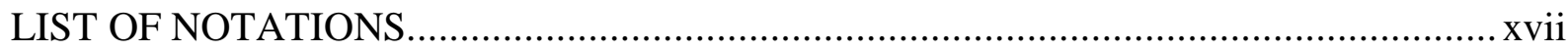

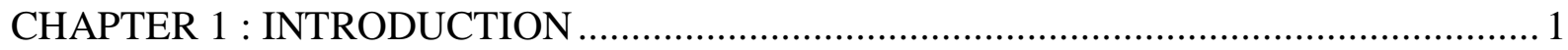

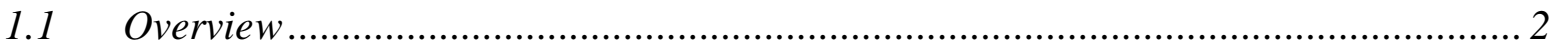

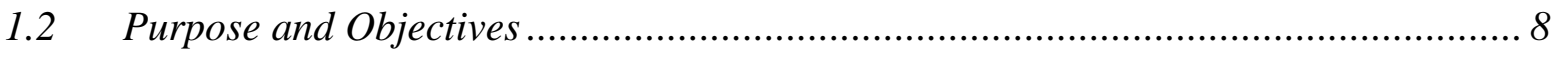

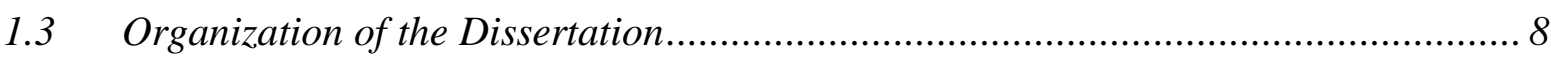

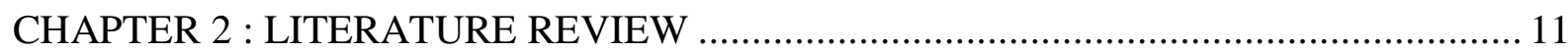

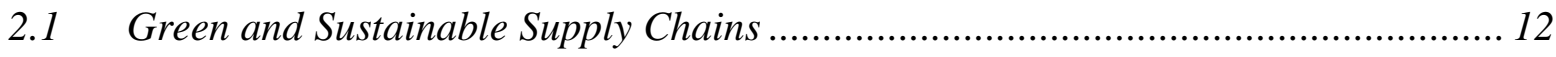

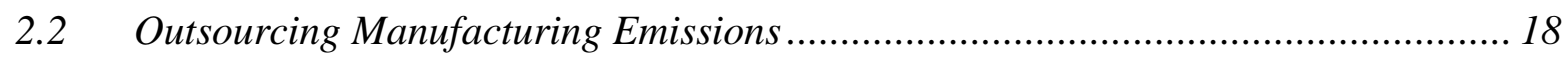

2.2.1 Manufacturing Emissions .......................................................................... 19

2.2.2 Energy Usage ............................................................................................ 20

2.2.3 Measures of Energy Efficiency ……………………........................................ 21

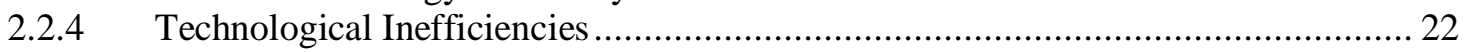

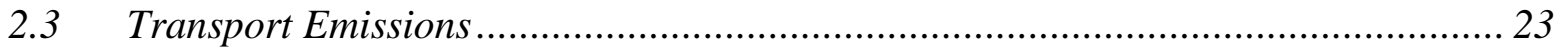

2.3.1 Modes of International Transport of Manufactured Goods ……………………... 23

2.3.2 Impact of International Transport on the Environment .......................................... 24

2.3.3 Technical Means of Reducing Emissions due to International Transport ................. 25

2.3.4 Non-Technical Means of Reducing Emissions due to International Transport ........ 26

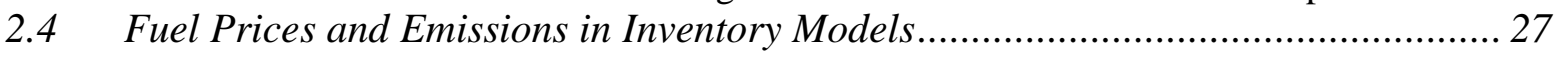

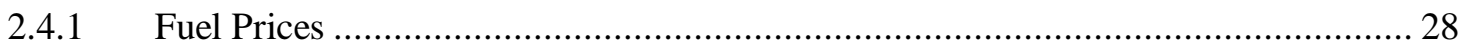

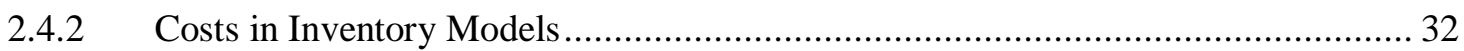

2.4.3 Emissions in Inventory Models........................................................................ 33

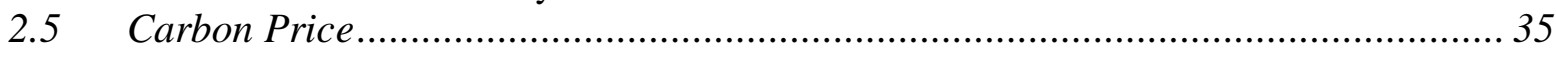

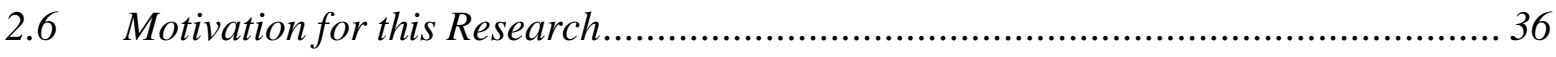

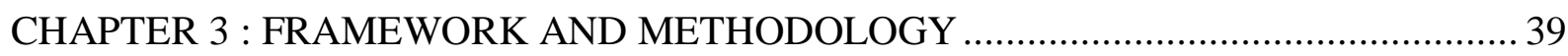

3.1 Terms for environmentally friendly supply chains ................................................... 43

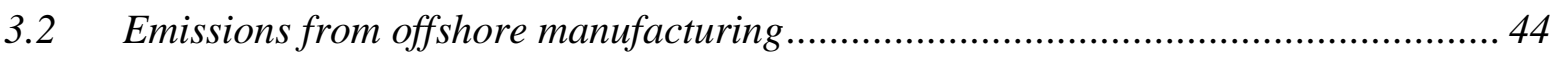

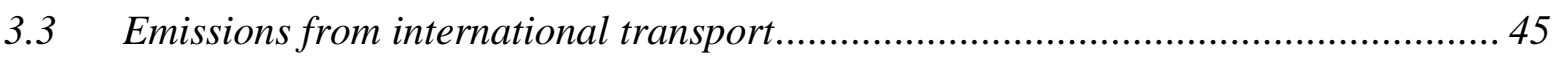

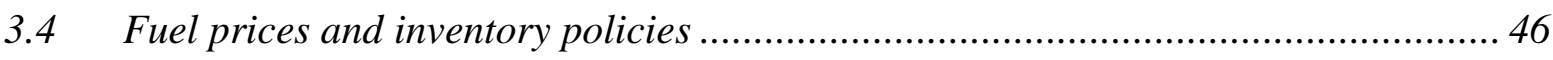

3.5 Effects of outsourcing on emissions and supply chain costs................................. 47 


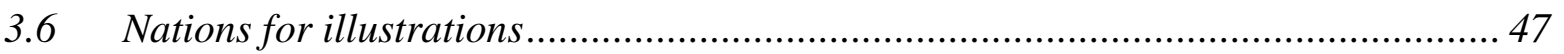

CHAPTER 4 : TERMS FOR ENVIRONMENTALLY FRIENDLY SUPPLY CHAINS ...... 49

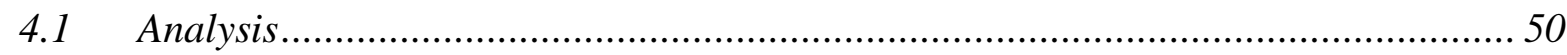

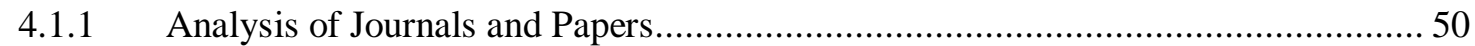

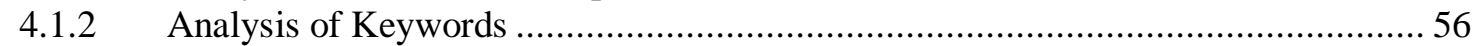

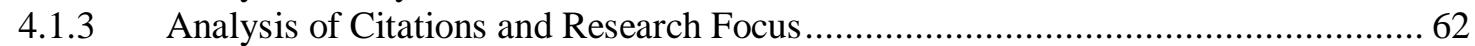

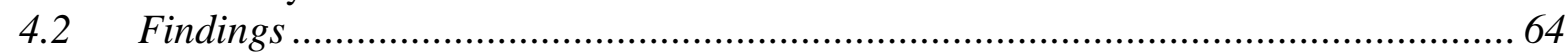

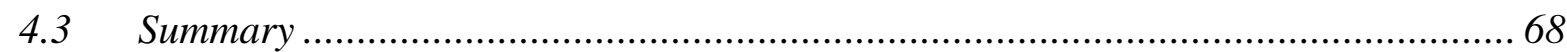

CHAPTER 5 : EMISSIONS FROM OFFSHORE MANUFACTURING......................... 71

$5.1 \quad$ Model Development for Total Emissions of a Country ........................................ 72

5.2 Model Development for Carbon Import Tax ................................................ 73

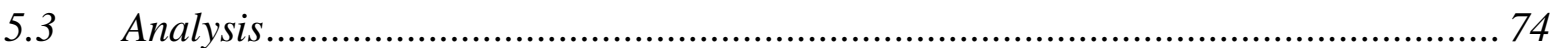

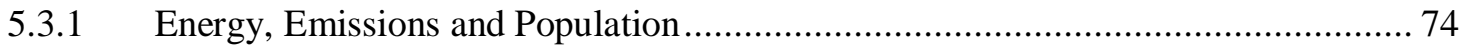

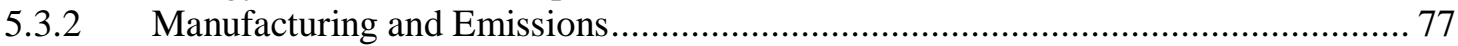

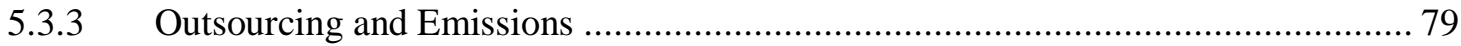

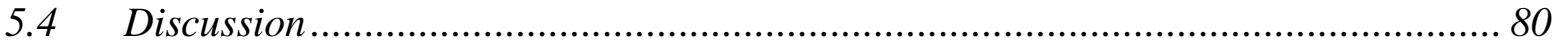

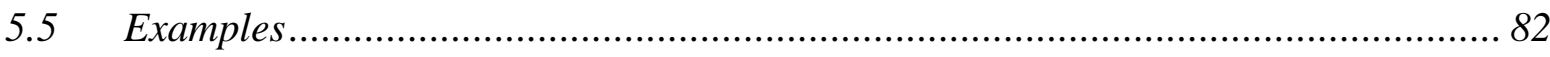

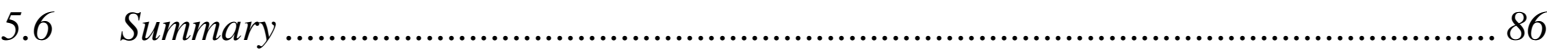

CHAPTER 6 : EMISSIONS FROM INTERNATIONAL TRANSPORT .......................... 87

6.1 Model for calculating international transport emissions ..................................... 88

$6.2 \quad$ Model for emissions tax on international transport .......................................... 89

6.3 Applications of the Models and Results....................................................... 89

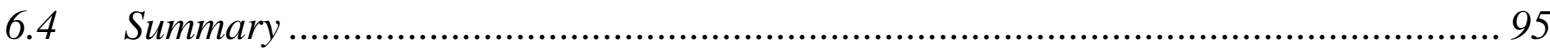

CHAPTER 7 : FUEL PRICES AND INVENTORY POLICIES ..................................... 97

7.1 The basic model with changing fuel price ............................................................ 98

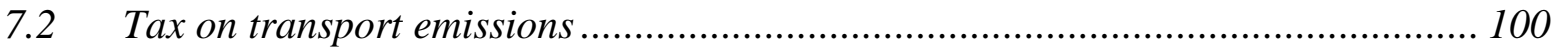

7.3 Model for two-level coordinated supply chain ............................................. 100

7.4 Solution Procedure ....................................................................................... 106

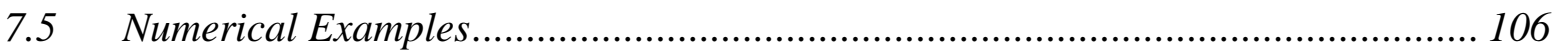

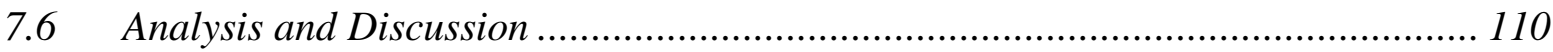

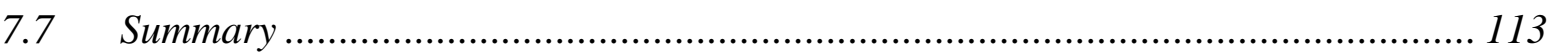

CHAPTER 8 : EFFECTS OF OFFSHORING ON EMISSIONS AND SUPPLY CHAINS 115

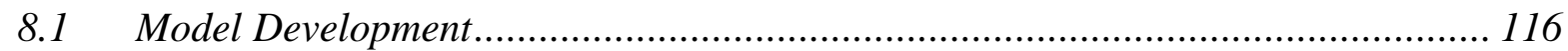

8.1.1 Outsourced Emissions for a Nation ................................................................ 116

8.1.2 Impact of a Carbon Price and Increases in Fuel Prices on Supply Chain Costs ..... 117

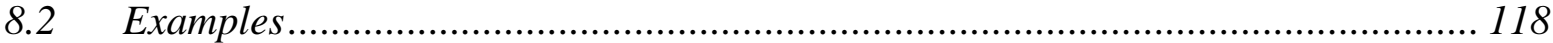

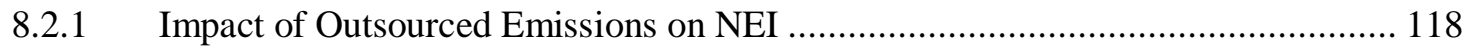

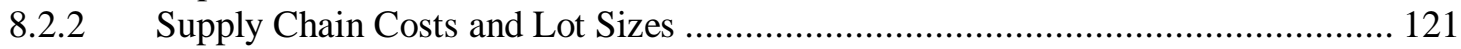

8.3 Sensitivity to Carbon Tax Rate and Fuel Price ................................................ 123

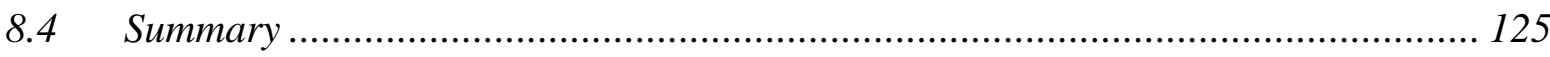




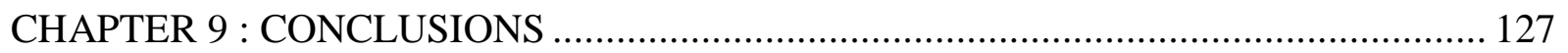

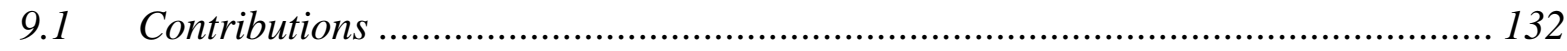

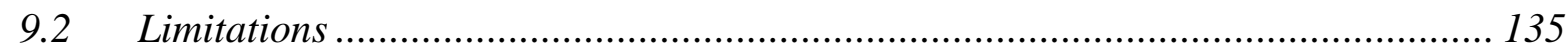

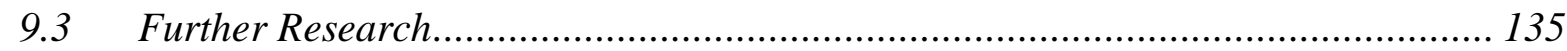

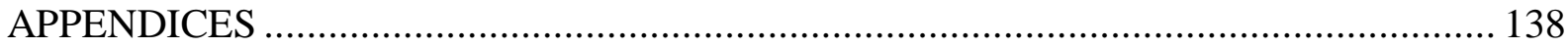

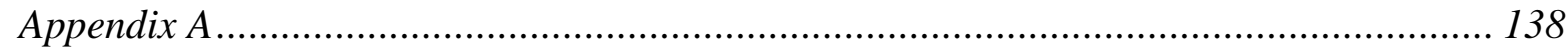

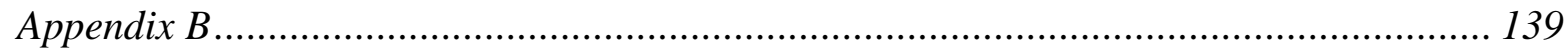

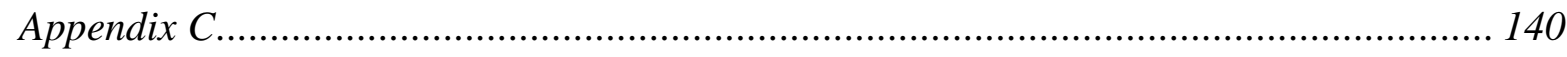

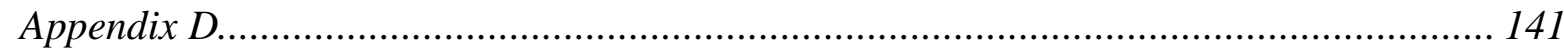

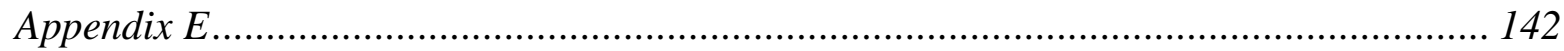

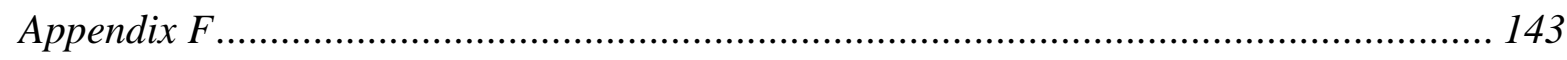

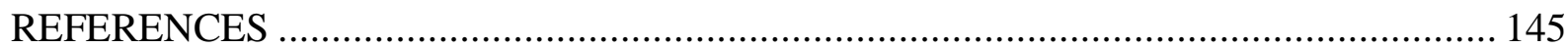

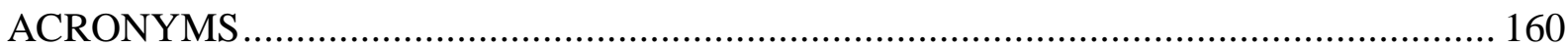




\section{LIST OF TABLES}

\section{Table No.}

Description

Page No.

\section{Chapter 2}

Table 2.1 Summary of review papers on supply chains with a focus on environment

Table 2.2 The shares of renewable and non-renewable sources in the global primary energy supply for 2007 and 2050

Table 2.3 Comparison of emissions indicators for 2009

Table 2.4 Previous contributions

\section{Chapter 3}

Table $3.1 \quad$ Interaction levels

Table 3.2 Rationale for selecting the countries for illustrations

\section{Chapter 4}

Table 4.1 Names of journals and the number of published papers

Table 4.2 Matrix showing a combination of number of papers published by journals by year

Table 4.3 Changes in the number of journals between 2007-2012

Table 4.4 Number of journals that did not publish any paper during a period 55

Table 4.5 Analysis of journals that published one paper in a year 55

Table 4.6 Combination of keywords and number of papers for multiple 56 searches by year

Table 4.7 Number of papers containing searched keywords in various years 57

$\begin{array}{lll}\text { Table } 4.8 \text { Count of unique keywords across years } & 60\end{array}$

$\begin{array}{lll}\text { Table } 4.9 & \text { Frequency of the most used keywords } & 60\end{array}$

Table 4.10 Statistics on low frequency keywords 61

Table 4.11 Citation count for the 10 most cited papers 63 


\section{Table No.}

\section{Chapter 5}

Table 5.1 Change in Carbon dioxide emissions during 1991-2009 and 1960- 76 2009 in China, Germany and the USA

Table 5.2 Change in Carbon dioxide emissions due to manufacturing 77 activities

$\begin{array}{lll}\text { Table 5.3 Data used for analysis } & 83\end{array}$

Table 5.4 Changes in emissions after adjusting for imports and exports using 84 the model

Table 5.5 Impact of emissions import tax on the profitability of Wal-Mart 86

\section{Chapter 6}

Table 6.1 Capacity of container ships $\quad 92$

Table 6.2 US data on imports by containers ships and air cargo 93

Table 6.3 International transport emissions and emissions tax on imports in 94 the USA

\section{Chapter 7}

Table 7.1 Changes in order cost and lot-size due to transport and emissions cost

Table 7.2 Changes in order cost and lot-size due to changes in transport distance in 2014

Table 7.3 Effect of changes in fuel consumption on order cost and lot-size

Table 7.4 Comparison of annual costs of ownership for diesel and hybrid

\section{Chapter 8}

Table 8.1 Emissions due to outsourcing to Germany and China by the USA

Table 8.2 Carbon tax on outsourced emissions to Germany and China by the USA 


\section{LIST OF FIGURES}

Figure No.

Description

Page No.

\section{Chapter 2}

Figure 2.1 Lifecycle GHG emissions based on the sources of energy 20

$\begin{array}{lll}\text { Figure 2.2 World oil consumption } & 29\end{array}$

$\begin{array}{lll}\text { Figure 2.3 World oil production } & 29\end{array}$

$\begin{array}{lll}\text { Figure 2.4 Inflation adjusted oil prices } & 30\end{array}$

Figure 2.5 Oil prices based on annual inflation 31

\section{Chapter 3}

Figure 3.1 Framework of the research 40

$\begin{array}{lll}\text { Figure } 3.2 & \text { Process for the research } & 42\end{array}$

\section{Chapter 4}

Figure 4.1 Contributing disciplines $\quad 51$

Figure 4.2 Changes in the use of keywords in papers between 2007 and 58 2012

Figure 4.3 Number of keywords used in the paper 59

$\begin{array}{lll}\text { Figure } 4.4 & \text { Top contributing countries } & 64\end{array}$

Figure 4.5 Annual number of authors and countries that contributed to 66 the research

$\begin{array}{lll}\text { Figure 4.6 Citation contribution of papers by year } & 67\end{array}$

\section{Chapter 5}

Figure 5.1 Changes in the sources of energy between 1965 and 2010 in

China, Germany and the USA

Figure 5.2 Changes in per capita energy consumption between 1965 and 2010 in China, Germany and the USA

Figure 5.3 Changes in the Carbon Dioxide emissions from manufacturing activities

Figure 5.4 Comparison of GHG emissions by sector 
Figure No.

Figure 5.5 Net exports and imports as a percentage of GDP

Figure 5.6 Carbon Dioxide emissions with respect to GDP

80

Figure 5.7 Correlation between GDP and exports, and GDP and $\mathrm{CO}_{2}$ emissions in China

Figure 5.8 A proposed relationship between emissions and exports

\section{Chapter 6}

Figure 6.1 Major sources of imports of containerized items in the USA

\section{Chapter 7}

Figure 7.1 Inventory movement in Banerjee's (1986) and Goyal's (1988) models

Figure 7.2 Comparison of Hill's (1999) and Braglia \& Zavanella's (2003) models

\section{Chapter 8}

Figure 8.1 Carbon tax revenue (total) on imports from China and Germany

Figure 8.2 Changes in order cost (\$) due to a price on emissions and increasing fuel price for imports from Germany with respect to manufacturing in the USA

Figure 8.3 Changes in order cost (\$) due to a price on emissions and increasing fuel price for imports from China with respect to manufacturing in the USA 


\section{LIST OF APPENDICES}

\begin{tabular}{cllc}
\hline Appendix & \multicolumn{1}{c}{ Description } & Related to & Page No. \\
\hline A & $\begin{array}{l}\text { Representative Definitions of Search } \\
\text { Keywords }\end{array}$ & Sub-section 2.1 & 138 \\
B & $\begin{array}{l}\text { Containerized commodities in tons, TEU and } \\
\text { value of cargo }\end{array}$ & Sub-section 2.3/6.3 & 139 \\
C & List of Search Keywords and Related Papers & Sub-section 3.1 & 140 \\
D & List of Other Disciplines & Sub-section 4.1 & 141 \\
E & Explanation of the term in equation 7.10a & Sub-section 7.3 & 142 \\
F & Explanation of the term in equation 7.11a & Sub-section 7.3 & 143 \\
\hline
\end{tabular}




\section{LIST OF NOTATIONS}

\section{Notation}

\section{Description}

$\varepsilon_{b, m} \quad$ capacity utilization towards origin (Backhaul efficiency for ships)

capacity utilization towards destination (Headhaul efficiency for ships)

$\varepsilon_{h, m}$

$\varepsilon_{m}$

$A_{0} \quad$ transport cost at the start of an order point

$A_{l} \quad$ annual incremental increase in transport cost

$A_{\phi} \quad$ transport cost for $\phi^{\text {th }}$ shipment

$C_{i} \quad$ annual emissions in Country $i$

$C_{i(m)} \quad$ emissions due to outsourcing of manufacturing for Country $i$

$C_{i(o)} \quad$ emissions due to outsourcing for Country $i$

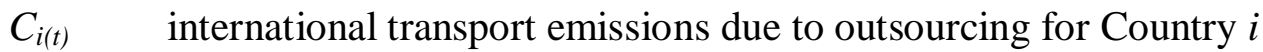

$C_{m} \quad \mathrm{GHG}$ emissions for a transport carrier/mode

D demand (consumption) rate per unit time

$d \quad$ distance travelled

$d_{m, j} \rightarrow^{i}$

$E_{i \rightarrow j}$

$E_{i \rightarrow w}$

$G_{i} \quad$ GDP of Country $(i)$

$h \quad$ unit holding cost per unit of time; subscript $b$ and $v$ are added to show buyer and vendor

$k \quad$ category of items according to SITC, Rev.3

$K \quad$ order cost per cycle; subscript $b$ and $v$ are added to show buyer and vendor

$l \quad$ fuel consumption

$m \quad$ carrier/mode of transportation

$n \quad$ vendor's cycle

\section{Unit}

$\%$

$\%$

$\%$

$\$$

$\$$

$\$$

$\mathrm{Kg}$

$\mathrm{Kg}$

$\mathrm{Kg}$

$\mathrm{Kg}$

g/Ton/km

units/year

$\mathrm{km}$

$\mathrm{km}$

$\$$

$\$$

$\$$

$\$$

unit-less

$\$$

liters/km

unit-less

unit-less 


\begin{tabular}{|c|c|c|}
\hline$P$ & production rate per unit time & units/year \\
\hline$q$ & lot-size & units \\
\hline$q^{*}$ & optimal lot-size with transport cost & units \\
\hline$q_{e}^{*}$ & optimal lot-size with transport cost and emissions cost & units \\
\hline$q_{E}$ & EOQ without transport and emissions costs & units \\
\hline$t$ & cycle time for a lot (fraction) $[t=q / D]$ & year \\
\hline$T_{c i}$ & carbon tax on emissions in a country & \$/Ton \\
\hline$T C_{i}\left(q^{*}\right)$ & total cost per unit time of the $\phi^{\text {th }}$ order with transport costs & $\$$ \\
\hline$T C_{i, e}\left(q^{*}\right)$ & $\begin{array}{l}\text { total cost per unit time of the } \phi^{\text {th }} \text { order with transport and emissions } \\
\text { costs }\end{array}$ & $\$$ \\
\hline$T C_{\phi}$ & cost of the $\phi^{\text {th }}$ order with transport cost & $\$$ \\
\hline$T_{e}$ & total carbon tax on transport emissions & $\$$ \\
\hline$T_{i(m)}$ & total tax on manufacturing emissions from outsourcing for Country $i$ & $\$$ \\
\hline$T_{i(m d)}$ & $\begin{array}{l}\text { tax on differential manufacturing emissions from outsourcing for } \\
\text { Country } i\end{array}$ & $\$$ \\
\hline$T_{i(o)}$ & total tax on emissions from outsourcing for Country $(i)$ & $\$$ \\
\hline$T_{i(t)}$ & total tax on transport emissions from outsourcing for Country $(i)$ & $\$$ \\
\hline$W_{k, j \rightarrow i}$ & annual exports of item of category $(k)$ from Country $j$ to Country $(i)$ & Ton \\
\hline$\alpha$ & $\begin{array}{l}\text { fuel price at the time of the first order } \\
\text { (from Figure } 2.4 ; \alpha=(2.8917 x+11.802) / \gamma, \text { where } x \text { is the time in } \\
\text { years between the first order since 1990) }\end{array}$ & $\$$ \\
\hline$\beta$ & $\begin{array}{l}\text { annual incremental increase in fuel price } \\
\text { (from Figure } 2.4 ; \beta=2.8917 / \gamma,\end{array}$ & $\$$ \\
\hline$\gamma$ & conversion factor from barrel to liter ( 1 oil barrel US $=159$ liter) & unit-less \\
\hline$\lambda$ & number of shipment lots from a single production cycle, integer & unit-less \\
\hline$\phi$ & order number & unit-less \\
\hline
\end{tabular}




\section{CHAPTER 1 : INTRODUCTION}




\subsection{Overview}

The development of global supply chains due to offshore production or offshore outsourcing has gained a lot of momentum since the beginning of the $21^{\text {st }}$ century, though it is important to stress that the concepts of outsourcing and global supply chains are not entirely new. Despite increases in cost due to international freight transportation, offshore outsourcing led to reductions in operating costs and thus, more organizational profits. Transport costs are affected by fossil fuel prices and emissions are affected by the burning of fossil fuel. An increase in international freight transport results in both an increase in global emissions, which influences the overall sustainability, and transport costs, which influences the costs of supply chains. Therefore, the concepts of global supply chains, offshore outsourcing, fossil fuel prices, and sustainability are intertwined and a holistic approach is required in addressing these issues. This research is an attempt to study these interactions, and their impacts on global emissions and supply chain costs.

The activities associated with modern supply chains have been carried out for centuries, though the use of the term "supply chain" is relatively recent. Despite the long history, the focus of research in the area of supply chain management (SCM) is relatively new as compared to other areas of engineering and management. The study of SCM has generated a lot of interest among academicians and practitioners in the last three decades. The earliest documented use of the term "supply chains" could be traced back to the middle of the $20^{\text {th }}$ century in the context of petroleum products for a Shell refinery in Essex (Petroleum Times, 1951). Later, this term was used in the context of electricity supply networks (Banbury, 1975) and optimization of inventories in multi-echelon supply chains (Burns \& Sivazlian, 1978).

The globalization of manufacturing and trading activities resulted in an increase in the complexities of supply chains and helped in popularizing the term SCM. These increased complexities required a better understanding of many variables involved in global supply chains. The challenges of optimizing supply chain performance have made SCM a key competitive advantage in a number of industries over the last two decades. The scope of SCM, as defined in most of the earlier literature, is from the acquisition of raw materials and parts through delivery of the finished products to end customers. One of the earliest definitions of supply chains was "the supply chain is the connected series of activities which is concerned with planning, 
coordinating and controlling material, parts and finished goods from supplier to customer" (Stevens, 1989). More recently, the Canadian Supply Chain Sector Council (CSCSC, 2014) explained that a supply chain encompasses "supply of materials to a manufacturer", "the manufacturing process", and "the distribution of finished goods through a network of distributors and retailers to a final customer".

In the mid-1980s, a number of authors identified the need for integrating sustainability into various aspects of businesses, particularly with respect to ensuring broad coverage of large geographic areas (De Laet, 1985; Jacobs, 1985; Lowry \& Carpenter, 1985; Khosla et al., 1986; Westing, 1986). However, publication of the "Report of the World Commission on Environment and Development: Our Common Future" (WCED, 1987), famously known as Brundtland Report, marked a historic moment in popularizing the concept of sustainability and underlined the urgent need to integrate sustainability into businesses. The literature on sustainability began a rapid expansion following the publication of this report. The Brundtland report defined sustainable development as "the development that meets the needs of the present without compromising the ability of future generations to meet their own needs." It highlighted the need for development that supports the environment by minimizing pollution in all countries. In other words, sustainability was defined as the use of natural resources in such a way that future generations are not deprived of these natural resources. This is possible when the rate of consumption for natural resources is the same as or less than the rate of renewal for those resources. Another corollary to this definition is that the rate of generating pollution (to air, water, and land) must be kept the same as or less than the time required to absorb and completely disintegrate that pollution in the environment (Daly, 1990; Costanza \& Daly, 1992). Further, sustainability has been discussed based on the degree to which it focuses on "natural capital". Sustainability, where natural capital and man-made capital are treated in a similar manner, i.e. there is no special consideration for natural capital, is referred to as "weak sustainability". On the other hand, the concept of "strong sustainability" suggests that natural and man-made capital need to be kept separate and treated separately because it take a very long time to generate natural capital (Gutés, 1996; Ahi \& Searcy, 2013a). These concepts form the basis for different approaches to sustainability management. By the late 1990s, sustainability made its way into the literature on supply chains. However, it was not until the last decade that both academicians and 
practitioners began widely embracing the idea of sustainability of supply chains (Taticchi et al., 2013).

In an organizational context, sustainability is often closely linked to the concept of corporate social responsibility (CSR) (Hutchins \& Sutherland, 2008). Both of these concepts tend to emphasize triple bottom line (TBL) performance as essential aspects of business success. The TBL explicitly requires emphasis on the organization's performance in the economic, environmental, and social dimensions of sustainability. Sustainability in a supply chain context can, therefore, no longer be viewed as being limited to economic or environmental sustainability alone. Sustainable supply chains are expected to address the TBL of sustainable performance, i.e. economic, environmental, and social sustainability.

Offshore outsourcing or offshoring is defined as "a business's (or a government's) decision to replace domestically supplied service functions with imported services produced offshore" (OECD, 2013a). For the purpose of this research, offshore outsourcing of manufacturing activities means transferring manufacturing activities from a country of consumption to a country of manufacturing. The concept of outsourcing has been practiced for a long time. The primary reason for outsourcing, whether onshore or offshore, is reducing cost, thereby improving operating efficiency and profitability (Briggs, 2005; Suhaimi et al., 2007; Bahrami, 2009; and and Varadarajan, 2009; Susomrith \& Brown, 2013). However, the concept of offshore outsourcing is relatively new and still evolving. Ongoing reductions in communication costs and transport time, along with the availability of cheap labor and the lack of stringent environmental laws in economically less developed places, have greatly facilitated the move to globalized supply chains. To date, the move to globalize supply chains has been driven by economic advantages. Historically, little attention has been paid to the adverse impacts of the globalization of supply chains on the environment and society. However, there is a growing awareness of the need to accommodate environmental and social considerations in decision-making for supply chains. Offshore outsourcing has many effects of varying intensities at different levels (Bonney \& Jaber, 2011). The most predominant positive effect is socioeconomic development in outsourcee countries. Offshore outsourcing has facilitated the sharing of knowledge across the organizations involved in outsourcing activities in different countries. This has increased 
cooperation among governments of trading countries, made them more interdependent and receptive to the needs of other countries. However, these positive effects are accompanied by some negative ones as well. For example, complexities in global supply chains have increased. The majority of the literature in this area is focused on the positive effects of offshore outsourcing of manufacturing activities (Gater, 2002; Cooke, 2004; Kakumanu \& Portanova, 2006), with very few studies that explored their negative effects. One of the biggest negative effects has been on the environment, which is a common global resource. Further, reporting emissions at a country level skews the optics and increases complexities in devising corrective actions because outsourcing shifts the sources of emissions from the countries of consumption to the countries of manufacturing (Davis et al., 2011).

Offshore outsourcing led to an increase in international freight transportation between countries on different continents. This has resulted in increasing global emissions. However, it is important to note that the United Nations Framework Convention on Climate Change (UNFCCC) excluded emissions from international aviation and maritime transport (known as international bunker fuel emissions) from national emissions inventories (NEI) (UNFCCC, 2013a; Andersen et al., 2010; Peters, 2008). Exports of manufactured goods (excluding agriculture, fuel, and mining products) were valued at $\$ 11.5$ trillion USD in 2011 , which accounted for $64.6 \%$ of global merchandise exports (WTO, 2013). This number is sizeable and cannot be ignored in considerations for decisions related to the environment in supply chains.

The need to consider environmental factors in decision-making in the manufacturing industry has been acknowledged in the literature (Kinkel, 2012). There is also a specific recognition of the need to improve understanding of the GHG emissions due to manufacturing and their broader impacts (Hill, 2001). For example, many jurisdictions have taken steps to reduce their carbon footprints through efforts such as diversification of the energy mix and promotion of renewable energy. A carbon footprint "measures the total amount of GHG emissions that are directly and indirectly caused by an activity or are accumulated over the life stages of a product (including services)" (Galli et al., 2012). However, as implied by the GHG Protocol (GHG Protocol, 2012), the total direct $\mathrm{CO}_{2}$ emissions of a country are not a true reflection of its emissions. Indirect 
emissions should also be captured. This dissertation argues that this can be done only if the emissions due to offshore outsourcing and international transport are taken into account.

For better management of carbon emissions, proper accounting of GHG emissions is required. One of the mechanisms to improve accounting of carbon emissions is to account for emissions based on nations of consumption rather than nations of origin (manufacturing). Further, introducing a carbon pricing mechanism on excess emissions generated in other countries due to outsourcing and due to international transport will reduce the cost advantage of using less efficient technologies, which have higher rate of emissions. The concept of imposing a carbon tax on emissions due to outsourcing has been previously discussed. For example, Elliott et al., (2010) introduced the concept of assigning a carbon tax on the imports from developing countries. They concluded that "increased $\mathrm{CO}_{2}$ emissions in developing countries would undo over 20 percent of the reductions made by the Annex B Kyoto region" and suggested imposing a carbon tax on producers for neutralizing this. However, the environmental costs associated with the international transportation of these manufactured goods are not accounted for by either the importing or exporting nation. Assigning a value on emissions due to international transport and charging it to importing organizations will induce a rethinking for the most cost effective destinations for outsourcing. For example, Lee et al., (2013) studied the effect of a carbon tax on international container shipping and estimated that it will influence international trade negatively depending on the rate of a carbon tax. This does not suggest that imports or all of their associated emissions are entirely avoidable. Nonetheless, there is a need to broaden considerations in outsourcing decisions beyond direct labor and purchasing costs. Environmental impact imposes costs on society over the long run and must be considered. Bonney and Jaber (2011) have discussed various challenges in including environmental issues in inventory management and stressed the need for assigning a cost to make balanced and meaningful decisions. Similarly, the concept of assigning a value to transport emissions is necessary to give importing organizations a sense of the total cost of offshore outsourcing.

In order to reduce global GHG emissions, these should be considered at the global level and a global approach is therefore required. The focus of this research was to explore the effects of offshore outsourcing of manufacturing activities on the environment, with an emphasis on GHG 
emissions. This research analyzed the changes in GHG emissions at the national levels due to outsourcing of manufacturing activities and due to additional international transport related to moving these products from places of manufacturing to places of consumption, and suggested a mechanism to calculate a "fair" carbon price that reduces the GHG emissions. The emissions adjusted price is likely to reduce the cost advantage of offshore outsourcing to countries where emissions for a unit dollar of manufacturing activities are high due to the use of older and less efficient technologies, and due to the choices of energy sources in those countries. This, in turn, is expected to encourage nations to choose renewable sources of energy, and organizations to consider outsourcing to countries, where net emissions, in addition to manufacturing cost, are lower than their own country.

The concept of putting a value on emissions started in 1990 (EPA, 2013a) with the introduction of a carbon tax by Finland in January of that year. However, the rate of carbon tax was considerably low and "the tax rate has evolved from $€ 1.12 / \mathrm{t}$ Carbon dioxide $\left(\mathrm{CO}_{2}\right)$ in 1990 to $€ 20 / \mathrm{t} \mathrm{CO}_{2}$ in 2010" (Ministry of Environment, Finland, 2012). Quebec (Canada) was the first province (state) to start a carbon tax in North America on October 1, 2007. British Columbia (Canada) introduced a carbon tax on July 1, 2008 at a rate of $\$ 10$ (Canadian) per metric ton of $\mathrm{CO}_{2}$ and rose $\$ 30$ per ton of $\mathrm{CO}_{2}$ in July 2012, which is one of the highest rates of carbon tax in the world (Carbontax, 2014). Boulder (Colorado) implemented the United States' first tax on carbon emissions from electricity, on April 1, 2007, at a level of approximately $\$ 7$ per ton of carbon (Carbontax, 2014). Sweden started a carbon tax in 1991, which has significantly increased over time, and presently it is more than EURO 100 (US\$ 138 as on March 28, 2014 at the exchange rate of $1 \mathrm{EURO}=1.38 \mathrm{USD}$ ) per ton of $\mathrm{CO}_{2}$ (Sweden Gov., 2014). Subsequently, a few other methods were suggested for reducing GHG emissions. Carbon taxes, carbon cap and trading schemes and a combination of the two are the most suggested methods for putting a value on GHG emissions. These mechanisms were aimed at reducing the harmful emissions of a nation or a region, such as the European Union (EU). The global economy, due to interdependence of nations for trade and outsourcing, has not only made nations more environmentally conscious but also made the management of environmental issues even more complex. Therefore, an additional aim of this research was to study offshore outsourcing at a macro level and analyze its impact on global emissions and to introduce a method for calculating a carbon price on additional 
emissions, if any, on outsourced items as a remedial measure to reduce emissions. Further, an additional aim was to analyze the impact on supply chains cost and lot-sizes due to inclusion of cost of emissions and increases in fuel prices.

\subsection{Purpose and Objectives}

The purpose of this research is (i) to analyze the changes in global emissions due to outsourcing, (ii) to analyze the cost of supply chains due to assigning a cost to additional emissions from offshore outsourcing of manufacturing activities and increasing fuel prices, and (iii) to propose a framework for improving sustainability through reduction in GHG emissions from global supply chains.

There were 5 objectives developed to support the purpose as given below. The first objective is an extension of the literature review. However, it has not been considered a part of the literature review due to the high level of original analysis, which is not conventionally done under a literature review. The last objective is an integration of the previous three objectives.

I. Conduct an analysis of terms used to represent environmentally friendly supply chains and any changes in usage in the literature over time.

II. Conduct an analysis of the changes in the GHG emissions as a result of offshore outsourcing of manufacturing activities.

III. Conduct an analysis of the changes in the GHG emissions due to additional international transportation as a consequence of offshore outsourcing of manufacturing activities.

IV. Analyze the impact of increases in fuel price on inventory policies (EOQ).

V. Analyze the effects of outsourcing on NEI, and the combined effect of a carbon price on additional emissions from manufacturing and transport along with increases in fuel prices on supply chain costs.

\subsection{Organization of the Dissertation}

The remainder of the dissertation is organized as follows: Chapter 2 discusses the relevant literature and the motivation for this research. Chapter 3 provides a discussion on the research 
framework and methodology. Chapter 4 through 8 provides detailed analysis and findings of objectives 1 to 5 , respectively. Chapter 9 provides conclusions, limitations and directions for future research followed by Appendices, References and Acronyms.

The overarching assumptions for all the models are (i) that price elasticity has not been considered, that is, it is assumed that demand will be unaffected by changes in the order costs which will affect the price to consumers, (ii) that in the case of a price increase, product substitutions are not considered, (iii) that the basic cost of an item in different parts of the world is the same, and (iv) the effect on General Agreement on Tariffs and Trade (GATT), which covers international trade in goods, has not been studied. These assumptions were selected to keep the modeling simple and to highlight the effects of changes of increases in fuel prices and impact of a carbon price on offshore emissions.

It is important to note that the chapters in this dissertation were developed, in part, based on peer-reviewed publications that either have been accepted or are under review. The publications are:

\section{Journal paper accepted:}

- Gurtu, A., Jaber, M.Y., \& Searcy, C. (2014). Impact of fuel price on inventory policies, Applied Mathematical Modelling, http://dx.doi.org/10.1016/j.apm.2014.08.001

The literature review has been used in Section 2.6, and the models and its applications, the

numerical examples, and the analyses and the discussions have been used in Chapter 7. Small parts from the introduction and the conclusion were included in Section 1.1 and Chapter 9, respectively.

- Gurtu, A., Searcy, C., \& Jaber, M.Y. (2015). An analysis of keywords used in the literature on green supply chains, Management Research Review, 38(2), accepted on 10 February 2014. 
The sections on the literature review and research design of this paper have been used in Section 2.1 and Section 3.1 respectively, and analyses and conclusions have been used in Chapter 4. Small parts from the introduction were included in sections 1.1.

\section{Journal papers under review:}

- Gurtu, A., Searcy, C., \& Jaber, M.Y. (2013). A model for imposing a carbon tax on outsourced emissions, Journal of Cleaner Production.

The main parts of the literature review have been used in Sections 2.2, 2.3, and 2.4. The proposed models and the analyses have been used in Chapter 5. Small parts from the literature review on carbon pricing, the introduction, and the conclusions were included in Section 2.7, Section 1.1, and Chapter 9, respectively.

- Gurtu, A., Searcy, C., \& Jaber, M.Y. (2014). Emissions from international transport in global supply chains, International Journal of Physical Distribution \& Logistics Management.

The main parts of the literature review, and the proposed models and analyses have been used in Section 2.5 and Chapter 6, respectively. Small parts from the literature on carbon pricing, the introduction, and the conclusions were included in Section 2.7, Section 1.1, and Chapter 9, respectively.

In each case, the publications were co-authored by Dr. Cory Searcy and Dr. Mohamad Y. Jaber. Their roles included providing assistance in concept development, supervision of the research process, and review of the papers for publication. 


\section{CHAPTER 2 : LITERATURE REVIEW}


This chapter has been divided into six sections. The first five sections, namely green and sustainable supply chains, outsourced manufacturing emissions, transport emissions, fuel prices, and carbon pricing are organized to address various objectives and provide a brief review of the relevant literature. The last section discusses gaps in the literature and provides a discussion for the motivation for this research.

\subsection{Green and Sustainable Supply Chains}

The term SCM gained importance after it was used in 1982 by Keith Oliver, a consultant at Booz Allen Hamilton (Feller et al., 2006). The scope of SCM, as defined in most of the earlier literature, is from the acquisition of the raw materials and parts through delivery of the finished products to the end customers. Over time, SCM has expanded to incorporate environmental concerns. Many of these terms, intended to represent environmentally friendly supply chains, have been used interchangeably in practice. Representative examples include: (i) Lin and Chang (2009) suggested that Green Supply Chain Management (GSCM) includes reverse supply chains; (ii) Louca and Kokkinaki (2011), and Olugu et al., (2011) considered green supply chain management (GSCM) to include reverse logistics; (iii) Beškovnik and Jakomin (2010) argued that green logistics is an extension of reverse logistics; (iv) and $\mathrm{Wu}$ and Pagell (2011) referred to their research focused on the environmental dimension of sustainability as "Balancing priorities: Decision-making in sustainable supply chain management". Representative examples of the definitions of the key terms are provided in Appendix A. Despite the fact that these terms are often used interchangeably in the literature, it is important to acknowledge that they initially emerged to characterize relatively distinct areas of work. Table 2.1 provides a representative summary of literature review studies on supply chains with an emphasis on the environment. To

illustrate, Srivastava (2007), the first paper listed in Table 2.1, falls under the Category "Definitions" with a focus on "green supply chains". Srivastava (2007) covered a "Time Horizon" from 1990 onwards and analyzed 227 papers. The remainder of this sub-section briefly presents a review of the evolution of SCM, its incorporation of environmental factors, and a review of several key definitions. 
Table 2.1: Summary of review papers on supply chains with a focus on environment.

\begin{tabular}{|c|c|c|c|c|c|}
\hline \multirow{2}{*}{ Category } & \multirow{2}{*}{ Area of research } & \multirow{2}{*}{$\begin{array}{l}\text { Author(s) and } \\
\text { year }\end{array}$} & \multicolumn{3}{|c|}{$\begin{array}{c}\text { Research parameters of the review } \\
\text { paper }\end{array}$} \\
\hline & & & Time Horizon & $\begin{array}{l}\text { No. of } \\
\text { journals }\end{array}$ & $\begin{array}{l}\text { No. of } \\
\text { papers }\end{array}$ \\
\hline \multirow[t]{3}{*}{ Definitions } & Green supply chains & $\begin{array}{l}\text { Srivastava } \\
(2007)\end{array}$ & 1990 onwards & $\mathrm{NS}^{1}$ & 227 \\
\hline & $\begin{array}{l}\text { Green supply chains } \\
\text { and sustainable supply } \\
\text { chains }\end{array}$ & $\begin{array}{l}\text { Ahi and Searcy } \\
(2013 b)\end{array}$ & $\begin{array}{l}2002-2012 \\
(\text { Jan })\end{array}$ & $\mathrm{NS}^{1}$ & 180 \\
\hline & $\begin{array}{l}\text { Sustainable supply } \\
\text { chains }\end{array}$ & $\begin{array}{l}\text { Seuring and } \\
\text { Müller (2008a) }\end{array}$ & $1994-2007$ & $\mathrm{NS}^{1}$ & 191 \\
\hline \multirow{4}{*}{$\begin{array}{l}\text { Evolution of } \\
\text { sustainable } \\
\text { supply chains }\end{array}$} & Theory development & $\begin{array}{l}\text { Carter and } \\
\text { Rogers (2008) }\end{array}$ & $\mathrm{NS}^{1}$ & $\mathrm{NS}^{1}$ & $\mathrm{NS}^{1}$ \\
\hline & Theory development & $\begin{array}{l}\text { Carter and } \\
\text { Easton }(2011)\end{array}$ & $\begin{array}{l}\text { 1991-2010 } \\
\text { (Jun) }\end{array}$ & 7 & 80 \\
\hline & $\begin{array}{l}\text { Social and } \\
\text { environmental } \\
\text { dimension of } \\
\text { sustainability }\end{array}$ & $\begin{array}{l}\text { Ashby et al., } \\
(2012)\end{array}$ & $1983-2011$ & 38 & 134 \\
\hline & $\begin{array}{l}\text { Drivers for green } \\
\text { initiatives }\end{array}$ & $\begin{array}{l}\text { Dube and } \\
\text { Gawande (2012) }\end{array}$ & $\begin{array}{l}30 \text { years }(\text { exact } \\
\left.\text { years } \mathrm{NS}^{1}\right)\end{array}$ & $\mathrm{NS}^{1}$ & $\mathrm{NS}^{1}$ \\
\hline \multirow{3}{*}{$\begin{array}{l}\text { Sustainability } \\
\text { themes \& } \\
\text { challenges }\end{array}$} & Ethics & Beamon (2005) & $\mathrm{NS}^{1}$ & $\mathrm{NS}^{1}$ & $\mathrm{NS}^{1}$ \\
\hline & $\begin{array}{l}\text { Key issues (using } \\
\text { Delphi technique) }\end{array}$ & $\begin{array}{l}\text { Seuring and } \\
\text { Müller (2008b) }\end{array}$ & $\mathrm{NS}^{1}$ & $\mathrm{NS}^{1}$ & $\mathrm{NS}^{1}$ \\
\hline & $\begin{array}{l}\text { Themes and } \\
\text { challenges }\end{array}$ & $\begin{array}{l}\text { Abbasi and } \\
\text { Nilsson (2012) }\end{array}$ & $\mathrm{NS}^{1}$ & 18 & 190 \\
\hline \multirow[t]{3}{*}{ Applications } & $\begin{array}{l}\text { Sustainability of } \\
\text { suppliers }\end{array}$ & $\begin{array}{l}\text { Gimenez and } \\
\text { Tachizawa } \\
(2012)\end{array}$ & $1996-2011$ & $\mathrm{NS}^{1}$ & 41 \\
\hline & $\begin{array}{l}\text { Organizational } \\
\text { theories for green } \\
\text { supply chains }\end{array}$ & $\begin{array}{l}\text { Sarkis et al., } \\
(2011)\end{array}$ & $\mathrm{NS}^{1}$ & $\mathrm{NS}^{1}$ & $\mathrm{NS}^{1}$ \\
\hline & Performance metrics & $\begin{array}{l}\text { Hassini et al., } \\
\text { (2012) }\end{array}$ & $\begin{array}{l}1999 \text { onwards } \\
\left(\text { end year NS }{ }^{1}\right)\end{array}$ & 29 & 87 \\
\hline
\end{tabular}

Jones and Riley (1985) explained that SCM techniques deal with the planning and control of total materials flow from suppliers through end-users". Mentzer et al., (2001) noted the variation in the definitions and scope of SCM. They defined a supply chain as "a set of three or more

\footnotetext{
${ }^{1}$ Not specified
} 
entities (organizations or individuals) directly involved in the upstream and downstream flows of products, services, finances, and/or information from a source to a customer". Many of the published definitions are consistent with Mentzer et al., (2001). They emphasized issues such as: “(1) supply of materials to a manufacturer, (2) the manufacturing process and (3) the distribution of finished goods through a network of distributors and retailers to a final customer" (CSCSC, 2014) and "the planning and management of all activities involved in sourcing and procurement, conversion, and all logistics management activities" (CSCMP, 2013).

Lummus et al., (2001) noted that the terms logistics and SCM are used interchangeably in the literature, despite the fact that logistics management is a part of SCM. According to the CSCMP (2013), "logistics management is that part of supply chain management that plans, implements, and controls the efficient, effective forward and reverse flows and storage of goods, services and related information between the point of origin and the point of consumption in order to meet customers' requirements". SCM, on the other hand, "encompasses the planning and management of all activities involved in sourcing and procurement, conversion, and all logistics management activities". The CSCMP further explains, "it also includes coordination and collaboration with channel partners, which can be suppliers, intermediaries, third party service providers, and customers. In essence, SCM integrates supply and demand management within and across companies".

Some authors have explored the measurement of environmental performance within the context of logistics. For example, Kim and Min (2011) worked on developing a new performance matrix in logistics by combining the logistics performance index (LPI) with the environmental performance index (EPI). They used the resulting green logistics performance index (GLPI) for ranking countries based on the environmental friendliness of their logistics' operations. Their analysis highlighted that economic activities of some countries increased with disproportionate increases in environmental degradation. "Reverse supply chains", "reverse logistics" and "closed-loop supply chains" are considered a step towards reducing negative impacts on the environment due to the end of life disposal processes. Although the terms "reverse supply chains", "reverse logistics" and "closed-loop supply chains" do not necessarily equate to a green/sustainable supply chain, these terms are used frequently in that context. 
Reverse logistics entails sending material in the reverse direction from a customer to upstream, manufacturers and/or suppliers, as a part of a reverse supply chain. The concepts of reuse/refurbish/remanufacture/recycle have been in practice for a very long time, though they were traditionally limited to a few industries or on a very small scale in selected geographies. For example, Guide et al., (2003) noted that the practice of reverse supply chains was established in the locomotive industry, as far back as the 1800s. As another example, recycling vendors in India visit residential communities regularly for buying papers, plastic, glass, brass, copper, steel, aluminum and other items at different rates. This practice has been in place for many decades. The token money in exchange is an added incentive to residents to keep these items segregated after use instead of throwing them in garbage. Guide and Wassenhove (2002) considered a reverse supply chain as an end-to-end process from acquiring used products from the customers to selling refurbished/remanufactured products back to different customers. Guide and Wassenhove broke down the reverse supply chains into five sequential steps: (i) Product Acquisition, (ii) Reverse Logistics, (iii) Inspection and Disposition, (iv) Reconditioning, and (v) Distribution and Sales. Each step can be further explored for reducing its impact on the environment. Erol et al., (2010) considered reverse supply chain management as a means to obtain products at the end of their useful lives primarily due to legislative liabilities. The inclusion of reverse supply chains into forward supply chains of an organization is referred to as "closed- loop supply chains". According to Flapper et al., (2005), closed-loop supply chains mean profitable recovery of value from these items (products, functional components, materials or packaging).

Beginning in the 1990s, new terms reflecting environmental consciousness, such as "greenpurchasing", "environmentally conscious buying", and similar terms, began to emerge. These terms have become increasingly common in the literature on supply chains. Examples include terms such as "green", "sustainable", "eco-friendly", and "responsible", among others. These terms will continue to evolve, and the meaning of each term will likely differ from one definition to another. Nevertheless, the central theme, which minimizes the negative impacts on the environment, will remain. The literature on the environmental impact of SCM is growing. Beamon (1999) explained that green supply chains are an extension of traditional supply chains to include activities that aim at minimizing the environmental impacts of a product throughout its 
entire lifecycle. Examples of these activities could include green design, resource saving, harmful material reduction, and product recycling or reuse. Srivastava (2007) presented a review of the literature on Green Supply Chain Management (GSCM) and considered activities throughout the lifecycle of a product in defining it. According to Srivastava "Green Supply Chain Management ranges from reactive monitoring of the general environment management programmes to more proactive practices implemented through various Rs (Reduce, Re-use, Rework, Refurbish, Reclaim, Recycle, Remanufacture, Reverse logistics, etc.)”. Beamon (2005) addressed the issues of environment and sustainability in SCM and interpreted sustainability in SCM as the consideration of the interests of current and future human generations. Building on the definitions above, a green/sustainable supply chain aims at eliminating or minimizing the negative impact of all the processes in the lifecycle of a product or a service on the environment for the present and future generations. There have also been efforts broadly to summarize the literature in this area. For example, Sarkis et al., (2011) categorized the GSCM literature under nine organizational theories. The review identified nine organizational theories which have been utilized to investigate various issue related to GSCM in the past: (1) complexity theory, (2) ecological modernization, (3) information theory, (4) institutional theory, (5) resource basedview, (6) resource dependence theory, (7) social network theory, (8) stakeholder theory, and (9) transaction cost economics. The theories were discussed with specific reference to green supply chains. They discussed five additional organizational theories for their suitability in this area, which are (1) Diffusion of innovation theory, (2) Path dependency theory, (3) Social embeddedness theory, (4) Structuration theory, and (5) Agency theory. Several authors have focused on exploring the organizational motivations for engaging in GSCM. Dube and Gawande (2012) reviewed the relevant literature and identified five drivers for such green initiatives as (1) Government Compliance, (2) Financial ROI, (3) Reverse Logistics, (4) Supply Chain Efficiency and (5) Corporate Responsibility. Hueting (2011) provided the conditions that supply chains have to attain to become environmental sustainable.

Several authors have focused on the broader area of sustainable supply chain management (SSCM). As one example of foundational research in this area, Carter and Rogers (2008) reviewed the literature and provided a framework for integrating sustainability into supply chains. They found that addressing more than one dimension of sustainability (environmental, 
social, and economic) yields better results, noting specifically that including the economic dimension with either of the remaining two (environment and social) is better than addressing only the environment and social dimensions and that, ultimately, addressing all three areas of the TBL is the best solution. As another example, Seuring and Müller (2008b) identified four key areas of concentration, which are: (i) "pressures and incentives for sustainable supply chain management", (ii) "identifying and measuring impacts on sustainable supply chain management", (iii) "supplier management (particularly addressing issues at the supplier-buyer interface)" and (iv) "supply chain management (dealing with issues across all companies involved in the supply chain)". Dey et al., (2011) studied the current state of sustainability in logistics and found many opportunities for improvements. The authors discussed the drivers for bringing sustainability into logistics, such as brand value, misuse of resources, government intervention, and international standards and regulations. They divided their implementation of the sustainability agenda into short-term and long-term recommendations. They stressed the urgency to "start today" and "start simple" under a proposed short-term plan. They also underlined that commitment of top management is paramount to the success of this approach and that this is a particularly important goal since a supply chain is the single largest cost in any manufacturing organization. Other aspects of SSCM have also been researched. For example, Gimenez and Tachizawa (2012) reviewed 41 papers to study the integration of sustainability among big corporations and their suppliers. The authors observed that even though the term "sustainable supply chains" implies an emphasis on the triple-bottom-line (economic, environmental and social sustainability), 25 out of 41 papers were focused primarily on green supply chains. The analysis focused on the identification of internal and external enablers of environmental performance and CSR for organizations. Abbasi and Nilsson (2012) identified five key challenges in implementing sustainability in supply chains namely cost, uncertainty, operationalization, culture and mindsets, and complexities. The authors concluded by emphasizing the need for having a holistic approach that helps in developing policies for, and integrating sustainability, in supply chains. As a final example, Ashby et al., (2012) investigated SCM within the context of sustainability and found that awareness about sustainability into supply chains is increasing. 
Several papers have previously highlighted problems associated with the lack of common terminology on GSCM. Mollenkopf et al., (2010) reviewed the literature on green, lean and global supply chains to find the interaction between these three areas. They found that the focus in these areas has been developed into three separate streams of research namely green, lean and global supply chains. Global supply chains focus on the complexities of supply chains due to offshore outsourcing of manufacturing activities. On the other hand, lean focuses on cost reduction while green focuses on environmental issues in a supply chain, which may have conflicting objectives. They observed the contradictory needs of the two, e.g., lean which focuses on inventory reduction methodologies (such as just-in-time) is in conflict with green initiatives due to more frequent trips due to smaller lot-sizes. A lack of common terminology in green, lean and global supply chains, according to Mollenkopf et al., is a barrier to achieving the optimal results. Mollenkopf et al., (2010) suggested developing and using a common terminology for these streams of supply chains for the purpose of consistency. Burgess et al., (2006) reviewed the literature on supply chains and concluded that there is a need for standardization of terminology. Ahi and Searcy (2013b) reached a similar conclusion. Based on the above, Objective 1 was proposed as follows:

Objective 1: Conduct an analysis of terms used to represent environmentally friendly supply chains and any changes in usage in the literature over time.

\subsection{Outsourcing Manufacturing Emissions}

This section provides insights into the literature on energy consumption and carbon footprints of manufacturing industries in outsourced countries. This section is divided into four sub-sections focusing on the literature on manufacturing emissions, energy usage in manufacturing in outsourced locations and system efficiencies. It discusses the level of emissions from the use of various technologies, the size of energy consumption from various sources, changes in consumption patterns, and future projections on energy consumption. Further, it presents a brief review of the literature on outsourcing emissions, some contemporary approaches for measuring emissions, and the role of technological inefficiencies in contributing to increased emissions. 


\subsubsection{Manufacturing Emissions}

Many countries that participated in the Kyoto agreement adopted the approach of NIMBY (not in my back yard) in dealing with the global carbon emissions. As an illustration of this point, Herrmann and Hauschild (2009) calculated the carbon emissions due to outsourcing of manufacturing activities from the UK and Denmark to China. They concluded that China produced much higher carbon emissions for the same activities due to older technology and inefficiencies in its manufacturing processes. By outsourcing to China, the UK and Denmark avoided about 15.6 and 1.8 million tons of $\mathrm{CO}_{2}$ respectively, while China added about 120 and 22 million tons of $\mathrm{CO}_{2}$ for the same exports to respective countries. However, Herrmann and Hauschild argued that 120 million tons of $\mathrm{CO}_{2}$ in China is not the same, if they were generated in the UK due to relative purchasing power parity (RPPP). Despite adjusting the RPPPs among the three countries, they determined that the emissions in China were about 3 times those in the UK or Denmark. That said, discounting carbon emissions due to RPPP is a flawed approach because GHG emissions accumulate in the atmosphere regardless of where they are generated. A second example is provided by Buxey (2000). Buxey studied the role of the Australian government in enabling globalization through tariff reductions. The paper concluded that the main impact of globalization has been a replacement of local manufacturing with cheap imports (with high emissions). Zhang and Beck (2013) studied the impact of the export driven economy of China on the local environment and found that it is a cause of concern for outsourcing countries. They suggested that moving away from energy intensive industries to focus more on the export of low embodied-emissions products would help China reduce emissions in the long-term.

As discussed in the introduction, Elliott et al., (2010) and Davis et al., (2012) suggested an emissions tax on imports/trade. Van der Zwaan and Rabl (2004) also suggested a policy of an "energy tax" based on emissions to bring parity among costs of energy from various sources to accelerate the use of solar energy, which is limited, due to the present technology, to stationary applications only. The approach in this dissertation differs from the approach discussed by Elliott et al., (2010). Elliott et al. focused only on importing countries, rather than producing countries. The approach suggested here differs from the approach suggested by Davis et al., (2011) because their approach of taxing fuel at the source, which will increase the cost of fuel for all, is economically disadvantageous to countries/organizations, which have invested in technology to 
minimize the emissions. Moreover, their approach neither offers any incentive to a country to reduce emissions nor to an organization to outsource to countries where emissions per unit Gross Domestic Product (GDP) are lower.

\subsubsection{Energy Usage}

Each source of energy has an associated impact on the environment, which can vary widely. Figure 2.1 provides a comparison of the lifecycle emissions from the most common sources of energy. The figure shows that renewable energy has a much lower impact on the environment as compared to non-renewable energy.

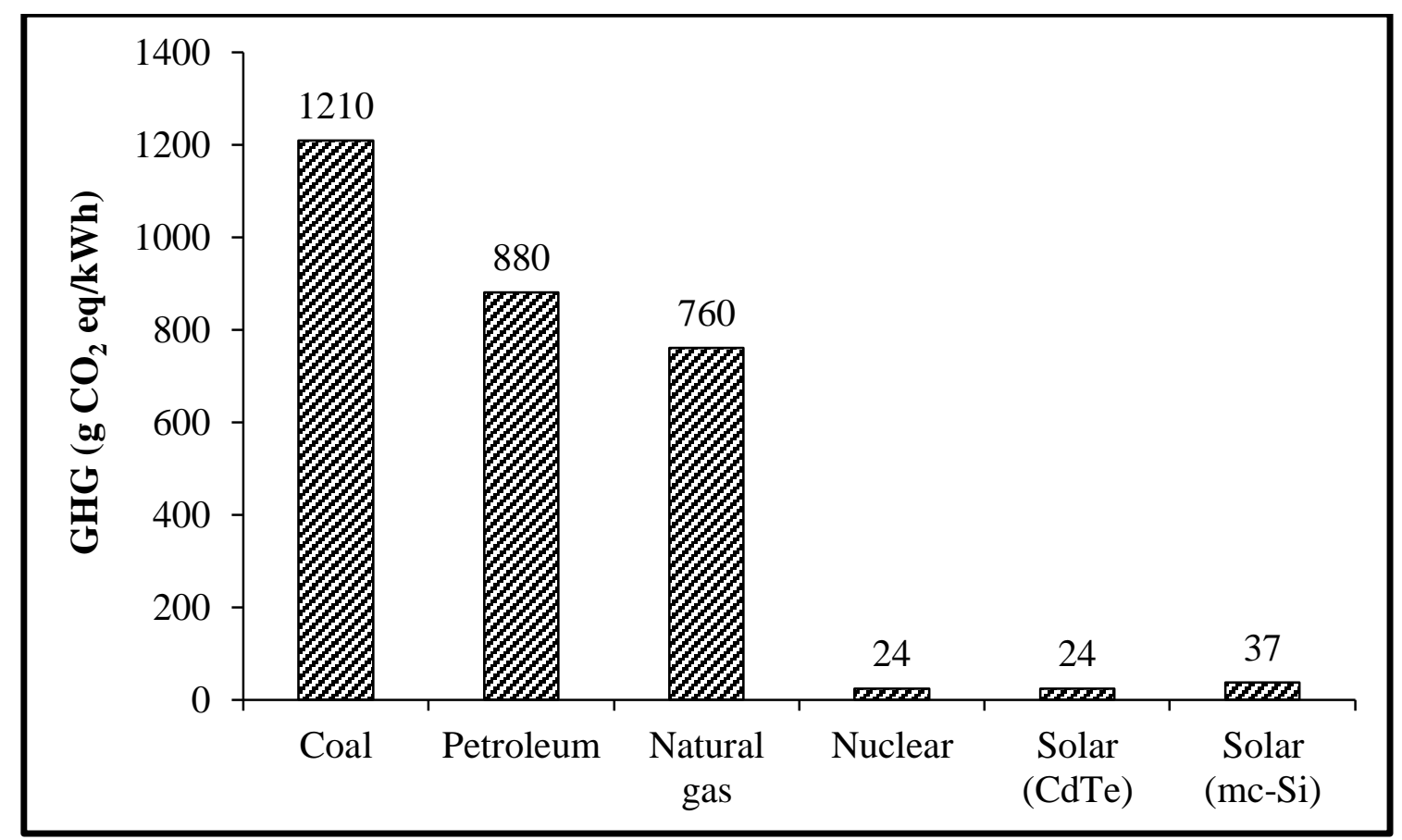

Figure 2.1: Lifecycle GHG emissions based on the sources of energy ${ }^{2}$ (Source: Fthenakis and Kim, 2011).

Nuclear energy is a key exception. Although the emissions from nuclear energy are low and in line with other renewable sources, the disposal of residual fuel and safety are major concerns associated with the generation of nuclear energy in addition to the availability of nuclear fuel. Koroneos et al., (2003) compared efficiencies of renewable and non-renewable energy sources

\footnotetext{
${ }^{2}$ CdTe - Cadmium Telluride; mc-Si - Multi-crystalline Silicon
} 
and concluded that available renewable energy technologies are not yet competitive to fossil fuel. However, renewable sources of energy are more competitive when GHG emissions are taken into account.

The nature of global energy consumption has changed over the last four decades. According to the IEA (2011), however, the sum of energy consumption in industry and transport together has not changed significantly. It is approximately $55 \%$ of the entire energy used. Additional changes are expected over the next several decades. Destouni and Frank (2010) projected the total global energy demand in 2050 as compared to 2007 and how the energy mix would undergo a change to reduce the dependence on fossil fuel, with the results summarized in Table 2.2. These results show that the world economy will continue to depend on conventional fuel as a primary source of energy for the next four decades.

Table 2.2: The shares of renewable and non-renewable sources in the global primary energy supply for 2007 and 2050.

\begin{tabular}{cccccc}
\hline Year & $\begin{array}{c}\text { Renewable } \\
\text { Energy } \\
\text { (TWh) }\end{array}$ & $\begin{array}{c}\text { Non- } \\
\text { renewable } \\
\text { Energy } \\
\text { (TWh) }\end{array}$ & $\begin{array}{c}\text { World } \\
\text { Energy } \\
\text { (TWh) }\end{array}$ & $\begin{array}{c}\text { \% of } \\
\text { Renewable } \\
\text { energy used }\end{array}$ & $\begin{array}{c}\text { \% of Non- } \\
\text { renewable } \\
\text { energy used }\end{array}$ \\
\hline 2007 & 16,800 & 123,200 & 140,000 & $12 \%$ & $88 \%$ \\
2050 & 59,500 & 110,500 & 170,000 & $35 \%$ & $65 \%$ \\
Change & $+254 \%$ & $-10 \%$ & $+21 \%$ & - & - \\
\hline
\end{tabular}

Source: Destouni and Frank, 2010.

\subsubsection{Measures of Energy Efficiency}

Emissions per capita and emissions per dollar of GDP are two common indicators of energy efficiency. As an example, Table 2.3 provides a comparison of these indicators for China, Germany, and the USA. A citizen of the USA pollutes the most of the three, while the German economy may be viewed as the greenest of the three since it generates fewer emissions per dollar. In interpreting these results, one should also look into the trade deficits between the three countries. For example, in 2010, the trade deficit (manufacturing items) between China and the USA was about $\$ 217$ billion (OECD, 2013b). This suggests that part of the emissions generated 
in China may be attributed to consumption in the USA. This leads to questions as to whether emissions per capita or emissions per dollar of GDP provide appropriate bases for comparison. Emissions per capita are not an appropriate measure for this analysis because the technology used for generating power and GDP per capita varies across countries. This research argues that a more appropriate measure of comparison would focus on GHG emissions per unit GDP, which is related to emissions from all economic activities of a country because emissions increase disproportionately with the increase in economic activities.

Table 2.3: Comparison of emissions indicators for 2009.

\begin{tabular}{lccc}
\hline Country & $\begin{array}{c}\text { Global GDP } \\
\text { Rank }\end{array}$ & $\begin{array}{c}\mathbf{C O}_{2} \text { emissions } \\
\text { (metric tons per } \\
\text { capita) }\end{array}$ & $\begin{array}{c}\mathbf{C O}_{2} \text { emissions per dollar GDP } \\
\text { (kg CO } \mathbf{~} \text { / US dollar) } \\
\text { (2005 prices) }\end{array}$ \\
\hline China & 2 & 5.77 & 2.21 \\
Germany & 4 & 8.97 & 0.26 \\
United States & 1 & 17.28 & 0.42 \\
\hline
\end{tabular}

Source: World Bank, 2013.

\subsubsection{Technological Inefficiencies}

The inefficiencies of the technologies used in power generation and in manufacturing in many developing countries have raised concerns. These problems have been attributed as one of the main reasons for persistently high GHG emissions. Choi et al., (2012) used a nonparametric efficiency analysis technique to calculate the efficiency of the energy sources and the corresponding emissions generated to understand how one can improve the efficiency and reduce emissions and related costs in China. Chang and Hu (2010) studied the energy productivity growth, technical progress, and efficiency changes in China and observed variations in emissions/development in different parts of China. Wei et al., (2011) compared energy efficiency across 156 countries from 1980 to 2007. Their results showed that China was ranked 147 (with 1 being the best) in a study of energy-efficient countries during this period. They also observed that China has made some improvements in the last 28 years. Yet China's rank in 2007 alone was 127 among the sample of 150 countries.

Based on the four sub-sections (2.2.1 through 2.2.4) above, Objective 2 was proposed as follows: 
Objective 2: Conduct an analysis of the changes in the GHG emissions as a result of offshore outsourcing of manufacturing activities.

\subsection{Transport Emissions}

This section provides a brief review of the literature on modes of international transportation and changes in transport activities over time. This section is divided into four sub-sections each focusing on modes of international transportation, impacts of international transport, technical means of reducing emissions and non-technical means of reducing emissions. It further explores how increases in transport activities affect carbon emissions. This provides a basis for a brief review of options to reduce carbon emissions. This section closes with a discussion on the policies available for reducing GHG emissions from international transport.

\subsubsection{Modes of International Transport of Manufactured Goods}

As Rodrigue et al., (2013) explain, "Transport modes are the means by which people and freight achieve mobility. They fall into one of three basic types, depending on over what surface they travel - land (road, rail and pipelines), water (shipping), and air". Data availability may vary for different modes of transport. Global transport activities were 9,644,216 million ton-km by railways and 176,760 million ton-km by air in 2011, 8,029,486 million ton-km by road in 2010 (World Bank, 2013), and 71,264,000 million ton-km by water in 2012 (UNCTD, 2012). The data from IMO (The International Maritime Organization) is consistent with these figures and reported that around $90 \%$ of the world trade is carried by the international shipping industry (IMO, 2013). All data sources clearly indicate that water freight transport is many times greater than the total of the other available options. International freight transport is clearly heavily dependent on the cargo shipping industry.

Manufactured items are transported internationally in huge quantities in cargo containers. Containers are chosen for shipping because it makes handling at the ports very easy as well as in switching between different modes of transportation such as ships, railways and trucks (Crist, 2009). Since Malcom McLean invented the use of the present day metal containers in 1956 there has been a phenomenal growth in containerized trade (The Economist, 2013). However, a similar 
concept of using boxes was used for combined rail and horse-drawn transport as early as 1792 in England. Drewry Shipping Consultants estimated that the world's seaborne trade carried by maritime container accounts for over $70 \%$ of the total trade value (Crist, 2009). According to another estimate, containerships carry about $60 \%$ of the value of goods transported worldwide (World Shipping Council, 2013a). Moreover, the increase in outsourcing of manufacturing activities has led to an increase in international transportation activities, particularly containerized shipping.

Ocean cargo for containerized items increased from 717 million tons in 1970 to 3,475 million tons in 2011, whereas remaining cargo (oil and gas, and bulk items such as iron ore, grain, coal, bauxite/alumina and phosphate) increased from 1,888 million tons to 5,273 million tons during the same period (UNCTD, 2012). In other words, containerized cargo increased 4.8 times, while shipping of non-containerized items increased 2.8 times during the same period (UNCTD, 2012). This shows that container-traffic has increased faster than other methods of ship transportation. It also indicates that trading of manufactured items, which are transported primarily though containers, is increasing faster than other items. Crist (2009) reached a similar conclusion. The author found that international maritime trade has doubled between 1985 and 2007, while containerized trade has grown eightfold during this period. A more recent statistic on container traffic shows a growth by 172\% worldwide between 2004 and 2011 (World Bank, 2013). All available data clearly show huge increases in containerized shipping over time.

\subsubsection{Impact of International Transport on the Environment}

Dalsøren et al., (2009) analyzed the impact of three ship types on the environment: bulk carriers, tank vessels, and container ships. The environmental impacts of container ships are the biggest among the three. The container ships have the largest total emissions on a per ship basis by a wide margin. Crist (2009) noted that container ships account for $25 \%$ of the total fuel consumption for 4,138 ships, while all crude and other tanker vessels combined represent $28 \%$ of the total fuel consumption for 12,930 ships. The remaining fuel is consumed for other ships such as passenger and bulk transportation (grains, ores, minerals etc.). Thus, reducing emissions from container ships will have the biggest potential impact on reducing ship emissions due to international transport of manufactured goods. 


\section{Chapter 2: Literature Review}

There is a large body of literature that has been published in the recent years emphasizing the need to reduce emissions from transport due to offshore outsourcing (Cadarso et al., 2010; Eyring et al., 2010; Howitt et al., 2011; Gilbert \& Bows, 2012; Cristea et al., 2013). As one illustration, Howitt et al., (2011) highlighted that GHG emissions from international air transport are excluded from reduction targets under the Kyoto Protocol and emphasized the need for reducing these emissions. They presented two methodologies for calculating $\mathrm{CO}_{2}$ emissions using factors of $0.82 \mathrm{~kg} \mathrm{CO}_{2}$ per t-km and $0.69 \mathrm{~kg} \mathrm{CO}_{2}$ per t-km for short haul and long haul journeys respectively. Their research showed that a total of 1.2 Million Ton of $\mathrm{CO}_{2}(44 \%$ for exports and $56 \%$ for imports) was generated due to air transportation of imports and exports activities for New Zealand in 2007. As a second illustration, Endresen et al., (2003) also concluded that there is a need for reducing GHG emissions since any increase affects the environment and contributes to global warming. For example, Radiative Forcing (RF) is a measure of radiant energy where a positive RF indicates an increase in atmospheric temperature. Endresen et al., (2003) studied the impact of an increase in marine transport on the environment and found an increase in RF due to an increase in GHG emissions. They also found an alarming increase in acidification of oceans, particularly near coastal and port areas. Hassellöv et al., (2013) further confirmed this phenomenon and reached a similar conclusion regarding the increase in acidification in coastal areas. They also mentioned that an increase in acidity could adversely affect marine ecosystems, such as the hatching of fish. As a final example, Andersen $e t$ al., (2010) analyzed the changes in emissions from transport due to exports from China. They concluded that it is large and demands attention. Transport emissions from international trade in China are in excess of 300 Million Tons of $\mathrm{CO}_{2}$. They also found that transport-related emissions are comparably high due to the lower efficiency of bunker fuel produced in China.

\subsubsection{Technical Means of Reducing Emissions due to International Transport}

Vöhringer et al., (2013) studied the emissions from international transport and found that they are significant. They suggested considering emissions as one of the factors in developing policies on international trade. As a part of this argument, they acknowledged the lack of policies on emissions from international transport. Gilbert and Bows (2012) studied the emissions from shipping and found a lack of policies on curtailing $\mathrm{CO}_{2}$ emissions in this area. They argued that 
there is a need for a global policy for reducing emissions from shipping. However, there is no meaningful policy in place to address the impacts of shipping on the environment (as of 2012). They also anticipated the development of a possible policy by the EU by 2013. The European Commission came out with a three-step approach of integrating emissions from ships into the policy of reducing national GHG emissions in June 2013. The first step is to implement MRV systems (Monitor, Report and Verification of $\mathrm{CO}_{2}$ emissions) for large ships using EU ports beginning January 1,2018 . The next step is a reduction in $\mathrm{CO}_{2}$ emissions by up to $2 \%$ by 2030 and lastly introduction of global market-based measures (MBMs) (European Commission, 2014). It is a beginning worth welcoming, but the targets for reduction are likely too small to make any meaningful impact on the emissions, particularly since they are limited to EU members. Lamas and Rodríguez (2012) have worked on reducing $\mathrm{NO}_{\mathrm{x}}$ (a generic term for mono-nitrogen oxides $\mathrm{NO}$ and $\mathrm{NO}_{2}$ ) from marine engines. They acknowledged the lack of policies for dealing with emissions from ships. They worked within the limitations of the only available and a dated policy (MARPL 73-78) for reducing $\mathrm{NO}_{\mathrm{x}}$. $\mathrm{NO}_{\mathrm{x}}$ reduction is important because it can travel between 400 to $1,200 \mathrm{~km}$ and more than $70 \%$ of these emissions are generated within $400 \mathrm{~km}$ of the coastline. Cristea et al., (2013) looked at the GHG emissions from international freight transport and found that $33 \%$ of the emissions from international trade are due to transport activities. They also noted that including the emissions related to transport in international trading would change the NEI per dollar of trade. Cadarso et al., (2010) studied changes in emissions from outsourcing for the Spanish economy and calculated an increase in $\mathrm{CO}_{2}$ emissions of $4.16 \%$ between 1995 and 2000 due to international freight transportation. They suggested assigning emissions associated with outsourcing to consumers.

\subsubsection{Non-Technical Means of Reducing Emissions due to International} Transport

The literature on non-technical means of reducing emissions caused by international transport include port and warehouse layout, speed of handling containers (so that ship loading/unloading time is minimal), and ship capacity utilization, among others. Better utilization of container and ship capacity has been identified by a number of authors as a notable method in helping to reduce emissions. Wu (2012) studied capacity utilization for container ships for three organizations (among the top 20 shippers in the world) and found it to be close to $70 \%$. Wu 
identified two critical factors, demand and global shipping alliances, for improving capacity utilization for container shipping. Wang et al., (2013) studied the effect of demand and route on capacity utilization between European and Asian countries. Their capacity utilization estimates ranged between $81.5 \%(\max )$ and $55.7 \%(\min )$. A case study in a different context presented data on container capacity utilization. The data presented showed that $96 \%$ of the containers had less than $80 \%$ of the max weight and $64 \%$ containers had less than $50 \%$ of the max weight (Garratt \& Teodoro, 2013). Further details on container capacity (by weight) utilization are available in Appendix B.

Lee et al., (2013) acknowledged that the current GTAP-E (Global Trade Analysis Project) excludes international transport emissions and there is a lack of literature on mechanisms for deploying a carbon tax on emissions from international transport. However, they developed potential scenarios on the impact of a carbon tax (on emissions from international transport) on total shipping costs and on shipping routes. They concluded that it would affect economic growth negatively. The use of a carbon tax in international transport to reduce the environmental impact of international transportation (due to outsourcing) has been largely overlooked in the literature. The lack of development in this area may be due to the positive impact that outsourcing has on developing nations, the financial benefits to outsourcing organizations, and the lack of policies by the UN or the WTO. However, this is an important oversight given the importance of a carbon tax in encouraging reductions in emissions due to the international transportation of manufactured goods.

$* * *$

Based on the four sub-sections (2.3.1 through 2.3.4) above, Objective 3 was proposed as follows:

Objective 3: Conduct an analysis of the change in the GHG emissions due to additional transportation as a consequence of offshore outsourcing of manufacturing activities.

\subsection{Fuel Prices and Emissions in Inventory Models}

This section provides a brief review of the literature on fuel prices, as well as the inclusion of increasing fuel cost and a carbon price on emissions from transport in supply chain models. This section is divided into 3 sub-sections each focusing on fuel prices, costs in inventory models and 
emissions in inventory models. This section closes with a discussion on the interactions of these two parameters in supply chain in the context of outsourcing.

\subsubsection{Fuel Prices}

In the context of a supply chain, transportation involves moving raw materials, semi-finished and finished products, from one entity (an origin) to another (a destination). The primary mode of transportation for global supply chains is cargo ships. The price of fuel influences the cost of cargo shipping as well as the configuration of supply chains. Sahin et al., (2009) analyzed the components in transport costs under different modes of transportation and found that fuel cost alone accounts for $32 \%, 46 \%$ and $60 \%$ of the total transport costs for marine, railways and road transportation respectively. The cost of bunker fuel in cargo shipping is about $30 \%$, though this varies slightly based on the speed and the size of the vessel, of the total cost of transportation, which is a significant contributor to the overall cost (Notteboom \& Vernimmen, 2009). Notteboom and Vernimmen (2009) discussed the effects of high fuel prices on marine cargo liners between the Far East and Europe and found that an increase in fuel prices increases their operating cost and erodes their profitability. In a related example, Jeihani and Sibdari (2010) studied the impact of gas prices on the auto industry and found that as the price of fuel increases, buyers switch to smaller cars to save on operating (fuel) cost. Fuel cost, as a fraction of the total cost of transportation, for cargo planes and trucks is about 33\% and 35\% respectively (IATA, 2013 and ATRI, 2013).

Fossil fuel, comprising of coal, oil, petroleum, and natural gas products, is still the single largest source of energy, satisfying $87 \%$ for global needs (BP, 2012). A lot of progress has been made in the area of renewable energy in the last decade; however its use is mainly limited to stationary applications and its share in overall energy consumption is negligible (BP, 2012), 1.3\% excluding hydro and $7.8 \%$ including hydro in 2010. Fuel cell technology, which has the potential to replace fossil fuel in transport in the future, is still in its infancy. This technology breaks water into oxygen and hydrogen, and uses hydrogen as fuel. The handling of hydrogen in transport vehicles is a safety concern and a challenge for designers. Although engineers are continuously striving for improving the energy efficiencies of transport vehicles, improvements made in the 
efficient use of fuel are offset by significantly higher demand. Figure 2.2 provides a summary of the trend in global oil consumption, which has been increasing steadily.

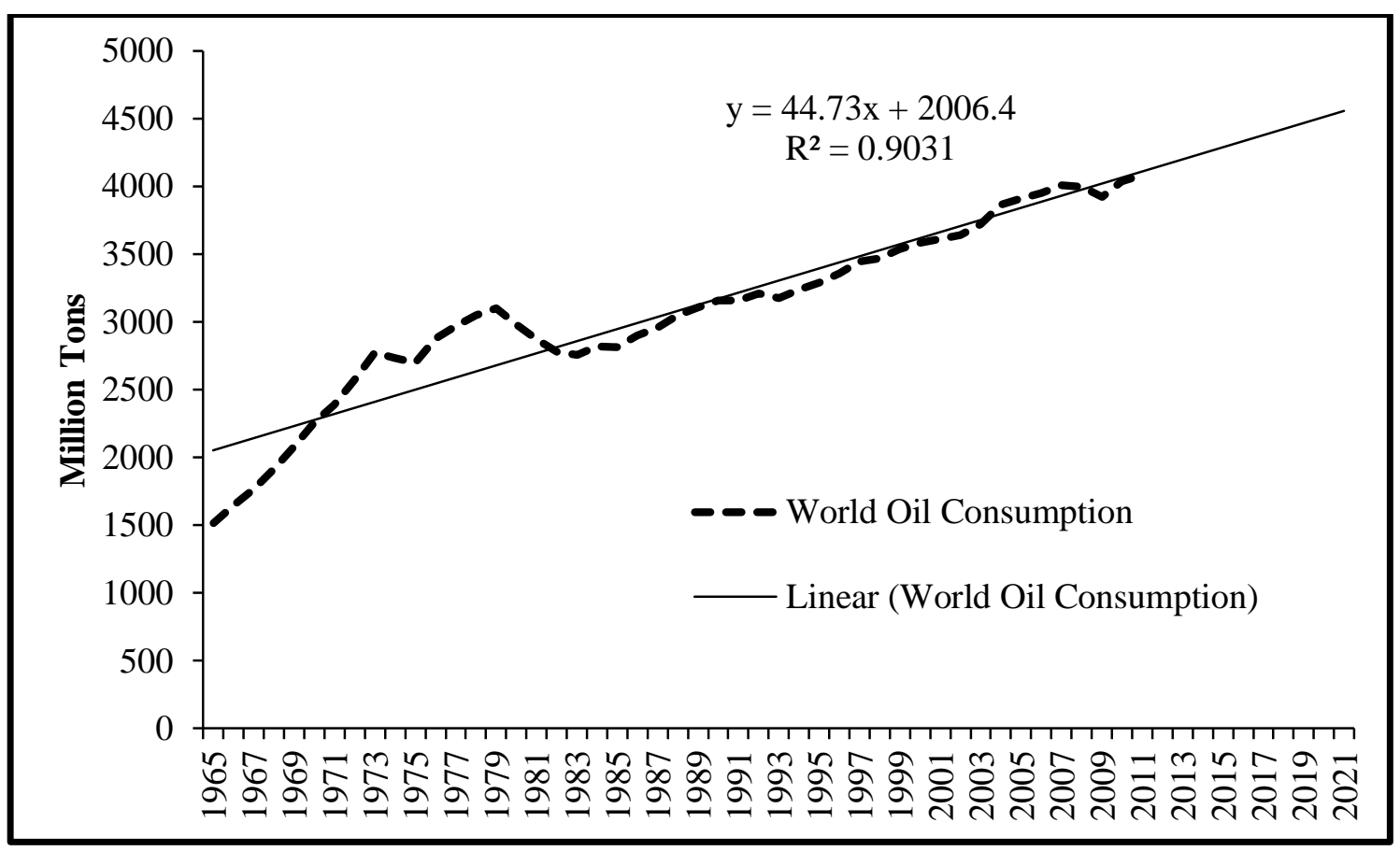

Figure 2.2: World oil consumption (Data Sources: BP, 2012).

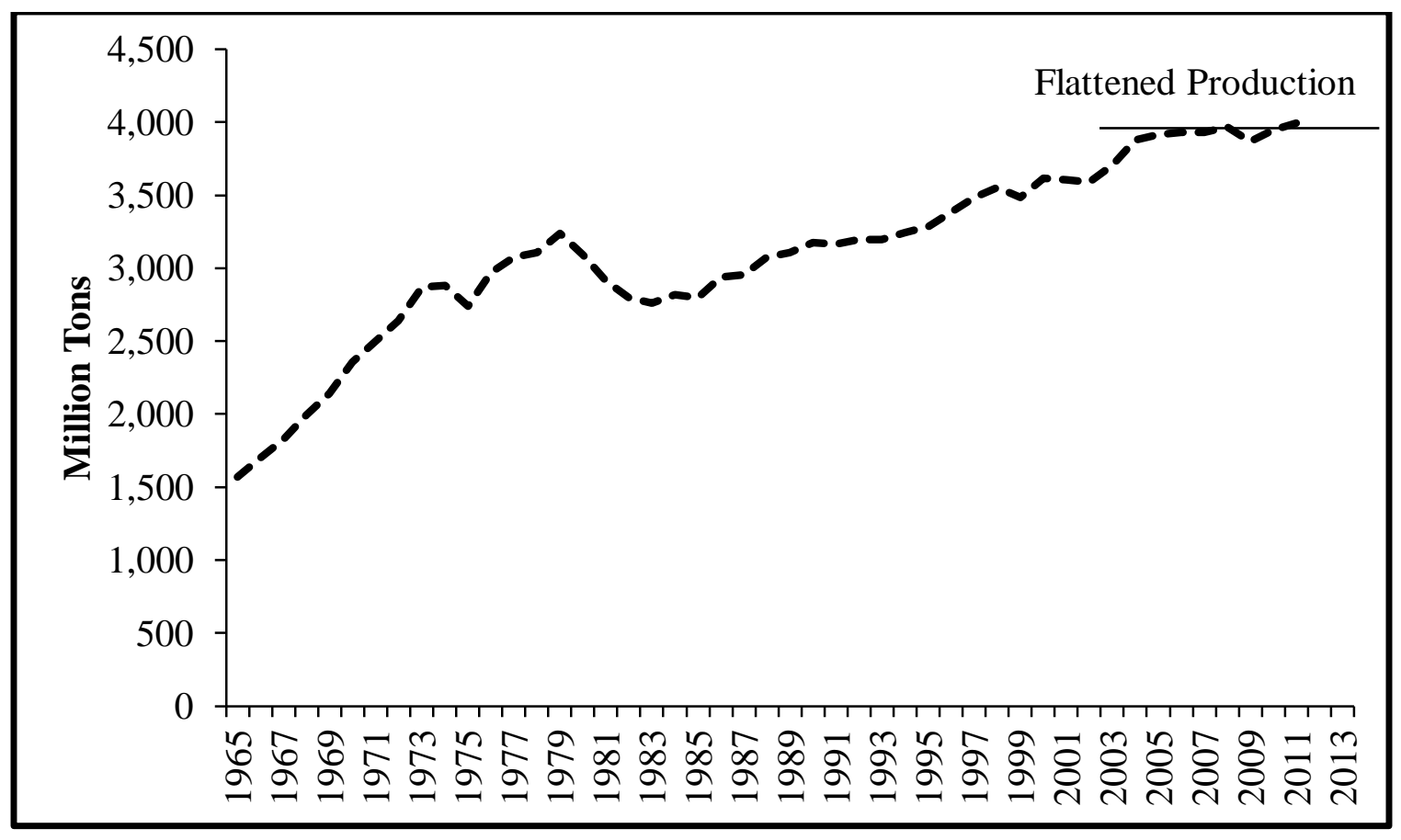

Figure 2.3: World oil production (Data Source: BP, 2012). 
The possibility of exhaustion of oil and the associated concept of "peak oil" was given by Hubbert $(1949,1956)$. This is commonly referred to as "Hubbert's Peak", which is the point in time where the maximum rate of global petroleum extraction is reached, after which the rate of production enters terminal decline. The rate of global oil production has not increased in line with the demand as shown in the Figure 2.3. Oil production in the last decade has been almost constant while the demand has been increasing. This trend started well before the recent global financial crisis, which started in the second half of 2008. This trend has put pressure on oil prices and contributed to an increase in oil prices greater than overall inflation.

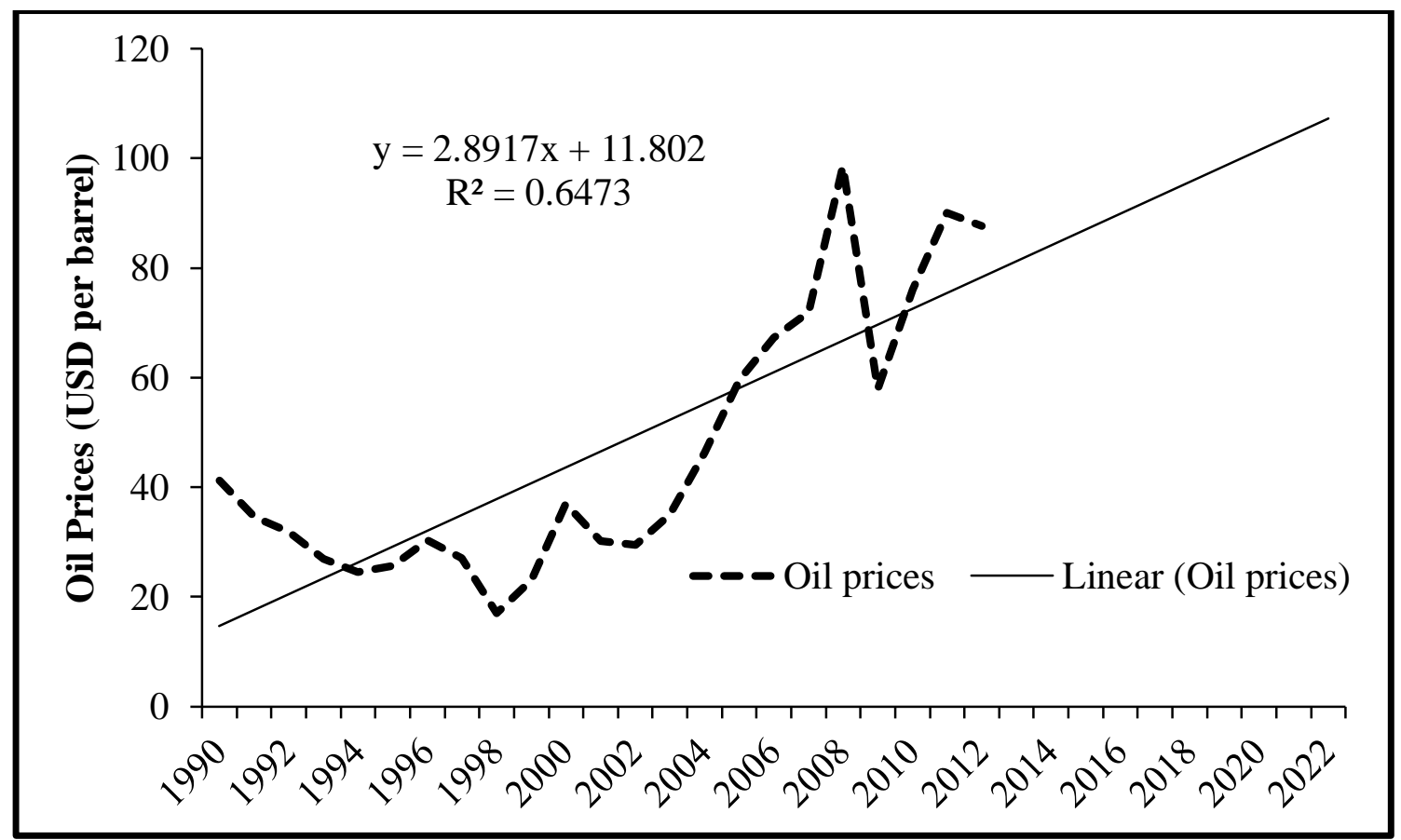

Figure 2.4: Inflation adjusted oil prices (Data sources: inflationdata.com, 2013).

The price of a commodity is a function of demand and supply. Fuel prices are experiencing pressure from both ends, i.e., increasing demands and depleting supplies. The increase in demand for energy due to industrialization in developing countries, the global increase in population and the depletion of oil reserves are putting pressure on the prices of fossil fuel. Oil prices have been steadily increasing over the years as shown in Figure 2.4. The best-fit curve for the price of oil 
per barrel in US dollars is a function of the form $y=2.8917 x+11.802$ where $x$ is the number of years counting from 1990.

Oil prices based on annual inflation, starting at every decade since 1950 until 2000, are given in Figure 2.5. The oil price calculated based on annual inflation, with an exception of 1980, should have been in the range of $\$ 21$ to $\$ 34$ per barrel in 2012. However, the annual average price of oil in 2012 was about $\$ 86$ per barrel. This indicates that oil prices are increasing at about 3 times the rate of overall annual inflation (which includes oil). Therefore, fuel prices are required to be considered differently in variable transport cost and supply chains. The price calculated based on annual inflation from 1980 is an anomaly due to political disturbance in Iran in the late 1970s.

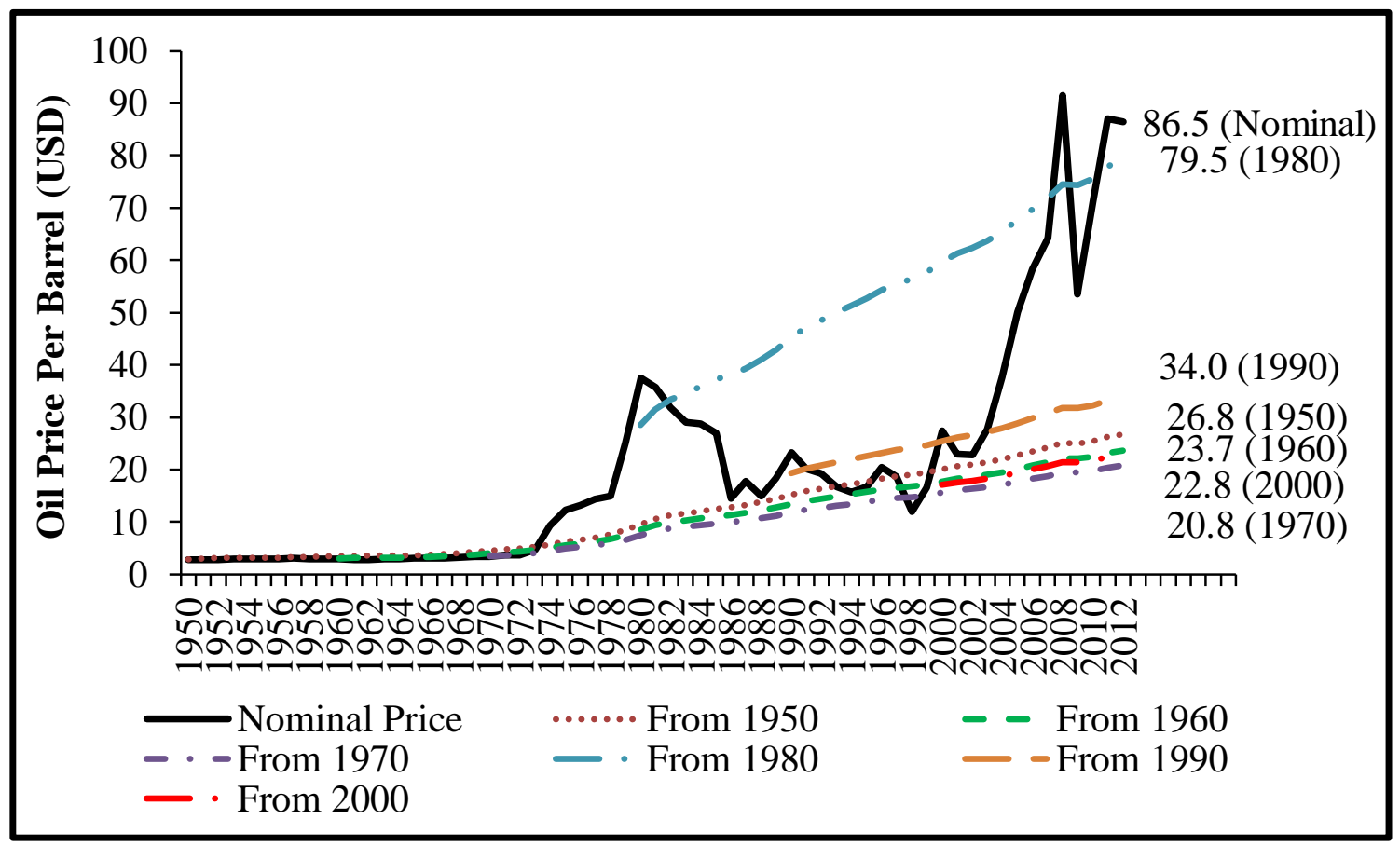

Figure 2.5: Oil prices based on annual inflation (Data source: inflationdata.com, 2013).

The cost of production as well as the corresponding cost of transportation will go up due to increases in energy prices. Renewable sources of energy, such as solar, wind, tidal, and geothermal, may dampen the rate of increase in the price of energy for industrial and domestic purposes in stationary applications. However, the use of energy from any other source for transport application in global supply chains is less likely to be available in the near term. Thus, organizations that have outsourced their manufacturing activities to offshore vendors will most 
likely face a challenge in determining workable inventory policies as fuel prices continue to increase.

\subsubsection{Costs in Inventory Models}

Some researchers have investigated the effects of transportation costs on lot-size decisions. For example, Goyal and Szendrovits (1986) modeled lot-sizes based on the constraint of truck/container capacity and fixed transport cost. They found that a firm could experience cost savings by allowing both equal and unequal lot-sizes at different stages of a production line (or a supply chain) as compared to models that require equal lot-sizes alone. Swenseth and Godfrey (2002) discussed inventory replenishment decisions due to price discounts on higher weight in transportation cost and found that transporting in larger quantities saves money. Russell and Krajewski (1991) discussed the transport cost in a supply chain when calculating the lot-size quantity based on weight discounts. In the case of partial truckloads (e.g., half a truck load), they found that declaring higher weights than the actual weight, costs less due to differences in rates. Ertogral et al., (2007) added a step-function of the transport cost in a two-level (supplier-buyer) supply chain cost function based on volume discounts with and without over-declaration. They found a potential for savings by explicitly integrating the transportation cost into the total supply chain cost as it alters inventory (and production) decisions. However, these studies, as others in the literature, did not factor the changes in the price of fuel over time explicitly into transport cost in their equations.

Corbey and Jansen (1993) studied the impact of various costs on the economic lot-size quantity and emphasized the inclusion of variable costs in its calculation. Zhao et al., (2004) have worked on adding transport costs for whenever multiple trips per day, within cities or in close proximities are possible. They found, adding fuel cost changes the lot-sizes. Most of the supply chain literature adopts a centralized policy approach by determining the joint sizing policy or the joint economic lot-size problem (JELSP) that minimizes the total supply chain cost. Existing literature either ignores the direct fuel cost in the cost analysis or implicitly considered it a part of the fixed order costs. This indicates a need for assessing the impact of changes in fuel prices, which affect the cost of transportation, on the EOQ model. In support of this notion, readers may refer to the work by Jaber and Zolfaghari (2008) and Glock (2012) for reviews on the JELSP. 


\subsubsection{Emissions in Inventory Models}

Chaabane et al., (2012) studied production processes and transportation systems in the aluminum industry and found that the current legislation and Emissions Trading Schemes (ETS) need to be strengthened and harmonized at the global level in order to drive a meaningful environmental strategy. Jaber et al., (2013) worked on the emissions in supply chains and presented a model for optimizing the cost of emissions under various scenarios. The importance of designing more environmentally responsible inventory models has been discussed by Bonney (2009). Later Bonney and Jaber (2011) also discussed various challenges in including the cost of impacts on the environment in inventory management; they stressed the need for assigning a cost of environmental impact for taking meaningful decisions. The importance of the relationship between energy and inventory was discussed by Zanoni and Zavanella (2009). Benjaafar et al., (2013) provided a generic model to account for emissions associated with ordering, inventory holding, and production. Chen et al., (2013) further extended the work of optimizing the order quantities (EOQ) while minimizing emissions. Hua et al., (2011) studied the impact of carbon trading schemes on lot-size.

Ulku (2012) acknowledged the need for improving environmental performance of transportation and developed a model for consolidating the consignments, which showed improvements both in cost and in environmental performance. Further, Pan et al., (2013) stressed the need for reducing GHG emissions from freight transport and developed a model for the pooling of supply chains as one of the viable options for reducing global GHG emissions. Using data from two French retail chains, Pan et al., found a reduction in emissions by combining the two supply chains through road and rail transport. Wahab et al., (2011) addressed the environmental impact of imperfect quality from an offshore vendor and suggested a dual supply chain (one offshore and the other onshore) as a solution. Rosic and Jammernegg (2013) used a dual sourcing model (one offshore and the other onshore) for minimizing the environmental impact of transport. They found that less sourcing from offshore improves the environmental performance of an organization, though its economic performance is negatively affected. Piecyk and McKinnon (2010) explored the impact of road transport in supply chains on carbon emissions by 2020. They concluded that some of the established practices such as the centralization of manufacturing and warehousing, 
JIT replenishment, and the outsourcing of non-core activities would not be sustainable. Bonney and Jaber (2011) also acknowledged the finite nature of fossil fuel and made similar comments about these practices due to fuel/energy cost in the future. The European Commission (1999) provided a detailed methodology for calculating emissions from transport. However, Ubeda et al., (2011) acknowledged that it is difficult to precisely estimate fuel consumption and emissions from transport and suggested the use of averages. They studied the impact of routing (in relatively close proximities) for Eroski, a Spanish retailer, in reducing emissions. The analysis in Chapter 7 uses average fuel consumption and tests the sensitivities for variation in average fuel consumption and travel distances.

Organizations with offshore-outsourced manufacturing and global supply chains have the additional challenge of reducing GHG emissions from transport. One prominent illustration of this challenge is that the EU has proposed a regulation for reducing $\mathrm{CO}_{2}$ emissions from light commercial vehicles. The proposed regulation targets a $\mathrm{CO}_{2}$ emissions reduction to $175 \mathrm{~g}$ $\mathrm{CO}_{2} / \mathrm{km}$ by 2016 (IEA, 2010). As a second example, the US Environment Protection Agency (ECFR, 2013) has new exhaust emissions standards (Subpart B, 1037.106) for $\mathrm{CO}_{2}$ for tractors above 26,000 pounds GVWR (gross vehicle weight rating). For a tractor with GVWR > 33,000 Pounds (16.5 Ton), high-roof sleeper cab, the maximum $\mathrm{CO}_{2}$ limit for years 2014-2016 is 75 $\mathrm{g} /$ Ton-mile $\mathrm{CO}_{2}$. This emissions value is used in the Chapter 7 to show its impact on the EOQ model.

To address these gaps in the literature, a cost function for variable fuel cost and a cost to emissions from transportation through a carbon tax are assigned and studied to determine its impact (in combination with variable fuel cost in transport) on supply chain costs in Chapter 7. ***

Based on the three sub-sections (2.4.1 through 2.4.3) above, Objective 4 was proposed as follows:

Objective 4: Study the impact of fuel cost, due to additional distance in supply chain, on inventory policies (EOQ). 


\subsection{Carbon Price}

Two methods of accounting for environmental impacts are to impose a carbon tax on emissions and a carbon-cap-and-trade scheme. There is increased interest in the literature focusing on a carbon tax on emissions and cap-and-trade schemes on carbon emissions. "A carbon tax is usually defined as a tax based on greenhouse gas emissions (GHG) generated from burning fuels" (British Columbia, 2013). "Cap and Trade is a market-based system for managing and reducing industrial greenhouse gas (GHG) emissions. In a cap-and-trade system, government sets a yearly cap, which limits the amount of greenhouse gases emitted. The cap is based on oneton units called 'allowances' which are distributed to the covered facilities. Facilities that emit more than the number of allowances they own must buy more allowances in the market" (Ontario Ministry of the Environment, 2013). Both of these methods have their pros and cons with respect to ease of implementation and effectiveness in reducing emissions. Avi-Yonah and Uhlmann (2009) compared these two schemes and acknowledged that cap and trade schemes seem popular. However, they argued in favor of a carbon tax scheme because they found that the effectiveness of a carbon tax is greater in reducing emissions. Wittneben (2009) also reached a similar conclusion in favor of a carbon tax. Cleetus (2011) summarized the difference between the two systems as follows: "we can set a cap on the quantity of emissions and allow the market to determine the resulting price (via a cap-and-trade program); or we can set a price and allow the market to determine the corresponding quantity of emissions (via a carbon tax)". The purpose of these policies is to disincentivize GHG emissions. Questions have been raised regarding the effectiveness of current programs to limit emissions (Jaehn \& Letmathe, 2010; Reyes \& Gilbertson, 2010). Nonetheless, Maruyama (2011) reviewed cap-and-trade versus a carbon tax as policies and recommended a carbon or energy tax for curbing emissions.

Bruvoll and Larsen (2004) did not find a carbon tax as an effective tool for reducing emissions. They studied the effects of a carbon tax on GHG emissions in Norway and found that the partial effects of lower energy intensity and energy mix changes caused a reduction in $\mathrm{CO}_{2}$ emissions of $14 \%$ while carbon taxes contributed to only a $2 \%$ reduction. Chaabane et al., (2012) studied the impact of supply chains on the environment in the aluminum industry. Their results suggested that the current legislation and Emissions Trading Schemes (ETS) must be strengthened and harmonized at the global level in order to drive a meaningful environmental strategy. Gerlagh 
and Lise (2005) presented a model to study the effects of carbon taxes on carbon-free energy and $\mathrm{CO}_{2}$ emissions. They emphasized the need for technological changes and showed that induced technological changes accelerate the substitution of carbon-free energy. Goulder and Mathai (2000) showed the cost-benefit analysis and effectiveness of a carbon tax in inducing technological changes for optimal $\mathrm{CO}_{2}$ reduction. Wahab et al., (2011) studied the changes in lot-size due to emissions costs in an international two-level supply chain and found that the lotsize increases when emissions costs are considered. Jaber et al., (2013) investigated the European Union Emissions Trading System (EU-ETS) in a two-level (vendor-buyer) supply chain context and presented a model for optimizing production under various scenarios. They suggested a policy that considers a combination of a carbon tax and an emissions penalty as the most effective over cap-and-trade and tax alone. Wang et al., (2012) suggested that the present Export Value-added-tax (VAT) Refund Rebate and Export Tax (EVRRET) in China does not capture carbon emissions and recommended a case for introducing an explicit carbon price into China's export tax. Mallah and Bansal (2012) proposed a carbon tax for the energy sector in India as a means of achieving the target reduction (20\% to $25 \%$ reduction by the year 2020) agreed to at the United Nations Climate Change Conference in Copenhagen (December 2009). Based on the above, Objective 5 was proposed as follows:

Objective 5: Study the effects of a carbon price on supply chain costs and the global emissions.

\subsection{Motivation for this Research}

As stated earlier, the concepts of global supply chains, offshore outsourcing, fossil fuel prices, and sustainability require a holistic approach to address them. This research is an attempt in that direction. A representative summary of the main contributions in the area of carbon pricing, emissions from outsourcing, emissions from sources of energy, environment in inventory models, environment in manufacturing, offshore outsourcing, supply chain coordination, supply chain emissions, transport emissions, and transportation cost is provided in Table 2.4. This helped clarify the gaps in the literature. A tick mark $(\checkmark)$ in a cell indicates the area of research done by the corresponding author(s) in the respective area(s). Further, this sub-section discussed the significance of addressing gap (i.e. impacts of offshore outsourcing on global emissions and 
effects of increasing fuel prices and a carbon price on additional emissions due to offshore outsourcing on supply chain costs and lot sizes) in literature.

Outsourcing of manufacturing activities led to changes in global GHG emissions due to differences in emissions per unit economic activity between countries and emissions due to additional transportation needs. In the majority of cases, activities are outsourced to countries, which are monetarily cheaper in part because they use older and less efficient technology in manufacturing and in power generation, which led to increases in global emissions (Herrmann \& Hauschild, 2009). This is more complex by the fact that there is no monetary value assigned to the additional emissions as a result of outsourcing in either corporate or national budgets. Although the generation of GHG emissions associated with manufacturing and/or transportation has been covered separately in the literature, there is little literature on the analysis of GHG emissions due to offshoring and from additional international transportation, and the combined effect of emissions and fuel cost on the supply chain due to offshoring. Burniaux et al., (2013) raised the concern that reduction in GHG emissions in a country may not yield the desired results in the global reductions of emissions due to leakage from other countries. They also acknowledged the needs for a carbon-based border tax adjustment (BTA) as a means of reducing global GHG emissions. Offshoring transfers the ownership of generating emissions to outsourcee countries without any liability on a corporate balance sheet or the national government allowing such imports.

However, there is little work on the cost of supply chains as a consequence of global emissions from offshore outsourcing from the use of energy in manufacturing, additional international transportation and increasing fuel prices. This research filled this void in the literature and also suggested a carbon price as a mechanism for reducing the global emissions. This also examined the impact on lot-sizes under different inventory policies. This research is aimed at addressing this gap in the literature and developing a framework for improving sustainability through reduction in GHG emissions from global supply chains. It is achieved through analyses of the changes in the cost of supply chains taking into considerations the increasing fuel prices and assigning a carbon price on emissions from manufacturing activities and additional transportation due to offshore outsourcing. 
Table 2.4: Previous contributions.

\begin{tabular}{|c|c|c|c|c|c|c|c|c|c|c|c|}
\hline Area of Study & & & 氖 & $\ddot{\overline{0}}$ & $\vec{b}$ & 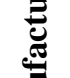 & & 氖 & & & \\
\hline $\begin{array}{c}\text { Author(s) } \\
\downarrow\end{array}$ & $\begin{array}{c}\text { Year } \\
\downarrow\end{array}$ & Uై & 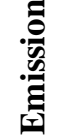 & 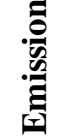 & 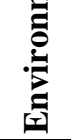 & 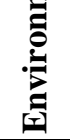 & 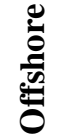 & $\begin{array}{l}\bar{D} \\
\overline{2} \\
\overline{2} \\
\overline{\mathscr{n}}\end{array}$ & $\begin{array}{l}\bar{J} \\
\frac{\lambda}{2} \\
\overline{\bar{Z}}\end{array}$ & 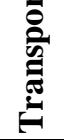 & : \\
\hline Andersen et al., & 2010 & & & & & $\checkmark$ & & & & & \\
\hline Bahrami & 2009 & & & & & & $\checkmark$ & & & & \\
\hline Bonney and Jaber & 2011 & & & & $\checkmark$ & & & & & & \\
\hline Braglia and Zavanella & 2003 & & & & & & & $\checkmark$ & & & \\
\hline Briggs & 2005 & & & & & & $\checkmark$ & & & & \\
\hline Cadarso et al., & 2010 & & & & & & & & & $\checkmark$ & \\
\hline Choi et al., & 2012 & & & $\checkmark$ & & & & & & & \\
\hline Cleetus & 2011 & $\checkmark$ & & & & & & & & & \\
\hline Dalsøren et al., & 2009 & & & & & & & & & $\checkmark$ & \\
\hline Davis et al., & 2011 & & $\checkmark$ & & & & & & & & \\
\hline Ertogral et al., & 2007 & & & & & & & & & & \\
\hline Eyring et al., 2010; & 2010 & & & & & & & & & $\checkmark$ & \\
\hline Goyal & 1977 & & & & & & & $\checkmark$ & & & \\
\hline Herrmann and Hauschild & 2009 & & $\checkmark$ & & & & & & & & \\
\hline Hill & 1999 & & & & & & & $\checkmark$ & & & \\
\hline Howitt et al., & 2011 & & & & & & & & & $\checkmark$ & \\
\hline Jaber et al., & 2013 & $\checkmark$ & & & & & & & $\checkmark$ & & \\
\hline Kinke & 2012 & & & & & $\checkmark$ & & & & & \\
\hline Lee et al., & 2013 & $\checkmark$ & $\checkmark$ & & & & & & & & \\
\hline Notteboom and Vernimmen & 2009 & & & & & & & & $\checkmark$ & & \\
\hline Piecyk and McKinnon & 2010 & & & & & & & & & $\checkmark$ & \\
\hline Russell and Krajewski & 1991 & & & & & & & & & & $\checkmark$ \\
\hline Sahin et al., & 2009 & & & & & & & & & & $\checkmark$ \\
\hline Seuring and Müller & $2008 \mathrm{a}$ & & & & $\checkmark$ & & & & & & \\
\hline Srivastava & 2007 & & & & $\checkmark$ & & & & & & \\
\hline Suhaimi et al., & 2007 & & & & & & $\checkmark$ & & & & \\
\hline Susomrith and Brown & 2013 & & & & & & $\checkmark$ & & & & \\
\hline Swenseth and Godfrey & 2002 & & & & & & & & & & $\checkmark$ \\
\hline Varadarajan & 2009 & & & & & & $\checkmark$ & & & & \\
\hline Zanoni and Zavanella & 2009 & & & & & & & & $\checkmark$ & & \\
\hline
\end{tabular}




\section{CHAPTER 3 : FRAMEWORK AND METHODOLOGY}


This chapter covers the overall framework for the research and the methodology used. This is an original framework for analyzing and quantifying the differential emissions associated with outsourcing of manufacturing activities. The framework is logical and powerful, though relatively simple and institutive, in assessing the impact of outsourcing on the emissions and supply chain costs. The use of this framework has been shown for outsourcing of manufacturing activities in this research. However, the framework is extendable to outsourcing of other sectors. The uniqueness and usefulness of this framework is in its applications at various levels, which range from making global policy guidelines by international organizations, developing a policy on a carbon tax on imports for nations, and using it as a decision making tool in corporate organizations for finding overall emissions and economically efficient places for operations and sourcing.

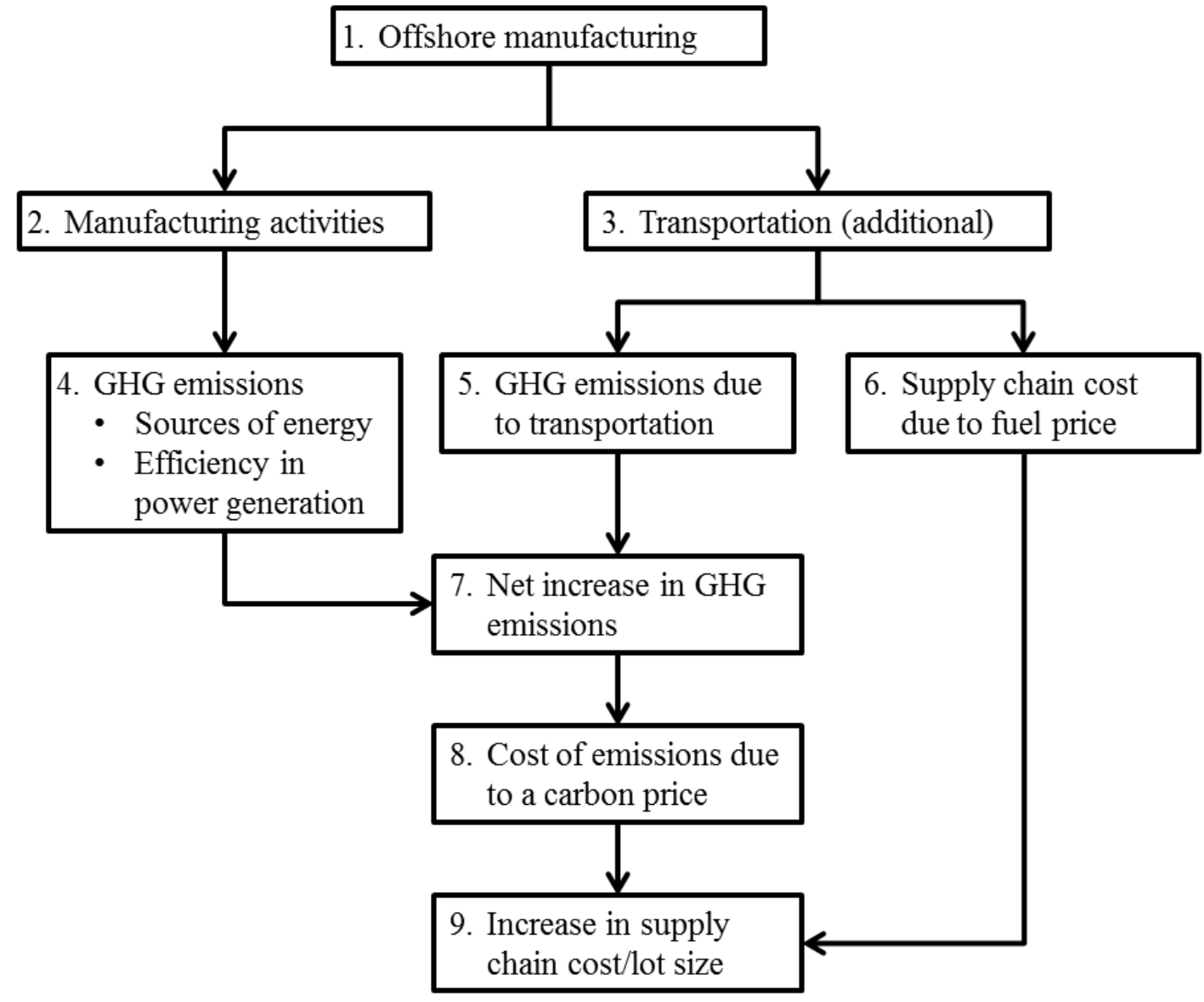

Figure 3.1: Framework of the research 
The framework is further described using a schematic diagram. Figure 3.1 provides an overview of the framework. The two main sources of emissions from offshore outsourcing (Box 1) are manufacturing activities (Box 2) and transport activities (Box 3). The choice of sources of energy and technology used in the country of manufacturing effects the manufacturing emissions (Box 4). Offshoring increases the need for additional transport in every case. Additional transport generates proportionately higher GHG emissions (Box 5). Therefore, both offshore manufacturing and associated transport add to global emissions (Box 7). Additional transportation also affects supply chain costs due to a proportional increase in fuel cost (Box 6). Logistics costs of global supply chains are further affected by an increase in fuel prices. A carbon price is suggested on the net emissions generated due to outsourcing (Box 8). A carbon pricing policy on additional emissions from manufacturing and transportation, coupled with increasing fuel prices will affect the overall cost of offshore manufacturing (Box 9). It is anticipated that the carbon pricing will reduce the cost advantage of offshore outsourcing to inefficient places, and motivate organizations to consider sourcing destinations, which are environmentally friendly. These actions would help reduce global emissions.

Table 3.1: Interaction levels.

\begin{tabular}{lccc}
\hline & Global & National & Organizational Individual \\
\hline Emissions & $\checkmark$ & $\checkmark$ & \\
Policies & & $\checkmark$ \\
\hline Direct effects of these policies & & \\
\hline \multicolumn{1}{c}{ Emissions } & $\checkmark$ & \\
Profitability & & $\checkmark$ \\
Tax revenues & $\checkmark$ & \\
\hline Indirect effects of these policies & \\
\hline Employment & \\
\hline
\end{tabular}

The proposed carbon pricing will affect many entities at different levels. The interactions of emissions and policies can be discussed at many levels. In this research, emissions are considered at the global level but policies suggested for minimizing emissions are at a national 
level (Table 3.1). However, the direct effect of these policies will be on global emissions, profitability of organizations, national tax revenues and indirect effect of these policies will be on national employment, and prices of items to consumers.

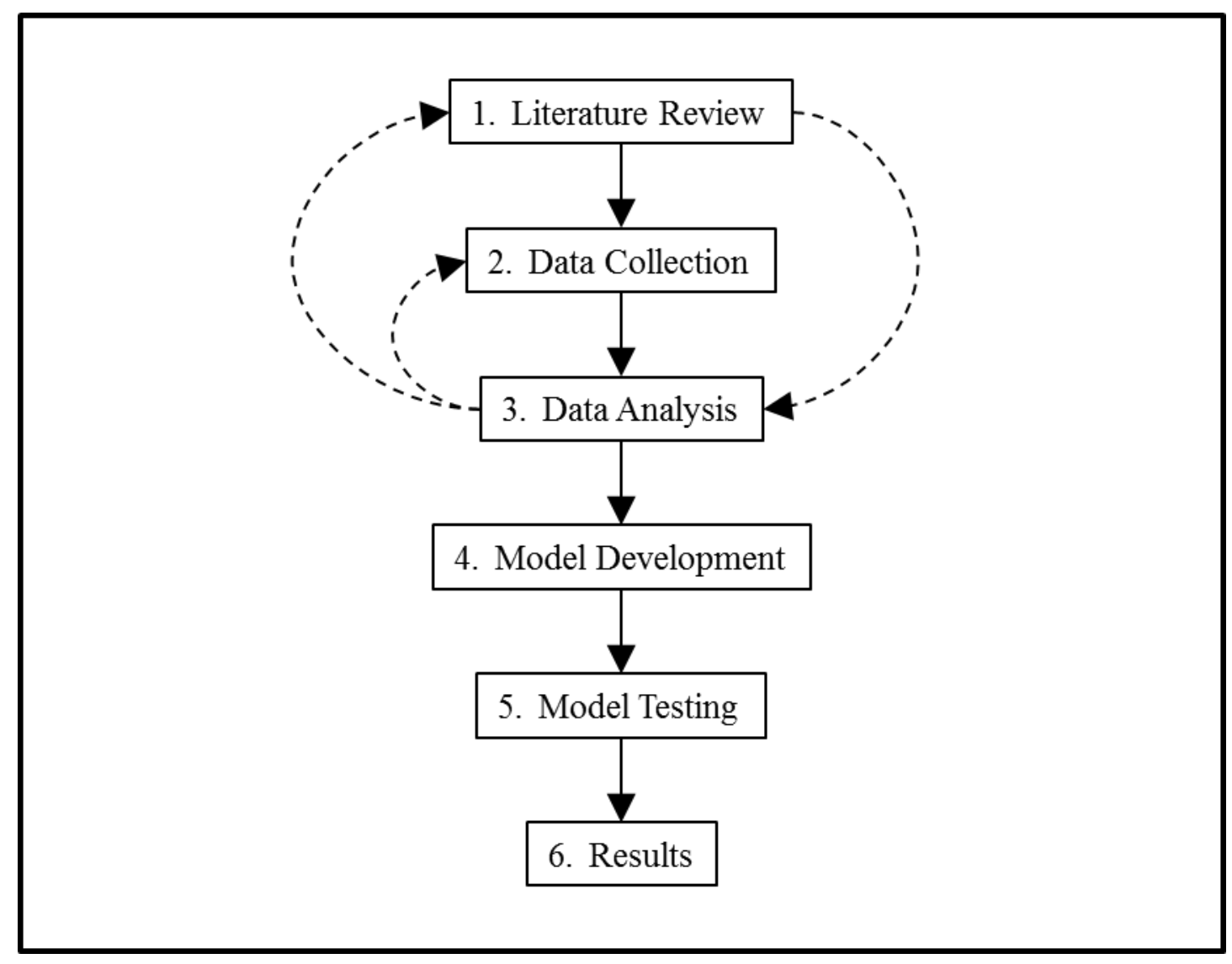

Figure 3.2: Process for the research

Each of the five objectives has been addressed through a structured process consisting of a literature review followed by data collection and analysis, modeling, and testing models (Figure 3.2). In some cases, data analysis led to the need for either additional data or review of additional literature to find if the finding already existed in literature. The dotted connectors between Box 3, 2 and 1 show the iterative nature of these processes. Objective 1 and Objective 5 have some exceptions to this process due to the nature of these objectives. Objective 1 did not develop any model as it is essentially an extension of literature review. However, it is argued that it merits its own chapter (Chapter 3) due to the nature of the extensive analysis involved. Therefore, steps 4 and 5 were omitted for Objective 1. Similarly, Objective 5 is a consolidation of the models 
developed in Objectives 2, 3 and 4, and did not require a separate literature review, data collection, and data analysis. Therefore, steps 1, 2 and 3 were omitted for Objective 5. Scopus and Compendex (Engineering Village) databases were used for the literature reviews. Both Compendex and Scopus are large interdisciplinary databases. The process followed for each objective is discussed briefly in subsequent sub-sections.

\subsection{Terms for environmentally friendly supply chains}

(Objective 1: Conduct an analysis of terms used to represent environmentally friendly supply chains and any changes in usage in the literature over time. Paper accepted for publication in Management Research Review)

As shown in Figure 3.1, there are a number of different sources of emissions in supply chains. The first step was to explore the literature for various terms used in the literature on supply chains, with an emphasis on minimizing emissions (Box 1; Figure 3.2). The research started with the identification of the keywords used in the literature on supply chains with a focus on the environment, selection of a database that published papers on supply chains and environment (sustainability), and the determination of the period of study. This was followed by cleaning up the data of the identified papers to be included in the sample by reviewing the keywords given by the authors.

The Scopus database was selected for this objective (Box 2; Figure 3.2). The reason for choosing this database is that it is one of the most comprehensive academic databases, which contains papers from engineering, management, operations research, and environmental science. The search was limited to research and review papers published in the English language during the six-year period between 2007 and 2012 in order to focus on the terms most recently used in the literature. Generating the list of keywords was an iterative process. An initial list was derived from a review of published literature reviews. It was further expanded based on a study of the keywords used in an initial sample of papers extracted from Scopus. This process was repeated until no new keywords focused on environmental aspects of SCM emerged. The output of this process was a final list of keywords to be used in subsequent searches. Each keyword has at least one variant and some keywords have more variants. As an example, variants of "eco-logistics" 
are "eco-logistic", "eco logistic" and "eco logistics". In the analysis below, minor variants such as those were treated as one keyword. Thirteen core keywords were used in identifying the relevant publications. Accounting for all variants, 32 searches were conducted. Details of the keywords used, their variants, and the number of papers found in each search is given in Appendix C.

The sample of papers was analyzed in order to determine the main journals publishing these papers, their publication frequency, frequency of usage of the keywords, and the papers, which appeared in multiple keyword searches (Box 3; Figure 3.2). The consolidated list of unique papers can be regenerated by typing the syntax without quotation marks "(AUTHKEY(\{closed loop supply chain OR \{closed-loop supply chain $\}$ OR \{closed loop supply chains OR \{closedloop supply chains $\}$ OR \{Eco-logistic $\}$ OR \{Eco-Logistics $\}$ OR \{Eco logistic $\}$ OR \{Eco logistics $\}$ OR \{Eco-Supply Chain $\}$ OR \{Eco-Supply Chains $\}$ OR \{Eco Supply Chain $\}$ OR \{Eco Supply Chains\} OR \{Environmentally Friendly Logistic\} OR \{Environmentally Friendly Logistics\} OR \{Environmentally Friendly Supply Chain\} OR \{Environmentally Friendly Supply Chains OR \{Green Logistic OR \{Green Logistics\} OR \{Green Reverse Logistic\} OR \{Green Reverse Logistics\} OR \{Green Reverse Supply Chain\} OR \{Green Reverse Supply Chains \} OR \{Green Supply Chain\} OR \{Green Supply Chains\} OR \{Responsible Supply Chain OR \{Responsible Supply Chains OR \{Reverse Logistic OR \{Reverse Logistics\} OR \{Reverse Supply Chain\} OR \{Reverse Supply Chains\} OR \{Sustainable Supply Chain\} OR \{Sustainable Supply Chains \}) AND DOCTYPE(ar OR re) AND PUBYEAR > 2006 AND PUBYEAR < 2013 AND LANGUAGE(English) AND SRCTYPE(j))" in the advanced search tab in the Scopus database. It is important to note that using the above syntax might give a discrepancy in the number of citations as this keeps changing with time. The data for the analysis was taken on October 12, 2013. Further analyses (Box 3) and the results (Box 6) are discussed in detail in Chapter 4.

\subsection{Emissions from offshore manufacturing}

(Objective 2: Conduct an analysis of the changes in the GHG emissions as a result of offshore outsourcing of manufacturing activities. Paper submitted to Journal of Cleaner Production) 
The review of existing literature (Box 1; Figure 3.2) highlighted some interesting trends, particularly the reduction in emissions in some countries while their imports were increasing. At the same time, the countries where emissions were increasing showed a trend of increasing exports. The literature also showed gaps in the accounting of global GHG emissions and provided a basis for data collection (Box 2; Figure 3.2). The data were collected on energy consumption, emissions, GDP, imports-exports between countries for analysis from publicly available sources, such as the World Bank, the World Trade Organization (WTO), and the Organization for Economic Co-operation and Development (OECD). The data collected was analyzed (Box 3; Figure 3.2) to see the trends and anomalies. Based on the trends and anomalies, a model was developed to address the identified gaps in the literature (Box 4; Figure 3.2). The model adjusts the emissions for a nation based on consumption. The model was tested based on economic activities among the USA, Germany and China (Box 5; Figure 3.2). The reasons for choosing these three countries were the sizes of their GDP indices, imports-exports of manufactured goods to the world and among these countries, and the sources of energy they use and the amount of emissions they produce. The model suggested that outsourcing increased the global GHG emissions but shifted its origin from a consuming nation to an outsourced manufacturing nation (Box 6; Figure 3.2). Further analyses (Box 3; Figure 3.2), model development (Box 4; Figure 3.2), model testing (Box 5; Figure 3.2), and results (Box 6; Figure 3.2) are discussed in detail in Chapter 5.

\subsection{Emissions from international transport}

(Objective 3: Conduct an analysis of the changes in the GHG emissions due to additional international transportation as a consequence of offshore outsourcing of manufacturing activities. Paper submitted to International Journal of Production Economics)

The focus of this objective was on developing a model that shows emissions from additional transportation of manufactured goods due to offshore outsourcing. Therefore, relevant transport data were collected and segregated before analyses. Secondly, continued economic development in the world is expected to increase transportation proportionately. However, technological 
development and environmental awareness should reduce emissions per unit weight per unit distance travelled. With these basic assumptions, the initial literature review (Box 1; Figure 3.2) showed an increase in transportation and emissions due to offshoring. The data were collected from national and international databases. It showed increases in transportation through different modes in the world and also between countries. These changes in transportation and its modes affected global GHG emissions (Box 2; Figure 3.2). Following analysis (Box 3; Figure 3.2), a model was developed to quantify the changes in emissions from transportation due to offshoring (Box 4; Figure 3.2). A generic model for calculating emissions from transportation associated with offshore outsourcing between various countries was developed and tested (Box 5; Figure 3.2). Further analyses (Box 3; Figure 3.2), model development (Box 4; Figure 3.2), model testing (Box 5; Figure 3.2), and results (Box 6; Figure 3.2) are discussed in detail in Chapter 6.

\subsection{Fuel prices and inventory policies}

(Objective 4: Analyze the impact of increases in fuel price on inventory policies (EOQ). Paper under revision with Applied Mathematical Modelling)

For objective 3, the literature review revealed a gap that transport cost is generally merged in the order cost and there is almost no literature available on the effects of increases in fuel prices on lot-size or economic order quantity (EOQ). The literature review also showed that fuel price is very important in transport cost (Box 1; Figure 3.2). The data analyses (Box 2-3; Figure 3.2) showed that fuel prices are increasing at a rate much higher than overall inflation over time. A function for increasing fuel prices was developed. This function was used to calculate variable fuel (transport) cost and was added to the EOQ model. The modified EOQ model developed considered fuel cost as separate cost, a variable function increasing over time (Box 4). The developed model was used to find the lot-size and order price for various inventory policies. The results showed that the changes in fuel price will impact the inventory policies (EOQ), overall cost and emissions due to an increase in travel distance under the offshore outsourcing scenario (Box 5-6; Figure 3.2). Further analyses (Box 3; Figure 3.2), model development (Box 4; Figure 3.2), model testing (Box 5; Figure 3.2), and results (Box 6; Figure 3.2) are discussed in detail in Chapter 7. 


\subsection{Effects of outsourcing on emissions and supply chain costs}

(Objective 5: Analyze the effects of outsourcing on NEI, and the combined effect of a carbon price on additional emissions from manufacturing and transport along with increases in fuel prices on supply chain costs.)

The last objective, which is a consolidation of previous models, did not require a separate literature review, data collection, and data analysis. A consolidated model was developed to calculate the differential emissions from manufacturing and additional emissions from transport activities due to outsourcing for a nation. The model was modified to calculate the effect of a carbon price on import costs. Further, models for inventory policies were modified to include the cost of emissions from manufacturing and transport and increasing fuel prices (Box 4; Figure 3.2). A carbon price was applied to the consolidated models. The model was tested to see the effect of outsourcing to two countries on emissions inventories of a nation. Similarly, varying fuel prices in addition to a carbon price on emissions were applied to the consolidated models under different inventory policies at different points starting from January 2014 to evaluate the combined effect of changes in fuel prices and a carbon price on supply chain policies (Box 5; Figure 3.2). Overall changes in NEI were reported. Annual order cost and lot-sizes were compared for various policies under the same conditions to see which policy works best (Box 6; Figure 3.2). Further model development (Box 4; Figure 3.2), model testing (Box 5; Figure 3.2), and results (Box 6; Figure 3.2) are discussed in detail in Chapter 8.

\subsection{Nations for illustrations}

Three nations, namely China, Germany and the USA have been identified for the purpose of illustrations, and applications of the framework and the models. The data for these three nations have been used to analyze the impact of outsourcing for a combination of factors, such as size of economy (GDP), ranking in international trade and annual emissions among others. The following table highlights the ranking of the three countries on the selected parameters. 
Table 3.2: Rationale for selecting the countries for illustrations

\begin{tabular}{lccc}
\hline \multicolumn{1}{c}{ Ranking } & USA & Germany & China \\
\hline GDP $^{3}$ & 1 & 4 & 2 \\
Manufacturing emissions $^{4}$ & 2 & 7 & 1 \\
Emissions per capita $^{5}$ & 10 & 33 & 61 \\
Trade partners of the USA $^{6}$ & - & 2 & 5 \\
Global merchandize exporter $^{7}$ & 2 & 3 & 1 \\
Global merchandize importer $^{6}$ & 1 & 3 & 2 \\
Distance from the USA $^{8}$ & - & 13,559 & 12,088 \\
Trading route with the USA $^{8}$ & - & Trans-Atlantic & Trans-Pacific \\
\hline
\end{tabular}

Similarly, some countries, which have one or two parameters very close to the identified factors, such as Japan, which ranks $3^{\text {rd }}$ in GDP, or any of the remaining BRIC countries, which have higher emissions than Germany, have not been including in this research due to the combination of the same factors. A brief explanation for not selecting some of the seemingly prominent countries for comparisons is as follows:

- Japan - the emissions are much lower than those of China, though it falls on the transpacific route for trade with the USA and ranks $3^{\text {rd }}$ in GDP.

- India - the exports of manufactured items are negligible, though emissions are higher than those of Germany.

- Brazil - the exports of manufactured items are negligible and the distance between the USA and Brazil is very small, though emissions are very close to those of Germany.

- Russia - the exports of manufactured items are negligible, though emissions are higher than those of Germany.

However, the framework and models developed are applicable to an individual country, a combination of any number of countries or to an organization.

\footnotetext{
${ }^{3}$ World Bank, 2011

${ }^{4}$ World Bank, 2010

${ }^{5}$ World Bank, 2009 (lower rank means high emissions per capita)

${ }^{6}$ The United States Census, 2013

${ }^{7}$ World Trade Organization (WTO), 2012

${ }^{8}$ Details explained in Chapter 6
} 


\section{CHAPTER 4 : TERMS FOR ENVIRONMENTALLY FRIENDLY SUPPLY CHAINS}


This chapter provides an analysis and a summary of the results obtained for Objective 1: Conduct an analysis of terms used to represent environmentally friendly supply chains and any changes in usage in the literature over time. It has two parts. Sub-Section 4.1 provides analysis of the data on terms used for environmentally friendly supply chains and sub-section 4.2 provides findings.

\subsection{Analysis}

This section is further divided into 3 sub-sections. Each sub-section focused on different aspects of the analysis, though there were some overlaps. The first sub-section focused on the analysis of journals and papers, the second sub-section focused on the analysis of keywords, and the last sub-section focused on citations and countries involved in research in this area.

\subsubsection{Analysis of Journals and Papers}

The total number of papers gathered was 698. Several top-level analyses of the papers were conducted. The analysis began with the identification of the papers that have more than one of the searched for keywords in a single paper. It was determined that there were 65 papers where authors have used two of the identified keywords in the same paper and there were two instances were authors have used three of the identified keywords in a single paper. Therefore, 65 papers counted two times and two papers three times in the total of 698 papers. No paper contained more than three of the searched keywords. This initial screening highlighted that most of the authors chose only one of the selected terms as the keyword for their research in this area. After removing the papers that were counted multiple times, the unique number of papers was 629 $(698-65 * 1-2 * 2=629)$. The title of each paper was then analyzed to determine whether it contained any of the searched for keywords. It was found that $57 \%$ titles of the 629 paper contained at least one of those keywords. An additional $12 \%$ of the titles contained partial terms like "green/ greener/ greening", "environment/ environmental", "eco", and "sustainable/ sustainability". The classification of each paper (e.g., review paper or research paper), as listed in the Scopus database, was also analyzed. Out of the 629 papers, only 32 were categorized as review papers. Among the papers containing multiple keywords, eight were categorized as 
review papers. The remaining papers were classified as articles, which include research papers, conceptual papers, and case studies.

By analyzing the 629 unique papers, it was found that these papers were published in 214 journals from 20 disciplines. Figure 4.1 provides a summary of the disciplines that have been involved in this research. Figure 4.1 also highlights the changes in focus on research in the area of green supply chains across disciplines. The subject areas for each journal were taken from the Scopus database as defined by the journals. Out of the disciplines represented in the sample, Business Management and Accounting, Engineering, and Decision Sciences accounted for about $62 \%$ of the 629 published research papers. Over the last 6 years, the contribution of the Business

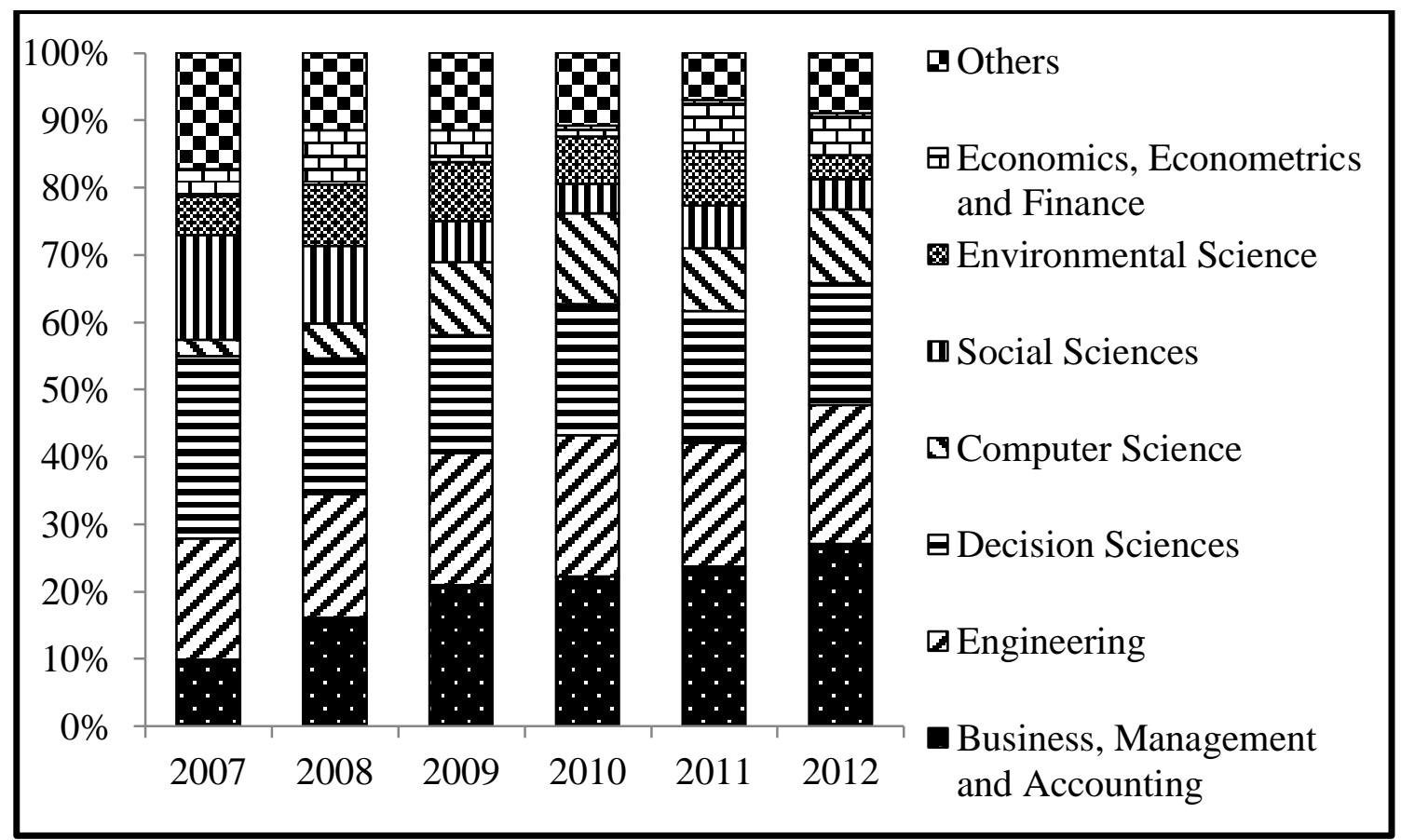

Figure 4.1: Contributing disciplines.

Management and Accounting discipline has almost tripled, while the contribution of Decision Sciences has reduced by one third. Incidentally, Environmental Science and Social Science lost contributions on a relative scale. There are 13 disciplines categorized as "others" (Appendix D), which had relatively limited contributions. The spread of disciplines brings different perspective and helps in building a rich literature for an evolving area. While it helps in developing an area 
of research; however, it also contributes to the issue of authors using different terms interchangeably due to differences in definitions between the disciplines.

Table 4.1: Names of journals and the number of published papers.

\begin{tabular}{|c|c|c|c|c|c|c|c|c|c|c|}
\hline Journal & હ્ণิ & $\stackrel{\infty}{\stackrel{\overbrace{}}{్}}$ & $\stackrel{\overbrace{}}{\overparen{్}}$ & $\stackrel{\ominus}{\stackrel{\theta}{\ominus}}$ & $\overline{\bar{乛}}$ & בָำ & 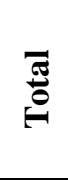 & $\%$ & $\begin{array}{c}\text { Total No. of } \\
\text { papers } \\
\text { published by } \\
\text { journal }^{9}\end{array}$ & $\begin{array}{l}\text { \% papers on } \\
\text { supply chain } \\
\text { with focus on } \\
\text { environment }\end{array}$ \\
\hline $\begin{array}{l}\text { International Journal of } \\
\text { Production Research }\end{array}$ & 8 & 2 & 4 & 7 & 7 & 20 & 48 & 7.6 & 1995 & 2.4 \\
\hline $\begin{array}{l}\text { International Journal of } \\
\text { Production Economics }\end{array}$ & 5 & 11 & 2 & 1 & 8 & 20 & 47 & 7.5 & 1647 & 2.9 \\
\hline $\begin{array}{l}\text { International Journal of } \\
\text { Logistics Systems and } \\
\text { Management }\end{array}$ & 1 & 6 & 2 & 4 & 7 & 6 & 26 & 4.1 & 283 & 9.2 \\
\hline $\begin{array}{l}\text { European Journal of } \\
\text { Operational Research }\end{array}$ & 3 & 3 & 6 & 5 & & 2 & 19 & 3.0 & 4030 & 0.5 \\
\hline $\begin{array}{l}\text { Transportation Research } \\
\text { Part E Logistics and } \\
\text { Transportation Review }\end{array}$ & & 4 & 2 & 1 & 6 & 5 & 18 & 2.9 & 456 & 3.9 \\
\hline $\begin{array}{l}\text { Computers and Operations } \\
\text { Research }\end{array}$ & 10 & 3 & & 2 & 1 & 1 & 17 & 2.7 & 1423 & 1.2 \\
\hline $\begin{array}{l}\text { Computers and Industrial } \\
\text { Engineering }\end{array}$ & & 1 & 3 & 4 & 3 & 5 & 16 & 2.5 & 1171 & 1.4 \\
\hline $\begin{array}{l}\text { Resources Conservation } \\
\text { and Recycling }\end{array}$ & & 1 & 2 & & 10 & 3 & 16 & 2.5 & 765 & 2.1 \\
\hline $\begin{array}{l}\text { Journal of Cleaner } \\
\text { Production }\end{array}$ & 2 & 4 & 3 & 2 & 2 & 2 & 15 & 2.4 & 1402 & 1.1 \\
\hline $\begin{array}{l}\text { International Journal of } \\
\text { Sustainable Engineering }\end{array}$ & & 3 & 4 & & 4 & 1 & 12 & 1.9 & 147 & 8.2 \\
\hline $\begin{array}{l}\text { Subtotal of top } 10 \\
\text { journals }\end{array}$ & 29 & 38 & 28 & 26 & 48 & 65 & 234 & 37 & - & - \\
\hline $\begin{array}{l}\text { Subtotal of remaining } 204 \\
\text { journals }\end{array}$ & 27 & 39 & 41 & 62 & 85 & 141 & 395 & 63 & - & - \\
\hline Total $^{11}(10+204=214)$ & 56 & 77 & 69 & 88 & 133 & 206 & 629 & 100 & - & - \\
\hline
\end{tabular}

The journals publishing the majority of the papers were heavily concentrated. The top ten journals accounted for 234 of the published papers; that is, about 5\% (10/214=0.047) of the journals published about $37 \%(234 / 629=0.372)$ of the papers. Details of these top ten journals

\footnotetext{
${ }^{9}$ Sum of all the papers published on any discipline by the corresponding journal between 2007 and 2012

${ }^{10} \%$ of papers $=($ Total $/$ Total No. of papers published by a journal $) \times 100$

${ }^{11}$ Total number of journals in this study is 214
} 
and the number of papers published in each year are given in Table 4.1. It shows that the International Journal of Production Research (IJPR) and the International Journal of Production Economics (IJPE) are the top two journals. These two journals alone published 48 and 47 papers respectively, which is about $15 \%((48+47) / 629=0.151)$ of the total papers.

The highest number of papers published by a single journal in a year on these topics was 20 (by two journals in 2012, which are IJPE and IJPR). Table 4.2 provides a matrix of the number of journals that published a certain number of papers in a year. The total number of papers published in a single year has more than tripled from 56 in 2007 to 206 papers in 2012.

Table 4.2: A combination of number of papers published by journals by year.

\begin{tabular}{ccccccccc}
\hline $\begin{array}{c}\text { No. of papers } \\
\text { published in a journal } \\
\downarrow\end{array}$ & \multicolumn{6}{c}{$\begin{array}{c}\text { No. of journals (that published } \\
\text { corresponding No. of papers from the } \\
\text { first column) }\end{array}$} & $\begin{array}{c}\text { Total No. of } \\
\text { papers }\end{array}$ \\
\cline { 2 - 7 } & $\mathbf{2 0 0 7}$ & $\mathbf{2 0 0 8}$ & $\mathbf{2 0 0 9}$ & $\mathbf{2 0 1 0}$ & $\mathbf{2 0 1 1}$ & $\mathbf{2 0 1 2}$ & \\
\hline 2 & 22 & 26 & 30 & 37 & 50 & 77 & 242 \\
3 & 4 & 7 & 8 & 8 & 11 & 16 & 108 \\
4 & 1 & 4 & 3 & 3 & 5 & 4 & 60 \\
5 & - & 2 & 2 & 2 & 2 & 1 & 36 \\
6 & 1 & - & - & 1 & - & 3 & 25 \\
7 & - & 1 & 1 & 1 & 1 & 2 & 36 \\
8 & - & - & - & 1 & 2 & 2 & 35 \\
10 & 1 & - & - & - & 1 & - & 16 \\
11 & 1 & - & - & - & 1 & - & 20 \\
20 & - & 1 & - & - & - & - & 11 \\
\hline Total & - & - & - & - & - & 2 & 40 \\
\hline
\end{tabular}

The number of journals publishing these papers in a single year increased more than three times from 30 to 107 over the same period (Table 4.3). This indicates that the research in this area has intensified. Nevertheless, only four journals published papers with the specified keyword every year during this period, namely 
Chapter 4: Terms for Environmentally Friendly Supply Chains

i. $\quad$ International Journal of Production Economics (IJPE)

ii. International Journal of Production Research (IJPR)

iii. $\quad$ International Journal of Logistics Systems and Management (IJLSM)

iv. Journal of Cleaner Production (JCP)

Table 4.3: Changes in the number of journals between 2007-2012.

\begin{tabular}{lcccccc}
\hline & $\mathbf{2 0 0 7}$ & $\mathbf{2 0 0 8}$ & $\mathbf{2 0 0 9}$ & $\mathbf{2 0 1 0}$ & $\mathbf{2 0 1 1}$ & $\mathbf{2 0 1 2}$ \\
\hline A. No. of journals in the previous year & - & 30 & 41 & 44 & 53 & 73 \\
$\begin{array}{l}\text { B. No. of new journals added } \\
\begin{array}{l}\text { C. No. of journals dropped from the } \\
\text { previous year }\end{array}\end{array}$ & - & 31 & 27 & 40 & 47 & 78 \\
\hline $\begin{array}{l}\text { No. of journals that published paper(s) } \\
\text { (A+B-C) }\end{array}$ & $\mathbf{3 0}$ & $\mathbf{4 1}$ & $\mathbf{4 4}$ & $\mathbf{5 3}$ & $\mathbf{7 3}$ & $\mathbf{1 0 7}$ \\
\hline
\end{tabular}

While the total number of papers and journals has increased, there are many journals, which have either reduced or shifted their focus from publishing research in this area. Table 4.3 provides the changes in the number of journals publishing papers on supply chains in the context of environmental impact. It shows that many new journals were added every year while a number of other journals, which published previously, were dropped. Of the 214 journals, 107 journals (50\%) published at least one paper in this area in 2012. It is important to mention that the total number of journals does not represent the sum of journals for each year because many journals published multiple years (i.e., referring to the last row of Table 4.3; $30+41+44+53+73+107 \neq 214$ ). A journal publishing at least one paper in each of the 6 years will appear in the yearly count as one of the journals that published paper(s) each year. However, in total, it will appear as one journal in the count of unique journals. Therefore, 214 is the number of unique journals, which published at least one paper in the area of green supply chains over the 6-year period studied. Table 4.4 provides the data on the number of journals that did not publish any paper in a particular period (e.g., of the 214 journals, 23 journals did not publish any paper during 2009-2012). 
Chapter 4: Terms for Environmentally Friendly Supply Chains

Table 4.4: Number of journals that did not publish any paper during a period.

\begin{tabular}{lcc}
\hline \multicolumn{1}{c}{ Period } & No. & $\mathbf{\%}^{\mathbf{1 2}}$ (No./214) \\
\hline in 2012 & 107 & $50 \%$ \\
in 2011 and 2012 & 63 & $29 \%$ \\
between 2010 and 2012 & 41 & $19 \%$ \\
between 2009 and 2012 & 23 & $11 \%$ \\
between 2008 and 2012 & 10 & $5 \%$ \\
\hline
\end{tabular}

Many journals published as little as only one paper in any given year. Some journals published just one paper in the six-year period. Table 4.5 gives details on the number of journals that published only one paper in a year and their frequency. These numbers are not cumulative; that is, the number of journals that published a single paper for a year does not include the number of journals that published a single paper for two years. In addition, it does not include journals that published more than one paper in any year during this period. In other words, these journals never published more than a single paper in a year. Therefore, about $60 \%(129 / 214=0.603)$ of the journals published only one paper during this period totaling about $21 \%(129 / 629=0.205)$ of the papers reviewed.

Table 4.5: Analysis of journals that published one paper in a year.

\begin{tabular}{ccccc}
\hline Published Single Paper & $\begin{array}{c}\text { \# of } \\
\text { journals }\end{array}$ & $\begin{array}{c}\text { \# of } \\
\text { papers }\end{array}$ & $\begin{array}{c}\text { \% of } \\
\text { journals }^{\mathbf{1 3}}\end{array}$ & $\begin{array}{c}\text { \% of } \\
\text { papers }^{\mathbf{1 4}}\end{array}$ \\
\hline During the entire period & 129 & 129 & 60.3 & 20.5 \\
In any 2 years during the period & 18 & 36 & 8.4 & 5.7 \\
In any 3 years during the period & 8 & 24 & 3.7 & 3.8 \\
\hline Total & $\mathbf{1 5 5}$ & $\mathbf{1 8 9}$ & $\mathbf{7 2 . 4}$ & $\mathbf{3 0}$ \\
\hline
\end{tabular}

The above analysis indicated that research in this area in increasing. There are many disciplines doing research in this area. Similarly, there are many journals publishing research in this area, while many journals are dropping out of publishing research in this area. This is an indicator of the evolving nature of the field.

\footnotetext{
12 Total number of journals that published during this period is 214 .

$13 \%$ of journals $=(\#$ of journals $/ 214) \times 100$

${ }^{14} \%$ of papers $=(\#$ of papers/629 $) \times 100$
} 


\subsubsection{Analysis of Keywords}

Further analysis of the relationship between the keywords, which were used in the same paper and caused multiple counting of 67 papers, revealed that "closed-loop supply chains", "reverse logistics" and "green supply chains" were the most used combinations. All the combinations of keywords found in papers and their frequencies across years are given in Table 4.6.

Table 4.6: Combination of keywords and number of papers for multiple searches by year.

\begin{tabular}{|c|c|c|c|c|c|c|c|c|}
\hline \multirow{2}{*}{$\begin{array}{c}\text { No. of } \\
\text { key } \\
\text { words }\end{array}$} & \multirow[b]{2}{*}{ Combinations of keywords } & \multicolumn{7}{|c|}{ Number of papers } \\
\hline & & 气ิે & 啇 & ڤ్ & 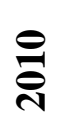 & 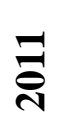 & 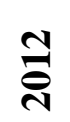 & $\stackrel{5}{0}$ \\
\hline 2 & Closed-loop supply chains + Reverse logistics & 2 & 5 & 3 & 4 & 7 & 10 & 31 \\
\hline 2 & Green supply chains + Reverse logistics & & 4 & 1 & & 2 & 2 & 9 \\
\hline 2 & Green logistics + Reverse logistics & 1 & 1 & & 2 & 1 & 2 & 7 \\
\hline 21 & Reverse logistics + Reverse supply chains & & & 1 & & 2 & 3 & 6 \\
\hline 2 & Closed-loop supply chains + Reverse supply chains & & & 1 & & 1 & & 2 \\
\hline 2 & $\begin{array}{l}\text { Closed-loop supply chains }+ \text { Sustainable supply } \\
\text { chains }\end{array}$ & & & 1 & & 1 & & 2 \\
\hline 2 & Green supply chains + Sustainable supply chains & & & & & & 2 & 2 \\
\hline 2 & Closed-loop supply chains + Green supply chains & & 1 & & & & 1 & 2 \\
\hline 21 & Reverse logistics + Sustainable supply chains & & & & & & 1 & 1 \\
\hline 21 & Eco-logistics + Eco-supply chains & 1 & & & & & & 1 \\
\hline 2 & Green supply chains + Reverse supply chains & & 1 & & & & & 1 \\
\hline 2 & Green logistics + Green supply chains & & & & & 1 & & 1 \\
\hline 3 & $\begin{array}{l}\text { Closed-loop supply chains }+ \text { Green supply chains }+ \\
\text { Reverse logistics }\end{array}$ & & & & & & 1 & 1 \\
\hline 3 & $\begin{array}{l}\text { Closed-loop supply chains + Green supply chains + } \\
\text { Sustainable supply chains }\end{array}$ & & & & & 1 & & 1 \\
\hline & Total & 4 & 12 & 7 & 6 & 16 & 22 & 67 \\
\hline & Number of keywords ${ }^{15}$ & 8 & 24 & 14 & 12 & 33 & 45 & 136 \\
\hline
\end{tabular}

\footnotetext{
${ }^{15}$ Sum of No. of keywords $\mathrm{x}$ No. of papers for a year
} 
Subsequent analysis of the frequency of papers that contained the identified keywords included multiple (double and triple) counting of $67(65+2=67)$ papers, that is, a total of 698 data points were used in the analysis of keywords. The ranking of the most used keywords in the literature related to green supply chains is given in Table 4.7. It is interesting to note that no paper ever used "green reverse logistics", "green reverse supply chains", "environmentally friendly logistics" and "environmentally friendly supply chains" as keywords.

Table 4.7: Number of papers containing searched keywords in various years.

\begin{tabular}{lcccccccc}
\hline \multicolumn{1}{c}{ Search keyword } & $\mathbf{2 0 0 7}$ & $\mathbf{2 0 0 8}$ & $\mathbf{2 0 0 9}$ & $\mathbf{2 0 1 0}$ & $\mathbf{2 0 1 1}$ & $\mathbf{2 0 1 2}$ & Total & \% $^{16}$ \\
\hline Reverse logistics & 37 & 49 & 48 & 48 & 72 & 82 & $\mathbf{3 3 6}$ & 48.1 \\
Green supply chains & 9 & 15 & 5 & 13 & 28 & 56 & $\mathbf{1 2 6}$ & 18.1 \\
Closed-loop supply chains & 7 & 13 & 14 & 23 & 25 & 39 & $\mathbf{1 2 1}$ & 17.3 \\
Sustainable supply chain & 1 & 4 & 4 & 5 & 11 & 26 & $\mathbf{5 1}$ & 7.3 \\
Reverse supply chains & 3 & 6 & 5 & 2 & 5 & 10 & $\mathbf{3 1}$ & 4.4 \\
Green logistics & 1 & 1 & - & 3 & 9 & 15 & $\mathbf{2 9}$ & 4.2 \\
Responsible supply chains & - & 1 & - & - & - & 1 & $\mathbf{2}$ & 0.3 \\
Eco-logistics & 1 & - & - & - & - & - & $\mathbf{1}$ & 0.1 \\
Eco-supply chains & 1 & - & - & - & - & - & $\mathbf{1}$ & 0.1 \\
\hline A. Total & $\mathbf{6 0}$ & $\mathbf{8 9}$ & $\mathbf{7 6}$ & $\mathbf{9 4}$ & $\mathbf{1 5 0}$ & $\mathbf{2 2 9}$ & $\mathbf{6 9 8}$ & \\
B. Double counted papers & 4 & 12 & 7 & 6 & 15 & 21 & $\mathbf{6 5}$ & \\
C. Triple counted papers & - & - & - & - & 1 & 1 & $\mathbf{2}$ & \\
\hline Unique papers (A-B-2*C) & $\mathbf{5 6}$ & $\mathbf{7 7}$ & $\mathbf{6 9}$ & $\mathbf{8 8}$ & $\mathbf{1 3 3}$ & $\mathbf{2 0 6}$ & $\mathbf{6 2 9}$ & \\
\hline
\end{tabular}

"Responsible supply chain", "eco-supply chains" and "eco-logistics" did not gain traction and were used for an insignificant number of times. "Eco-supply chains" and "eco-logistics" did not $16 \%=($ Total $/ 698) * 100$ 
reappear since 2007. However, "responsible supply chains" reappeared once in 2012 after a gap of 3 years. Table 4.7 also shows that during the same period the usage of the keywords "green supply chains", "green logistics" and "sustainable supply chains" has increased. "Reverse logistics" was the most used term every year during the period under study. The usage of "reverse logistics" has increased on an absolute scale from 37 to 82 between 2007 and 2012. However, it has dropped on a relative scale from $62 \%(37 / 60=0.6167)$ of the total keywords used in 2007 to $36 \%(82 / 229=0.3581)$ in 2012 . Similarly, relative use of the term "green supply chains" has increased from $15 \%(9 / 60=0.15)$ of the total keywords used in 2007 to about $25 \%$ $(56 / 229=0.2445)$ in 2012 . Figure 4.2 provides a summary of the relative changes in the terms over the period of study. The term "sustainable supply chains" has seen the largest relative increase (from 1 to 26) followed by "green logistics" (from 1 to 15), see Table 4.7.

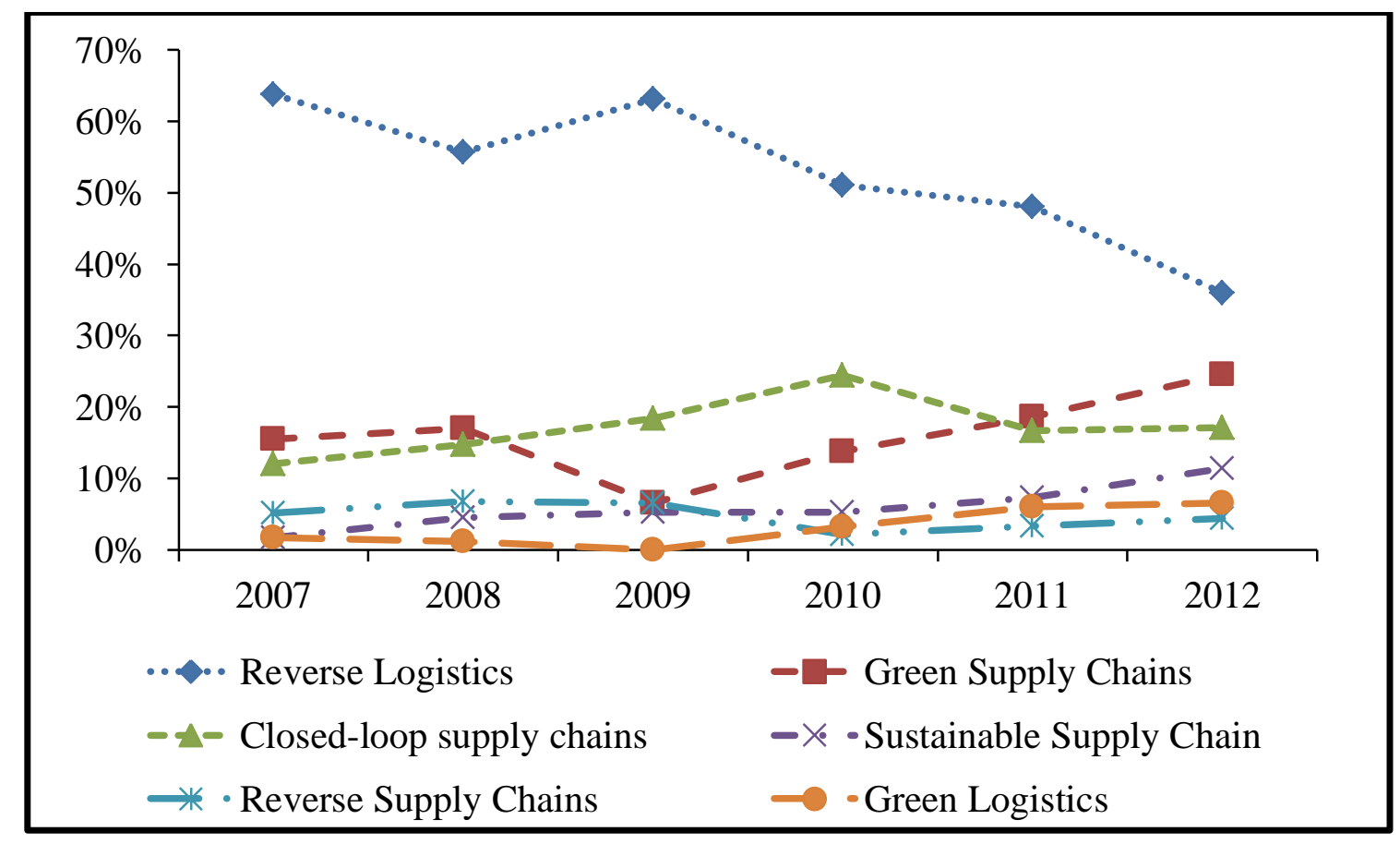

Figure 4.2: Changes in the use of keywords in papers between 2007 and 2012.

Further analysis on the usage of keywords revealed that a total of 3,119 keywords; i.e., $\sum_{i=1}^{14} i P_{i}=3,119$, where $P_{i}$ is the total number of papers with $i$ number of keywords used by 
authors in a paper averaging about five keywords per paper $\left(\frac{\sum_{i=1}^{14} i P_{i}}{\sum_{i=1}^{14} P_{i}}=\frac{3,119}{629}=4.96\right)$. The maximum number of keywords used in a paper was 14 and the minimum was one, both occurring in one paper each. A breakdown of the number of keywords appearing in a paper is given in Figure 4.3. This includes multiple counting of a keyword in various papers. Counting these keywords just once, reduced the list to 1,565 keywords. Then, by removing minor differences (from the 1,565 keywords) primarily due to writing style, such as 'database' and 'data-base' or '3PL' and 'third party logistics', a list of 1094 unique keywords was generated. Table 4.8 provides the appearance of unique terms across the years. The number is not cumulative; that is, the terms appearing in any two years are not included in the term appearing for one year. There are only 26 keywords, which appeared in at least one paper every year for 6 years.

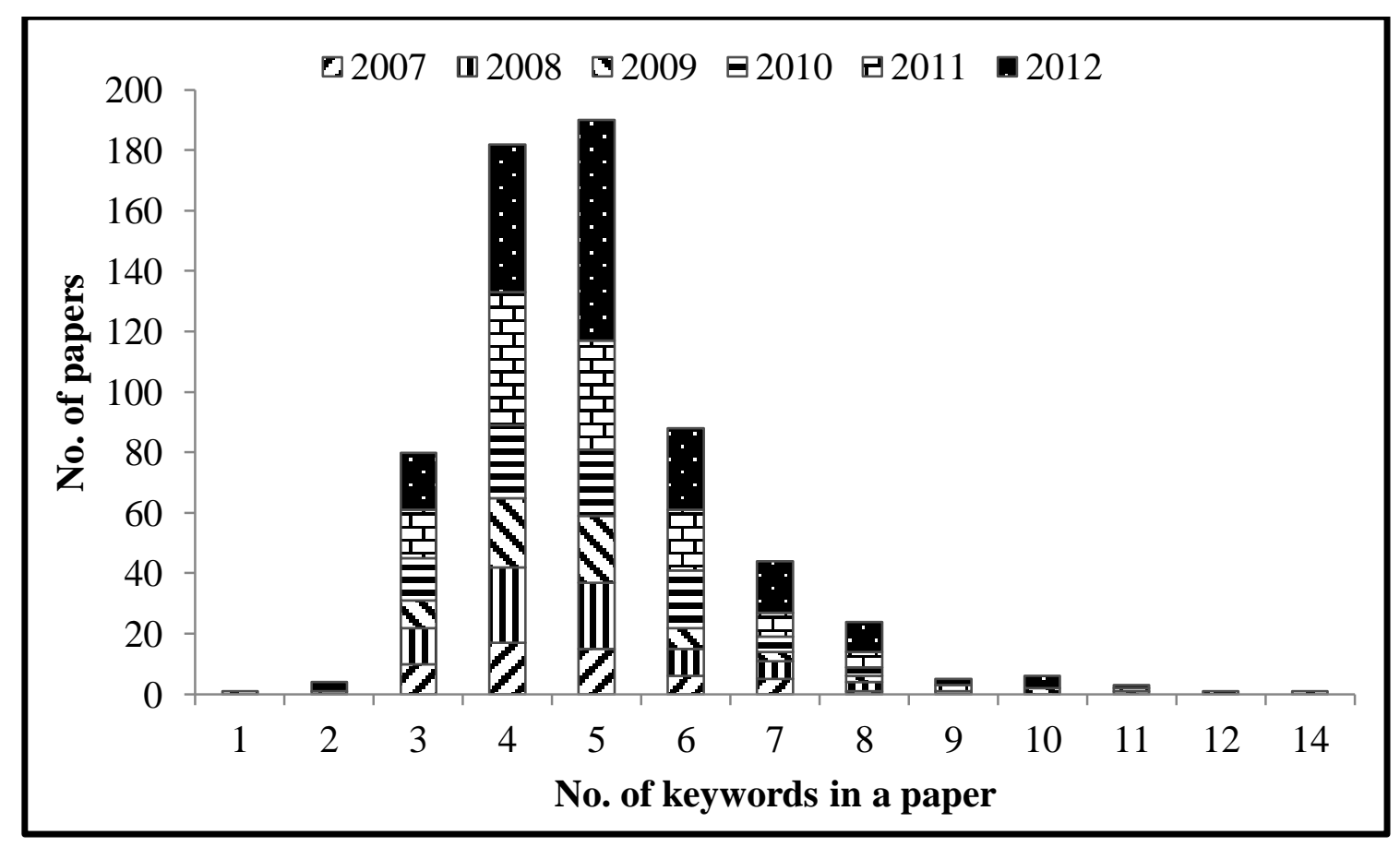

Figure 4.3: Number of keywords used in the paper. 
Table 4.8: Count of unique keywords across years.

\begin{tabular}{lcc}
\hline Unique keywords that appeared & No. & \% $^{\mathbf{1 7}}$ \\
\hline Every year for 6 years & 26 & 2.4 \\
5 years & 20 & 1.8 \\
4 years & 35 & 3.2 \\
3 years & 41 & 3.7 \\
2 years & 155 & 14.2 \\
1 year & 817 & 74.7 \\
\hline Total keywords & $\mathbf{1 0 9 4}$ & $\mathbf{1 0 0}$ \\
\hline
\end{tabular}

Table 4.9: Frequency of the most used keywords.

\begin{tabular}{|c|c|c|c|c|c|c|c|c|}
\hline \multirow{2}{*}{ Keyword } & \multicolumn{7}{|c|}{$\begin{array}{l}\text { No. of papers (that used the keywords from } \\
\text { left column) }\end{array}$} & \multirow{2}{*}{$\%^{18}$} \\
\hline & 2007 & 2008 & 2009 & 2010 & 2011 & 2012 & $\begin{array}{c}\text { Tota } \\
\quad 1\end{array}$ & \\
\hline Reverse logistics & 35 & 49 & 55 & 50 & 71 & 85 & 345 & 11.1 \\
\hline Green supply chains & 10 & 17 & 5 & 14 & 31 & 61 & 138 & 4.4 \\
\hline Closed-loop supply chains & 7 & 14 & 14 & 23 & 27 & 40 & 125 & 4.0 \\
\hline Remanufacturing & 8 & 6 & 10 & 15 & 13 & 20 & 72 & 2.3 \\
\hline Supply chain management & 6 & 3 & 4 & 6 & 15 & 24 & 58 & 1.9 \\
\hline Sustainable supply chains & 1 & 4 & 4 & 5 & 11 & 30 & 55 & 1.8 \\
\hline $\begin{array}{l}\text { Environmental } \\
\text { management }\end{array}$ & 4 & 6 & 2 & 8 & 5 & 24 & 49 & 1.6 \\
\hline Recycling & 5 & 6 & 5 & 8 & 7 & 13 & 44 & 1.4 \\
\hline Reverse supply chains & 3 & 6 & 6 & 2 & 5 & 11 & 33 & 1.1 \\
\hline Sustainability & 1 & 2 & 4 & 3 & 11 & 11 & 32 & 1.0 \\
\hline $\begin{array}{llll}\begin{array}{l}\text { Subtotal of } \\
\text { keywords }\end{array} & \text { top } & 10 \\
\end{array}$ & 80 & 113 & 109 & 134 & 196 & 319 & 951 & 30.5 \\
\hline $\begin{array}{l}\text { Subtotal of other keywords } \\
(1084)\end{array}$ & 187 & 253 & 230 & 296 & 455 & 747 & 2168 & 69.5 \\
\hline Total (1094) & 267 & 366 & 339 & 430 & 651 & 1066 & 3119 & 100 \\
\hline
\end{tabular}

Note: total unique keywords are 1094 and total count of keywords in all the papers is 3119.

\footnotetext{
$17 \%=($ No./1094) $\times 100$

$18 \%=($ Total $/ 3119) \times 100$
} 
Table 4.9 shows the top ten keywords that appeared in the searches (including the terms that appeared in Table 4.7). The top 10 keywords appeared a total of 951 times. In other words, less than $1 \%(10 / 1,094=0.00914)$ of keywords accounted for about $30 \%(951 / 3,119=0.304)$ of the usage. The number against the keywords in this table is slightly more than the number in the Table 4.7 due to consolidation of some keywords, such as counting 3PRLP (third party reverse logistics processes) as reverse logistics.

Table 4.10: Statistics on low frequency keywords

\begin{tabular}{lcc}
\hline \multicolumn{1}{c}{ Low frequency keywords } & Number of keywords & \% \\
\hline Keywords that appeared 1 time & 777 & 71.0 \\
Keywords that appeared 2 times & 156 & 14.3 \\
Keywords that appeared 3 times & 46 & 4.2 \\
Keywords that appeared 4 times & 26 & 2.4 \\
Keywords that appeared 5 times & 11 & 1.0 \\
Keywords that appeared 6 times & 11 & 1.0 \\
Keywords that appeared 7 times & 10 & 0.9 \\
Keywords that appeared 8 times & 9 & 0.8 \\
Keywords that appeared 9 times & 7 & 0.6 \\
Keywords that appeared 10 times & 5 & 0.5 \\
\hline Subtotal of low frequency keywords & $\mathbf{1 0 5 8}$ & $\mathbf{9 6 . 7}$ \\
\hline Subtotal of 26 keywords (including top ten) that & 36 & 3.3 \\
appeared more than 10 times & $\mathbf{1 0 9 4}$ & $\mathbf{1 0 0}$ \\
\hline Total &
\end{tabular}

There were a large number of terms that appeared only once in the entire dataset. Table 4.10 provides data on the low frequency keywords. Many keywords, such as ecofriendly, ecologistics, and eco-supply chains appeared only once in the literature in the six year period of the study. The number of appearances for such keywords is 777 . They accounted for $71 \%$ $(777 / 1,094=0.7102)$ of unique keywords and $25 \%(777 / 3,119=0.2491)$ of the use. The number of keywords that appeared 10 times or less is 1058 which accounted for 96.7\% (1058/1094= 0.967) of all the unique keywords. It is important to highlight the difference in this analysis with 
the data presented in Table 4.8, where 817 keywords appeared only one year during this period of study (Table 4.8) but 777 keywords appeared only once in the entire data set (Table 4.10), which means the 777 keywords are included in the overall total of 817 . The remaining 40 (817777) keywords appeared more than once in a year. For example, "warehousing" was used as a keyword in 2 different papers only in 2012. It was never used as a keyword in any other year. This is counted among 817 keywords that appeared any one of years in Table 4.8 and is counted among 156 keywords, which appeared 2 times in the dataset in Table 4.10. Therefore, Table 4.8 provides the count of unique words used by years and Table 4.10 provides 10 low frequency keywords in the entire dataset. The data above indicated that there are many new terms being used only once or a few times but only a few get traction to be repeated more than a few times. The majority of highly repeated terms were concentrated on a few terms and there is some convergence among those terms.

\subsubsection{Analysis of Citations and Research Focus}

A citation analysis of the papers reviewed was also done. It was found that these papers were cited in Scopus 7,583 times. However, 10 papers accounted for about 17\% $(1,323 / 7,583=0.174)$ of the total citations. Table 4.11 provides the list of the top ten cited papers and their citation count. Our results also showed that about $72 \%(455 / 629=0.7233)$ of papers were cited 10 times or less and about $20 \%(123 / 629=0.1955)$ of the papers were never cited.

A further analysis of the papers reviewed in this study showed that researchers publishing in the broad area of green supply chains were from 60 countries. However, the research focus was concentrated among a few countries. These countries were determined based on the location of affiliated institutes of each of the authors in the unique papers. There was a small amount of multiple counting of countries, though negligible in number, where an author has shown affiliation to more than one institution in the same paper. Figure 4.4 shows countries that published 20 or more papers in this area during the identified 6-year period. The results showed that research in the area of GSCM has been going on both in developed and developing countries. 
Chapter 4: Terms for Environmentally Friendly Supply Chains

Table 4.11: Citation count for the 10 most cited papers.

\begin{tabular}{clcc}
\hline Rank & \multicolumn{1}{c}{ Paper Reference } & Type & Citations $^{\mathbf{1 9}}$ \\
\hline 1 & Seuring, S., and Muller, M. (2008a) & Article & 308 \\
2 & Ilgin, M.A., and Gupta, S.M. (2010) & Review & 142 \\
3 & Guide, V.D.R., and Wassenhove, L.N.V. (2009) & Article & 119 \\
4 & Ko, H.J., and Evans, G.W. (2007) & Article & 117 \\
5 & Zhu, Q., Sarkis J., and Lai, K.H. (2007) & Article & 114 \\
6 & Lu, Z., and Bostel, N. (2007) & Article & 112 \\
7 & Salema, M.I.G., Barbosa-Povoa, A.P., and Novais, A.Q. & Article & 109 \\
& (2007) & & \\
8 & Srivastava, S.K. (2007) & Article & 108 \\
9 & Zhu, Q., Sarkis, J., and Lai, K.H. (2008) & Article & 106 \\
10 & Vlachos, D., Georgiadis, P., and Iakovou, E. (2007) & Article & 88 \\
\hline & & Total & $\mathbf{1 3 2 3}$ \\
\hline
\end{tabular}

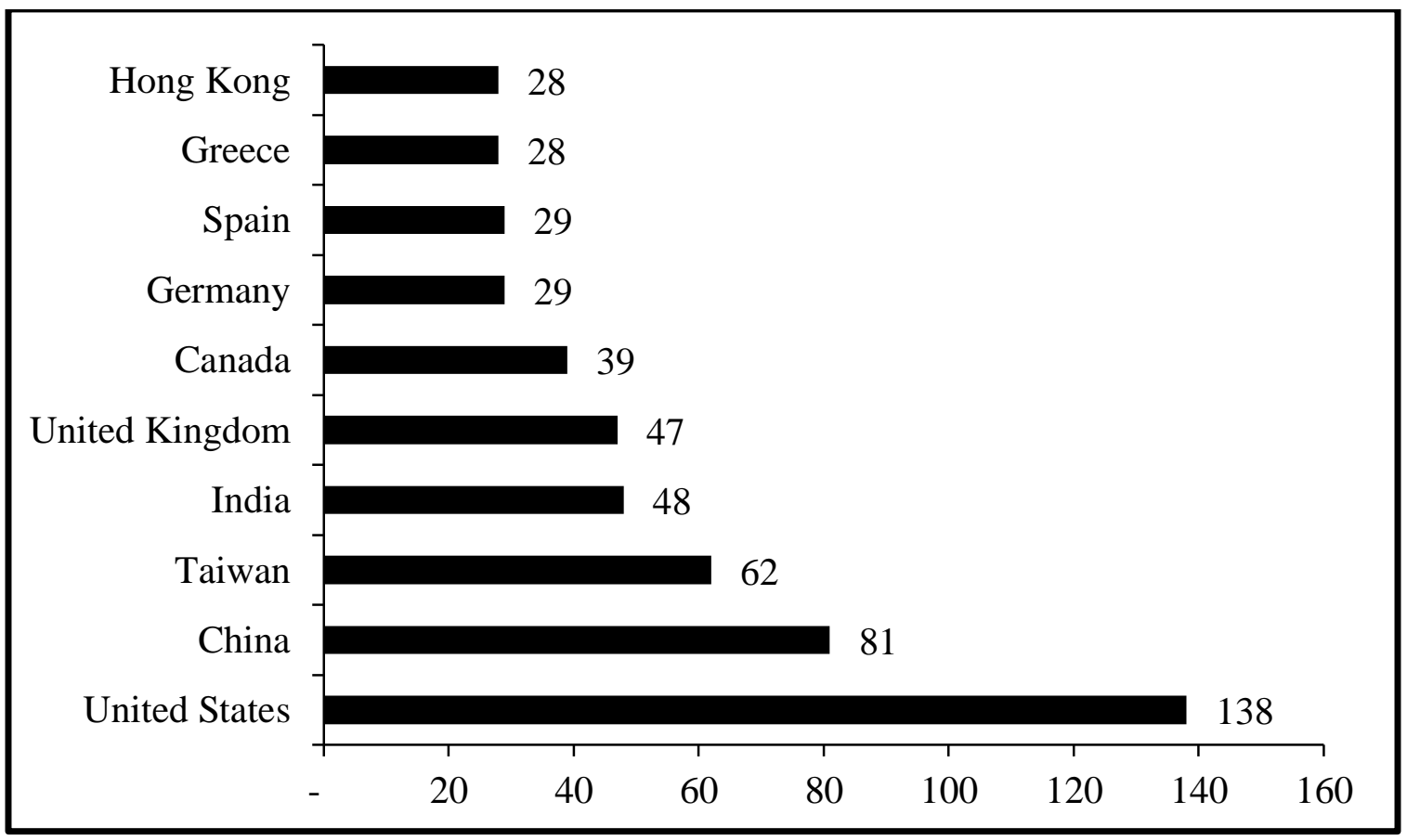

Figure 4.4: Top contributing countries

\footnotetext{
${ }^{19}$ As of October 12, 2013
} 
The data in this sub-section suggested that the research in the area of supply chains, which focus on environment, is widespread but the bulk of research is very concentrated among a few countries. Similar to the finding of publication by journals in sub-section 4.1.1, the citation of papers is highly concentrated as well.

\subsection{Findings}

A number of authors have studied the literature concerning the environmental impact of supply chains. For example, Burgess et al., (2006) reviewed 100 randomly selected peer reviewed papers with the objective of defining the scope of SCM. They found that the papers reviewed were published in 31 journals but were concentrated in a relatively small number of two journals. The Journal of Supply Chain Management and Supply Chain Management: An International Journal published 21 and 27 papers, respectively. This accounted for 48 percent of the publications they reviewed. They also found that the remaining $52 \%$ of papers were spread across 29 journals (94\% of 31). This indicates that research on supply chains cuts across many disciplines (Figure 4.1) and fits into the objectives of many journals, which aligns with the findings presented in the sub-section 4.1. However, relatively few papers have specifically investigated the keywords utilized in research on the environmental impact of supply chains.

Ashby et al., (2012) provided a useful reference point for reflecting on the findings in subsection 4.1, though it is important to acknowledge that there are some differences - notably in the sample size and breadth of search terms utilized. Ashby et al., selected 38 journals based on the Association of Business School's (ABS), 2010) rating between 2-4 and journals that specifically focused on research in the area of supply chains and environment. They then conducted a search

of papers published in these 38 journals using three databases (Science Direct, EBSCO and Emerald Full-text) during the period between 1983 and 2011. The papers were identified through a search of 10 terms focusing on supply chains and sustainability. Similar to the findings presented in this analysis, Ashby et al., (2012) found that the number of papers published on these topics increased over time. They also found that the largest number of papers published focused on Green Supply Chains. Conversely, the analysis in this section reported that "reverse logistics" was the most used term, which Ashby et al., (2012) did not consider. In both the cases, however, an increase in the number of papers focused on sustainable supply chains, i.e., those 
addressing the triple-bottom-line, indicated that researchers are broadening their focus from environmental or social impacts to simultaneously considering all three areas of the triplebottom-line.

As shown in sub-section 4.1, it is clear that the usage of the identified keywords has changed over time. In particular, the use of keywords focused on green supply chains and sustainable supply chains have been increasing. There is some evidence that these terms are being used interchangeably. Strictly speaking, definitions of green supply chains imply an exclusive emphasis on the environmental dimension of the triple-bottom-line. Definitions of sustainable supply chains imply an emphasis on all three dimensions. However, these distinctions are not always made in practice (Ahi \& Searcy, 2013a). This raises the possibility that the terms 'green' and 'sustainable' will converge to become one term over time as 'green' is a part of 'sustainable' supply chains. Likewise, the diminishing usage of the terms associated with logistics may indicate a convergence towards green or sustainable supply chains. Supply chains encompass reverse logistics when they are considered from a closed-loop perspective.

Changes in the usage of terms were also analyzed based on the country of origin of the publishing authors. The usage of terms changed almost uniformly in different countries in the same year. This indicates that there was no clear origin or preferences for the usage of the searched key terms. This was interesting giving the differences in usage of other environmentally related terms (Glavič \& Lukman 2007), such as "pollution prevention" (as used primarily in North America) and "cleaner production" (as used primarily elsewhere in the world). Analysis at the continent level did not give any meaningful trend because the number of countries varies widely among continents. As an example, authors from 28 countries in Europe contributed to the research whereas authors from three countries each in North America and South America contributed. There is little evidence for preference in different countries for using a singular versus a plural form of a term, such as logistic versus logistics or supply chain versus supply chains. In addition, there is no clear pattern for increases and/or decreases in the use of any terms in a particular country. The range is very wide to draw any meaningful conclusions. Notwithstanding the above, the data regarding geographical preferences for terms must be used with caution because it is based on the association of authors at the time of publication. 
The analysis also showed that the total number of countries engaged in research on environmental impacts of supply chains has been increasing and the number of authors publishing their research has been steady (Figure 4.5). Even though the number of authors has been steady every year, the majority of the individual authors changed every year. Therefore, the cumulative number of countries and authors is less than the sum of yearly numbers. The cumulative number of countries and authors that have contributed to research during this period is 60 and 757 respectively. This indicates that the environmental impacts of supply chains are being taken seriously in many countries irrespective of the size of their economies. Taiwan, for example, is a relatively small economy, but ranked among the top three contributors. Developing economies like India and China are also working in this area and both appeared in the list of top ten countries. The growth in the number of countries has come from many countries in every geographic region. Nevertheless, the highest number of authors is from the United States.

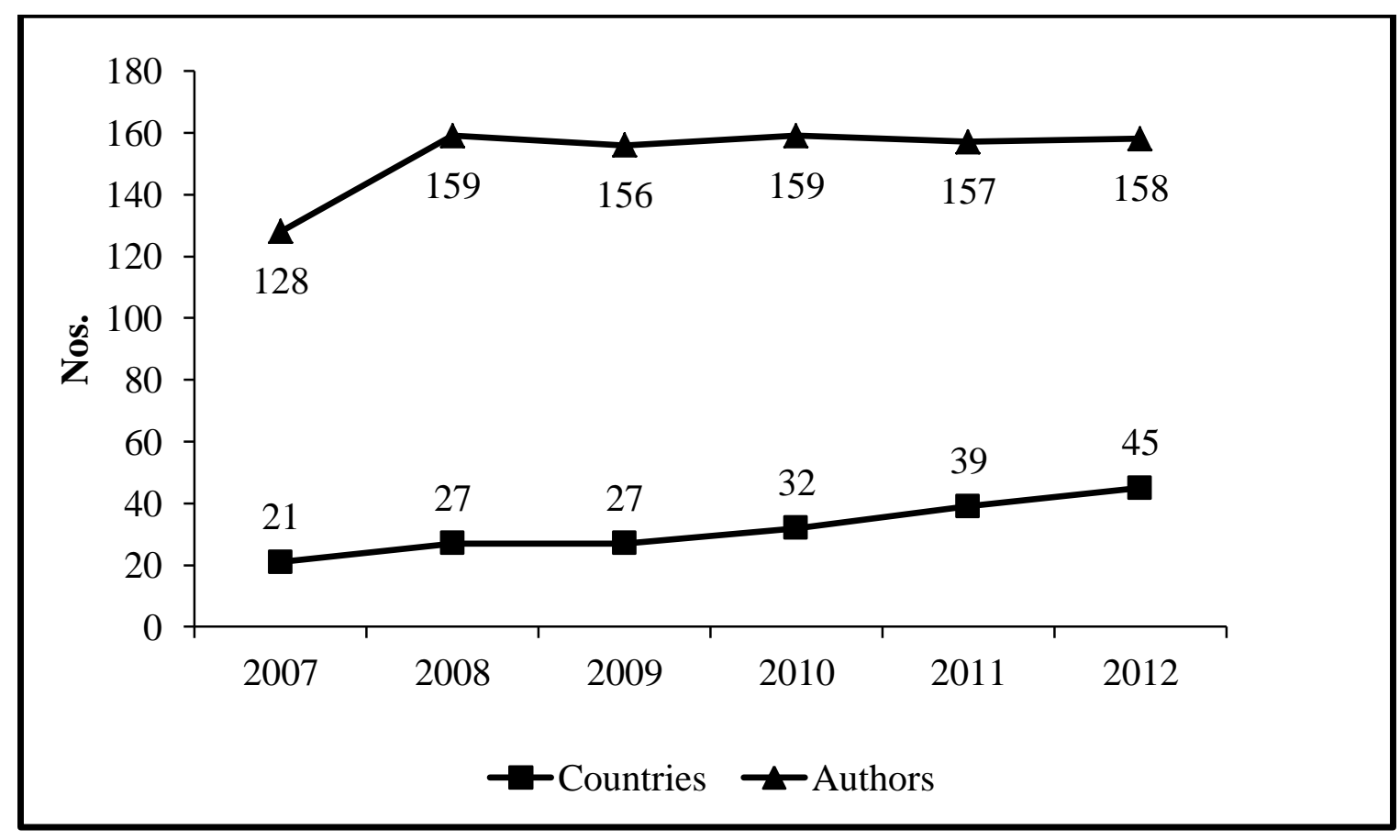

Figure 4.5: Annual number of authors and countries that contributed to the research.

The analysis on usage of terms by journals provided little evidence on preference for usage of a particular keyword in specific journals. This could be due, in part, to the fact that only a few journals published more than 10 papers using any of the keywords or published relevant papers 
every year. However, there are a few interesting observations. The highest variety of searched keywords used by a journal was six in the International Journal of Production Economics. The next highest number of keywords (5) was used by three journals, namely the International Journal of Production Research, the International Journal of Logistics Systems and Management, and the International Journal of Physical Distribution and Logistics Management. Green supply chains and sustainable supply chains were both used as keywords in six of the top 10 journals. "Closed-loop supply chains" and "reverse logistics" were the only keywords, which were used in every journal among the top 10.

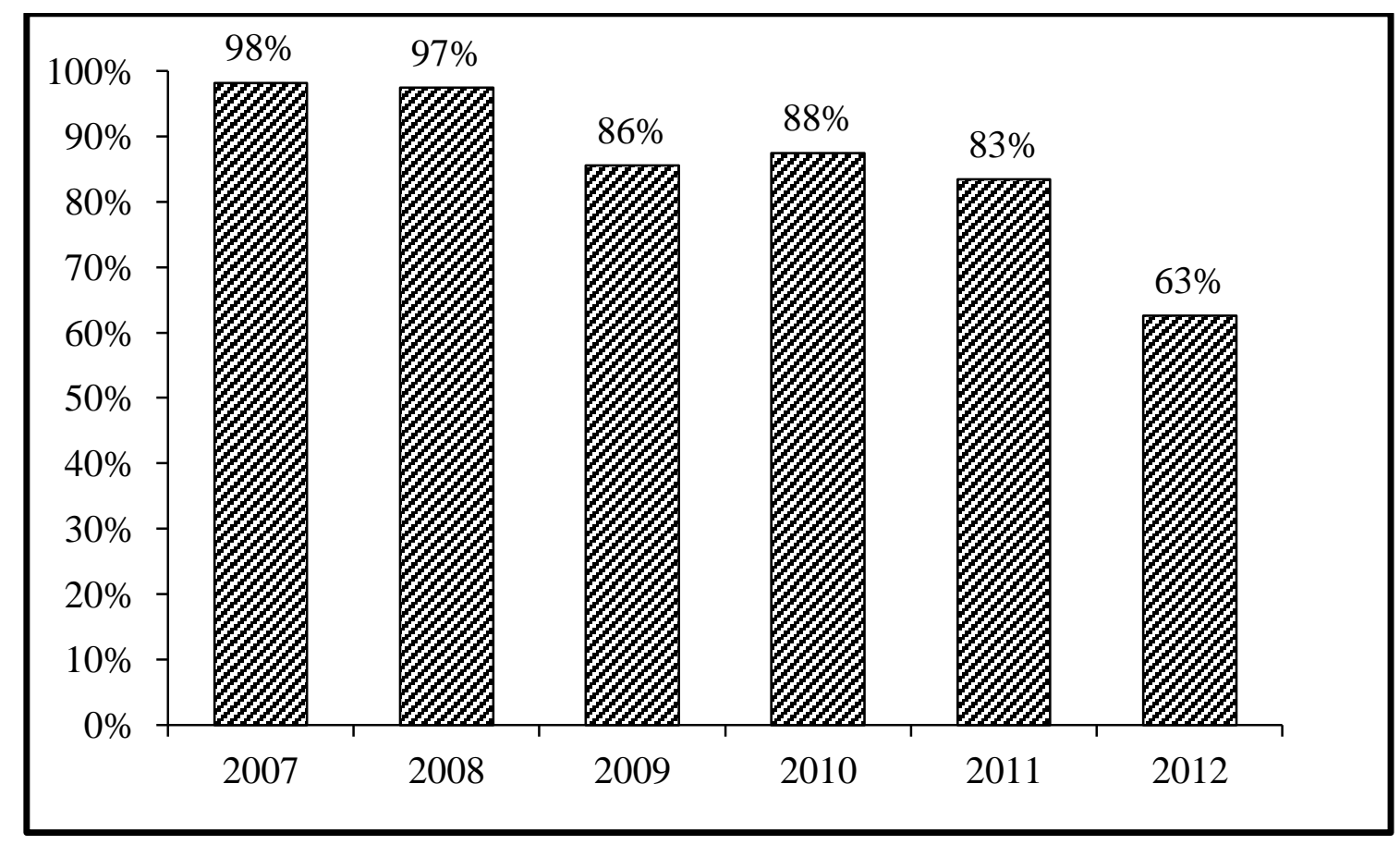

Figure 4.6: Citation contribution of papers by year.

The single most cited paper is on sustainable supply chains by Seuring and Müller (2008a) and accounts for 308 (4.5\%) of the total citations (as of October 12, 2013), which highlights the emerging focus on sustainability in supply chains. The papers published earlier have clear advantages in citations (Figure 4.6), where 98\% of the papers published in 2007 have been cited at least once whereas only $63 \%$ of the papers published in 2012 have been cited at least once. However, this advantage is not uniformly distributed across papers and the disadvantage to recently published papers appears to diminish after about 2 years. The citation data for the most cited papers generally do not suggest that year of publication has a strong correlation with 
citation count. As an example, the paper with the second highest citation was published in 2010 and the paper with the tenth highest citation was published in 2007.

\subsection{Summary}

Overall, the research presented in this chapter provided several insights that extend the existing research on trends in green supply chain management. The iterative process of sorting, combining and grouping keywords has resulted in the identification of high frequency keywords, with "reverse logistics", "green supply chains", "closed-loop supply chains" and "sustainable supply chains" being the most commonly used terms. Given the embryonic nature of research on the environmental impact of supply chains, the wide differences in the usage of keywords is both unsurprising and healthy. In the early stages of a research, a variety of perspectives helps ensure that no promising alternatives are overlooked. The term reverse logistics is used for the logistics activities of sending the items up the supply chain, which could be due to many reasons such as receiving defective/broken items, warranty failures and repair/refurbishment among others. These can be classified as short-term and long-term reverse logistics. Return of goods from customers for non-performance and rental returns are example of short-term reverse logistics, whereas sending back the items for upgrade, repairs, and refurbishment are some examples of long-term reverse logistics. The fact that reverse logistics was the most used term in this area over the last six years may be viewed as an indication that focus is shifting towards lifecycle management of products as opposed to the limited focus on forward supply chains only. The growth in the use of the term "closed-loop supply chains" further reinforces this point. The underlying belief in transitioning towards lifecycle management is that it will result in meaningful reductions in the environmental impact of supply chains. Nonetheless, further convergence on a few keywords could promote greater clarity in research conducted in this area.

The usage of several keywords, notably "reverse supply chains" and "reverse logistics" is declining and, as suggested by the data, is being replaced by terms more explicitly focused on "sustainable supply chains" and "green supply chains". The use of other terms, such as "responsible supply chains", "environmentally friendly logistics", and "eco-supply chains/logistics", has not drawn much attention among authors. The usage of the keywords "green supply chains" and "green logistics" has increased suggesting some convergence. The 
increase in the usage of the term "green supply chains" indicates that there has been an increase in focus on environmental issues in supply chains. It is interesting to note that the relative usage of "reverse logistics" and "green supply chains" are showing almost mirror images of each other (Figure 4.2). This could imply that the use of "green supply chains" is replacing "reverse logistics". "Green supply chains" could be used as a generic term to indicate a supply chain and related activities which intend to reduce its impact on the environment.

The data did not suggest any preferences for using different terms related to "green supply chains" or its forms (singular versus plural) in any geographic location. This may be due to the availability of research simultaneously across the world in the present digital age and/or due to the mobility of researchers. The review also showed that the number of papers published in the general area of green supply chains has more than tripled over the last 6 years. This is an indication that researchers have intensified their focus on the environmental impacts of supply chains. The number of journals has also more than tripled in the same period indicating an appetite for publishing research in this area. The reason for the large number of journals publishing research in this area is probably the multidisciplinary nature of the research, which suggests that there is no single journal addressing this need. This also poses a challenge to researchers in selecting a suitable avenue for publishing their research.

There are some limitations of this analysis due to the keywords searched, database used, and period of study. The searches did not pick papers that had used keywords other than the variants given in Appendix $\mathrm{C}$ or did not have a keywords at all. As an example, the seminal work on "green supply chain management" by Srivastava (2007) did not appear in our searches because it does not have any keywords. However, it has been cited for 349 times (as on October 2012), which is higher than that of the most cited paper in our sample. Nevertheless, research focusing on the environmental impact of supply chains remains a relatively new area and this chapter provided some unique insights on changes in usage and convergence of the terms in the past six years. 



\section{CHAPTER 5 : EMISSIONS FROM OFFSHORE MANUFACTURING}


This chapter presents the analysis and results for Objective 2: Conduct an analysis of the changes in the GHG emissions as a result of offshore outsourcing of manufacturing activities. The premise of the model is that the government of importing countries has the responsibility of reducing GHG emissions for their own consumption. For the purpose of illustration, exports between the world's three largest exporters, i.e., the USA, Germany and China, have been considered. However, the model is generic and expandable to ' $\mathrm{n}$ ' number of trading countries and any number of sectors. The model is developed to account for different rate of emissions per unit GDP between countries. The portion of the emissions associated with exports of manufacturing items is attributed to the outsourcing (i.e., importing country) and a carbonimport-tax is suggested to recognize these emissions. The purpose of a carbon import tax is to neutralize the effects of excess emissions. The carbon tax is applied on the net, instead of entire emissions.

\subsection{Model Development for Total Emissions of a Country}

In this section, the model for total emissions of a country is developed. The model focuses on imbalances due to imports and exports between countries where rate of emissions from economic activities is different. Emissions from energy generation and from manufacturing activities are not corrected due to differences in technology/efficiency and purchasing power of a currency.

Exports of emissions per unit GDP by Country $i$ to the world:

$$
\frac{C_{i}}{G_{i}} E_{i \rightarrow w}
$$

Exports ratio of Country $i$ to Country $j$, and Country $i$ to the world:

$$
\frac{E_{i \rightarrow j}}{E_{i \rightarrow w}}
$$

Multiplying Eq. (5.1) and Eq. (5.2) provides emissions exported by Country $i$ to Country $j$ :

$$
\frac{C_{i}}{G_{i}} E_{i \rightarrow w} \times \frac{E_{i \rightarrow j}}{E_{i \rightarrow w}}=\frac{C_{i}}{G_{i}} E_{i \rightarrow j}
$$

Net emissions in Country $i$ after trading with countries $j$ and $k$ : 


$$
C_{i}-\frac{C_{i}}{G_{i}} E_{i \rightarrow j}-\frac{C_{i}}{G_{i}} E_{i \rightarrow k}+\frac{C_{j}}{G_{j}} E_{j \rightarrow i}+\frac{C_{k}}{G_{k}} E_{k \rightarrow i}
$$

A general expression of Eq. (5.4) for the net manufacturing emissions of Country $i$ after trading with $n$ countries can be written as:

$$
C_{i(m)}=\frac{C_{i}}{G_{i}}\left(G_{i}-\sum_{\substack{x=1 \\ x \neq i}}^{n} E_{i \rightarrow x}\right)+\sum_{\substack{x=1 \\ x \neq i}}^{n} \frac{C_{x}}{G_{x}} E_{x \rightarrow i}
$$

This model illustrates the true global emissions of a country considering emissions associated with imports and exports.

\subsection{Model Development for Carbon Import Tax}

In this section, the model presented in Section 5.1 is extended for implementing a carbon tax on imports. Under the conditions proposed by the model, when the emissions per unit GDP for two countries are the same and the trade balance between the two countries is null, there will be no transfer of emissions. However, this is very unlikely to occur in practice. Therefore, a method for calculating a carbon tax on imports from a country with higher emissions per unit GDP, by applying the model from Eq. (5.5) is presented here, assuming no change in demand.

The differential rate of emissions for Country $i$ on imports from Country $j$ is:

$$
\left(\frac{C_{j} G_{i}}{C_{i} G_{j}}-1\right)
$$

Multiplying Eq. (5.6) by carbon import tax rate for Country $i$ gives the effective carbon tax rate for imports from Country $j$ as

$$
T_{C_{i}}\left(\frac{C_{j} G_{i}}{C_{i} G_{j}}-1\right)
$$

With an annual carbon tax on differential emissions:

$$
\left\{T _ { C _ { i } } ( \frac { C _ { j } G _ { i } } { C _ { i } G _ { j } } - 1 ) \left\{\left\{E_{j \rightarrow i}\left|\frac{C_{j}}{G_{j}}-\frac{C_{i}}{G_{i}}\right|\right\}\right.\right.
$$

A general form of Eq. (5.7b) providing total annual carbon tax for a country can be written as 


$$
T_{i(m)}=T_{c i} \sum_{\substack{x=1 \\ x \neq i}}^{n} E_{x \rightarrow i}\left\{E_{j \rightarrow i}\left|\frac{C_{j}}{G_{j}}-\frac{C_{i}}{G_{i}}\right|\right\}\left(\frac{C_{x} G_{i}}{C_{i} G_{x}}-1\right)
$$

Since the tax rate depends upon the differential emissions between two countries, there would, therefore, be different tariffs on imports from various countries. The tax collected could be used for reducing emissions through various programs, such as carbon sequestration (Brainard et al., 2009) or creating carbon sinks (Kula \& Gunalay, 2012). However, the objective of a carbon import tax is to promote outsourcing to/imports from energy efficient countries and to reduce global emissions.

Bocken and Allwood (2012) suggested incentives as another strategic lever, besides tax, in reducing emissions. The model suggested can be used for defining incentive policies, which will encourage imports from countries that have lower emissions per unit GDP than the importing country. When $\frac{C_{x}}{G_{x}}<\frac{C_{i}}{G_{i}}$ in Eq. (5.8), i.e., the emissions per unit GDP of an importing country are higher than that of the exporting country, the carbon import tax for the country will be negative. This can be treated either as no carbon import tax or paid back to the importing organization as an incentive for importing from emissions efficient countries.

\subsection{Analysis}

To demonstrate the application of the model, this section presents an analysis involving the three largest exporting nations in the world: China, Germany and the USA. In order to apply the model, it is first necessary to review key data related to energy, population, emissions, and outsourcing in the three case countries. The data used in this analysis has been collected from publicly available sources. Following a review of the appropriate data, the application of the model is presented and discussed.

\subsubsection{Energy, Emissions and Population}

This sub-section compares energy consumption, associated carbon emissions and gross economic activities in China, Germany and the USA. Global energy consumption increased by 
3.19 times between 1965 and 2010 (BP, 2011). Over the same period, the world population grew by 2.07 times, suggesting that the net increase in energy consumption is not in line with population growth. Despite improvements in efficiency in many respects, global energy consumption, increased from 3.8 billion ton equivalent of oil to 12 billion ton equivalent of oil during this period, which represents a per capita increase of about 50\%. Increases in efficiencies resulted in a reduction of operational costs. Paradoxically, reduction in operating costs resulted in increased consumption due to the lower costs of consumption on a per unit basis, offsetting the advantage of efficiency gains (Greening et al., 2000). In a similar vein, Bonney and Jaber (2011) observed that lower transport costs have led to increases in transportation activities.

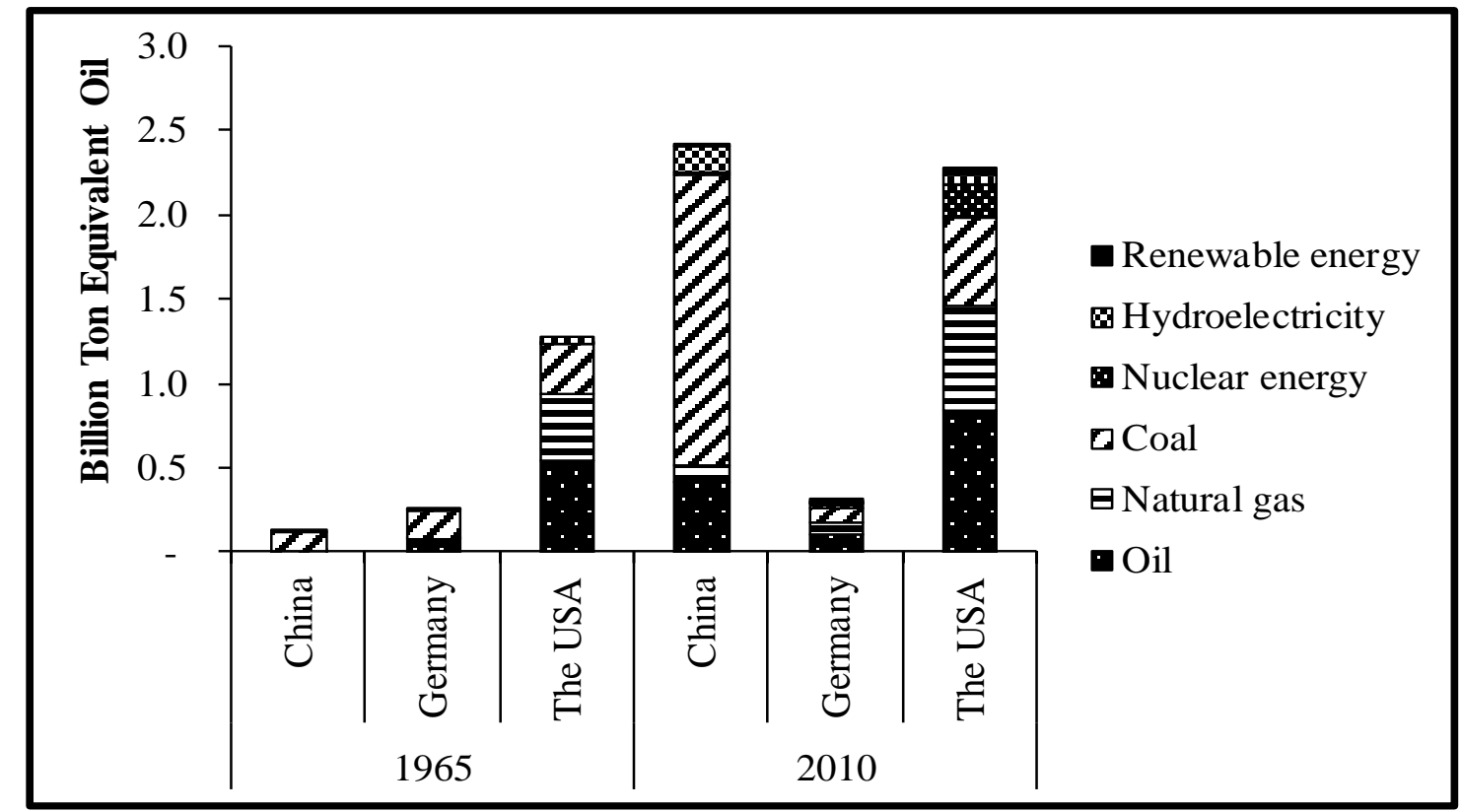

Figure 5.1: Changes in the sources of energy between 1965 and 2010 in China, Germany and the USA. (Source: BP, 2011)

Figure 5.1 shows that the changes in energy consumption in China, the USA and Germany (data includes both East and West Germany prior to 1989) from 1965 to 2010 were 18.81, 1.78 and 1.25 times, respectively. The figure also provides a breakdown of the changes in the sources of energy. There was an overall reduction in the use of non-renewable energy and an increase in the use of renewable energy for meeting energy needs in Germany and some increase in the use of non-renewable and renewable energy in the USA. Conversely, there has been a multifold increase in the use of non-renewable energy in China. Unlike China and the USA, Germany has 
been reducing its reliance on non-renewable energy sources. For example, the use of energy from coal reduced by half in Germany, while it increased by 1.8 and 15 times in the USA and China, respectively. Coal $(70 \%)$ is the single largest source of energy in China. Figure 5.2 shows the increase in per capita energy consumption for China, Germany and the USA from 1965 to 2010.

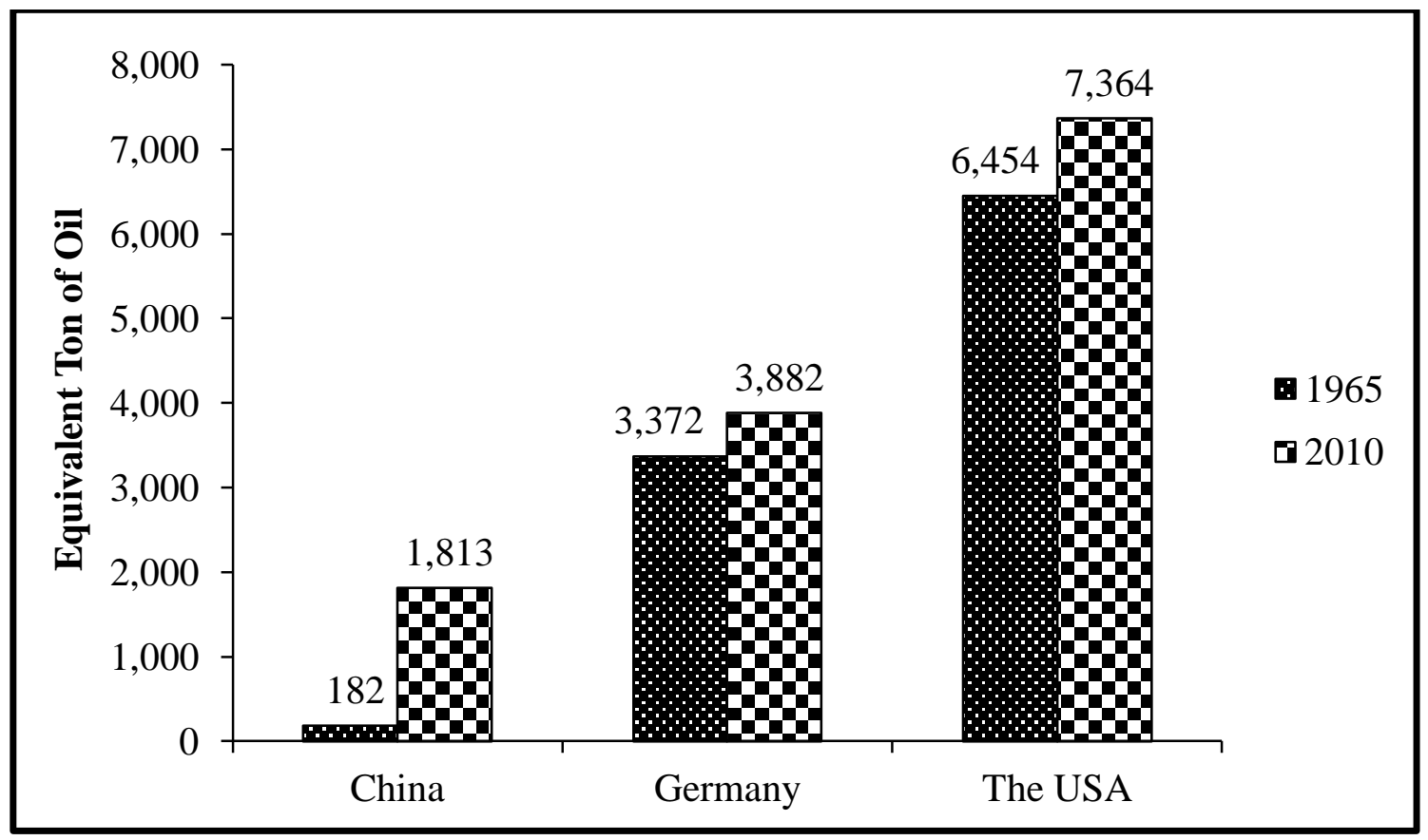

Figure 5.2: Changes in per capita energy consumption between 1965 and 2010 in China, Germany and the USA. (Source: World Bank, 2013)

Table 5.1: Change in $\mathrm{CO}_{2}$ emissions during 1991-2009 and 1960-2009 in China, Germany and the USA.

\begin{tabular}{lcccc}
\hline Country & \multicolumn{2}{c}{$\begin{array}{c}\text { Changes in } \mathrm{CO}_{2} \text { emissions } \\
\text { (metric tons per capita) }\end{array}$} & \multicolumn{2}{c}{ Changes in population } \\
& $\mathbf{1 9 9 1 - 2 0 0 9}$ & $\mathbf{1 9 6 0 - 2 0 0 9}$ & $\mathbf{1 9 9 1 - 2 0 0 9}$ & $\mathbf{1 9 6 0 - 2 0 0 9}$ \\
\hline China & $157 \%$ & $393 \%$ & $16 \%$ & $100 \%$ \\
Germany & $-23 \%$ & N.A. & $2 \%$ & $12 \%$ \\
United States & $-10 \%$ & $8 \%$ & $21 \%$ & $70 \%$ \\
\hline
\end{tabular}

Source: World Bank, 2013 
Results show that the increase in China was about $900 \%$ while it was about $15 \%$ for Germany and the USA. Table 5.1 shows the changes in $\mathrm{CO}_{2}$ emissions per capita in China, Germany and the USA. China experienced significant growth, and Germany and the USA experienced moderate reduction, while all the three countries experienced some growth in population. Effect of population growth is taken care of by comparing emissions per capita. Emissions per capita increased by $157 \%$ in China between 1991 and 2009 while Germany and the USA have experienced a reduction of $23 \%$ and $10 \%$, respectively, in per capita carbon emissions over the same period. Looking at a greater period of time, the increase in China between 1960 and 2009 is $393 \%$.

\subsubsection{Manufacturing and Emissions}

As a result of a surge in manufacturing activities and unchecked $\mathrm{CO}_{2}$ emissions, China has become the highest emitter of $\mathrm{CO}_{2}$ in the world. As shown in Table 5.2, China alone released more $\mathrm{CO}_{2}$ than the next top 11 countries combined in 2010. As shown in Figure 5.3, the highest reduction in $\mathrm{CO}_{2}$ emissions between 1971 and 2010 was 54\% in Germany followed by 35\% in the USA, while emissions increased by $473 \%$ in China.

Table 5.2: Change in Carbon dioxide emissions due to manufacturing activities.

\begin{tabular}{llc}
\hline & Country & $\begin{array}{r}\mathbf{C O}_{2} \text { emissions from manufacturing industries and } \\
\text { construction in 2010 (million tons) }\end{array}$ \\
\hline 1. & China & $2,327.6$ \\
2. & United States & 587.1 \\
3. & India & 400.9 \\
4. & Russian Federation & 294.3 \\
5. & Japan & 249.8 \\
6. & Indonesia & 125.0 \\
7. & Germany & 116.0 \\
8. & Brazil & 114.0 \\
9. & Canada & 100.8 \\
10. & Korea, Rep. & 98.6 \\
11. & Iran, Islamic Rep. & 95.9 \\
12. & Saudi Arabia & 86.3 \\
\hline
\end{tabular}

Source: World Bank, 2013. 


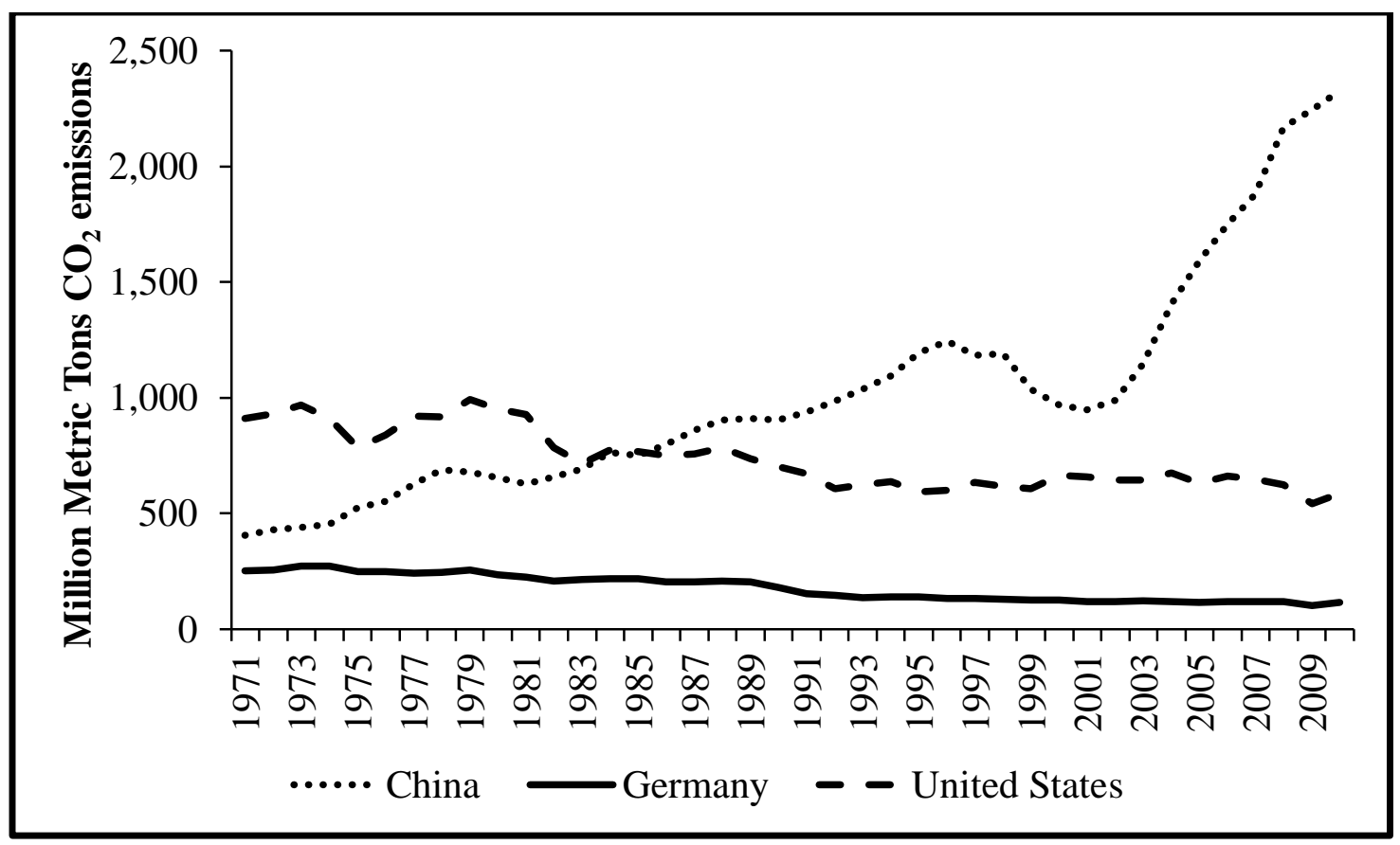

Figure 5.3: Changes in the Carbon Dioxide emissions from manufacturing activities. (Source: World Bank, 2013)

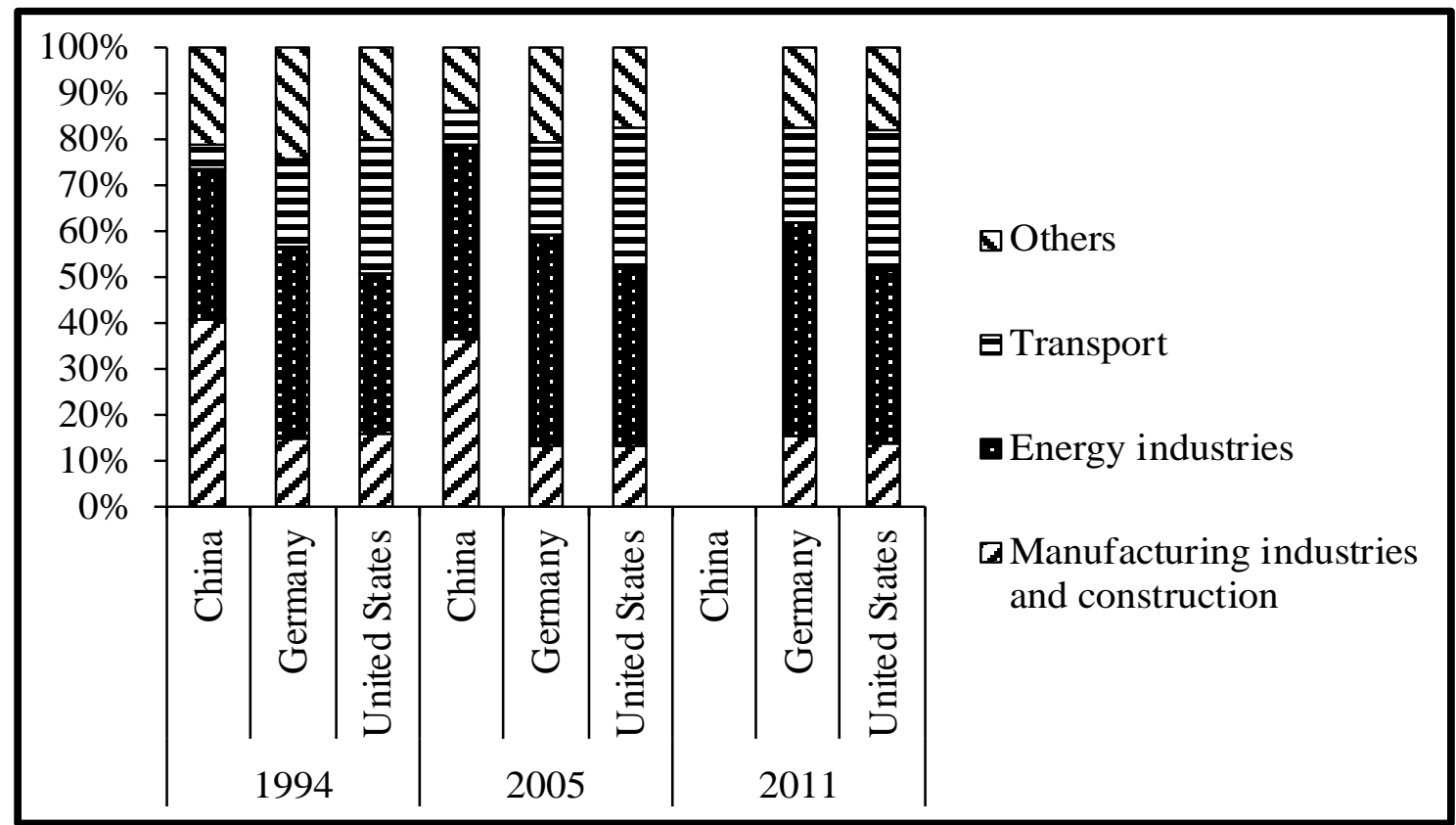

Figure 5.4: Comparison of GHG emissions by sector. (Source: UNFCCC, 2013b) 
Combining the findings from the previous sub-section, it can be inferred that the main reason for the increase in $\mathrm{CO}_{2}$ emissions is the growth in manufacturing activities (which include construction). Zhang and Beck (2013) also reached a similar conclusion. Figure 5.4 shows that GHG emissions from the manufacturing sector are the highest in China as compared to the emissions from manufacturing in the USA and Germnay. Data for emissions for China in 2011 is not available for comparison. However, there is no significant change in emissions in China between 1994 and 2005 and in Germany and the USA between 1994, 2005 and 2011.

\subsubsection{Outsourcing and Emissions}

Many US corporations have been outsourcing their manufacturing activities, mainly to China as a strategy to reduce cost. This helped the economy of China to grow rapidly and, with a surge in exports, its net exports (total exports - total imports) became similar to that of Germany. Figure 5.5 shows that trends in the net exports of the USA are essentially the opposite to that of Germany and China. Interestingly, the gap between net imports by the USA

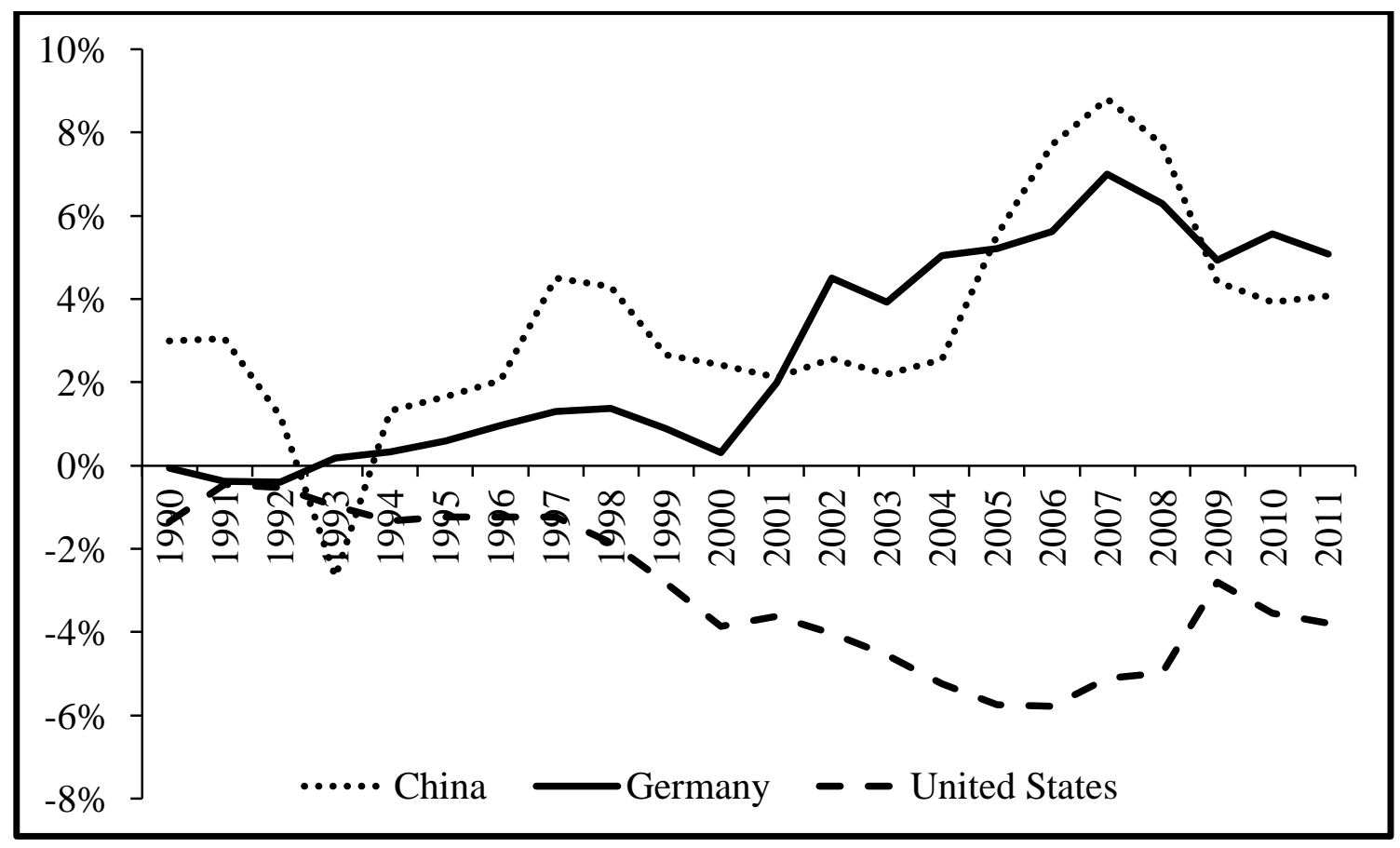

Figure 5.5: Net exports and imports as a percentage of GDP. (Source: World Bank, 2013) 
and net exports by China or Germany had been diverging steadily over the last two decades and was about $9 \%$ of the GDP in 2011. The trend is likely to continue in the future unless some major policy changes are introduced. This has caused a reduction in emissions as a percentage of GDP for China, yet these are about 5 times that of the USA or Germany. The $\mathrm{CO}_{2}$ emissions of the USA or Germany as a percentage of GDP had not only been about $20 \%$ of China's emissions but also declining at a slow and steady pace, while emissions of China as a percentage of GDP have been flat over the last decade (Figure 5.6).

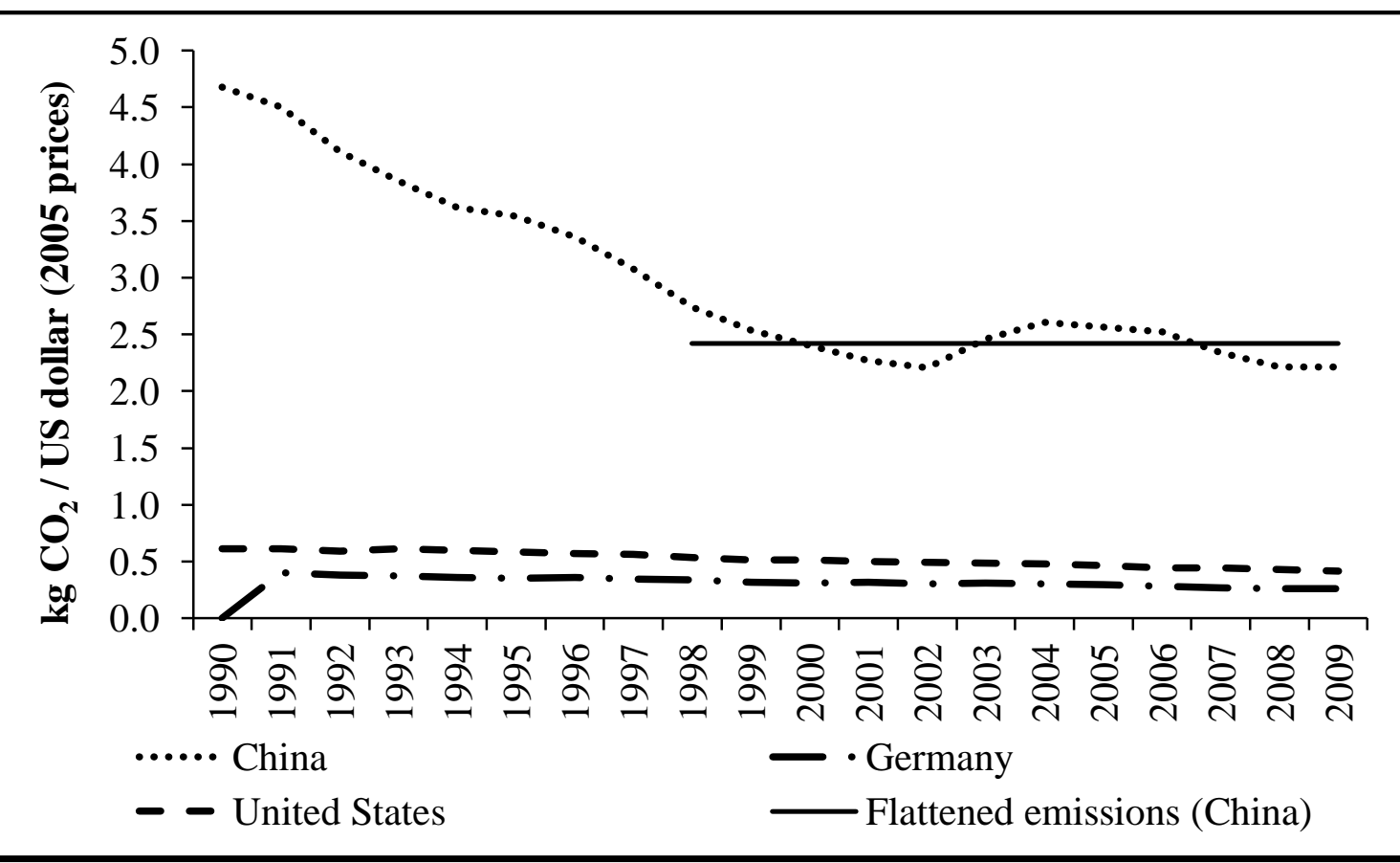

Figure 5.6: Carbon Dioxide emissions with respect to GDP (in USD 2005 prices).

(Source: World Bank, 2013)

\subsection{Discussion}

The above analysis indicated some important points related to energy consumption and $\mathrm{CO}_{2}$ emissions. A key reason for the high carbon emissions in China is the greater need for energy due to outsourced manufacturing activities and the choice of non-renewable sources of energy. Even though internal consumption has continued to increase in China, the increase in manufacturing activities is primarily due to the demand from exports (Figure 5.7). 


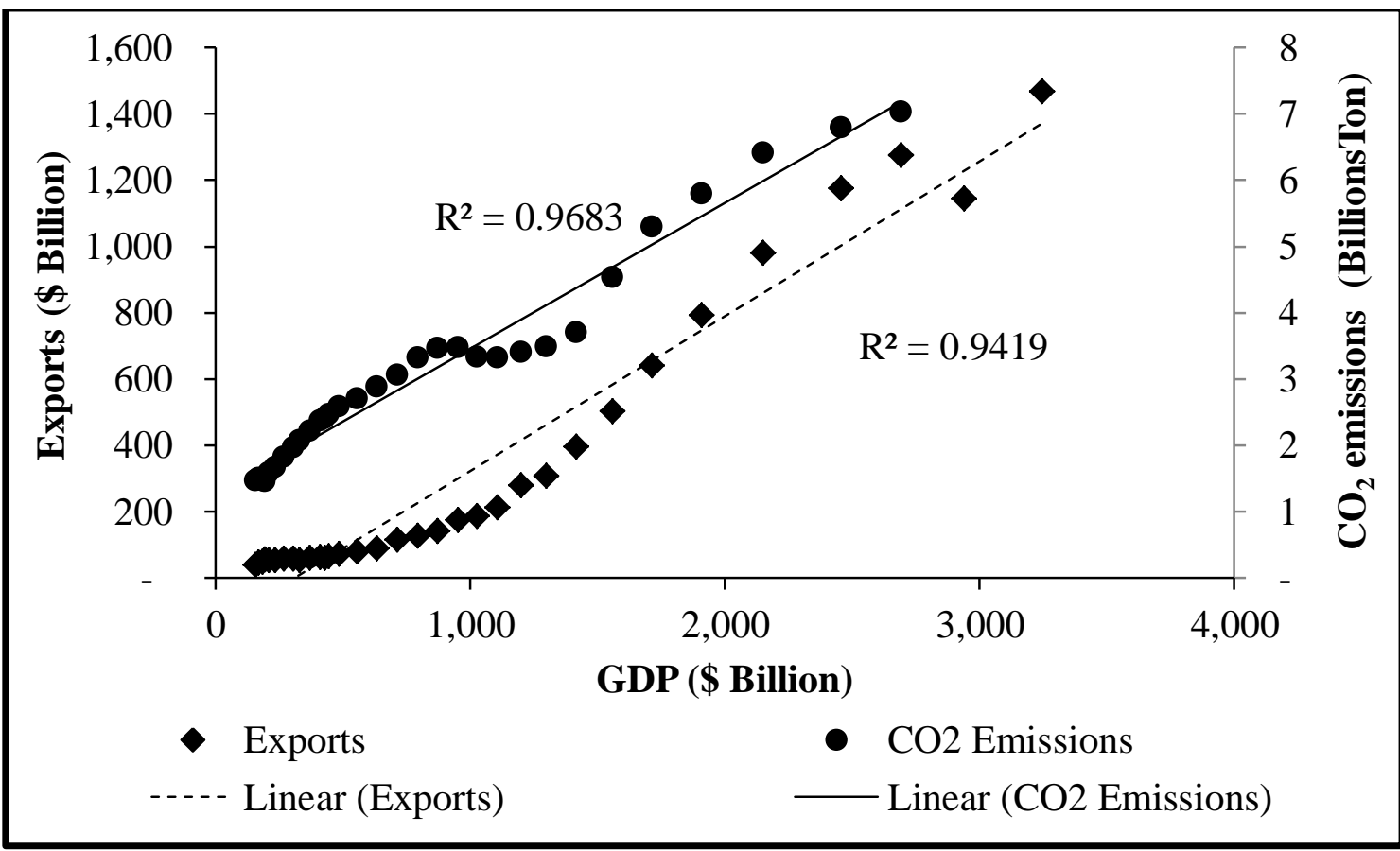

Figure 5.7: Correlation between GDP and exports, and GDP and $\mathrm{CO}_{2}$ emissions in China. (Source: World Bank, 2013)

Moreover, carbon emissions in China have increased in synch with the increase in the GDP (Figure 5.7), which is not unique to China. A similar relationship between economic growth and emissions was also observed in other parts of the world (De Freitas \& Kaneko, 2011, Lin \& Li, 2011, and Dagher \& Yacoubian, 2012). Lane (2011) has previously established the relationship between $\mathrm{CO}_{2}$ emissions and GDP. Figure 5.8 summarizes the relationship between GDP, emissions and exports. The reduction in emissions through outsourcing of manufacturing activities represents an artificial indicator of reduction in GHG emissions of a country. This indicator does not help in reducing the overall global emissions. It simply shifts the responsibility for the emissions from one geopolitical boundary to another.

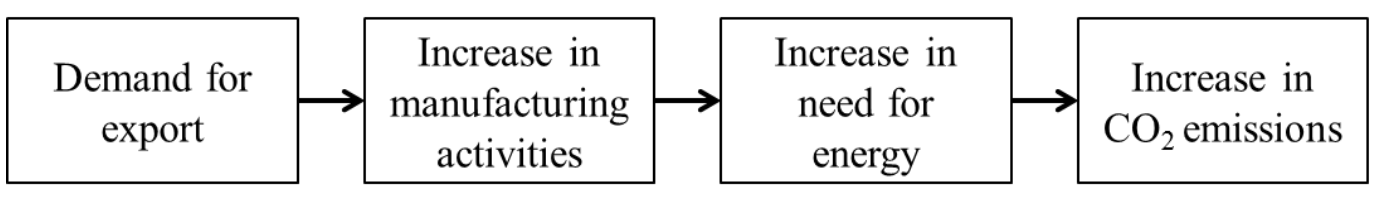

Figure 5.8: A proposed relationship between emissions and exports 
Applying the same logic, it is clear why energy consumption and carbon emissions in the USA have not increased in the same proportion as its GDP growth. The USA is the single largest importing partner of China ( $18 \%$ in 2011; ITC, 2012). Accounting for the GHG emissions generated as a result of exports from China to the USA and Germany and vice versa, will therefore change the total emissions of these countries substantially. The model proposed in the previous sub-sections will help countries address these imbalances.

\subsection{Examples}

Building on the data above, this section presents an application of the model considering the trade relationships between China, the USA, and Germany. Table 5.3 summarizes the GDP, imports, exports and emissions data used in the model Eq. (5.5).

Table 5.4 summarizes the transfer of emissions computed using the model and the impact of transferring the emissions due to outsourcing of manufacturing activities among these countries. The results show an increase in the $\mathrm{CO}_{2}$ emissions of the USA from 610 to 718 million metric tons in 2010. This increase in emissions in the USA is despite the benefits of exporting higher emissions per dollar to Germany and importing fewer emissions per dollar from Germany. In other words, the model assigns responsibility to the USA for emissions created in China and Germany that were generated as a result of American consumption.

Similarly, emissions in Germany have increased from 116 to 139 million metric tons in 2010. As a result of the transfer of emissions, China benefited from reduction in its emissions. This also means that the emissions in 2010 in the USA and Germany jumped by $18 \%$ and $20 \%$ respectively but emissions in China dropped by $6 \%$ only. The percentage reduction in emissions in China appears small because of the large denominator and the fact that its emissions efficiencies are generally very low.

Now using the model Eq. (5.8), a policy of carbon tax on excess emissions can be defined for the USA. This carbon tax is for neutralizing the excess emissions generated by the USA in any parts of the world. Assuming $\$ 30$ per ton differential rate of emissions as a carbon tax on imports from China, the USA would have generated about $\$ 24,425$ million in 2010 . It is worth reiterating that 
Table 5.3: Data used for analysis.

\begin{tabular}{|c|c|c|c|c|c|c|c|c|c|c|c|c|}
\hline & Unit & 2000 & 2001 & 2002 & 2003 & 2004 & 2005 & 2006 & 2007 & 2008 & 2009 & 2010 \\
\hline China- GDP ${ }^{20}$ & $\mathrm{Bn}^{21} \mathrm{US} \$$ & 1,198 & 1,325 & 1,454 & 1,641 & 1,932 & 2,257 & 2,713 & 3,494 & 4,522 & 4,991 & 5,931 \\
\hline Germany- GDP ${ }^{20}$ & Bn US\$ & 1,886 & 1,881 & 2,007 & 2,424 & 2,726 & 2,766 & 2,903 & 3,324 & 3,624 & 3,299 & 3,284 \\
\hline United States- GDP ${ }^{20}$ & Bn US\$ & 9,899 & 10,234 & 10,590 & 11,089 & 11,798 & 12,564 & 13,315 & 13,962 & 14,219 & 13,898 & 14,419 \\
\hline Exports from China to Germany ${ }^{22}$ & Bn US\$ & 9.2 & 9.7 & 11.3 & 17.3 & 23.6 & 32.3 & 40.1 & 48.5 & 58.9 & 49.6 & 67.7 \\
\hline Exports from China to the USA ${ }^{22}$ & Bn US\$ & 51.4 & 53.9 & 69.5 & 92.0 & 124.4 & 162.0 & 202.4 & 231.9 & 251.3 & 220.2 & 282.4 \\
\hline Exports from Germany to China ${ }^{22}$ & Bn US\$ & 8.2 & 10.4 & 13.4 & 20.1 & 25.3 & 25.4 & 33.1 & 39.0 & 47.6 & 49.0 & 68.7 \\
\hline Exports from Germany to the USA ${ }^{22}$ & Bn US\$ & 55.7 & 59.5 & 63.2 & 68.5 & 79.0 & 84.3 & 95.8 & 98.2 & 102.5 & 73.5 & 84.4 \\
\hline Exports from the USA to China ${ }^{22}$ & Bn US\$ & 13.3 & 16.2 & 18.6 & 21.7 & 26.7 & 33.1 & 42.9 & 50.1 & 52.5 & 49.8 & 65.0 \\
\hline Exports from the USA to Germany ${ }^{22}$ & Bn US\$ & 26.9 & 27.8 & 24.4 & 26.6 & 28.9 & 31.6 & 38.0 & 45.6 & 49.9 & 39.8 & 43.4 \\
\hline China- $\mathrm{CO}_{2}$ emissions ${ }^{23}$ & $\mathrm{MMT}^{24}$ & 1134 & 1136 & 1144 & 1328 & 1596 & 1830 & 1949 & 2048 & 2156 & 2233 & 2321 \\
\hline Germany- $\mathrm{CO}_{2}$ emissions $^{23}$ & MMT & 126 & 120 & 120 & 118 & 121 & 120 & 122 & 124 & 123 & 106 & 116 \\
\hline United States- $\mathrm{CO}_{2}$ emissions ${ }^{23}$ & MMT & 665 & 657 & 645 & 645 & 677 & 631 & 660 & 648 & 625 & 541 & 610 \\
\hline
\end{tabular}

\footnotetext{
${ }^{20}$ Current GDP (Source: World Bank, 2013).

${ }^{21}$ Billion

${ }^{22}$ Manufacturing industries only (Source: OECD, 2013b).

${ }^{23}$ From manufacturing industries and construction (Source: World Bank, 2013).

${ }^{24}$ Million metric ton
} 
Table 5.4: Changes in emissions after adjusting for imports and exports using the model.

\begin{tabular}{|c|c|c|c|c|c|c|c|c|c|c|c|c|}
\hline & Unit & 2000 & 2001 & 2002 & 2003 & 2004 & 2005 & 2006 & 2007 & 2008 & 2009 & 2010 \\
\hline China- $\mathrm{CO}_{2}$ adjusted emissions ${ }^{25} 26$ & $\mathrm{MMT}^{27}$ & 1,078 & 1,083 & 1,082 & 1,242 & 1,477 & 1,675 & 1,778 & 1,887 & 2,012 & 2,116 & 2,189 \\
\hline Germany- $\mathrm{CO}_{2}$ adjusted emissions ${ }^{25} 28$ & MMT & 132 & 126 & 126 & 129 & 137 & 143 & 147 & 149 & 149 & 126 & 139 \\
\hline United States- $\mathrm{CO}_{2}$ adjusted emissions ${ }^{25} 29$ & MMT & 715 & 704 & 701 & 720 & 780 & 762 & 806 & 784 & 744 & 638 & 718 \\
\hline China-Changes in emissions ${ }^{26}$ & MMT & -56 & -53 & -62 & -86 & -120 & -155 & -171 & -161 & -144 & -117 & -132 \\
\hline Germany-Changes in emissions ${ }^{28}$ & MMT & 6 & 6 & 6 & 11 & 17 & 23 & 25 & 25 & 25 & 20 & 23 \\
\hline The USA-Changes in emissions ${ }^{29}$ & MMT & 50 & 47 & 56 & 75 & 103 & 132 & 145 & 135 & 119 & 97 & 109 \\
\hline China-Changes in emissions ${ }^{26}$ & $\%$ & $-5 \%$ & $-5 \%$ & $-5 \%$ & $-6 \%$ & $-7 \%$ & $-8 \%$ & $-9 \%$ & $-8 \%$ & $-7 \%$ & $-5 \%$ & $-6 \%$ \\
\hline Germany-Changes in emissions ${ }^{28}$ & $\%$ & $5 \%$ & $5 \%$ & $5 \%$ & $10 \%$ & $14 \%$ & $19 \%$ & $21 \%$ & $21 \%$ & $20 \%$ & $19 \%$ & $20 \%$ \\
\hline The USA-Changes in emissions ${ }^{29}$ & $\%$ & $7 \%$ & $7 \%$ & $9 \%$ & $12 \%$ & $15 \%$ & $21 \%$ & $22 \%$ & $21 \%$ & $19 \%$ & $18 \%$ & $18 \%$ \\
\hline US emissions tax on imports from China & Mn US\$ & 17,745 & 15,858 & 18,042 & 26,755 & 38,486 & 56,004 & 54,761 & 43,640 & 32,128 & 28,333 & 24,425 \\
\hline $\begin{array}{l}\text { US Emissions tax on imports from } \\
\text { Germany }\end{array}$ & Mn US\$ & 0.0 & 0.0 & 0.0 & -3.3 & -7.0 & -2.3 & -3.3 & -5.4 & -6.9 & -2.6 & -3.0 \\
\hline $\begin{array}{l}\text { US Emissions tax on imports from China } \\
\text { and Germany }\end{array}$ & Mn US\$ & 17,74 & 15,858 & 18,042 & 26,75 & 38,47 & 56,00 & 54,758 & 43,63 & 32,122 & 28,33 & 24,422 \\
\hline
\end{tabular}

\footnotetext{
${ }^{25}$ From manufacturing industries and construction.

${ }^{26}$ Emissions adjusted due to imports and exports with Germany and the USA; positive numbers indicate an increase and negative numbers indicate a reduction.

${ }^{27}$ Million Metric Ton.

${ }^{28}$ Emissions adjusted due to imports and exports with China and the USA.

${ }^{29}$ Emissions adjusted due to imports and exports with China and Germany.
} 
$\$ 24,425$ million of carbon tax is not on the entire emissions due to imports. This tax is on the excess emissions generated due to the outsourcing of manufacturing only to China. Since the emissions per unit GDP in Germany are less than that of the USA, there will not be any tax on imports from Germany. Therefore, imports from Germany will not generate any revenue. Thus, it acts as an incentive policy for organizations and encourages them to import from less polluting countries like Germany. This logic is expandable to other trading partners.

Further, the application of this model and its implications for an organization are examined. The model is applied to Wal-Mart, an organization in the retail industry. The reason for choosing the retail industry for application of this model is that imports are for final consumption by its customers and not for further processing or exporting. Wal-Mart has been selected for this analysis because it is the biggest retailer in the world. Wal-Mart's total retail sales were $\$ 446,950$ Million in 2011, which is more than the combined global sale revenues of next top four retailers (Deloitte, 2013). Wal-Mart was also the USA's biggest importer in 2012 (JOC, 2013). Wal-Mart imported items worth \$26,700 Mn from China alone in 2006 (EPI, 2007), the most recent year for which data is publicly available. Applying the above model to Wal-Mart's imports from China in 2006, Wal-Mart generated an additional 19.17 MMT equivalent $\mathrm{CO}_{2}$ emissions in China (excluding emissions from additional transport activities) for its business in the USA. In other words, these emissions are over and above those that would have been produced had Wal-Mart chosen its suppliers from within the USA. Based on the model presented earlier and assuming $\$ 30$ per ton differential rate of emissions as a carbon tax on imports, WalMart would be required to pay $\$ 7,244 \mathrm{Mn}$ due to imports of additional emissions. It is recognized that an increase in the cost due to a carbon import tax will have negative repercussions for an organization. There are three potential strategies to mitigate these negative effects, though each has its pros and cons. Absorbing the entire cost by an organization will reduce its profitability. In the case of Wal-Mart, assuming all else was equal, its net income (profit after tax at the effective tax rate) would have been reduced by approximately $\$ 4,811 \mathrm{Mn}$ in 2006, which represents a $43 \%$ reduction in its net income (Table 5.5). Recovering this cost from the customers would result in an increase of prices to customers. This could cause WalMart to lose its competitive advantage as a low cost retailer, which in turn will hurt their net sales. The third option is to buy (import) from emissions efficient countries, which is also likely 
to increase prices to customers. However, it will induce investment in technology and accelerate the pace of reducing emissions globally.

Table 5.5: Impact of emissions import tax on the profitability of Wal-Mart.

\begin{tabular}{llccc}
\hline \multicolumn{1}{c}{ Parameters } & Unit & $\mathbf{2 0 0 1}$ & $\mathbf{2 0 0 6}$ \\
\hline A. & Net Sales* & $\$ \mathrm{Mn}$ & 180,787 & 312,427 \\
B. & Effective tax rate* & $\%$ & $36.5 \%$ & $33.4 \%$ \\
C. & Net income (Profits after tax)* & $\$ \mathrm{Mn}$ & 6,235 & 11,231 \\
D. & Import from China** & Mn US\$ & 9,500 & 26,700 \\
E. & Export to China** & Mn US\$ & 0 & 100 \\
F. & Net imports of emissions [using Eq. (5.5)] & MMT & 8.15 & 19.17 \\
G. & Emissions Tax @ \$30 per Ton [using Eq. (5.8)] & Mn US\$ & 2,796 & 7,224 \\
H. & Net income (profit after tax) after emissions tax & Mn US\$ & 4,460 & 6,420 \\
& [C - G(1 - B)] & & & \\
I. & Reduction in net income due to emissions tax (C - H) & Mn US\$ & 1,775 & 4,811 \\
J. & Reduction in net income due to emissions tax (I / C) & $\%$ & 28 & 43 \\
\hline
\end{tabular}

Data sources: * Wal-Mart Annual Reports-2006; ** EPI-2007.

\subsection{Summary}

This chapter emphasized the need for considering emissions generated anywhere in the world for consumption in a country. The examples further reinforced the idea of including the emissions generated outside the national boundaries into NEI for a more holistic picture of the emissions of a nation. The examples showed that differential emissions of the USA and Germany increased by about $18 \%$ and $20 \%$ respectively due to outsourcing of manufacturing activities among the USA, Germany and China. A carbon price highlighted its impact on the profitability of an organization. As an example, Wal-Mart's net profits were reduced by $43 \%$ for 2006 due to a carbon price on imports from China. Therefore, these models (Eq. $5.5 \& 5.8$ ) will help national governments in reducing emissions generated anywhere in the world for serving the needs of their people. The carbon price will force organizations to include global emissions as one of the important criteria into their sourcing decisions. Organizations will explore destinations where the cost of sourcing including a carbon price on emissions is the least and help in reducing global emissions. These models can be used by international organizations like the UN and WTO to help promote international trade while reducing global emissions. 


\section{CHAPTER 6 : EMISSIONS FROM INTERNATIONAL TRANSPORT}


This chapter presents the results for Objective 3: Conduct an analysis of the changes in the GHG emissions due to additional international transportation as a consequence of offshore outsourcing of manufacturing activities. The model presented here provides a method to calculate emissions due to international transport as a consequence of outsourcing. It also assigns a carbon tax on emissions from international transport due to imports. The reason for doing this is to provide a realistic picture of emissions due to outsourcing because emissions from international transport are not included in NEI. A carbon tax on emissions from international transport is suggested to motivate national government agencies, as well as corporate leaders, to integrate the cost of carbon emissions into their decision-making criteria. Charging a tax on emissions will help provide a level playing field for local and regional manufacturers.

\subsection{Model for calculating international transport emissions}

The model developed is generic and can be used for any mode of transportation. However, the purpose here is to calculate emissions from international transport (international bunker fuel emissions). Annual transport emissions per unit weight for Country $i$ using a mode $(m)$ from a port of Country $(j)$

$$
C_{j}=\frac{C_{m}}{\varepsilon_{m}} d_{m, j \rightarrow i}
$$

where $\varepsilon_{m}=\frac{\varepsilon_{h, m}+\varepsilon_{b, m}}{2}$. Annual emissions from imports of a category of items $(k)$ through a mode $(m)$ from a port of Country $(j)$

$$
\frac{C_{m}}{\varepsilon_{m}} d_{m, j \rightarrow i} W_{k, j \rightarrow i}
$$

Therefore, total international emissions for Country $i$ due to imports of items of all categories from various ports of every exporting country through different modes of transportation can be written in a general form as 


$$
C_{i(t)}=\sum_{x=1}^{j}\left\{\sum_{y=1}^{m} \frac{C_{y}}{\varepsilon_{y}} d_{y, x \rightarrow i}\left(\sum_{z=1}^{k} W_{z, x \rightarrow i}\right)\right\}
$$

where $x, y$ and $z$ are independent variables representing exporting country, mode of transportation, and category of items respectively.

\subsection{Model for emissions tax on international transport}

This section uses the previous equations to calculate an emissions tax on international transport from imports. The tax on emissions from international transport for a category of items $(k)$

through a mode $(m)$ from Country $j$ can be computed as $T_{(k, j, m)}=T_{c i} C_{j}$, which can be written as

$$
T_{(k, j, m)}=T_{c i} \frac{C_{m}}{\varepsilon_{m}} d_{m, j \rightarrow i} W_{k, j \rightarrow i}
$$

Therefore, the general expression for the total emissions tax in a country from international transport due to imports from various countries will be

$$
T_{i(t)}=T_{c i} \sum_{x=1}^{j}\left\{\sum_{y=1}^{m} \frac{C_{y}}{\varepsilon_{y}} d_{y, x \rightarrow i}\left(\sum_{z=1}^{k} W_{z, x \rightarrow i}\right)\right\}
$$

where $x, y$ and $z$ are independent variables representing exporting countries, mode of transportation, and category of items respectively.

\subsection{Applications of the Models and Results}

This section will demonstrate an application of the above equations (6.3 \& 6.5) for imports by the USA from China and Germany through sea and air transport. The analysis is limited to items brought in containers through ships and items brought through air cargo. This is based on the assumption that the majority of manufactured goods are transported in container ships and some high value items in small quantity are transported as air-cargo. The weight of manufactured 
goods transported by air is less as compared to the weight transported through containers. Nevertheless, it is important to include emissions from air transport because the rate of emissions is about 36 times greater than container transportation.

International trading in the USA is predominantly between two broad directions. Trading between the USA and countries in Asia is called Trans-Pacific trade and trading between the USA and European countries is called Trans-Atlantic trade. These account for $60 \%$ and $20 \%$, respectively (World Shipping Council, 2013b). Figure 6.1 shows the containerized imports from major trading partners. This analysis shall use China and Germany as the biggest representative importing partner on each major trading route. China and Germany represented $47 \%$ and $3 \%$, respectively, for containerized imports in 2012 (USDoT, 2013). There are a few other elements, which influence emissions, such as the size of the ship, gross weight, and speed. These are discussed further below.

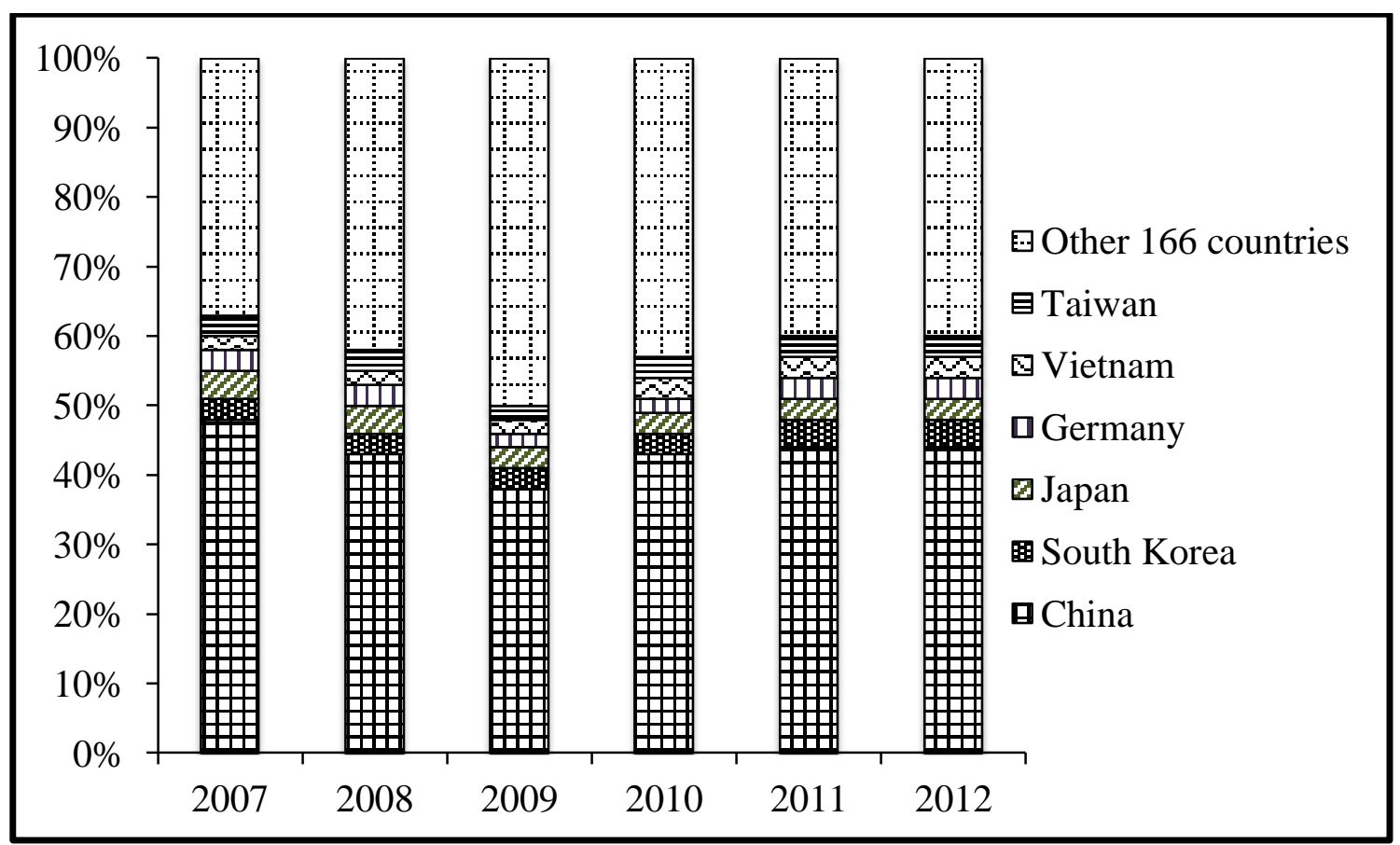

Figure 6.1: Major sources of imports of containerized items in the USA.

The majority of manufactured goods are shipped internationally through containers. There are two common types of shipping containers. These are classified as 20-foot $(6.09 \mathrm{~m})$ and 40 -foot 
$(12.18 \mathrm{~m})$ containers. There are other standard sizes, such as 45-foot $(13.7 \mathrm{~m}), 48$-foot $(14.6 \mathrm{~m})$, and 53-foot $(16.15 \mathrm{~m})$ containers for seamlessly moving between various modes of transportation. The 20-foot container is referred to as a Twenty-foot Equivalent Unit (TEU) and is treated as the industry standard. The 40 -foot long container is known as 2-TEU and is the most frequently used container (World Shipping Council, 2013c). Maximum gross weight of a TEU is 24 Ton (ISO 6346:2013). However, the weight and monetary value of each TEU container varies based on the density of packed items and their value. Garratt \& Teodoro (2013) studied a representative weight and value of TEUs in the biggest ship from Asia to Europe. According to the data from their study, the weight of a TEU varies significantly between approximately 2 Ton to 20 Ton, where the lowest weight per TEU is for professional, scientific and controlling instruments (SITC Code 87), perhaps due to more packaging needs in transit and shipping a few instruments in the entire container (as these are not mass production items). The highest weight is for manufactured goods-non-metallic mineral manufactures (SITC Code 66). Similarly, the (custom) value of a TEU also varies significantly between approximately $\$ 11,000$ to $\$ 186,000$ USD, where the lowest value is for synthetic textile fibers (SITC Code 26) and the highest value is for office machines (SITC Code 75) (Refer Appendix B for details). A custom value of the container is the value used by port authorities for custom/port duties and insurance purposes. It is lower than the total sale price of the items in a container.

Similarly, there is a variety of ships used for transporting containers. The speed, capacity, and emissions vary by ship size. Table 6.1 provides changes in the capacity of container ships over time. Bigger ships are preferred because of higher speeds and lower emissions. However, concerns have been expressed on the increasing container ship sizes due to the accident of the MOL Comfort (Mitsui O.S.K. Lines, Ltd.) in July 2013, which resulted in the sinking of the ship and the loss of 4,382 TEUs (Garratt \& Teodoro, 2013). Vessels used for transport on transatlantic and transpacific routes generally contain more than 4,000 containers. Smaller vessels are used on shorter international routes or within a nation or region. 
Chapter 6: Emissions from International Transport

Table 6.1: Capacity of container ships

\begin{tabular}{ccl}
\hline Class & Container Capacity (TEU) & \multicolumn{1}{c}{ Remarks } \\
\hline A & 500 & Early containerships (1956) \\
& 2,500 & Fully cellular (1970) \\
B & $3,000-3,400$ & Panamax (1980) \\
& $3,400-4,500$ & Panamax Max (1985) \\
C & $4,000-5,000$ & Post Panamax (1988) \\
& $6,000-8,000$ & Post Panamax Plus (2000) \\
D & 12,500 & New Panamax (2014) \\
E & 15,000 & Post New Panamax (2006) \\
& 18,000 & Triple E (2013)
\end{tabular}

Source: Data derived from Rodrigue et al., (2013).

Emissions from a ship depend on the type of ship, load carried, and travelling speed of the vessel. Average $\mathrm{CO}_{2}$ emissions from ships over $8000 \mathrm{dwt}$ (dead weight tonnage), ships between 2000 and $8000 \mathrm{dwt}$, trucks, and airplanes are 15, 21, 50 and 540 gram per ton-km respectively (ICS, 2013). Deadweight tonnage is the maximum allowable weight a ship can carry safely. From emissions perspective, ships should, therefore, be preferred over any other modes of transportation for moving goods where possible. However, the issue remains that international transport emissions are not generally accounted for in outsourcing decisions. The decisions on outsourcing of manufactured goods are primarily driven by cost (due to availability of cheap labor in economically weaker places) rather than by the overall sustainability (triple bottom-line of economic, environmental, and social impacts) of the business. In addition to the above, international transport does not eliminate or reduce the need for transporting goods within the importing nation and exporting nation.

Table 6.2 provides data for imports of containers (marine cargo) from China and Germany between 2007 and 2012. As previously noted, these serve as representative examples of imports from Trans-Pacific and Trans-Atlantic countries to the USA. The ports of Shanghai (China), Hamburg (Germany), Los Angeles (USA), Long Beach (USA), and New York (USA) were globally ranked \#1, \#14, \#16, \#23 and \#25 respectively for handling containers in 2012 (World 
Shipping Council, 2013d). The total number of containers handled at the Los Angeles and Long Beach ports together in 2012 was less than the number of containers received from China alone on trans-Pacific route. For the purposes of the example, therefore, it is assumed here that ships from each route were distributed across different ports in the USA. All shipments from the China and Germany were assumed to originate from the ports of Shanghai and Hamburg, respectively. Distances were therefore calculated based on an average of the distances between Shanghai and Hamburg and the top three ports in the USA.

Table 6.2: US data on imports by containers ships and air cargo.

\begin{tabular}{lccccccc}
\hline Origin & Unit & $\mathbf{2 0 0 7}$ & $\mathbf{2 0 0 8}$ & $\mathbf{2 0 0 9}$ & $\mathbf{2 0 1 0}$ & $\mathbf{2 0 1 1}$ & $\mathbf{2 0 1 2}$ \\
\hline \multicolumn{7}{l}{ Imports by } \\
\hline Chintainer ships $($ Source: USDoT & $(2013)$ \\
Germany & TEU & $8,810,347$ & $8,047,542$ & $6,948,065$ & $8,045,391$ & $8,088,623$ & $8,169,484$ \\
China & TEU & 500,547 & 474,061 & 384,483 & 440,937 & 511,240 & 560,502 \\
Germany & MMT & 52.14 & 47.86 & 40.81 & 46.97 & 47.56 & 48.90 \\
\hline Imports by & air cargo & (Source: & US Census $(2014)$ & & & \\
\hline China & MMT & 0.98 & 0.88 & 0.84 & 1.11 & 0.99 & 1.04 \\
Germany & MMT & 0.35 & 0.31 & 0.22 & 0.31 & 0.37 & 0.31 \\
\hline
\end{tabular}

The distances between Shanghai and Hamburg, and the above mentioned US ports are representative of distances between the USA and Asian/European countries. The distances between terminals were calculated using a web tool, SeaRates.com (http://www.searates.com/reference/portdistance). The distances between ports of Shanghai in China and Los Angeles, Long Beach, and New York in the USA are 10,597 km, 10,602 km, and 19,478 km respectively, and the distances between ports of Hamburg in Germany and Los Angeles, Long Beach, and New York ports in the USA are 14,931 km, 14,924 km, and 6,409 km respectively. Similar to the above discussion, air traffic on the trans-pacific route is considered between the airports of Shanghai (China) and Los Angeles (USA), and the distance is 10,456 km. Traffic on the trans-Atlantic route is considered between Hamburg (Germany) and Dallas (USA),

\footnotetext{
${ }^{30}$ MMT - Million Metric Tons
} 
and the distance is $8,275 \mathrm{~km}$. The data for distances between airports were taken from the following website: http://www.timeanddate.com/worldclock/distanceresult.html?p1=237\&p2=137.

Table 6.3: International transport emissions and emissions tax on imports in the USA.

\begin{tabular}{|c|c|c|c|c|c|c|c|}
\hline & Unit & 2007 & 2008 & 2009 & 2010 & 2011 & 2012 \\
\hline \multicolumn{8}{|l|}{ Marine Container Transport-Emissions } \\
\hline $\begin{array}{l}\text { A. } \mathrm{CO}_{2} \text { emissions on imports from China through } \\
\text { container ships }\end{array}$ & MMT & 14.1 & 13.0 & 11.1 & 12.7 & 12.9 & 13.3 \\
\hline $\begin{array}{l}\text { B. } \mathrm{CO}_{2} \text { emissions on imports from Germany through } \\
\text { container ships }\end{array}$ & MMT & 1.1 & 1.0 & 0.8 & 1.0 & 1.1 & 1.2 \\
\hline $\begin{array}{l}\text { C. Annual } \mathrm{CO}_{2} \text { emissions due to imports from China } \\
\text { and Germany through containers }(\mathrm{A}+\mathrm{B})\end{array}$ & MMT & 15.2 & 14.0 & 11.9 & 13.7 & 14.0 & 14.5 \\
\hline \multicolumn{8}{|l|}{ Air Cargo Transport-Emissions } \\
\hline $\begin{array}{l}\text { D. } \mathrm{CO}_{2} \text { emissions on imports from China through air } \\
\text { cargo }\end{array}$ & MMT & 3.07 & 2.76 & 2.62 & 3.47 & 3.12 & 3.25 \\
\hline $\begin{array}{l}\text { E. } \mathrm{CO}_{2} \text { emissions on imports from Germany through } \\
\text { air cargo }\end{array}$ & MMT & 1.09 & 0.96 & 0.68 & 0.97 & 1.15 & 0.97 \\
\hline $\begin{array}{l}\text { F. Annual } \mathrm{CO}_{2} \text { emissions due to imports from China } \\
\text { and Germany through air cargo }(\mathrm{D}+\mathrm{E})\end{array}$ & MMT & 4.2 & 3.7 & 3.3 & 4.4 & 4.3 & 4.2 \\
\hline
\end{tabular}

Impact on annual emissions from manufacturing and carbon tax

\begin{tabular}{|c|c|c|c|c|c|c|c|}
\hline $\begin{array}{l}\text { G. Annual } \mathrm{CO}_{2} \text { emissions due to imports from China } \\
\text { and Germany }(\mathrm{C}+\mathrm{F})\end{array}$ & MMT & 19.4 & 17.7 & 15.2 & 18.2 & 18.3 & 18.7 \\
\hline $\begin{array}{l}\text { H. } \mathrm{CO}_{2} \text { emissions from manufacturing industries and } \\
\text { construction in the USA }{ }^{31}\end{array}$ & MMT & 648 & 625 & 541 & 610 & 598 & - \\
\hline I. Impact on annual manufacturing emissions $(\mathrm{G} / \mathrm{H})$ & $\%$ & 3.0 & 2.8 & 2.8 & 3.0 & 3.1 & - \\
\hline $\begin{array}{l}\text { J. Carbon tax on total annual emissions due to } \\
\text { international transport ( } G^{*} @ \$ 30 \text { per Ton) }\end{array}$ & $\operatorname{Mn} \$^{32}$ & 582 & 532 & 456 & 545 & 549 & 561 \\
\hline
\end{tabular}

Table 6.3 provides emissions, its impact on annual manufacturing emissions, and the calculated emissions tax on international transport due to imports from China and Germany assuming all the containers were shipped using ships $>8000 \mathrm{dwt}$. The ship size of DWT $>8000$ was assumed because of non-availability of data by type of ship-category and weight combinations. Transport through smaller ships will lead to greater emissions and correspondingly bigger emissions taxes. Therefore, the emissions calculated (and emissions tax) are on the conservative side. It is

\footnotetext{
${ }^{31}$ Source: World Bank, 2013

${ }^{32}$ Million US Dollar
} 
assumed that head-haul efficiency is $80 \%$ and backhaul efficiency is 70\%. Wang et al., (2013) estimated capacity utilization for container ships between Europe and Asia and found it between

$81.5 \%(\max )$ and $55.7 \%(\min )$. The backhaul efficiency has been assumed higher than that of the efficiency determined by Wang et al. for conservative estimates.

The air cargo data do not provide a breakdown by categories of items. It is assumed that $50 \%$ of the items fall under the category of manufactured items and that planes utilize their capacity up to $90 \%$. Remaining items may include a range of perishable items, such as nuclear medicines (e.g., medicines for treating cancers, radioactive dyes for CT/MRI scans among others), vaccines, flowers etc.

The emissions from international transport through sea freight and airfreight from these two countries can be considered a part of manufacturing emissions of the USA because these imported goods will be consumed in the USA and these transport emissions are due to offshore outsourcing of manufacturing activities. Assuming these emissions to be a part of manufacturing emissions, the total manufacturing emissions in the USA will go up by about $3 \%$. The emissions tax has been considered at the present rate of $\$ 30$ per Ton of $\mathrm{CO}_{2}$ equivalent, as is the case in British Columbia, Canada (British Columbia, 2013). The impact of this increase will potentially lead to much higher costs to final customers and will force the organizations to rethink if outsourcing is the right strategy for them.

\subsection{Summary}

This chapter addressed the need for including emissions from international transport into NEI of an importing nation and highlighted its impact on NEI for the USA. As an illustration, the NEI for the USA increased by about 3\% of the entire manufacturing emissions in the USA for 2011. A carefully selected carbon tax on emissions from international transport will also push organizations to include emissions as one of the criteria into their sourcing decisions because a carbon tax will act as a disincentive to outsourcing strategy. Including international emissions will help nations get a real sense of the emissions for their needs and in turn provide an improved basis for making policies for reducing global emissions. The revenue generated through carbon pricing can be invested in cleaner technology for generating power. These models can be used by 
Chapter 6: Emissions from International Transport

international organizations like the UN and WTO to help promote international trade while reducing global emissions. 


\section{CHAPTER 7 : FUEL PRICES AND INVENTORY POLICIES}


This chapter presents the results for Objective 4: Analyze the impact of increases in fuel price on inventory policies $(E O Q)$. In this chapter, the EOQ model is revisited and modified to account for fuel prices. Further, the cost of emissions due to transportation has been added to the model. The applicability of the model is investigated in a two-level (vendor-buyer) supply chain, where the sum of the players' costs is jointly minimized by determining their respective lot-size and shipping quantities.

\subsection{The basic model with changing fuel price}

As discussed in Section 2.4 the increase in fuel prices can no longer be ignored and should be considered in inventory decisions. One common model in the existing literature is that the buyer (level 1 in the supply chain) orders according to the EOQ policy. The basic model is developed assuming that all other costs of manufacturing activities remains unchanged in different parts of the world. The order cost includes many components such as order processing labor costs, a portion of infrastructure cost, and transport cost, among others. Similarly, inventory carrying cost includes financial charges of carrying inventory, space, and obsolescence costs, among others. The models developed separate fuel cost (a part of transport cost) from order cost and treat it as a separate cost. This model is then expanded to a two-level supply chain that consists of a vendor (or manufacturer) and a buyer in the next section. The models of Banerjee (1986; referred onwards as B86), Goyal (1988; referred onwards as G88), Hill (1999; referred onwards as H99), and Braglia and Zavanella (2003; referred onwards as BZ03) were modified. B86 considered a lot-for-lot policy, G88 assumed that a vendor's cycle is an integer multiplier of the buyer's order quantity and that no shipment occurs during the production segment of a vendor' cycle, H99 developed a model similar to that of Goyal except that shipment occurs during the production

segment of a vendor' cycle, and BZ03 applied a Vendor Managed Inventory (VMI) with consignment policy, where a lot is shipped as soon as it is ready in a production cycle. These models have been selected because they are extensions of Harris' seminal work (Harris, 1913). The concept of JELSP was initiated by Goyal (1977). Hill (1999) assumed that production batches would increase by a fixed factor while shipment is possible both in equal and unequal lot-sizes. Braglia and Zavanella's (2003) consignment stock (CS) model is a relatively new concept where a buyer pays for what it has consumed. These are used in industry where the vendor and buyer have a long-term relationship. 
This model assumes: ( i) lead time is zero, (ii) infinite planning horizon, (iii) constant demand, $(i v)$ no shortages are allowed, $(v)$ holding cost is unaffected by the change in oil prices, ( $v i)$ a lot is delivered in a single shipment irrespective of truck/container capacity, (vii) transport cost is separate from setup or order cost and is paid by the buyer, (viii) production rate is higher than the demand rate.

Taking the fuel cost into account, the total cost for $\phi^{\text {th }}$ order is the sum of the order cost, inventory holding costs and transport cost, and is given by

$$
T C_{\phi}=K+\frac{h q}{2} t+A_{\phi}
$$

where transport cost $\left(A_{\phi}\right)$ can be written as

$$
A_{\phi}=A_{0}+A_{1}(\phi-1) \frac{q}{D}
$$

The transport cost $A_{0}=2 d l \alpha$ and $A_{1}=2 d l \beta$, where 2 represents a round trip, $d$ is the distance travelled in kilometer; $l$ is the fuel consumption in liters per $\mathrm{km} ; \alpha$ is the fuel price in $\$$ at the time of the first order (from Figure 2.4); $\alpha=(2.8917 x+11.802) / \gamma$, where $x$ is the time in years between the first order since 1990 and $\gamma$ is the conversion factor and is equal to 159 liter per barrel US; and $\beta$ is annual incremental increase in fuel price in $\$$ (from Figure 2.4); $\beta=2.8917$ / $\gamma$. The total cost including transport cost per unit time for a lot is obtained by dividing Eq. (7.1) by the cycle time, as $T C_{\phi}(q)=\frac{D}{q} K+\frac{h q}{2}+\frac{D}{q} A_{\phi}$ and replacing the value of $A_{\phi}$ from Eq. (7.2), it can be written as

$$
T C_{\phi}(q)=\frac{D}{q} K+\frac{h q}{2}+\frac{D}{q} A_{0}+A_{1}(\phi-1)
$$

The optimal value of $q$ that minimizes Eq. (7.3) is obtained by setting its first derivative with respect to $q$ equal to zero and solving for $q$ to get

$$
q^{*}=\sqrt{\frac{2 D\left(K+A_{0}\right)}{h}}
$$

Substituting the value of $q^{*}$ from Eq. (7.4) in Eq. (7.3) the minimum total cost will be

$$
T C_{\phi}\left(q^{*}\right)=\sqrt{2 h D\left(K+A_{0}\right)}+A_{1}(\phi-1)
$$


The EOQ formula without the transport cost is $q_{E}=\sqrt{2 K D / h}$, suggesting that $q^{*}>q_{E}$. Accounting for transportation cost recommends ordering in larger lots than suggested by the EOQ formula. Furthermore, as previously suggested, transportation cost is a function of fuel price, distance and fuel consumption, so the transport cost increases as the price of fuel, distance or fuel consumption increases. Subsequently, the lot-size increases. Generally, fuel consumption per unit distance travelled, though marginally, reduces over time due to advancements in technology but fuel price is a function of demand and supply, and distances in supply chains are affected by globalization.

\subsection{Tax on transport emissions}

Emissions are one of the consequences of fossil fuel-based transportation. Offshore outsourcing further increases emissions due to the need for additional transportation. This section shows the impact of adding an emissions tax, to neutralize the effects of emissions associated with transportation, on lot-sizes and supply chain costs.

It is assumed that the load of the vehicle does not significantly affect emissions. The emissions tax will be $T_{e}=2 d C_{m} T_{c i}$. The new cost function per unit time for the $\phi^{\text {th }}$ order

$$
T C_{\phi}(q)=\frac{D}{q} K+\frac{h q}{2}+\frac{D}{q} A_{\phi}+\frac{D}{q} T_{e}
$$

The lot-size that minimizes Eq. (7.6) and total cost per unit time for the $\phi^{\text {th }}$ order are given by

$$
\begin{aligned}
& q_{e}^{*}=\sqrt{\frac{2 D\left(K+A_{0}+T_{e}\right)}{h}} \\
& T C_{\phi, e}\left(q^{*}\right)=\sqrt{2 h D\left(K+T_{e}+A_{0}\right)}+A_{1}(\phi-1)
\end{aligned}
$$

where subscript $e$ stands for "with emissions".

\subsection{Model for two-level coordinated supply chain}

This section considers a two-level supply chain that consists of a vendor (manufacturer) and a buyer. The players in the chain can either coordinate or choose not to coordinate their supply chain. Since the non-coordinated supply chain results in higher cost, the model is developed for a 
coordinated model known as the Joint Economic Lot Size (JELS) model (Goyal, 1977). The scenarios explored and investigated are for a continuous increase in fuel price, which affects the order costs (and therefore, the unit price of an item). Banerjee (1986) developed a cost function for finite production rate and lot-for-lot production-shipment policy, i.e., $\phi=n$. Adding transport costs and an emissions tax, the unit time cost function becomes:

$$
A T C_{\phi}^{B 86}=\frac{D}{q}\left(K_{b}+K_{v}+A_{\phi}+T_{e}\right)+\frac{q}{2}\left(h_{b}+h_{v} \frac{D}{P}\right)
$$

The optimal value of $q$ that minimizes Eq. (7.9a) is obtained by setting its first derivative to zero and solving for $q$ to get

$$
q^{B 86}=\sqrt{\frac{2 D\left(K_{b}+K_{v}+A_{0}+T_{e}\right)}{h_{b}+h_{v} \frac{D}{P}}}
$$

Substituting the value of $q^{B 86}$ from Eq. (7.9b) in Eq. (7.9a) to get

$$
A T C_{\phi}^{B 86}=\sqrt{2 D\left(K_{b}+K_{v}+A_{0}+T_{e}\right)\left(h_{b}+h_{v} \frac{D}{P}\right)}+A_{1}(\phi-1)
$$

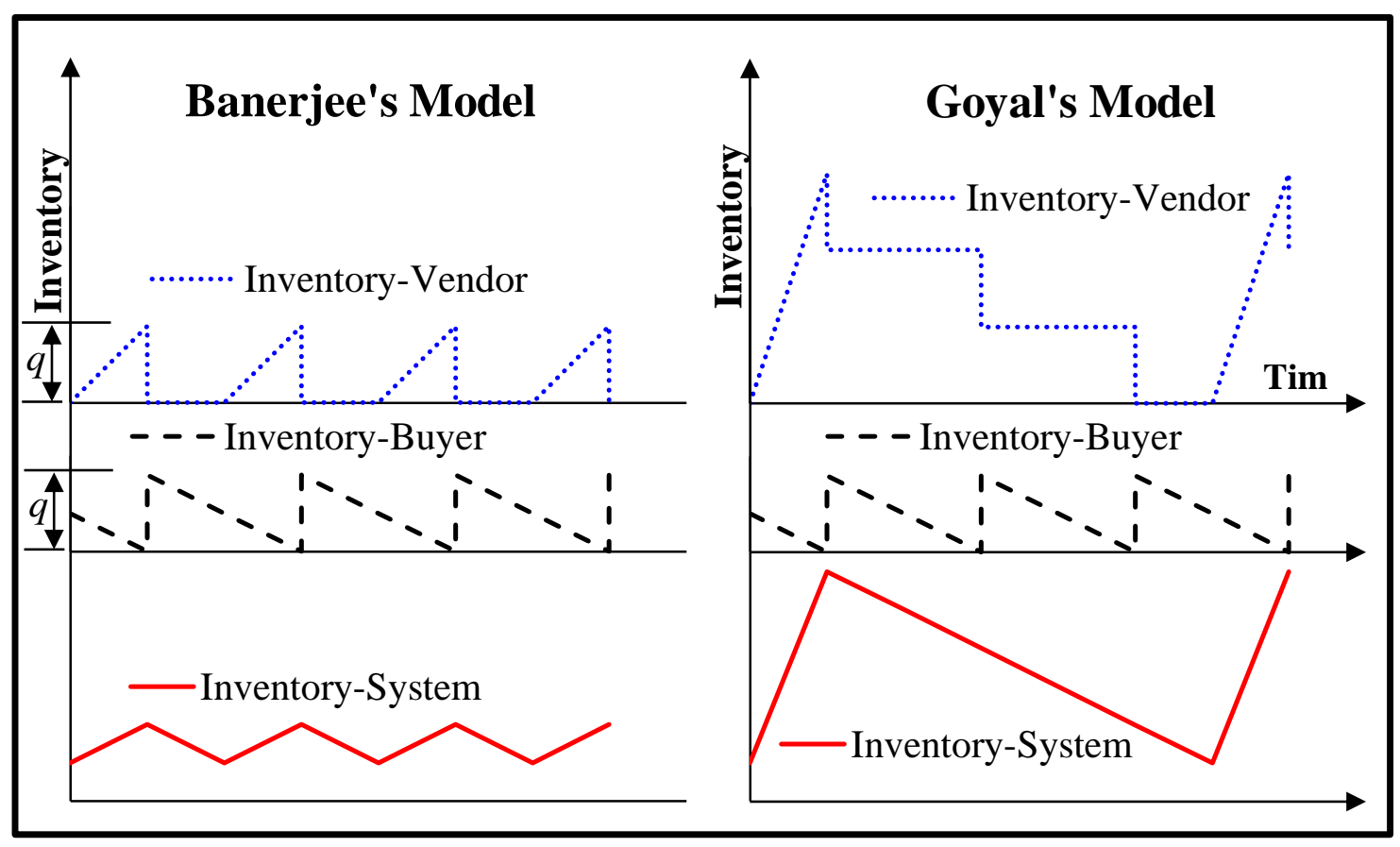

Figure 7.1: Inventory movement in Banerjee's (1986) and Goyal's (1988) models. 
Goyal (1988) relaxed the assumption of lot-for-lot policy in Banerjee's (1986) model, i.e. during the production cycle a vendor makes $\lambda$ shipments from a single setup. Graphical comparison of these two models is given in Figure 7.1. Therefore, the cost per unit time for vendor setup and buyer order will be $\left(K_{v}+\lambda K_{b}\right) D / \lambda q$. The vendor does not send the shipment to the buyer before the inventory is finished because $h_{b}>h_{v}$. The buyer receives a shipment as soon as the inventory is finished. The buyer's average inventory remains at $q / 2$.

The fuel price, and hence the transport cost, will increase between the first and subsequent shipments from a single production lot. This will change the lot-size from one shipment to the next shipment (within a production cycle). In order to avoid these increases between shipments and keep the planning simpler in practice, the average fuel cost of all the shipments from a production lot has been added as the variable transport cost for each shipment. Therefore, transport costs from a single production lot will be the same for all shipments. Adding the average transport cost and the emissions tax, Goyal's (1988) cost function and lot-size modifies to

$$
A T C_{n}^{G 88}=\frac{D}{q}\left(K_{b}+\frac{K_{v}}{\lambda}+A_{0}+T_{e}\right)+\frac{q}{2}\left\{\left(h_{b}-h_{v}\right)+\lambda h_{v}\left(1+\frac{D}{P}\right)\right\}+A_{1} \frac{(2 n \lambda-\lambda-1)}{2}
$$

The third term in Eq. (7.10a) is explained in Appendix E. The lot-size quantity that minimizes Eq. (10a) is obtained by setting the first derivative to zero and solving for $q$ to get

$$
q^{G 88}(\lambda)=\sqrt{\frac{2 D\left(K_{b}+\frac{K_{v}}{\lambda}+A_{0}+T_{e}\right)}{\left\{\left(h_{b}-h_{v}\right)+\lambda h_{v}\left(1+\frac{D}{P}\right)\right\}}}
$$

Replacing the value of $q^{G 88}(\lambda)$ from Eq. (7.10b) into Eq. (7.10a), the cost function becomes

$$
A T C_{n}^{G 88}(\lambda)=\sqrt{2 D\left(K_{b}+\frac{K_{v}}{\lambda}+A_{0}+T_{e}\right)\left\{\left(h_{b}-h_{v}\right)+\lambda h_{v}\left(1+\frac{D}{P}\right)\right\}}+A_{1} \frac{(2 n \lambda-\lambda-1)}{2}
$$


When $\lambda=1$, Eq. (7.10c), it reduces to $A T C_{i}^{B 86}$ making $A T C_{i}^{B 86}$ a special case of $A T C_{n}^{G 88}$. Eq.(7.10c) is a convex function is explained below. Eq. (7.10c) can be rewritten as a function of $\lambda$ as

$$
\operatorname{ATC}_{n}^{G 88}(\lambda)=\sqrt{\left(X+\frac{C}{\lambda}\right)(a+\lambda b)}+A_{1} \frac{(2 n \lambda-\lambda-1)}{2}=f(\lambda)+g(\lambda)
$$

where

$$
f(\lambda)=\sqrt{\left(X+\frac{C}{\lambda}\right)(a+\lambda b)}
$$

and

$$
g(\lambda)=A_{1} \frac{(2 n \lambda-\lambda-1)}{2}
$$

The optimal value of $f(\lambda)$ is obtained by differentiating Eq.(7.11e) with respect to $\lambda$ and setting its first derivative to zero and solving for $\lambda$ to get

$$
\lambda=\sqrt{\frac{C a}{b X}}
$$

$f^{\prime \prime}(\lambda)>0$ for every $\lambda>0$. Therefore, $f(\lambda)$ is convex in $\lambda$. Clearly, $g(\lambda)$ is an increasing function in $\lambda$. Then, the optimal value of Eq. (7.10c) occurs when $\operatorname{ATC}_{n}^{G 88}(\lambda-1)>A T C_{n}^{G 88}(\lambda)<A T C_{n}^{G 88}(\lambda+1)$.

Braglia and Zavanella (2003) modeled an industrial strategy for inventory management using Hill's (1997, 1999) model, who suggested increasing lot-size at a fixed rate for the optimal annual cost of the supply chain. The behavior of inventory at the vendor's and buyer's sides for the models of Hill (1999), and Braglia and Zavanella (2003) are shown in Figure 7.2. Braglia and Zavanella (2003) suggested a strategy of keeping inventories at the buyer's end but it is managed by the vendor, who is paid based on consumption (up to daily), which informs the vendor about the remaining inventory and helps in planning the next production lot. 


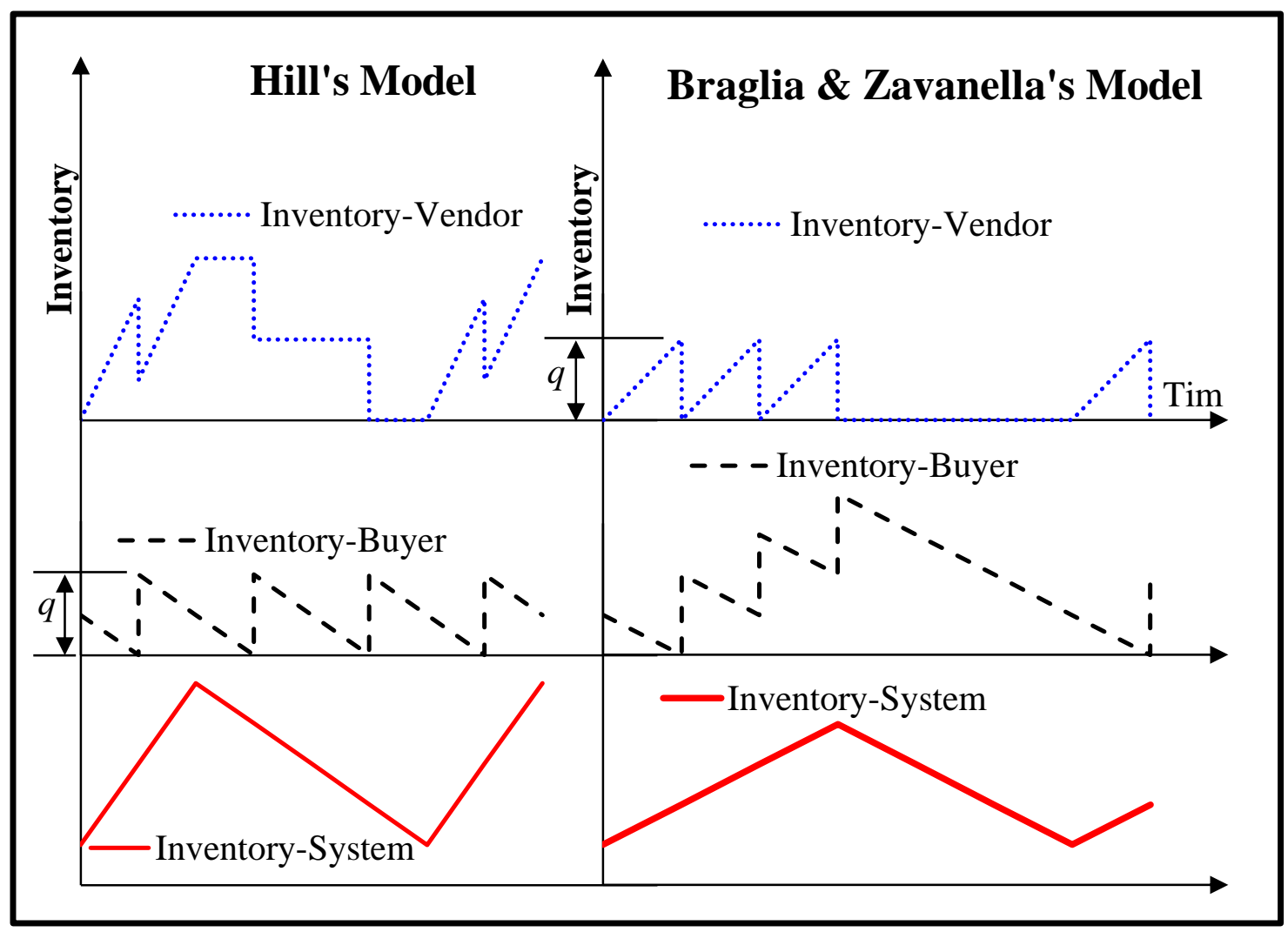

Figure 7.2: Comparison of Hill's (1999) and Braglia \& Zavanella's (2003) models.

Adding transport cost and the emissions tax in Hill's (1999) model, the cost function and lot-size changes to:

$$
\begin{aligned}
& A T C_{n}^{H 99}=\frac{D}{q}\left(\frac{K_{v}}{\lambda}+K_{b}+A_{0}+T_{e}\right)+q h_{v}\left\{\frac{D}{P}+\lambda\left(\frac{P-D}{2 P}\right)\right\}+\frac{\left(h_{b}-h_{v}\right) q}{2} \\
& +A_{1} \frac{(2 n \lambda-\lambda-1)}{2}
\end{aligned}
$$

The lot-size quantity that minimizes Eq. (7.11a) is given by setting the first derivative to zero and solving for $q$ to get

$$
q^{H 99}(\lambda)=\sqrt{\frac{D\left(\frac{K_{v}}{\lambda}+K_{b}+A_{0}+T_{e}\right)}{\left[h_{v}\left\{\frac{D}{P}+\lambda\left(\frac{P-D}{2 P}\right)\right\}+\frac{\left(h_{b}-h_{v}\right)}{2}\right]}}
$$


Substituting $q^{H 99}(\lambda)$ from Eq. (7.11b) in Eq. (7.11a), total cost function reduces to

$$
\begin{aligned}
& \operatorname{ATC}_{n}^{H 99}(\lambda)=2 \sqrt{D\left(\frac{K_{v}}{\lambda}+K_{b}+A_{0}+T_{e}\right)\left[h_{v}\left\{\frac{D}{P}+\lambda\left(\frac{P-D}{2 P}\right)\right\}+\frac{\left(h_{b}-h_{v}\right)}{2}\right]} \\
& +A_{1} \frac{(2 n \lambda-\lambda-1)}{2}
\end{aligned}
$$

The optimal value of Eq. (7.11c) occurs when $A T C_{n}^{H 99}(\lambda-1)>A T C_{n}^{H 99}(\lambda)<A T C_{n}^{H 99}(\lambda+1)$.

The expression for average transport cost from a production lot for Braglia and Zavanella's model (2003) is different and explained in Appendix F. Adding the average transport cost function to Braglia and Zavanella's cost function, it becomes

$$
\begin{aligned}
& A T C_{n}^{B Z 03}=\frac{D}{q}\left(\frac{K_{v}}{\lambda}+K_{b}+A_{0}+T_{e}\right)+q_{i} h_{b}\left\{\frac{D}{P}+\lambda\left(\frac{P-D}{2 P}\right)\right\}-\frac{\left(h_{b}-h_{v}\right) q_{i} D}{2 P} \\
& +(n-1) \lambda A_{1}+\frac{(\lambda-1)}{2} A_{1} \frac{D}{P} \\
& q^{B Z 03}(\lambda)=\sqrt{\frac{D\left(\frac{K_{v}}{\lambda}+K_{b}+A_{0}+T_{e}\right)}{\left[h_{b}\left\{\frac{D}{P}+\lambda\left(\frac{P-D}{2 P}\right)\right\}-\frac{\left(h_{b}-h_{v}\right) D}{2 P}\right]}}
\end{aligned}
$$

Substituting $q^{B Z 03}(\lambda)$ from Eq. (7.12b) in Eq. (7.12a), the cost function changes to

$$
\begin{aligned}
& \operatorname{ATC}_{n}^{B Z 03}(\lambda)=2 \sqrt{D\left(\frac{K_{v}}{\lambda}+K_{b}+A_{0}+T_{e}\right)\left[h_{b}\left\{\frac{D}{P}+\lambda\left(\frac{P-D}{2 P}\right)\right\}-\frac{\left(h_{b}-h_{v}\right) D}{2 P}\right]} \\
& +(n-1) \lambda A_{1}+\frac{(\lambda-1)}{2} A_{1} \frac{D}{P}
\end{aligned}
$$


The optimal value of Eq. (7.12c) occurs when $A T C_{n}^{B Z 03}(\lambda-1)>A T C_{n}^{B Z 03}(\lambda)<A T C_{n}^{B Z 03}(\lambda+1)$. The next section will provide the solution procedure.

\subsection{Solution Procedure}

This section provides a summary of the steps involved in finding the order cost and lot-size after adding the transport cost and the emissions tax.

Step 1: Define a starting date of the first shipment.

Step 2: Calculate the values of $\alpha, \beta, A_{0}, A_{1}$ and $T_{e}$ using the starting date chosen in step 1 .

Step 3: For any vendor cycle $n$, compute the corresponding $\operatorname{ATC}_{n}^{M}(\lambda)$ for model $M=$ $G 88, H 99$, and $B Z 03$ for $\lambda=1$ and 2.

Step 4: If the total $\operatorname{cost} A T C_{n}^{M}(1)<A T C_{n}^{M}(2)$, select $\lambda^{*}=1$ go to Step 5. Otherwise, repeat the step for the next value(s) of $\lambda$; i.e, $\lambda=3,4, \ldots$. Select the optimal value of $\lambda$ as $\lambda^{*}$, for which $A T C_{n}^{M}\left(\lambda^{*}-1\right)>A T C_{n}^{M}\left(\lambda^{*}\right)<A T C_{n}^{M}\left(\lambda^{*}+1\right)$.

Step 5: Using the optimal value of $\lambda^{*}$ from the Step 4, calculate the average shipment lotsize $q^{M}\left(\lambda^{*}\right)$ for a production lot for the corresponding model $M$.

The next section presents numerical examples and the subsequent section discusses the results to illustrate how these models behave with increasing fuel prices in order to draw some insights and managerial implications.

\subsection{Numerical Examples}

The values of the input parameters have been taken from the numerical example used by Braglia and Zavanella (2003). Then the variable transport cost and emissions tax have been added to illustrate the impact of fuel price on order cost lot-size. The data used are:

$\begin{array}{llr}\text { Demand rate (units/year) } & D & 1,000 \\ \text { Production rate (units/year) } & P & 3,200 \\ \text { Item price for buyer (\$/unit) } & P_{c} & 25 \\ \text { Buyer's order cost (\$/order) } & K_{b} & 25\end{array}$


$\begin{array}{lll}\text { Vendor's setup cost for producing per run (\$/batch) } & K_{v} & 400 \\ \text { Holding cost for the vendor (\$ /unit/ unit of time) } & h_{v} & 4.00 \\ \text { Holding cost for the buyer (\$ / unit/ unit of time) } & h_{b} & 5.00\end{array}$

The emissions considered in the analysis are $75 \mathrm{~g} /$ Ton-mile $\mathrm{CO}_{2}$ for GVWR > 33,000 Pounds (16.5 Ton) (ECFR, 2013). Therefore, emissions per kilometer for a 16.5 Ton trailer $(1$ mile $=1.6$ km) $C_{m}=75 \times 16.5 /(1.6 \times 1000000)=7.7344 \times 10^{-4}$ Ton per $\mathrm{km}$. Emissions tax at the rate of $\$ 30$ per Ton of $\mathrm{CO}_{2}$ equivalent has been used in the analysis (British Columbia, 2013). Table 7.1 provides the values of order cost, number of shipments per production cycle, shipment lot-size with and without transport, and emissions costs for ten production cycles. These costs are based on the assumption that the first order is placed on Jan 1, 2014 for one-way travel distance $(d)$ of $500 \mathrm{~km}$ taking fuel consumption $(l)$ as $0.3 \mathrm{Lt} / \mathrm{km}$ for the three policies discussed above. The data show that the lot-size more than doubled for all three policies. Order cost increases for every subsequent shipment. However, for the purpose of simplicity in real life, an average cost of all the shipment lots from a production lot, i.e., when $\lambda>1$, has been added to the function. The details for finding the average cost of transportation of all the shipments in a production cycle, i.e., where $\lambda>1$ has been given in Appendix E for Goayl's and Hill's models, in Appendix F for Braglia and Zavanella's model. Similarly, lot-sizes in a cycle, where $\lambda>1$, are the averages of all the shipments. The values for Goyal's model (1988) and Braglia and Zavanella's model (2003), when $\lambda=1$, i.e. lot-for-lot production, are the same as the values for Banerjee's model (1986). The data show that Hill's policy provided the least cost. One set of calculations, using the solution procedure described earlier, are given below for illustration purposes:

Step 1: the date of the first order is 1 January 2014.

Step 2: using the starting date chosen in Step 1, i.e., 1 January 2014, the values of $\alpha, \beta$,

$$
\begin{array}{ll}
A_{0}, A_{1} \text { and } T_{e} \text { are calculated as below: } \\
\begin{array}{lll}
\text { Number of years from } 1990(x) & =24 \\
\gamma & = & 159 \text { liter/barrel } \\
\alpha=\left(2.89175^{*} x+11.802\right) / \gamma & =\$ & 0.5107 \\
\beta=2.8917 / \gamma & =\$ & 0.0182 \\
A_{0}=2 d l \alpha & =\$ 153.21
\end{array}
\end{array}
$$




$$
\begin{array}{llr}
A_{l}=2 d l \beta & =\$ 5.46 \\
T_{e}=2 d . C_{m} \cdot T_{c i} & =\$ 23.20
\end{array}
$$

Step 3: For vendor cycle $n=1$, computed the corresponding $A T C_{1}^{H 99}(\lambda)$ for model $M=$ $H 99$ for $\lambda=1$ and 2.

Step 4: Calculated the total cost $A T C_{1}^{H 99}(1)=\$ 2,742$ and $A T C_{1}^{H 99}(2)=\$ 2,691$. Since, the total cost $A T C_{1}^{H 99}(1)>A T C_{1}^{H 99}(2)$, repeated the step for the next value of $\lambda=3$. The next value of total cost is $A T C_{1}^{H 99}(3)=\$ 2,810$. Therefore, the optimal value of $\lambda^{*}=2$ because $A T C_{1}^{H 99}(1)>A T C_{1}^{H 99}(2)<A T C_{1}^{H 99}(3)$ (refer Table 7.1, row 2, columns 5 and 6).

Step 5: Using the optimal value of $\lambda^{*}=2$ from the Step 4, calculated the average shipment lot-size $q^{H 99}(2)=299($ refer Table 7.1 , row 2, column 7).

\begin{tabular}{|c|c|c|c|c|c|c|c|c|c|}
\hline \multirow[b]{2}{*}{$\begin{array}{l}\text { Production lot } \\
\qquad(n) \downarrow\end{array}$} & \multicolumn{3}{|c|}{ Goyal 1988} & \multicolumn{3}{|c|}{ Hill 1999} & \multicolumn{3}{|c|}{ Braglia \& Zavanella 2003} \\
\hline & $\hat{A T C_{n}}{ }^{G 88}$ & $\lambda_{n}$ & $q^{G 88}(\lambda)$ & $A \hat{T} C_{n}{ }^{H 99}$ & $\lambda_{n}$ & $q^{H 99}(\lambda)$ & $A \hat{T C}_{n}^{B G Z}$ & $\lambda_{n}$ & $q^{B Z 03}(\lambda)$ \\
\hline (No.) & $(\$)$ & (No.) & (No.) & $(\$)$ & (No.) & (No.) & $(\$)$ & (No.) & (No.) \\
\hline $\begin{array}{l}\text { Without transport } \\
\text { emissions cost }\end{array}$ & 2,275 & 2 & 198 & 1,903 & 5 & 110 & 2,035 & 4 & 123 \\
\hline 1 & 2,742 & 1 & 439 & 2,691 & 2 & 299 & 2,742 & 1 & 439 \\
\hline 2 & 2,747 & 1 & 439 & 2,702 & 2 & 299 & 2,747 & 1 & 439 \\
\hline 3 & 2,753 & 1 & 439 & 2,713 & 2 & 299 & 2,753 & 1 & 439 \\
\hline 4 & 2,758 & 1 & 439 & 2,723 & 2 & 299 & 2,758 & 1 & 439 \\
\hline 5 & 2,764 & 1 & 439 & 2,734 & 2 & 299 & 2,764 & 1 & 439 \\
\hline 6 & 2,769 & 1 & 439 & 2,745 & 2 & 299 & 2,769 & 1 & 439 \\
\hline 7 & 2,775 & 1 & 439 & 2,756 & 2 & 299 & 2,775 & 1 & 439 \\
\hline 8 & 2,780 & 1 & 439 & 2,767 & 2 & 299 & 2,780 & 1 & 439 \\
\hline 9 & 2,785 & 1 & 439 & 2,778 & 2 & 299 & 2,785 & 1 & 439 \\
\hline 10 & 2,791 & 1 & 439 & 2,789 & 2 & 299 & 2,791 & 1 & 439 \\
\hline Average (1-10) & 2,766 & & & 2,740 & & & 2,766 & & \\
\hline
\end{tabular}

Table 7.1: Changes in order cost and lot-size due to transport and emissions cost. 
Subsequent results discussed in this section refer to the average of ten production cycles, i.e. equivalent of the last line from the Table 7.1. Order costs and lot-sizes increased as the distance increased. Table 7.2 shows the changes in lot-sizes and order costs by varying the distance. As the distance increases, transport cost increases, which results in bigger and infrequent lot-sizes. However, approximately at $600 \mathrm{~km}$, all the policies started behaving in the same manner, that is, lot-for-lot. For the distance less than $600 \mathrm{~km}$, Hill's policy provided the least cost per unit. This threshold of $600 \mathrm{~km}$ is for the first order placed in 2014 will decrease as the oil price goes up in following years.

Table 7.2: Changes in order cost and lot-size due changes in transport distance in 2014.

\begin{tabular}{cccccccccc}
\hline \multirow{2}{*}{$\begin{array}{c}\text { Distance } \\
\Downarrow\end{array}$} & \multicolumn{3}{c}{ Goyal 1988 } & \multicolumn{3}{c}{ Hill 1999 } & \multicolumn{3}{c}{ Braglia \& Zavanella 2003 } \\
& $A \hat{T C}_{n}{ }^{G 88}$ & $\lambda_{n}$ & $q^{G 88}(\lambda)$ & $A \hat{T C_{n}{ }^{H 99}}$ & $\lambda_{n}$ & $q^{H 99}(\lambda)$ & $A \hat{T C}_{n}{ }^{B G Z 3}$ & $\lambda_{n}$ & $q^{B Z 03}(\lambda)$ \\
\hline$(K m)$ & $(\$)$ & $(N o)$. & $(N o)$. & $(\$)$ & $(N o)$. & $(N o)$. & $(\$)$ & $(N o)$. & $(N o)$. \\
\hline 0 & 2,275 & 2 & 198 & 1903 & 5 & 110 & 2035 & 4 & 123 \\
100 & 2,404 & 1 & 384 & 2,149 & 3 & 182 & 2,256 & 2 & 232 \\
200 & 2,499 & 1 & 398 & 2,327 & 2 & 256 & 2,413 & 2 & 247 \\
300 & 2,591 & 1 & 412 & 2,471 & 2 & 271 & 2,562 & 2 & 261 \\
400 & 2,680 & 1 & 426 & 2,609 & 2 & 285 & 2,680 & 1 & 426 \\
500 & 2,766 & 1 & 439 & 2,740 & 2 & 299 & 2,766 & 1 & 439 \\
600 & 2,851 & 1 & 451 & 2,848 & 1 & 409 & 2,851 & 1 & 451 \\
700 & 2,933 & 1 & 464 & 2,933 & 1 & 464 & 2,933 & 1 & 464 \\
800 & 3,013 & 1 & 476 & 3,013 & 1 & 476 & 3,013 & 1 & 476 \\
900 & 3,091 & 1 & 487 & 3,091 & 1 & 487 & 3,091 & 1 & 487 \\
1000 & 3,167 & 1 & 499 & 3,167 & 1 & 499 & 3,167 & 1 & 499 \\
2000 & 3,858 & 1 & 602 & 3,858 & 1 & 602 & 3,858 & 1 & 602 \\
\hline
\end{tabular}

Long haul transportation of manufactured goods is mostly done by trailers/containers. The fuel consumption targets for a trailer up to 20 Ton and greater than 20 Ton are $3.09(\mathrm{~km} / \mathrm{L})$ and 2.01 $\mathrm{km} / \mathrm{L}$, respectively (IEA, 2010). The modified models are tested for changes in (average) shipment lot-sizes and order cost by varying the fuel consumption in this range and the results are given in Table 7.3. 
Table 7.3: Effect of changes in fuel consumption on order cost and lot-size.

\begin{tabular}{|c|c|c|c|c|c|c|c|c|c|}
\hline \multirow{2}{*}{$\begin{array}{c}\text { Fuel } \\
\text { Consumption } \\
\downarrow\end{array}$} & \multicolumn{3}{|c|}{ Goyal 1988} & \multicolumn{3}{|c|}{ Hill 1999} & \multicolumn{3}{|c|}{ Braglia \& Zavanella 2003} \\
\hline & $A \hat{T C}_{a v g}^{G 88}$ & $\lambda_{\text {avg }}$ & $q_{\text {avg }}^{G 88}$ & $A \hat{T} C_{a v g}^{H 99}$ & $\lambda_{\text {avg }}$ & $q_{\text {avg }}^{H 88}$ & $A \hat{T} C_{\text {avg }}^{B G Z 0}$ & $\lambda_{\text {avg }}$ & $q_{\text {avg }}^{H 88}$ \\
\hline$(\mathrm{Lt} / \mathrm{Km})$ & $(\$)$ & (No.) & (No.) & $(\$)$ & (No.) & (No.) & $(\$)$ & (No.) & (No.) \\
\hline 0.21 & 2,652 & 1 & 422 & 2,566 & 2 & 281 & 2,650 & 1 & 376 \\
\hline 0.22 & 2,665 & 1 & 424 & 2,586 & 2 & 283 & 2,665 & 1 & 408 \\
\hline 0.23 & 2,678 & 1 & 425 & 2,605 & 2 & 285 & 2,678 & 1 & 425 \\
\hline 0.24 & 2,691 & 1 & 427 & 2,625 & 2 & 287 & 2,691 & 1 & 427 \\
\hline 0.25 & 2,703 & 1 & 429 & 2,644 & 2 & 289 & 2,703 & 1 & 429 \\
\hline 0.26 & 2,716 & 1 & 431 & 2,664 & 2 & 291 & 2,716 & 1 & 431 \\
\hline 0.27 & 2,729 & 1 & 433 & 2,683 & 2 & 293 & 2,729 & 1 & 433 \\
\hline 0.28 & 2,741 & 1 & 435 & 2,702 & 2 & 295 & 2,741 & 1 & 435 \\
\hline 0.29 & 2,754 & 1 & 437 & 2,721 & 2 & 297 & 2,754 & 1 & 437 \\
\hline 0.30 & 2,766 & 1 & 439 & 2,740 & 2 & 299 & 2,766 & 1 & 439 \\
\hline 0.31 & 2,779 & 1 & 441 & 2,758 & 2 & 315 & 2,779 & 1 & 441 \\
\hline
\end{tabular}

\subsection{Analysis and Discussion}

The above analysis indicated that the impact of variable transport cost would become increasingly important in the context of global supply chains. It also highlighted the need to consider GHG emissions, which are rarely accounted for in existing models. By adding fuel and emissions costs, the shipment lot-sizes and order costs increased for all the three models tested. This resulted in less frequent shipments in larger sizes. As a consequence of the increase in order cost in each shipment, the unit cost of a product will go up over time. The unit cost of a product will also increase as the distance in a supply chain increases. The data from Table 7.3 indicated that the model is relatively less sensitive to fuel consumption. An increase in fuel consumption by about $40 \%$ (for a fixed distance) increased the annual order cost in the range of $4 \%$ to $7 \%$ for the three models. However, the model is slightly more sensitive to distance as depicted in Table 7.2. For a $40 \%$ increase in distance (from 500 to $700 \mathrm{~km}$ ), the cost went up by $6 \%$ to $7 \%$ and for a further $43 \%$ increase in distance (from 700 to $1000 \mathrm{~km}$ ), the cost went up by $8 \%$ for all the models. 
There are a few options to reduce supply chain costs and improve environmental performance. Reducing the distance between manufacturing and consumption locations is a logical choice for reducing variable fuel cost as well as emissions. Nevertheless, it is not possible to eliminate transportation from supply chains. It can only be reduced. Therefore, organizations have to make an effort in developing a culture of being eco-oriented for reducing their carbon footprint when designing and implementing logistics policies (Kim \& Lee, 2012). ]. A carbon tax is an enabler in improving the environmental performance. Choi (2013) studied the impact of a carbon price on sourcing in fashion industry. The author found a positive influence of a carbon tax on reducing environmental impacts by sourcing from local manufacturers.

The next option is to invest in alternate and efficient means of transportation. In order to address the need for reducing fuel costs, truck manufacturers have been developing vehicles that are more efficient and exploring the use of alternate fuel in long haul trucks. For example, researchers have recently developed a prototype car, which can run up to $125 \mathrm{mph}$ ( $200 \mathrm{Kmph}$ ) using chocolate as a fuel (University of Warwick, 2013). A Trans-Atlantic flight by a Swiss prototype solar powered plane is a major breakthrough in harnessing solar energy for mobile applications and may have considerable implications for transport vehicles in the future (Solar Impulse, 2013). Use of Compressed Natural Gas (CNG) as an alternate fuel in long haul trucks is being explored for reducing emissions. Hybrid electric trucks for city use have been developed (Iveco, 2013). Hybrid trucks for long haul applications are an interesting potential solution to reduce emissions and consumption of fossil fuel. However, hybrid trucks for long haul applications are still in various stages of development and have to overcome many technical challenges of reliability, performance, safety, and cost in addition to a psychological barrier of acceptance by the transport industry.

A high-level analysis of the financial viability of a hybrid truck, based on the limited information publicly available from Volvo on their long haul hybrid truck's performance, is provided here. These are expected to consume about 30\% less fuel and, therefore, generate 30\% less emissions (Volvo, 2013). A hybrid truck with a comparable performance to a diesel truck will be an economically viable option in the truck industry when the lifecycle cost, which includes 
acquisition, operations, maintenance and salvage values, of a hybrid truck is less than the lifecycle cost of a diesel truck, i.e.,

$$
C_{h}+M_{h}+A_{h}+E_{h}-S_{h}<C_{d}+M_{d}+A_{d}+E_{d}-S_{d}
$$

Suffix $d$ is for diesel trucks and $h$ is for hybrid trucks. $C_{d}$ and $C_{h}$ are purchase prices, $M_{d}$ and $M_{h}$ are maintenance costs, $A_{d}$ and $A_{h}$ are fuel cost, $E_{d}$ and $E_{h}$ are emissions costs and $S_{d}$ and $S_{h}$ are salvage value at the end of useful life of a diesel and a hybrid truck respectively. For the purposes of comparison, the following values are for a Volvo diesel truck.

Price of a diesel truck (Volvo $465 \mathrm{HP}$ )

Average annual distance travelled ( $\mathrm{km} /$ year)

Life of a truck $(\mathrm{km})$

Maintenance costs (\$/year)

Fuel consumption $(1 / \mathrm{km})$
$\$ 125,000$

200,000

$2,000,000$

15,000

0.30

The key assumption is that the annualized purchase price of a hybrid truck is double that of a diesel truck due to high research costs, high warranty costs, and low initial volumes. Annual maintenance costs are assumed to be $50 \%$ higher than that of a diesel truck. These costs are on the higher side as a worst-case scenario to avoid any surprises to transporters. Keeping the emissions tax as discussed earlier, a diesel truck is economically a better choice than a hybrid truck for about the next 5 years. The trend will start to shift in favour of hybrid truck beyond this point, see Table 7.4. If the initial cost is reduced, fuel savings are greater, or the emissions tax rate increases, the trend may shift in favour of a long haul hybrid truck sooner. 
Table 7.4: Comparison of annual costs of ownership for diesel and hybrid trucks.

\begin{tabular}{lcc}
\hline Year & Annual Cost of a diesel truck (\$) & Annual cost of a hybrid truck (\$) \\
\hline 2013 & 111,709 & 116,643 \\
2014 & 115,216 & 119,097 \\
2015 & 118,936 & 121,701 \\
2016 & 122,881 & 124,463 \\
2017 & 127,066 & 127,392 \\
2018 & 130,762 & 129,979 \\
2019 & 135,470 & 133,275 \\
2020 & 140,463 & 136,770 \\
\hline
\end{tabular}

Another corollary to the above analysis is to use more efficient means of transport technology that generates fewer emissions, such as railways. However, this requires a large investment in infrastructure, which takes years to build and is feasible only between the locations of hubs of economic activities for inland operations only. A combination of hybrid vehicles and railways would be a workable solution for surface transport. Cargo ships, which carry the biggest share of goods in global supply chains, still remain a challenge in reducing costs and emissions.

\subsection{Summary}

The important take away from this chapter is that fuel prices are becoming more important than ever before due to the compounding of increases in prices. Fuel prices have been increasing at a rate much higher than the overall inflation. Fuel prices (transport costs) were traditionally included in order cost. However, increases in fuel prices are putting pressure on transport costs and will soon greatly affect the overall cost of supply chains. The burning of fossil fuel, as discussed earlier, is the single largest source of anthropogenic emissions in the world. The example showed that the lot size increased by 2 to 3 times for a distance for $500 \mathrm{~km}$. The order cost also increased. However, the real impact on order cost is discussed in the next chapter. A carbon tax on emissions in conjunction with increasing fuel prices will put a lot of pressure on 
overall supply chain costs and supply chain and logistics professionals will be increasingly forced to consider their options to reduce these costs. These alternatives could include hybridvehicles as well as exploring the use of vendors in close proximities. These initiatives will reduce the operating cost and global emissions. 


\section{CHAPTER 8 : EFFECTS OF OFFSHORING ON EMISSIONS AND SUPPLY CHAINS}


This chapter presents the results for Objective 5: Analyze the effects of outsourcing on NEI, and the combined effect of a carbon price on additional emissions from manufacturing and transport along with increases in fuel prices on supply chain costs.

This model is developed based on a consolidation of the previous three chapters. The total additional GHG emissions from offshore outsourcing are the sum of the differential GHG emissions from manufacturing in an offshore location, which could be negative, zero or positive, and GHG emissions from additional international transport from the offshore manufacturing locations, which will always be positive. Therefore, the net of the differential GHG emissions from manufacturing and additional GHG emissions from international transport could be negative, zero or positive. Further, the cost of these net emissions is added to the EOQ model to show the impact of assigning a cost to these GHG emissions on supply chains.

\subsection{Model Development}

This section provides models for calculating net (differential manufacturing and additional transport) emissions for a country due to outsourcing. A carbon price on these emissions is suggested to see its impact of outsourced emissions. Further, the EOQ model is modified to include the same concept to see the impact of a carbon price on net outsourced emissions on supply chain costs and lot-size. The sub-sections 8.1.1 and 8.2.1 are on NEI, considering outsourced emissions and carbon pricing and sub-sections 8.1.2 and 8.2.2 are on the impacts of outsourcing on supply chain cost and lot-size due to a carbon price and increasing fuel prices.

\subsubsection{Outsourced Emissions for a Nation}

The net GHG emissions, as explained above, are the sum of the GHG emissions from manufacturing and the GHG emissions from additional international transport activities. The GHG emissions from additional onshore transport are not included in this model because it is assumed that the effect of outsourcing on onshore transport is minimal for the importing country. It is recognized that the in-land transport emissions in the exporting (manufacturing) country may be significant. However, it was not possible to include these in the model due to the difficulty in obtaining data regarding the distances traveled besides those are included in the NEI 
of the outsourcee country. Therefore, emissions due to outsourcing for Country $i$ can be written as

Emissions (outsourcing) $=$ Emissions (manufacturing) + Emissions (international transport)

From Eq. (5.5) and Eq. (6.3), net NEI for Country $i$ will be

$$
C_{i(o)}=\frac{C_{i}}{G_{i}}\left(G_{i}-\sum_{\substack{x=1 \\ x \neq i}}^{n} E_{i \rightarrow x}\right)+\sum_{\substack{x=1 \\ x \neq i}}^{n} \frac{C_{x}}{G_{x}} E_{x \rightarrow i}+\sum_{x=1}^{j}\left\{\sum_{y=1}^{m} \frac{C_{y}}{\varepsilon_{y}} d_{y, x \rightarrow i}\left(\sum_{z=1}^{k} W_{z, x \rightarrow i}\right)\right\}
$$

The emissions tax on differential emissions from outsourced manufacturing by modifying Eq. (5.8), will be

$$
T_{i(m d)}=T_{c i} \sum_{\substack{x=1 \\ x \neq i}}^{n} E_{x \rightarrow i}\left|\frac{C_{x}}{G_{x}}-\frac{C_{i}}{G_{i}}\right|\left(\frac{C_{x} G_{i}}{C_{i} G_{x}}-1\right)
$$

The total emissions tax on differential outsourced manufacturing and additional transport emissions, using Eq. (8.2) and Eq. (6.5), will be

$$
T_{i(o)}=T_{c i} \sum_{\substack{x=1 \\ x \neq i}}^{n} E_{x \rightarrow i}\left|\frac{C_{x}}{G_{x}}-\frac{C_{i}}{G_{i}}\right|\left(\frac{C_{x} G_{i}}{C_{i} G_{x}}-1\right)+T_{c i} \sum_{x=1}^{j}\left\{\sum_{y=1}^{m} \frac{C_{y}}{\varepsilon_{y}} d_{y, x \rightarrow i}\left(\sum_{z=1}^{k} W_{z, x \rightarrow i}\right)\right\}
$$

or

$$
T_{i(o)}=T_{c i}\left[\sum_{\substack{x=1 \\ x \neq i}}^{n} E_{x \rightarrow i}\left(\frac{C_{x}}{G_{x}}-\frac{C_{i}}{G_{i}}\right)\left(\frac{C_{x} G_{i}}{C_{i} G_{x}}-1\right)+\sum_{x=1}^{j}\left\{\sum_{y=1}^{m} \frac{C_{y}}{\varepsilon_{y}} d_{y, x \rightarrow i}\left(\sum_{z=1}^{k} W_{z, x \rightarrow i}\right)\right\}\right]
$$

where $i$ is an importing country, $x$ is an independent variable representing the exporting country $j=1,2,3 \ldots . . n$ such that $i \neq x$; and $y$ and $z$ are independent variables representing the mode of transportation and category of items respectively.

\subsubsection{Impact of a Carbon Price and Increases in Fuel Prices on Supply Chain Costs}

In this sub-section, the EOQ model has been modified to account for manufacturing and transport emissions, and increases in fuel prices for a two-level (vendor-buyer) supply chain. 
Hill's model has been chosen as an example for demonstration because Hill's model provided the least order cost in the previous section (Table 7.1). The emissions tax $\left(T_{e}\right)$ in the total cost function for Hill (1999) from Eq. (7.11a) was replaced with tax on emissions from additional transport $\left(T_{i(t)}\right)$ as explained in the previous sub-section. Tax per unit dollar on differential emissions from manufacturing $\left(T_{i(m)}\right)$ are applied on the purchase price (import price) $\left(P_{c}\right)$ of the item.

$$
\begin{aligned}
& A T C_{n}^{H 99}=\frac{D}{q}\left(\frac{K_{v}}{\lambda}+K_{b}+A_{0}+T_{i(t)}\right)+q h_{v}\left\{\frac{D}{P}+\lambda\left(\frac{P-D}{2 P}\right)\right\}+\frac{\left(h_{b}-h_{v}\right) q}{2} \\
& +A_{1} \frac{(2 n \lambda-\lambda-1)}{2}+D P_{c} T_{i(m)}
\end{aligned}
$$

Solving Eq. (8.4) for the minimum lot-size quantity, it reduces to Eq. (8.5) which is same as Eq. (7.11b) because the lot size does not depend on cost, which is a fixed cost per unit like material cost.

$$
q^{H 99}(\lambda)=\sqrt{\frac{D\left(\frac{K_{v}}{\lambda}+K_{b}+A_{0}+T_{i(t)}\right)}{\left[h_{v}\left\{\frac{D}{P}+\lambda\left(\frac{P-D}{2 P}\right)\right\}+\frac{\left(h_{b}-h_{v}\right)}{2}\right]}}
$$

Replacing the value of $q^{H 99}(\lambda)$ from Eq. (8.5) into Eq. (8.4), the annual cost function becomes

$$
\begin{aligned}
& \operatorname{ATC}_{n}^{H 99}(\lambda)=2 \sqrt{D\left(\frac{K_{v}}{\lambda}+K_{b}+A_{0}+T_{i(t)}\right)\left[h_{v}\left\{\frac{D}{P}+\lambda\left(\frac{P-D}{2 P}\right)\right\}+\frac{\left(h_{b}-h_{v}\right)}{2}\right]} \\
& +A_{1} \frac{(2 n \lambda-\lambda-1)}{2}+D P_{c} T_{i(m)}
\end{aligned}
$$

\subsection{Examples}

\subsubsection{Impact of Outsourced Emissions on NEI}

As an illustration of an impact of outsourcing for a nation, the additional emissions for the USA due to imports from Germany and China have been calculated. Applying Eq. 8.1, and using the 
manufacturing and the transport emissions data from Chapter 5 and Chapter 6, the additional emissions for the USA are given in Table 8.1.

Table 8.1: Emissions due to outsourcing to Germany and China by the USA.

\begin{tabular}{lccccc}
\hline & Unit & $\mathbf{2 0 0 7}$ & $\mathbf{2 0 0 8}$ & $\mathbf{2 0 0 9}$ & $\mathbf{2 0 1 0}$ \\
\hline $\begin{array}{l}\text { A. United States-CO } \\
\text { emissions }\end{array}$ & MMT & 648 & 625 & 541 & 610 \\
\hline
\end{tabular}

B. International transport emissions due to trading of manufacturing items with

\begin{tabular}{rccccc} 
C. China & MMT & 14.14 & 12.98 & 11.07 & 12.74 \\
D. Germany & MMT & 1.08 & 1.03 & 0.84 & 0.99 \\
\hline E. Sub-Total $(C+D)$ & MMT & 15.22 & 14.01 & 11.91 & 13.73 \\
\hline
\end{tabular}

F. Changes in manufacturing emissions due to trading of manufacturing items with

\begin{tabular}{llccccc} 
G. & China & MMT & 133.6 & 117.5 & 96.6 & 107.8 \\
H. Germany & MMT & 1.5 & 1.3 & 0.8 & 1.1 \\
\hline I. & Sub-Total $(G+H)$ & MMT & 135.2 & 118.8 & 97.4 & 108.9 \\
\hline
\end{tabular}

J. Total changes in emissions due to trading of manufacturing items with

\begin{tabular}{lccccc}
$\begin{array}{l}\text { K. China }(\mathrm{C}+\mathrm{G}) \\
\text { L. Germany }(\mathrm{D}+\mathrm{H})\end{array}$ & MMT & 147.8 & 130.5 & 107.6 & 120.5 \\
& $\mathrm{MMT}$ & 2.6 & 2.3 & 1.7 & 2.1 \\
\hline $\begin{array}{l}\text { M. Total }(E+I) \\
\text { N. Outsourced emissions as a fraction } \\
\begin{array}{l}\text { of total manufacturing emissions in } \\
\text { the USA }(\mathbf{M} / \mathbf{A} * \mathbf{1 0 0})\end{array}\end{array}$ & $\mathbf{\%}$ & $\mathbf{2 3}$ & $\mathbf{2 1}$ & $\mathbf{2 0}$ & $\mathbf{2 0}$ \\
\hline
\end{tabular}

Table 8.1 highlights that outsourced emissions represent a substantial portion of the manufacturing emissions in the USA, despite the fact that the outsourced emissions from only two countries were considered. The significance of the outsourced emissions is underlined by the fact that they are this large despite considering the differential manufacturing emissions, i.e., if these items were manufactured in the USA, the emissions from manufacturing these items in the USA were removed from the emissions generated in the respective manufacturing countries. It is also worth noting that manufacturing and transport emissions on imports from Germany are very small as compared to those of China. However, transport emissions from imports from Germany are almost same as manufacturing emissions. In other words, the advantage of fewer emissions

\footnotetext{
${ }^{33}$ Manufacturing industries only (Source: OECD, 2013b); same as in Table 5.3.
} 
for items manufactured in Germany is more than offset by the additional emissions from the required international transport.

To provide a disincentive to outsourced emissions, a carbon tax may be applied on these emissions. Table 8.2 provides the value and percentage of import value at the rate of $\$ 30$ per Ton of $\mathrm{CO}_{2}$ (British Columbia, 2013). It is important to stress that the carbon tax in this case is applied only on differential emissions. Therefore, if the same carbon tax is applied on emissions from onshore manufacturing, these values will go up. The tax on imports from Germany in 2008 is negative because there will not be a tax on negative emissions.

Table 8.2: Carbon tax on outsourced emissions to Germany and China for the USA ${ }^{34}$.

\begin{tabular}{lccccc}
\hline & Unit & $\mathbf{2 0 0 7}$ & $\mathbf{2 0 0 8}$ & $\mathbf{2 0 0 9}$ & $\mathbf{2 0 1 0}$ \\
\hline A. Imports from China & Mn US\$ & 231,948 & 251,298 & 220,171 & 282,392 \\
B. Imports from Germany & Mn US\$ & 39,044 & 47,587 & 49,012 & 68,700 \\
\hline C. Carbon tax on manufacturing emission on imports from & & & \\
\hline \multicolumn{7}{l}{ D. China } & Mn US\$ & 43,640 & 32,128 & 28,333 & 24,425 \\
E. Germany & Mn US\$ & -5.4 & -6.9 & -2.6 & -3.0 \\
\hline
\end{tabular}

F. Carbon tax on transport emissions of manufacturing items imported from

\begin{tabular}{llccccc} 
G. & China & Mn US\$ & 424.2 & 389.4 & 332.0 & 382.1 \\
H. & Germany & Mn US\$ & 32.3 & 31.0 & 25.3 & 29.8 \\
\hline
\end{tabular}

I. Total Carbon tax on imports of manufacturing items from

\begin{tabular}{llccccc} 
J. & China & Mn US\$ & 44,065 & 32,518 & 28,665 & 24,807 \\
K. & Germany & Mn US\$ & 27 & 24 & 23 & 27 \\
L. & Combined (China + Germany) & Mn US\$ & 44,091 & 32,542 & 28,688 & 24,834 \\
\hline
\end{tabular}

M. Total Carbon price on imports of manufacturing items from

\begin{tabular}{llccccc}
\hline N. & from China & $\%$ & 19.00 & 12.94 & 13.02 & 8.78 \\
O. & from Germany & $\%$ & 0.03 & 0.02 & 0.03 & 0.03 \\
P. & Combined (China + Germany) & $\%$ & 13.36 & 9.20 & 9.77 & 6.77 \\
\hline
\end{tabular}

The current rate of carbon tax vary significantly across nations. It ranges from no-tax in most of the jurisdictions to as high as US $\$ 138$ in Sweden. The values for a carbon tax would change

\footnotetext{
${ }^{34}$ Rows A and B are from Table 5.3.
} 
dramatically depending up on the tax rate. Figure 8.1 provides the value of total carbon tax in the USA for the year 2010 due to imports from China and Germany for different tax rates. It is logical that high rate of carbon tax will lead to higher tax revenue. However, it is important to keep in mind that emissions per unit \$ of economic activity is more important for reducing global emissions.

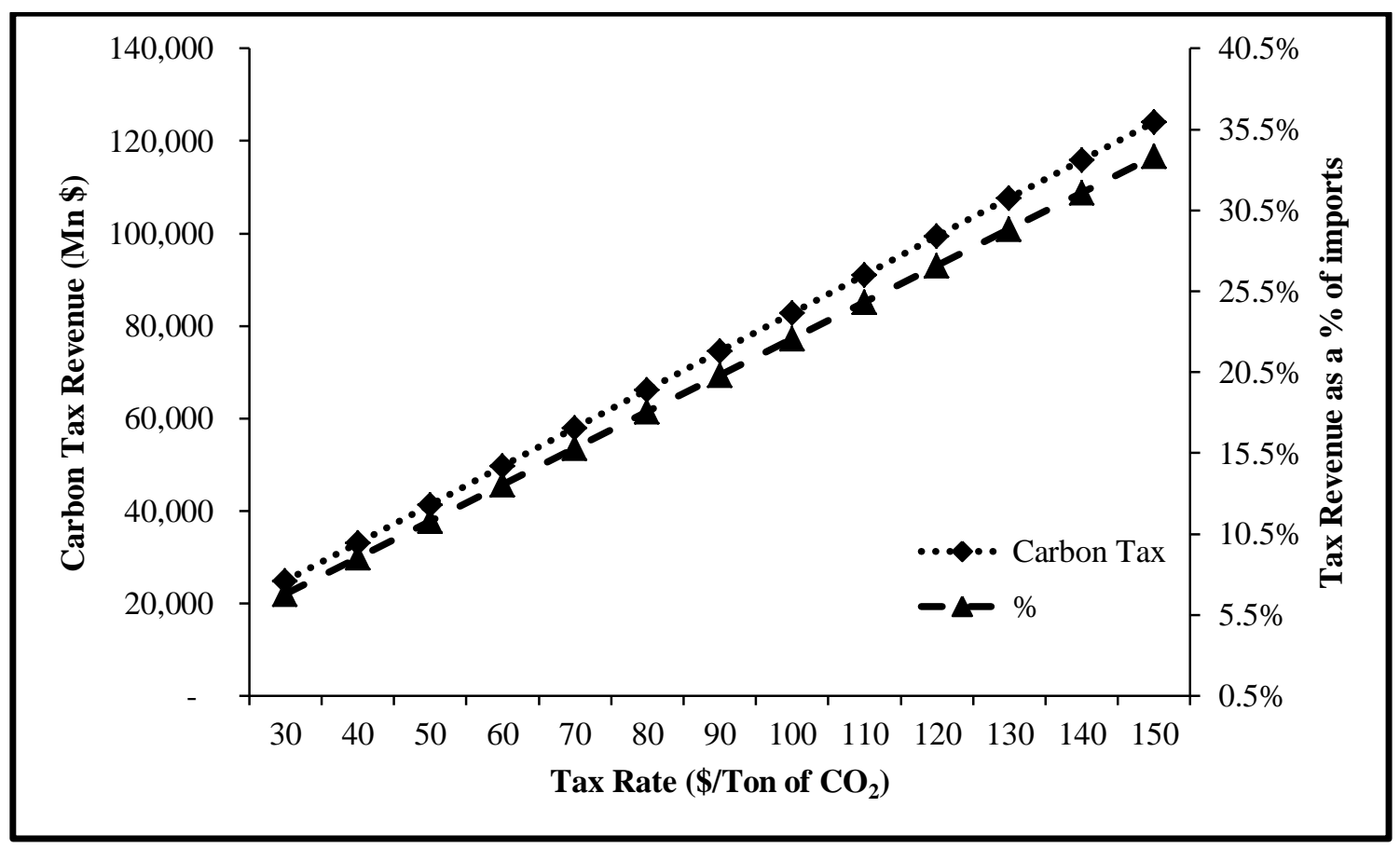

Figure 8.1: Carbon tax revenue (total) on imports from China and Germany.

\subsubsection{Supply Chain Costs and Lot Sizes}

This sub-section provides an analysis of the impact of changes in the rate of carbon tax and increases in fuel prices on annual order costs and lot-sizes. The illustration reused the data from the numerical example in Section 7.5. The manufacturing emissions per unit GDP for the USA, China and Germany were calculated from Section 5 (Table 5.3). The manufacturing emissions per unit GDP for each location were multiplied with the annual number of units and the unit cost to find the cost of manufacturing emissions at each location. The data for manufacturing in the USA assumes that there are only manufacturing emissions and no international transport emissions. Therefore, there is no cost of international transport emissions in cases where the manufacturing location is in the USA. The international transport distance between Germany and 
the USA, and China and the USA is same as explained in Section 6.3. The costs of international transport emissions due to imports from Germany and China were calculated as explained in Section 6. Since domestic transport and associated emissions for an outsourcing nation will remain the same, it has been ignored. Finally, combining the costs of manufacturing emissions, costs of international transport emissions and fuel (variable transport) cost on international transport starting from January 1, 2014, the lot-sizes and order costs were calculated using Eq. 8.8 and 8.9 under Hill's policy. The annual order costs and lot-sizes for sourcing the same item has been presented in Table 8.3. It provides the order costs and lot-sizes for 10 consecutive orders for an item produced in the USA, China, and Germany, and consumed in the USA in all the cases. The last line provides the average of the ten consecutive orders above.

Table 8.3: Changes in order cost and lot-size due to carbon tax.

\begin{tabular}{|c|c|c|c|c|c|c|c|c|c|}
\hline \multirow{2}{*}{$\begin{array}{c}\text { Production } \\
\text { lot }(n) \\
\downarrow\end{array}$} & \multicolumn{3}{|c|}{ Hill 1999 (USA) } & \multicolumn{3}{|c|}{ Hill 1999 (China) } & \multicolumn{3}{|c|}{ Hill 1999 (Germany) } \\
\hline & $\hat{T C}_{n}^{H 99}$ & $\lambda_{n}$ & $q^{H 99}(\lambda)$ & $\hat{T C}_{n}^{H 99}$ & $\lambda_{n}$ & $q^{H 99}(\lambda)$ & ${\hat{T C_{n}}}^{H 99}$ & $\lambda_{n}$ & $q^{H 99}(\lambda)$ \\
\hline (No.) & $(\$)$ & (No.) & $(N o)$. & $(\$)$ & (No.) & $($ No. $)$ & $(\$)$ & (No.) & (No.) \\
\hline 1 & 1,934 & 5 & 110 & 3,839 & 1 & 567 & 3,414 & 1 & 542 \\
\hline 2 & 1,934 & 5 & 110 & 3,857 & 1 & 567 & 3,403 & 1 & 542 \\
\hline 3 & 1,934 & 5 & 110 & 3,875 & 1 & 567 & 3,418 & 1 & 542 \\
\hline 4 & 1,934 & 5 & 110 & 3,893 & 1 & 567 & 3,433 & 1 & 542 \\
\hline 5 & 1,934 & 5 & 110 & 3,911 & 1 & 567 & 3,449 & 1 & 542 \\
\hline 6 & 1,934 & 5 & 110 & 3,929 & 1 & 567 & 3,464 & 1 & 542 \\
\hline 7 & 1,934 & 5 & 110 & 3,947 & 1 & 567 & 3,479 & 1 & 542 \\
\hline 8 & 1,934 & 5 & 110 & 3,965 & 1 & 567 & 3,494 & 1 & 542 \\
\hline 9 & 1,934 & 5 & 110 & 3,983 & 1 & 567 & 3,510 & 1 & 542 \\
\hline 10 & 1,934 & 5 & 110 & 4,001 & 1 & 567 & 3,525 & 1 & 542 \\
\hline $\begin{array}{c}\text { Average } \\
(1-10)\end{array}$ & 1,934 & 5 & 110 & $\mathbf{3 , 9 2 0}$ & 1 & 567 & $\mathbf{3 , 4 5 9}$ & 1 & 542 \\
\hline
\end{tabular}

The data from Table 8.3 indicate that least order cost and least lot-size is when the costs of the net of manufacturing and international transport emissions are the least. In this case, the costs of the net of manufacturing and transport emissions are least when an item is manufactured and consumed in the USA. They are highest when manufactured in China and consumed in the USA. As discussed in Section 8.2.1, the cost of emissions from manufacturing is the least in Germany. 
However, the advantage of the least cost of emissions from manufacturing in Germany has been neutralized by the cost of emissions from additional international transport and fuel cost.

\subsection{Sensitivity to Carbon Tax Rate and Fuel Price}

The example in sub-section 8.2.2 has been further extended for varying carbon tax and fuel prices for imports of an item from Germany (Figure 8.2) and China (Figure 8.3) for consumption in the USA. The axes of both the figures are kept identical for easy comparison. Superimposing all the three graphs in one does not provide a very clear picture as the graphs do not intersect at any point, i.e., annual order costs for China is higher than those of Germany and the USA for every corresponding point. Similarly, annual order costs for Germany is higher than those of the USA for every corresponding point. Figure 8.2 provides the variation in annual order cost for Hill's model with a varying rate of carbon taxes and fuel prices for outsourcing to Germany. The data in the figure are averages of the ten consecutive orders, as explained in the previous subsection, starting at different points in time.

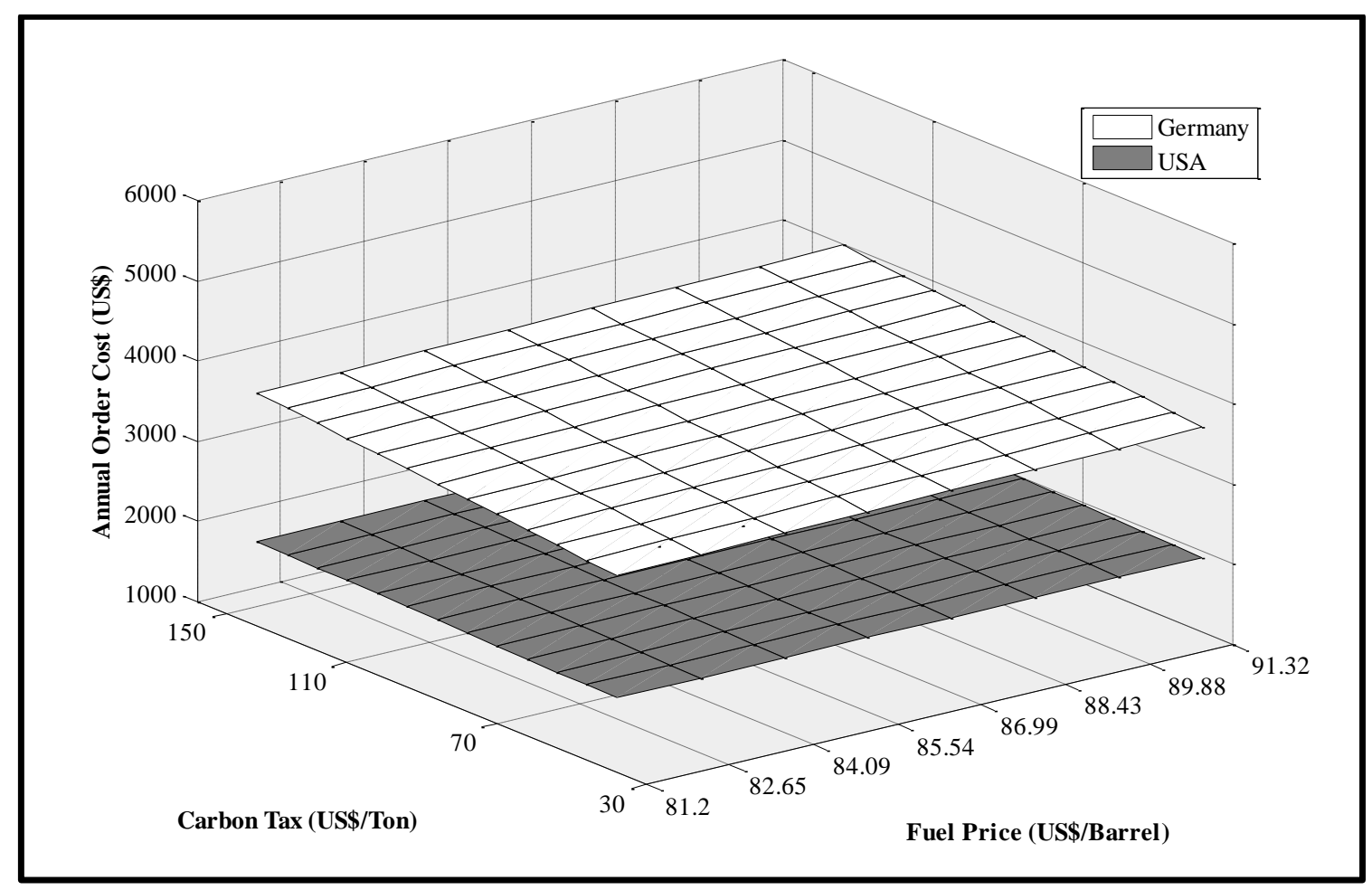

Figure 8.2: Changes in order cost (\$) due to a price on emissions and increasing fuel price for imports from Germany with respect to manufacturing in the USA 
Figure 8.2 shows the composite effect of carbon tax rates and increases in fuel prices on annual order cost for an item manufactured in the USA or Germany and consumed in the USA. Since the fuel function is a straight line, the data is linear. The impact of the tax rate is high because the tax at any given time is changing up to 5 times ( $\$ 30$ to $\$ 150$ per ton of $\mathrm{CO}_{2}$ ).

Figure 8.3 provides the variation in annual order cost for Hill's model with varying rates of carbon taxes and fuel prices for imports from China. The data in this figure are also averages of the ten consecutive orders starting at different points in time. Since, manufacturing emissions per unit GDP is the highest for China, values are higher than that of Germany. Figure 8.3 provides a comparison for the same item produced in the USA and China and consumed in the USA.

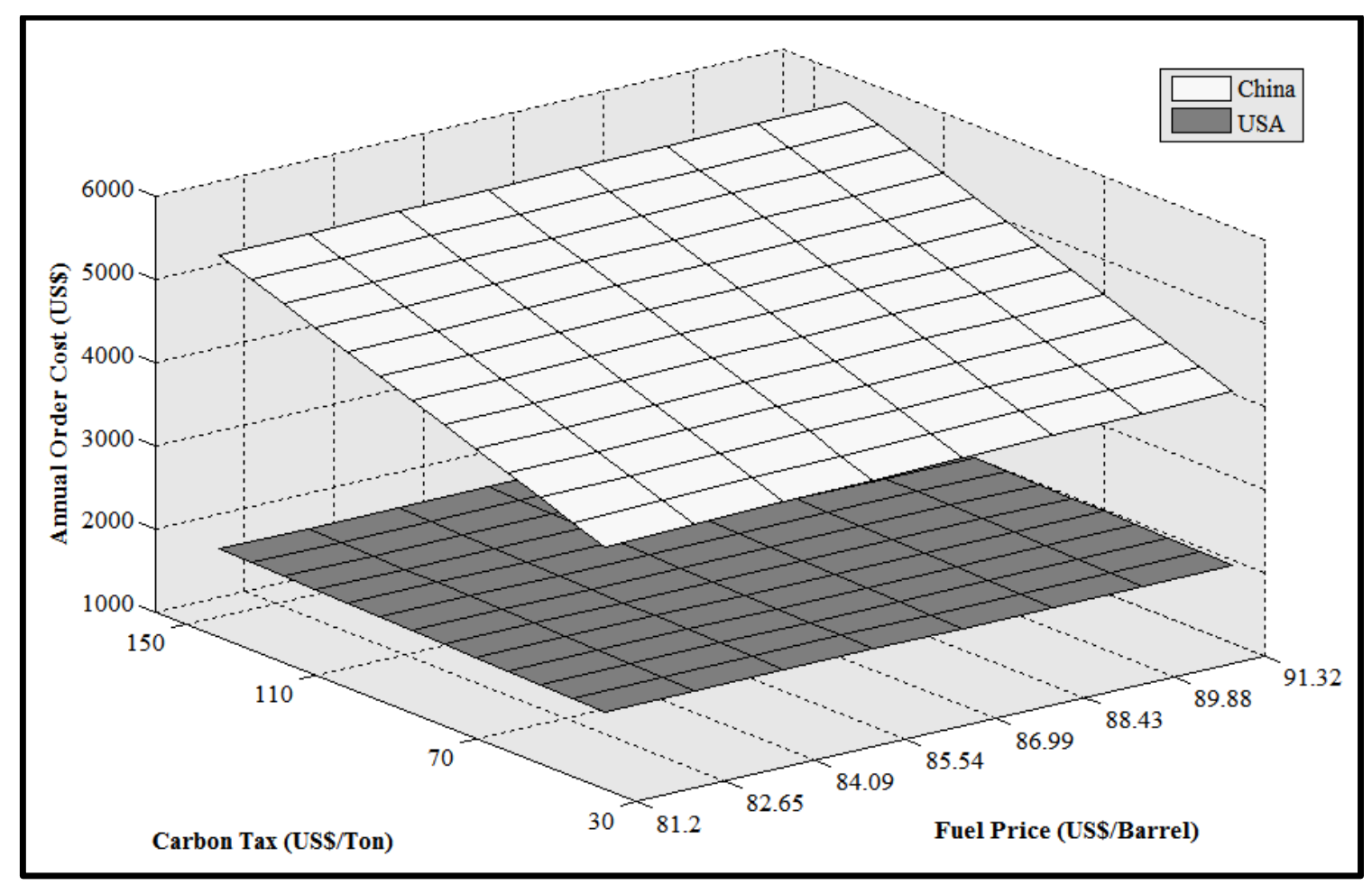

Figure 8.3: Changes in order cost (\$) due to a price on emissions and increasing fuel price for imports from China with respect to manufacturing in the USA

The figures indicate that a carbon tax, if applied, will affect the order cost and hence, price to consumers. In the above examples, the distance is kept fixed for all imports from one country. 
This can be altered to compare the overall cost of supply chains as well as cost of emissions on imports from different locations.

\subsection{Summary}

Global GHG emissions are affected by the rate of differential manufacturing emissions, transport distances between the place of manufacturing and consumption, and the rate of emissions for transport vehicles. The cost of emissions is affected by carbon tax rates and efficiencies in power generation, manufacturing machines, and transport vehicles. The overall cost of supply chains (order cost) is affected by fuel prices and a carbon tax on emissions. Currently, there is no carbon tax on emissions generated on imports from other countries. Applying a carbon tax on excess emissions by importing nations will lead to very different sourcing strategies and potentially help in reducing global emissions. Similarly, including the cost of increasing fuel prices (for the next couple of years) in addition to a cost of emissions in supply chains could lead to very different sourcing decisions by corporate organizations.

The examples showed that outsourcing for the USA from Germany and China resulted in an increase of about $20 \%$ emissions and is about $6.8 \%$ of the import price. Also the model showed that the lot size from Germany as well as China increased 5 times due to a carbon price though manufacturing emissions are less in Germany as compared to the USA and more in China as compared to the USA. This was due to the inclusion of emissions from international transport, which are currently ignored by all countries. 

CHAPTER 9 : CONCLUSIONS 
The analyses in the previous sections have highlighted the need to account better for GHG emissions and fuel costs in offshore outsourcing. Currently, these costs are typically overlooked. Failing to take these costs into account means that the true costs associated with offshore outsourcing are not reflected in outsourcing decisions. This leaves outsourcing organizations vulnerable to sudden changes in carbon tax rates and fuel costs. It also leaves the substantial contribution of offshore outsourcing to global GHG emissions largely unaccounted for.

This research presented generic models to account for emissions generated as a result of outsourced manufacturing activities and from the associated international transport of those items. Further, a combined model accounting for the total differential emissions from manufacturing and transport activities was presented. The idea of reducing emissions from manufacturing or international transport is not new. However, the models presented here are the first to link outsourced manufacturing and international bunker fuel emissions to the application of a carbon tax to reduce emissions from outsourcing activities. The models can be used to compare the emissions due to offshore outsourcing for items produced in any geographic location. The models can accommodate different modes of international transportation, such as air and sea transport. Moreover, the models are transparent, simple to implement, and provide a needed strategic tool to guide the abatement of global GHG emissions.

The models proposed in this dissertation can be used as a framework for imposing a carbon tax on differential emissions due to outsourcing, which will help in reducing global GHG emissions. The models were developed in recognition of the need to assign responsibility for the true level of GHG emissions associated with national consumption. Failing to recognize this responsibility may give the impression that countries with large amounts of outsourcing have reduced their carbon footprints when, in reality, they have merely transferred emissions to another country. This is not to suggest that a nation producing goods for export bears no responsibility for reducing emissions. However, this dissertation argues that those who consume the goods must adopt the responsibility for the differential emissions in order to avoid shifting the burden from one nation to another. The problem is compounded when outsourcing destinations have higher emissions from a unit of an economic activity. In these situations, much higher emissions are generated globally rather than merely shifting the origin of emissions. GHG emissions are a 
global environmental challenge and cannot be viewed through the prism of only direct national or regional emissions. Imposing a carbon tax on imports from countries with higher rates of emissions will increase accountability for consumption-related impacts and provide an incentive to reduce overall global emissions. The proposed models may therefore be useful tools in national and international policymaking.

Outsourcing has many positive impacts on the economic development of outsourcee countries. It provides employment opportunities in outsourcee countries and affects social life positively (Kahai et al., 2011). It motivates people to acquire new skills and to grow the economy. In addition to many positives for outsourcee countries, it also helps lower the cost of manufacturing for outsourcing organizations and improves their profitability. It often leads to lower prices for consumers. The increase in transportation activities also provides more employment opportunities in transportation and logistics.

Despite all these positive effects of outsourcing and assuming all things in the importing and exporting nations, such as technology in manufacturing, power generation, and transportation, are equal, the increase in transportation will result in more environmental problems. These environmental problems have a wide range such as (i) "release of oil and chemicals: through accidental spills and operational discharges"; (ii) "transfer of invasive alien species: through ballast water and on ship hulls"; (iii) "release of biocides: from toxic chemicals used in antifouling paints"; (iv) "dumping of waste: such as garbage and sewage"; (v) "air pollution: through emission of sulphur dioxide, nitrogen oxides, and carbon dioxide"; (vi) "physical and other damage: through dropping of anchors, noise and wave disturbances, and striking of whales and other marine mammals" (WWF, 2014). The impacts of international transportation, as stated earlier, are neither accounted for in NEI of any country nor is it generally considered in corporate decision making for outsourcing. Outsourced manufacturing serves the needs of people of an importing nation. Organizations, which outsource manufacturing activities to different countries, benefit financially. Consumers have very limited say in choosing places of manufacturing, but ultimately bear some responsibility for generating emissions elsewhere due to their consumption behavior. With these points in mind, this research contends that all emissions from every activity associated with consumption in a country must be accounted for in the national inventories of 
that country. Thus, it becomes the primary responsibility of the governments of importing nations to develop policies for reducing emissions associated with overseas manufacturing and international transportation due to outsourcing.

Applying the models in practice may help curtail the financial advantage to organizations that outsource to lower their operating costs and it will provide a level playing field for manufacturers interested in contributing to reduce global GHG emissions. These models will also better prepare manufacturers to respond to sudden changes in either carbon taxes or fuel prices. The application of the models was demonstrated through an analysis of the trading relationship between the three largest exporting countries in the world, namely China, the USA, and Germany. However, it is important to stress that the models could have been applied to any trading relationship including onshore operations.

The analysis showed that international transport emissions due to outsourcing have reached a significant level so that they can no longer be overlooked on the pretext of the difficulty in calculating them precisely. Moreover, emissions are likely to continue to increase dramatically in the absence of a policy designed to mitigate emissions (Heitmann \& Khalilian, 2011). There will undoubtedly be challenges in implementing a carbon tax on international emissions. It will not be a popular measure, particularly among corporate leaders in strong economies and political leaders of weaker economies. This will also not be welcomed by overseas manufacturing partners and their employees. The majority of consumers are unlikely to appreciate it either because prices will likely go up. However, the imposition of a carbon tax is needed to better show the true cost of emissions resulting from outsourced manufacturing.

Many outsourcing organizations have recognized a huge, yet hidden, cost of outsourcing to the natural environment. A number of these organizations have pledged to reduce the environmental impact of their operations. As an example, Wal-Mart (2013) has pledged "the production or procurement of 7 billion kWh of renewable energy globally every year, a 600 percent increase over 2010 levels" by Dec. 31, 2020. These organizations can benefit from using the models presented in this research in their decision-making about outsourcing destinations. The tools provided here are a practical basis for corporations to assess the sustainability of outsourcing 
businesses and help in taking outsourcing decisions based on a more representative picture of the actual costs of outsourcing.

Furthermore, as the application of the model in Section 8 demonstrated, it can be concluded that the order cost and lot-size are affected by changes in the fuel price, emissions tax, fuel consumption, and distances travelled. As the fuel price increases, the cost of every subsequent order will also increase resulting in an increase in average order cost for all the shipments in a production cycle. Fuel cost is proportional to the distance, but fuel prices are increasing at a rate much higher than overall inflation. Therefore, supply chains with large distances between the buyer's and vendor's locations will feel a relatively larger impact on their supply chain costs. In addition to the fuel price, growing awareness of the environmental impacts of transport emissions might prompt governments to impose a higher tax on those emissions. This insight has both strategic and operational implications for organizations. In order to accommodate rapidly increasing oil prices, supply chain professionals will either adjust transport costs at a much higher rate than overall inflation or pay for the fuel at the prevailing (higher) prices at the time of shipment. Either way, the costs of transportation and supply chains will go up in the short term, which is an operational issue. Organizations that have their vendors in relatively close proximity will be at an advantageous position in managing their supply chain costs more effectively in the future. On the other hand, organizations that have invested heavily in global supply chains will need to re-examine their supply chain strategy to overcome cost challenges. The increases in fuel prices will affect their profitability. This may lead to changing vendor bases to a nearby location or increasing the prices to customers, which will reduce their competitive advantage or absorbing the increased cost of fuel, which will reduce their profitability.

Financial options and hedging are tactical tools for reducing volatility in fuel prices over a short period. Technological development of transport vehicles, such as cargo ships, which generate fewer emissions and use alternate fuel, thereby reducing dependence on fossil fuel, might represent a long-term strategic solution. As discussed earlier, hybrid vehicles for long haul road applications are a strong contender for a technological breakthrough in surface transport. However, it does not help offshore outsourcing operations and there is a need for action in this area. 
As fuel prices increase, buyers will look for alternative vendors that are closer to the point of consumption. This could fundamentally change the pace and direction of globalization. These findings align with those of Bonney and Jaber (2011), who note: "Perhaps the continued increase in energy prices may result in deglobalisation of markets, if not decentralization. In other words, a move towards smaller self-sustainable markets would be a strategic solution to consider." This research provides an understanding of the importance of fossil fuel prices in global supply chain costs. It also demonstrated the impact of increasing fuel prices and an emissions tax on various inventory policies.

\subsection{Contributions}

There has been a lot of work done in the area of sustainable supply chains, outsourcing, GHG emissions, carbon pricing, and economic lot-size in coordinated supply chains. The central theme of this research suggests that offshore outsourcing of manufacturing activities is not a viable or an attractive strategy, when assigning a cost to the environmental factors. The analyses showed that outsourcing increases global emissions and assigning a cost to emissions will erode the economic advantages to outsourcing organizations. The main contribution is the development of a framework for quantifying the changes in the emissions due to offshore outsourcing of manufacturing activities and from associated transportation. This framework is intended to provide a basis for reducing emissions and costs from global supply chains. The examples of outsourcing between three countries namely, the USA, Germany and China showed an increase in the global emissions. Similarly, an example of a carbon pricing on additional emissions from outsourcing for Wal-Mart showed a reduction in net profit (profit after tax) by about 19\%, which is significant. A summary of main contributions of this research is provided below:

The research started with a literature review and it was observed that the terms on environmentally friendly supply chains were used interchangeably. A need was identified for analyzing the terms used for supply chains that include environmental impacts. This analysis was extension of the of literature review. However, the detailed analysis conducted on the use of various terms related to GSCM and SSCM seem more appropriate as a part of main analysis. This led to finalizing the first objective: conduct an analysis of terms used to represent 
environmentally friendly supply chains and any changes in usage in the literature over time. A comprehensive analysis of 629 papers confirmed that terms are being used interchangeably. The analysis also showed some reduction in the use of the term "reverse supply chains" and some convergence towards the use of GSCM and SSCM for supply chains that include environmental impacts. The study also highlighted the need for the standardization of definitions. The study provided some context for the research that followed, which was focused on the core issue of reducing GHG emissions due to offshore outsourcing.

The second objective was to conduct an analysis of the changes in the GHG emissions as a result of offshore outsourcing of manufacturing activities. This was carried out to identify the impacts of outsourcing on global emissions and to determine if the decrease in GHG emissions in developed countries represented a true reduction in global GHG emissions. It was found the outsourcing has not only shifted the origin of GHG emissions from developed countries to developing countries, but has also resulted in substantially increased global emissions due to inefficiencies in power generation and manufacturing. A model was developed to account for manufacturing emissions based on consumption for a nation. The application of the model, using data on manufacturing, imports-exports, GPD and GHG emissions from publicly available sources for the USA, Germany and China, showed that GHG emissions for countries that have outsourced manufacturing increased after including the differential manufacturing emissions from outsourcee countries. This tool can be used to find emissions efficient destinations for sourcing both onshore and offshore.

The third objective was to conduct an analysis of the changes in the GHG emissions due to additional international transportation as a consequence of offshore outsourcing of manufacturing activities. This was important because (i) emissions from international transport are not included in NEI of either outsourcing (importing) or outsourcee (exporting) nations and (ii) international transport and, therefore, associated emissions increase due outsourcing in every single case. A model was developed to find the impacts of emissions in NEI of outsourcing/outsourcee nations and a carbon price was suggested to deincentivize it. The analyses showed that emissions from outsourcing of manufacturing goods are significant and a 
carbon price might help in looking for alternate sourcing locations, which generate fewer emissions.

The fourth objective was to analyze the impact of increases in fuel price on inventory policies $(E O Q)$. There was no literature that studied the impact of increasing fuel prices on supply chain costs and lot-sizes. This was important because fuel prices are increasing at a rate much higher than overall inflation. The EOQ model was modified for a two-level-coordinated supply chain (Goyal, 1988). The study was further extended to other inventory policies (Hill, 1999 and Braglia \& Zavanella, 2003). The results showed that order cost and lot-sizes increased for all the three cases. However, Hill's policy provided the best results. This analysis also showed that globalization, which requires additional transportation, would not be sustainable with the current technology due to increases fuel prices.

The last objective was to analyze the effects of outsourcing on global emissions, and the combined effect of a carbon price on manufacturing and transport emissions along with increases in fuel prices on supply chain costs. This was a consolidation of the previous three objectives to see the overall impact on NEI and supply chains costs. A model was developed to calculate NEI, which was essentially a consolidation of models for calculating emissions from manufacturing and international transportation, developed under objectives 2 and 3. Further, it was expanded to calculate a carbon price. Later this was combined in the EOQ model to study the impact on the cost of a supply chain under Hill's (1999) policy for producing in the USA with outsourcing to Germany and China. The results showed an increase in both NEI for outsourcing nations and order costs for an outsourcing organization.

A carbon price has been suggested on additional GHG emissions generated due to outsourcing. This is expected to disincentivize outsourcing organization to energy inefficient places and to reduce global GHG emissions. The carbon tax will also work as a revenue stream for national governments for investments in cleaner technology and carbon sequestration (Brainard et al., 2009) or creating carbon sinks (Kula \& Gunalay, 2012). The carbon price will also reduce the cost advantages to outsourcing organizations and provide a more level playing field to indigenous organizations that have invested in cleaner technology. The overarching contribution 
of this research is to provide a holistic framework for reducing global GHG emissions through reduction in emissions from the supply chain in the context of outsourcing.

\subsection{Limitations}

One of the key limitations of using these models in practice is the availability of data, its accuracy, and currency. In the absence of accurate data, the computation of differential emissions and associated carbon taxes is based on the data from a previous year. Also, if the data is more than $\sim 2$ years old, the applied tax may be possibly different (both less or more) than it should be. Moreover, it is assumed the manufacturing emissions data measurement and collection procedures, measuring accuracies, and reporting practices are consistent across countries. This is not always the case, though there are efforts to standardize these practices (e.g., through the GHG Protocol, 2012). In the models presented in this dissertation, the transport data were based on (sea) containers and air cargo received between countries. However, when the consignments are routed though intermediate countries (due to consolidation or partial shiploads), it will show as imports from the country of the last port instead of the country of manufacturing. This poses a challenge in accurately calculating the carbon tax on emissions from international transport. In particular, it introduces the possibility of circumventing the tax system by routing it through ports that have shorter distances to final destinations and through ships that have lesser emissions ratings. However, in the absence of a directive from the UN or a global policy agreement, the models provide a simple and transparent method of accounting for emissions from international transport in global supply chains.

\subsection{Further Research}

This research can be further expanded in many ways. For example, it could explore expanding the models to accommodate the impacts of emissions from additional surface transportation in global supply chains due to outsourcing. It could also study the impact of a carbon tax on the profitability of industries, and on the exports (and associated emissions) of developing countries. It can be extended to study the size of global trade when differential emissions become null. It could also be extended to consider the impact of cap-and-trade schemes, which have already been established in several jurisdictions. Another possible extension is to study the possibilities 
of circumventing a carbon tax on international transport and designing a carbon tax on international transport in such a way that it includes the entire emissions from an origin to a final destination. It can also be extended to design the rate of carbon tax, which will stop outsourcing to energy inefficient destinations.

This work can be extended by relaxing any of the overarching assumption, such as including the effects of price elasticity, changes in demand due to price increases and/or product substitutions and including effects on the General Agreement on Tariffs and Trade (GATT). This can also be extended by refining the cost break up of an item in different countries. This work can be extended to investigate the impact of different items within a category of goods. There is a huge variety of items within a category (using 3 digit SITC codes). This work can also be extended to study how the density of items in a container will influence the cost of an outsourced item and profitability of organizations. A further possible extension is to show how changes in packaging will affect container weights, capacity utilization of ships, emissions, and the profitability of the shipping industry. Currently it has been studied for a two level coordinated supply chain. This can be extended to 3-level or n-level of coordinated supply chains as well as in reverse supply chains. There is a need for additional packaging during transportation from offshore destinations. Also the majority of items, which break in transit, during warranty or after use end up in landfill due to lack of skills for repairing, availability of spare parts and non-viability of sending the items back to the manufacturers. Another possible extension of this research could be assign a cost to these factors to see the viability of global supply chains and estimating the cost of keeping waste in the backyard such as building additional land fill sites and its long term effect on the environment. This can further be extended by including social parameters and finding relationships between outsourcing and healthcare/social costs.

An example of sea transport for a global supply chain and truck transport on inland activities were provided. However, the model is adaptable to any combination of road, marine, and air transport in global supply chains. The example assumed that a shipment lot would go in one truck/container irrespective of the lot-size. This could be extended by relaxing this assumption and adding the constraint of a truck/container capacity to the models presented. This research can also be extended to investigate the effects of emissions minimizing policies, such as a carbon tax 
or cap and trade scheme, on the changes in transport, manufacturing and energy generation technology. Other possible extensions include the estimation of the rate of carbon tax and fuel price, which will force organizations to include these factors in their decision-making. Additional work could focus on using more precise fuel consumption and emissions data (rather than averages). A case study using actual fuel consumption and emissions could potentially provide such data. A case study would also provide an opportunity to investigate the model developed in a real-world global supply chain context. The models could also be extended to include other costs where energy is used, such as in manufacturing and storage, particularly for refrigerated storage and/or refrigerated transportation, where energy needs are significantly different. This work can be extended to include the quality failures and its environmental costs. Exergy (energy generation efficiency) and emissions of different sources of energy are different. This work can be extended to explore exergy in supply chains. Another possible extension is defining hierarchy of terms within the context of SSCM, and defining those terms and their boundaries. Undoubtedly, there are other potential extensions of the models presented in this dissertation. It is argued that they provide a strong basis for future academic and practitioner work. 


\section{APPENDICES}

Appendix A

Sub-section 2.1

Representative Definitions of Search Keywords

\begin{tabular}{|c|c|c|}
\hline Keyword & Definition & Reference \\
\hline $\begin{array}{l}\text { Closed-Loop } \\
\text { Supply } \\
\text { Chains }\end{array}$ & $\begin{array}{l}\text { "A closed loop supply chain includes the returns processes and } \\
\text { the manufacturer has the intent of capturing additional value } \\
\text { and further integrating all supply chain activities". }\end{array}$ & $\begin{array}{l}\text { Guide } \text { et al., } \\
\text { 2003; Page } 3 .\end{array}$ \\
\hline Eco-Logistics & $\begin{array}{l}\text { "Eco-logistics is a state in the supply chain where enterprises, } \\
\text { that is, suppliers and customers are collaboratively using } \\
\text { environment friendly materials in production and transportation, } \\
\text { which aims to minimise hazardous waste from the logistical } \\
\text { operations." }\end{array}$ & $\begin{array}{l}\text { Koh, et al., } \\
\text { 2007; Page } 94 .\end{array}$ \\
\hline $\begin{array}{l}\text { Eco-Supply } \\
\text { Chains }\end{array}$ & $\begin{array}{l}\text { "When these (eco-logistics) practices are realised, the supply } \\
\text { chain can be inferred as an eco-supply chain." }\end{array}$ & $\begin{array}{l}\text { Koh, et al., } \\
\text { 2007; Page } 94 .\end{array}$ \\
\hline $\begin{array}{l}\text { Green } \\
\text { Logistics }\end{array}$ & $\begin{array}{l}\text { "Attempts to measure and minimize the ecological impact of } \\
\text { logistics activities". }\end{array}$ & $\begin{array}{l}\text { Rogers and } \\
\text { Tibben- } \\
\text { Lembke, 1998; } \\
\text { Page 258. }\end{array}$ \\
\hline $\begin{array}{l}\text { Green Supply } \\
\text { Chains }\end{array}$ & $\begin{array}{l}\text { "The scope of GrSCM (GSCM) ranges from reactive } \\
\text { monitoring of the general environment management } \\
\text { programmes to more proactive practices implemented through } \\
\text { various Rs (Reduce, Re-use, Rework, Refurbish, Reclaim, } \\
\text { Recycle, Remanufacture, Reverse logistics, etc.)." }\end{array}$ & $\begin{array}{l}\text { Srivastava, } \\
\text { 2007; Page } 54 .\end{array}$ \\
\hline $\begin{array}{l}\text { Responsible } \\
\text { Supply } \\
\text { Chains }\end{array}$ & $\begin{array}{l}\text { "A responsible supply chain as a link of business actors who } \\
\text { jointly adopt, implement and coordinate values, strategies and } \\
\text { tactics in order to connect all levels of corporate social } \\
\text { responsibility to the business processes in the chain." }\end{array}$ & $\begin{array}{l}\text { Vaaland and } \\
\text { Owusu, 2012; } \\
\text { Page 160. }\end{array}$ \\
\hline $\begin{array}{l}\text { Reverse } \\
\text { Logistics }\end{array}$ & $\begin{array}{l}\text { "The process of planning, implementing, and controlling the } \\
\text { efficient, cost effective flow of raw materials, in-process } \\
\text { inventory, finished goods and related information from the point } \\
\text { of consumption to the point of origin for the purpose of } \\
\text { recapturing value or proper disposal" (Glossary). }\end{array}$ & $\begin{array}{l}\text { Rogers and } \\
\text { Tibben- } \\
\text { Lembke, 1998; } \\
\text { Page 2. }\end{array}$ \\
\hline $\begin{array}{l}\text { Reverse } \\
\text { Supply } \\
\text { Chains }\end{array}$ & $\begin{array}{l}\text { "It's the series of activities required to retrieve a used product } \\
\text { from a customer and either dispose of it or reuse it." }\end{array}$ & $\begin{array}{l}\text { Guide and } \\
\text { Wassenhove, } \\
\text { 2002; Page 25. }\end{array}$ \\
\hline $\begin{array}{l}\text { Sustainable } \\
\text { Supply } \\
\text { Chains }\end{array}$ & $\begin{array}{l}\text { "The management of material, information and capital flows as } \\
\text { well as cooperation among companies along the supply chain } \\
\text { while taking goals from all three dimensions of sustainable } \\
\text { development, i.e., economic, environmental and social, into } \\
\text { account which are derived from customer and stakeholder } \\
\text { requirements." }\end{array}$ & $\begin{array}{l}\text { Seuring and } \\
\text { Müller, 2008a; } \\
\text { Page 1700. }\end{array}$ \\
\hline
\end{tabular}




\section{Appendix B}

Sub-section 2.3.4

Containerized commodities in tons, TEU and value of cargo

\begin{tabular}{|c|c|c|c|}
\hline Top 20 SITC $^{35}$ at two-digit level & $\begin{array}{c}\text { 000s } \\
\text { Tons }\end{array}$ & TEU & $\begin{array}{c}\text { TEU Value } \\
\text { (million } \\
\text { US\$) }\end{array}$ \\
\hline Electrical machinery, apparatus and appliances & 5.7 & 954 & 82 \\
\hline Telecommunications and sound-recording equipment & 2.9 & 855 & 85 \\
\hline Manufactures of metals & 7.3 & 840 & 25 \\
\hline Furniture & 4.1 & 752 & 19 \\
\hline Rubber manufactures & 2.2 & 703 & 11 \\
\hline Textile yarn, fabrics, and made-up articles & 3.3 & 617 & 18 \\
\hline Articles of apparel and clothing accessories & 3.4 & 569 & 68 \\
\hline Road vehicles parts & 7.8 & 561 & 34 \\
\hline Office machines and automatic data-processing machines & 2.3 & 552 & 102 \\
\hline Non-metallic mineral manufactures & 10.6 & 542 & 12 \\
\hline $\begin{array}{l}\text { Prefabricated buildings; sanitary, plumbing, heating and } \\
\text { lighting goods }\end{array}$ & 1.3 & 523 & 10 \\
\hline Footwear & 1.7 & 510 & 22 \\
\hline Travel goods, handbags and similar containers & 1.0 & 429 & 10 \\
\hline General industrial machinery and equipment & 3.2 & 322 & 33 \\
\hline Vegetables and fruit & 4.1 & 318 & 5 \\
\hline Machinery specialized for particular industries & 2.4 & 210 & 13 \\
\hline Fish (not marine mammals), crustaceans and molluscs & 1.5 & 198 & 6 \\
\hline Professional, scientific and controlling instruments & 0.4 & 184 & 25 \\
\hline Coffee, tea, cocoa, spices, and manufactures thereof & 1.5 & 182 & 4 \\
\hline Textile fibers and their wastes & 0.7 & 176 & 2 \\
\hline All others & 58.4 & 3,502 & 160 \\
\hline Grand Total & 125.8 & $\mathbf{1 3 , 5 0 0}$ & 744 \\
\hline
\end{tabular}

Source: Garratt and Teodoro (2013).

${ }^{35}$ Standard international trade classification 


\section{Appendix C}

Sub-section 3.1

\section{List of Search Keywords and Related Papers}

\begin{tabular}{|c|c|c|c|}
\hline \multicolumn{2}{|r|}{ Keyword } & Variants Searched & \multirow{2}{*}{$\begin{array}{c}\begin{array}{c}\text { Papers } \\
\text { (Nos.) }\end{array} \\
19\end{array}$} \\
\hline \multirow{4}{*}{\multicolumn{2}{|c|}{ 1. Closed-Loop Supply Chains }} & 1.1. Closed Loop Supply Chain & \\
\hline & & 1.2. Closed Loop Supply Chains & 4 \\
\hline & & 1.3. Closed-Loop Supply Chain & 68 \\
\hline & & 1.4. Closed-Loop Supply Chains & 30 \\
\hline \multirow{4}{*}{\multicolumn{2}{|c|}{ 2. Eco-Logistics }} & 2.1. Eco Logistic & - \\
\hline & & 2.2. Eco-Logistic & - \\
\hline & & 2.3. Eco Logistics & - \\
\hline & & 2.4. Eco-Logistics & 1 \\
\hline \multirow{4}{*}{\multicolumn{2}{|c|}{ 3. Eco-Supply Chains }} & 3.1. Eco Supply Chain & - \\
\hline & & 3.2. Eco Supply Chains & - \\
\hline & & 3.3. Eco-Supply Chain & 1 \\
\hline & & 3.4. Eco-Supply Chains & - \\
\hline \multirow{2}{*}{\multicolumn{2}{|c|}{$\begin{array}{l}\text { 4. Environmentally Friendly } \\
\text { Logistics }\end{array}$}} & 4.1. Environmentally Friendly Logistic & - \\
\hline & & 4.2. Environmentally Friendly Logistics & - \\
\hline \multirow{2}{*}{\multicolumn{2}{|c|}{$\begin{array}{l}\text { 5. Environmentally Friendly Supply } \\
\text { Chains }\end{array}$}} & 5.1. Environmentally Friendly Supply Chain & - \\
\hline & & 5.2. Environmentally Friendly Supply Chains & - \\
\hline \multirow{2}{*}{\multicolumn{2}{|c|}{ 6. Green Logistics }} & 6.1. Green Logistic & - \\
\hline & & 6.2. Green Logistics & 29 \\
\hline \multirow{2}{*}{\multicolumn{2}{|c|}{ 7. Green Reverse Logistics }} & 7.1. Green Reverse Logistic & - \\
\hline & & 7.2. Green Reverse Logistics & - \\
\hline \multirow{2}{*}{\multicolumn{2}{|c|}{ 8. Green Reverse Supply Chains }} & 8.1. Green Reverse Supply Chain & - \\
\hline & & 8.2. Green Reverse Supply Chains & - \\
\hline \multirow{2}{*}{\multicolumn{2}{|c|}{ 9. Green Supply Chains }} & 9.1. Green Supply Chain & 120 \\
\hline & & 9.2. Green Supply Chains & 6 \\
\hline \multirow{2}{*}{\multicolumn{2}{|c|}{ 10. Responsible Supply Chains }} & 10.1. Responsible Supply Chain & 2 \\
\hline & & 10.2. Responsible Supply Chains & - \\
\hline \multirow{2}{*}{\multicolumn{2}{|c|}{ 11. Reverse Logistics }} & 11.1. Reverse Logistic & 8 \\
\hline & & 11.2. Reverse Logistics & 328 \\
\hline \multirow{2}{*}{\multicolumn{2}{|c|}{ 12. Reverse Supply Chains }} & 12.1. Reverse Supply Chain & 22 \\
\hline & & 12.2. Reverse Supply Chains & 9 \\
\hline \multirow{2}{*}{\multicolumn{2}{|c|}{ 13. Sustainable Supply Chains }} & 13.1. Sustainable Supply Chain & 35 \\
\hline & & 13.2. Sustainable Supply Chains & 16 \\
\hline \multicolumn{3}{|c|}{ Number of searches } & 32 \\
\hline \multirow{2}{*}{\multicolumn{3}{|c|}{$\begin{array}{ll}\text { A. } & \text { Total number of papers } \\
\text { B. } & \text { Papers containing two kevwords }\end{array}$}} & 698 \\
\hline \multicolumn{2}{|c|}{ B. Papers containing two keywords } & & 65 \\
\hline \multicolumn{3}{|c|}{$\begin{array}{l}\text { Papers containing three keywords } \\
\text { Number of unioge naners }(\mathbf{A}-\mathbf{B}-2 * \mathbf{C})\end{array}$} & 2 \\
\hline & Number of unique papers & $(A-B-2 * C)$ & 629 \\
\hline
\end{tabular}




\section{Appendix D \\ Sub-section 4.1 \\ List of Other Disciplines}

1. Agricultural and Biological Sciences

2. Arts and Humanities

3. Biochemistry, Genetics and Molecular Biology

4. Chemical Engineering

5. Earth and Planetary Sciences

6. Energy

7. Materials Science

8. Mathematics

9. Medicine

10. Multidisciplinary

11. Physics and Astronomy

12. Psychology

13. Veterinary 


\section{Appendix E}

Sub-section 7.3

\section{Explanation of the term in equation 7.10a}

Considering a model with multiple shipments from a single production lot based on consumption like Goyal (1988) or Hill (1999) (refer Appendix F for Braglia and Zavanella, 2003) one has to take into consideration that the transport cost increases with every subsequent shipment to the buyer. Transport cost to a buyer's $1^{\text {st }}$ shipment $i=1$, in the first vendor cycle, $n=1$, would be $A_{i}=A_{0}+A_{1}(i-1) \frac{q}{D}=A_{0}$, the transport cost of the second shipment would be $A_{0}+A_{1} \frac{q}{D}$, and the transport cost of the third shipment would be $A_{0}+2 A_{1} \frac{q}{D}$, etc. Therefore, if the vendor sends $\lambda$ shipment to the buyer, then the cost of the $\lambda^{\text {th }}$ shipment would be $A_{0}+(\lambda-1) A_{1} \frac{q}{D}$. In a vendor's cycle, the total shipping cost is $\lambda A_{0}+\sum_{i=1}^{\lambda}(i-1) A_{1} \frac{q}{D}=\lambda A_{0}+\frac{\lambda-1}{2} \lambda A_{1} \frac{q}{D}$. In the second vendor cycle, $n=2$, the total shipping cost is $\lambda A_{0}+\sum_{i=\lambda+1}^{2 \lambda}(i-1) A_{1} \frac{q}{D}=$ $\lambda A_{0}+\sum_{i=1}^{2 \lambda}(i-1) A_{1} \frac{q}{D}-\sum_{i=1}^{\lambda}(i-1) A_{1} \frac{q}{D}=\lambda A_{0}+A_{1} \frac{2 \lambda(2 \lambda-1)-\lambda(\lambda-1)}{2} \frac{q}{D}$, with the general expression for the total shipping cost in the vendor's cycle $n$ can be written as $\lambda A_{0}+\sum_{i=1}^{n \lambda}(i-1) A_{1} \frac{q}{D}-\sum_{i=1}^{(n-1) \lambda}(i-1) A_{1} \frac{q}{D}=\quad \lambda A_{0}+A_{1} \frac{q}{D}\left\{\frac{n \lambda(n \lambda-1)-\lambda(n-1)(\lambda(n-1)-1)}{2}\right\}$
$=\lambda A_{0}+A_{1} \frac{q}{D} \frac{\lambda(2 n \lambda-\lambda-1)}{2}$

Therefore, the average transport cost for a shipment $=A_{0}+A_{1} \frac{q}{D} \frac{(2 n \lambda-\lambda-1)}{2}$ 


\section{Appendix F}

Sub-section 7.3

\section{Explanation of the term in equation 7.11a}

In case of Braglia and Zavanella's model (2003), the shipments from a production lot take place based on production of a shipment lot $(q)$ and there is an interval between the last shipment from a production lot and the first shipments from the following production lot. The method for calculating transport cost for $n^{\text {th }}$ production cycles and $i^{\text {th }}$ shipment, where $\lambda$ is the total shipments from a production lot, is given below:

Production Cycle (n) Shipment (i) Transport Cost

1

$$
\begin{aligned}
& 1 \\
& 2 \\
& 3 \\
& 4 \\
& \\
& \\
& \\
& \\
& \lambda
\end{aligned}
$$

$A_{0}$

$$
A_{0}+A_{1} \frac{q}{P}
$$$$
A_{0}+2 A_{1} \frac{q}{P}
$$$$
A_{0}+3 A_{1} \frac{q}{P}
$$$$
A_{0}+(\lambda-1) A_{1} \frac{q}{P}
$$

For $n=1$, average cost per shipment $=\frac{1}{\lambda}\left[\lambda A_{0}+\frac{\lambda(\lambda-1)}{2} A_{1} \frac{q}{P}\right]=A_{0}+\frac{(\lambda-1)}{2} A_{1} \frac{q}{P}$

$$
\begin{array}{ll}
1 & A_{0}+A_{1} \frac{\lambda q}{D} \\
2 & A_{0}+A_{1} \frac{\lambda q}{D}+A_{1} \frac{q}{P} \\
3 & A_{0}+A_{1} \frac{\lambda q}{D}+2 A_{1} \frac{q}{P} \\
4 & A_{0}+A_{1} \frac{\lambda q}{D}+3 A_{1} \frac{q}{P} \\
\ldots . & \ldots . \\
\lambda & A_{0}+A_{1} \frac{\lambda q}{D}+(\lambda-1) A_{1} \frac{q}{P}
\end{array}
$$


For $n=2$, average cost per shipment $=A_{0}+A_{1} \frac{\lambda q}{D}+\frac{(\lambda-1)}{2} A_{1} \frac{q}{P}$

$$
\begin{array}{ll}
3 & A_{0}+2 A_{1} \frac{\lambda q}{D} \\
2 & A_{0}+2 A_{1} \frac{\lambda q}{D}+A_{1} \frac{q}{P} \\
3 & A_{0}+2 A_{1} \frac{\lambda q}{D}+2 A_{1} \frac{q}{P} \\
4 & A_{0}+2 A_{1} \frac{\lambda q}{D}+3 A_{1} \frac{q}{P} \\
\cdots & \cdots \\
\lambda & A_{0}+2 A_{1} \frac{\lambda q}{D}+(\lambda-1) A_{1} \frac{q}{P}
\end{array}
$$

For $n=3$, average cost per shipment $=A_{0}+A_{1} \frac{2 \lambda q}{D}+\frac{(\lambda-1)}{2} A_{1} \frac{q}{P}$

General expression for average cost per shipment $=A_{0}+(n-1) \lambda A_{1} \frac{q}{D}+\frac{(\lambda-1)}{2} A_{1} \frac{q}{P}$ 


\section{REFERENCES}

Abbasi, M., \& Nilsson, F. (2012). Themes and challenges in making supply chains environmentally sustainable. Supply chain management, 17(5), 517-530.

Ahi, P., \& Searcy, C. (2013a). A stochastic approach for sustainability analysis under the green economics paradigm. Stochastic Environmental Research and Risk Assessment, 1-11.

Ahi, P., \& Searcy, C. (2013b). A comparative literature analysis of definitions for green and sustainable supply chain management. Journal of Cleaner Production, 52(1), 329-341.

Andersen, O., Gössling, S., Simonsen, M., Walnum, H.J., Peeters, P., \& Neiberger, C. (2010). $\mathrm{CO}_{2}$ emissions from the transport of China's exported goods. Energy Policy, 38(10), 5790-5798.

Ashby, A., Leat, M., \& Hudson-Smith, M. (2012). Making connections: a review of supply chain management and sustainability literature. Supply Chain Management: An International Journal, $17(5), 497-516$.

ATRI (2013). ATRI-An Analysis of the Operational Costs of Trucking: A 2012 Update, ATRI. Retrieved May 30, 2013 from http://atrionline.org/?s=An+Analysis+of+the+Operational+Costs+of+Trucking\%3A+2012+Update\&searc hsubmit=.

Avi-Yonah, R., \& Uhlmann, D. (2009). Combating global climate change: Why a carbon tax is a better response to global warming than cap and trade. Stanford Environmental Law Journal, 28(1), 3-50.

Bahrami, B. (2009). A look at outsourcing offshore. Competitiveness Review: An International Business Journal incorporating Journal of Global Competitiveness, 19(3), 212-212.

Banbury, J.G. (1975). Distribution - the final link in the electricity-supply chain. Electronics and Power, 21(13), 773.

Banerjee, A. (1986). A joint economic-lot-size model for purchaser and vendor. Decision Sciences, 17(3), 292-311.

Beamon, B.M. (1999). Designing the green supply chain. Logistics Information Management, 12(4), 332-342.

Beamon, B.M. (2005). Environmental and sustainability ethics in supply chain management. Science and Engineering Ethics, 11(2), 221-234.

Benjaafar, S., Li, Y., \& Daskin, M. (2013). Carbon Footprint and the Management of Supply Chains: Insights From Simple Models. IEEE Transactions on Automation Science and Engineering, 10(1), 99-116. 


\section{References}

Beškovnik, B., \& Jakomin, L. (2010). Challenges of green logistics in Southeast Europe. Promet - Traffic - Traffico, 22(2), 147-155.

Bocken, N.M.P., \& Allwood, J.M. (2012). Strategies to reduce the carbon footprint of consumer goods by influencing stakeholders. Journal of Cleaner Production, 35, 118-129.

Bonney, M. (2009). Inventory planning to help the environment. Inventory management: NonClassical Views, Jaber, M. Y. (Ed.), (pp. 43-74), ISBN: 978-1-4200-7998-2 CRC Press.

Bonney, M., \& Jaber, M.Y. (2011). Environmentally responsible inventory models: Nonclassical models for a non-classical era. International Journal of Production Economics, 133(1), 43-53.

BP, (2011). Statistical Review of World Energy 2011, BP. Retrieved 16 April 2012 from http://www.bp.com/en/global/corporate/about-bp/statistical-review-of-world-energy-2011.html.

BP, (2012). Statistical Review of World Energy 2012. BP. Retrieved Dec 29, 2012 from http://www.bp.com/assets/bp_internet/globalbp/globalbp_uk_english/reports_and_publications/st atistical_energy_review_2011/STAGING/local_assets/pdf/statistical_review_of_world_energy_f ull_report_2012.pdf.

Braglia, M., \& Zavanella, L. (2003). Modelling an industrial strategy for inventory management in supply chains: The 'consignment stock' case. International Journal of Production Research, 41(16), 3793-3808.

Brainard, J., Bateman, I.J., \& Lovett, A.A. (2009). The social value of carbon sequestered in Great Britain's Woodlands. Ecological Economics, 68(4), 1257-1267.

Briggs, B. (2005). Offshore outsourcing poses risks. Health data management, 13(2), 68-72.

British Columbia (2013). Ministry of Finance - Province of British Columbia. Retrieved 17 Dec 2013 from http://www.fin.gov.bc.ca/tbs/tp/climate/A4.htm.

Bruvoll, A., \& Larsen, B.M. (2004). Greenhouse gas emissions in Norway: Do carbon taxes work? Energy Policy, 32(4), 493-505.

Burgess, K., Singh, P.J., \& Koroglu, R. (2006). Supply chain management: a structured literature review and implications for future research. International Journal of Operations \& Production Management, 26(7), 703-729.

Burniaux, J.M., Chateau, J. \& Duval, R. (2013). Is there a case for carbon-based border tax adjustment? An applied general equilibrium analysis. Applied Economics, 45(16), 2231.

Burns, J.F. \& Sivazlian, B.D. (1978). Dynamic analysis of multi-echelon supply systems. Computers and Industrial Engineering, 2(4), 181-193.

Buxey G. (2000). Strategies in an era of global competition. International Journal of Operations \& Production Management, 20(9), 997-1016. 
Cadarso, M-A., López, L-A., Gómez, N., \& Tobarra, M-A. (2010). CO 2 emissions of international freight transport and offshoring: Measurement and allocation. Ecological Economics, 69(8), 1682-1694.

Carbontax (2014), Carbon Tax Center. Carbon Tax Center. Retrieved April 7, 2014 from http://www.carbontax.org/progress/where-carbon-is-taxed.

Carter, C.R., \& Easton, P.L. (2011). Sustainable supply chain management: evolution and future directions. International Journal of Physical Distribution \& Logistics Management, 41(1), 4662.

Carter, C.R., \& Rogers, D.S. (2008). A framework of sustainable supply chain management: moving toward new theory. International Journal of Physical Distribution \& Logistics Management, 38(5), 360-387.

Chaabane, A., Ramudhin, A., \& Paquet, M. (2012). Design of sustainable supply chains under the emission trading scheme. International Journal of Production Economics, 135(1), 37-49.

Chang, T., \& Hu, J. (2010). Total-factor energy productivity growth, technical progress, and efficiency change: An empirical study of China. Applied Energy, 87(10), 3262-3270.

Chen, X., Benjaafar, S., \& Elomri, A. (2013). The Carbon-Constrained EOQ. Operations Research Letters, 41(2), 172-179.

Choi, Y., Zhang, N., \& Zhou, P. (2012). Efficiency and abatement costs of energy-related $\mathrm{CO}_{2}$ emissions in China: A slacks-based efficiency measure. Applied Energy, 98, 198-208.

Choi, T. (2013). Local Sourcing and Fashion Quick Response System: The Impacts of Carbon Footprint Tax. Transportation research Part E, 55, 43-54.

Cleetus, R. (2011). Finding common ground in the debate between carbon tax and cap-and-trade policies. Bulletin of the Atomic Scientists, 67(1), 19-27.

Cooke, B. (2004). HR/Benefits Outsourcing: Updating the Conventional Thinking. Employee Benefit Plan Review, 58(8), 18.

Corbey, M., \& Jansen, E. (1993). The economic lot-size and relevant costs. International Journal of Production Economics, 30(1), 519-530.

Costanza, R., \& Daly, H.E. (1992). Natural capital and sustainable development. Conservation Biology, 6(1), 37-46.

Crist, P. (2009). Greenhouse gas emissions reduction potential from international shipping. OECD Discussion Paper No. 2009-11.

Cristea, A., Hummels, D., Puzzello, L., \& Avetisyan, M. (2013). Trade and the greenhouse gas emissions from international freight transport. Journal of Environmental Economics and Management, 65(1), 153-173. 
CSCMP, (2013). Supply Chain Management. Council of Supply Chain Management Professionals. Retrieved May 3, 2013 from http://cscmp.org/about-us/supply-chainmanagement-definitions.

CSCSC (2014). Supply Chain Definitions. Canadian Supply Chain Sector Council. Retrieved April 19, 2014 from http://www.supplychaincanada.org/en/supply-chain.

Dagher, L., \& Yacoubian, T. (2012). The causal relationship between energy consumption and economic growth in Lebanon. Energy Policy, 50, 795.

Dalsøren, S.B., Eide, M.S., Endresen, Ø., Mjelde, A., Gravir, G., \& Isaksen, I.S.A. (2009). Update on emissions and environmental impacts from the international fleet of ships: The contribution from major ship types and ports. Atmospheric Chemistry and Physics, 9(6), 21712194.

Daly, H.E. (1990). Toward some operational principles of sustainable development. Ecological Economics, 2(1), 1-6.

Davis, S.J., Peters, G.P., \& Caldeira, K. (2011). The supply chain of $\mathrm{CO}_{2}$ emissions. Proceedings of the National Academy of Sciences of the United States of America, 108(45), 18554-18559.

De Freitas, L.C., \& Kaneko, S. (2011). Decomposition of $\mathrm{CO}_{2}$ emissions change from energy consumption in Brazil: Challenges and policy implications. Energy Policy, 39, 1495-1504.

De Laet, C. (1985). Developing networks and institutions in support of sustainable development. Landscape Planning, 12(3), 301-309.

Deloitte, (2013). Global Powers of Retailing 2013. Deloitte. Retrieved 11 July 2013 from https://www.deloitte.com/view/en_GX/global/industries/consumerbusiness/retail/a336253eda30c310VgnVCM2000003356f70aRCRD.htm.

Destouni, G., \& Frank, H. (2010). Renewable Energy. Ambio, 39, 18-21.

Dey, A., LaGuardia, P., \& Srinivasan, M. (2011). Building sustainability in logistics operations: A research agenda. Management Research Review, 34(11), 1237-1259.

Dube, A.S., \& Gawande, R.R. (2012). A review on green supply chain management. International Journal of Computer Applications, 10.

ECFR, (2013). Electronic Code of Federal Regulations. ECFR - Code of Federal Regulations. Retrieved 23 Apr. 2013 from http://www.ecfr.gov/cgi-bin/textidx?c=ecfr \&SID=7d5b4b07a299df765ea0353bea3a981f\&rgn=div5\&view=text\&node=40:34.0.1 $.1 .4 \&$ idno $=40$.

Elliott, J., Foster, I., Kortum, S., Munson, T., Cervantes, F.P., \& Weisbach, D. (2010). Trade and Carbon Taxes. The American Economic Review, 100(2), 465-465. 
Endresen, Ø., Sørgård, E., Sundet, J.K., Dalsøren, S.B., Isaksen, I.S.A., Berglen, T.F., \& Gravir, G. (2003). Emission from international sea transportation and environmental impact. Journal of Geophysical Research D: Atmospheres, 108(17), ACH 14-1 - ACH 14-22.

EPA (2013a). Energy/carbon Taxes. Environmental Protection Agency. Retrieved Jan 14, 2013, from

http://yosemite.epa.gov/ee/epa/eed.nsf/eacd459aaeabd8ce8525766200639df1/50a39751d15c4eb $785257746000 a f f 6 c$.

EPA (2013b). Global Emissions. US Environmental Protection Agency. Retrieved Jan 18, 2013 from http://www.epa.gov/climatechange/ghgemissions/global.html.

EPI (The Economic Policy Institute), (2007), Economic Policy Institute. Retrieved July 8, 2013 from http://www.epi.org/publication/ib235.

Erol, I., Velioğlu, M.N., Şerifoğlu, F.S., Büyüközkan, G., Aras, N., Çakar, N.D., \& Korugan, A. (2010). Exploring reverse supply chain management practices in Turkey. Supply Chain Management: An International Journal, 15(1), 43-54.

Ertogral, K., Darwish, M., \& Ben-Daya, M. (2007). Production and shipment lot sizing in a vendor-buyer supply china with transportation cost. European Journal of Operational Research, $176(3), 1592-1606$.

European Commission, The, (1999). Directorate-General Transport 1999, Meet: methodology for calculating transport emissions and energy consumption. ISBN: 92-828-6785-4.

European Commission, The, (2014). Reducing Emissions from the Shipping Sector. European Commission. Retrieved Jan 11, 2014 from http://ec.europa.eu/clima/policies/transport/shipping/index_en.htm.

Eyring, V., Stevenson, D.S., Isaksen, I.S.A., Berntsen, T., Collins, W.J., Corbett, J.J., \& Schlager, H. (2010). Transport impacts on atmosphere and climate: Shipping. Atmospheric Environment, 44(37), 4735-4771.

Feller, A., Shunk, D., \& Callarman, T. (2006). Value chains versus supply chains. BPTrends, March 2006.

Flapper, S.D.P., Nunen, J.A.E.E.v., \& Wassenhove, L.N.V. (2005). Managing closed-loop supply chains. (eBook).

Fthenakis, V.M., \& Kim, H.C. (2011) Photovoltaics: Life-cycle analyses. Solar Energy, 85(8), 1609-1628.

Galli, A., Wiedmann, T., Ercin, E., Knoblauch, D., Ewing, B., \& Giljum, S. (2012). Integrating ecological, carbon and water footprint into a "footprint family" of indicators: Definition and role in tracking human pressure on the planet. Ecological Indicators, 16, 100-112. 


\section{References}

Garratt, M., \& Teodoro, A. (2013). Too many eggs in too few baskets? MDS Transmodal. Retrieved Dec 6, 2013 from http://www.mdst.co.uk/articles/downloads .

Gater, L. (2002). Everyone benefits from outsourcing medical services. Corrections Forum, $11(5), 37$.

Gerlagh, R., \& Lise, W. (2005). Carbon taxes: A drop in the ocean, or a drop that erodes the stone? The effect of carbon taxes on technological change. Ecological Economics, 54(2), 241260.

GHG Protocol (Greenhouse Gas Protocol), (2012). Greenhouse Gas Protocol. Retrieved May 24, 2012 from http://www.ghgprotocol.org/.

Gilbert, P., \& Bows, A. (2012). Exploring the scope for complementary sub-global policy to mitigate $\mathrm{CO}_{2}$ from shipping. Energy Policy, 50, 613-622.

Gimenez, C., \& Tachizawa, E.M. (2012). Extending sustainability to suppliers: a systematic literature review. Supply Chain Management: An International Journal, 17(5), 531-543.

Glavič, P., \& Lukman, R. (2007). Review of sustainability terms and their definitions. Journal of Cleaner Production, 15(18), 1875-1885.

Glock, C.H. (2012). The joint economic lot-size problem: A review. International Journal of Production Economics, 135(2), 671-686.

Goulder, L.H., \& Mathai, K. (2000). Optimal $\mathrm{CO}_{2}$ Abatement in the Presence of Induced Technological Change. Journal of Environmental Economics and Management, 39(1), 1-38.

Goyal, S. K. (1988). A joint economic-lot-size model for purchaser and vendor: a comment', Decision Sciences, 19(1), 236-241.

Goyal, S.K. (1977). An integrated inventory model for a single supplier-single customer problem. International Journal of Production Research, 15(1), 107-111.

Goyal, S.K., \& Szendrovits, A.Z. (1986). A constant lot-size model with equal and unequal sized batch shipments between production stages. Engineering Costs and Production Economics, 10(1), 203-210.

Greening, L.A., Greene, D.L., \& Difiglio, C. (2000). Energy efficiency and consumption — the rebound effect - a survey. Energy Policy, 28(6), 389-401.

Guide, V.D.R., \& Wassenhove, L.N.V. (2002). The reverse supply chain. Harvard Business Review, 80(2), 25.

Guide, V.D.R., \& Wassenhove, L.N.V. (2009). The evolution of closed-loop supply chain research. Operations Research, 57(1), 10-18. 


\section{References}

Guide, V.D.R., Harrison, T.P., \& Wassenhove, L.N.V. (2003). The Challenge of Closed-Loop Supply Chains. Interfaces, 33(6), 3-6.

Gutés, C. M. (1996). The concept of weak sustainability. Ecological Economics, 17(3), 147-156.

Harris, F.W. (1913). How many parts to make at once. Factory, The Magazine of Management, $10(2), 135-136, \& 152$.

Hassellöv, I.-M., Turner, D.R., Lauer, A., \& Corbett, J.J. (2013). Shipping contributes to ocean acidification. Geophysical Research Letters, 40(11), 2731-2736.

Hassini, E., Surti, C., \& Searcy, C. (2012). A literature review and a case study of sustainable supply chains with a focus on metrics. International Journal of Production Economics, 140(1), 69-82.

Heitmann, N., \& Khalilian, S. (2011). Accounting for carbon dioxide emissions from international shipping: Burden sharing under different UNFCCC allocation options and regime scenarios. Marine Policy, 35(5), 682-691.

Herrmann, I.T., \& Hauschild, M.Z. (2009). Effects of globalisation on carbon footprints of products. CIRP Annals - Manufacturing Technology. 58(1), 13-16.

Hill, M.R. (2001). Sustainability, greenhouse gas emissions and international operations management. International Journal of Operations \& Production Management, 21(12), 15031520 .

Hill, R.M. (1997). The single-vendor single-buyer integrated production-inventory model with a generalised policy. European Journal of Operational Research, 97(3), 493-499.

Hill, R.M. (1999). The optimal production and shipment policy for the single-vendor single buyer integrated production-inventory problem. International Journal of Production Research, $37(11), 2463-2475$.

Howitt, O.J.A, Carruthers, M.A., Smith, I.J., \& Rodger, C.J. (2011). Carbon dioxide emissions from international air freight. Atmospheric Environment, 45(39), 1352-2310

Hua, G., Cheng, T.C.E., \& Wang, S. (2011). Managing carbon footprints in inventory management. International Journal of Production Economics, 132(2), 178-185.

Hubbert, M.K. (1949). Energy from fossil fuels. Science, 109(2823), 103-109.

Hubbert, M.K. (1956). Nuclear Energy and the Fossil Fuels. Presented Before the Spring Meeting of the Southern District. American Petroleum Institute, Plaza Hotel, San Antonio, Texas, March 7-8-9, 1956.

Hueting, R. (2011). Sustainable national income: Information for attaining sustainability. Management Research Review, 34(11), 1190-1201. 


\section{References}

Hutchins, M.J., \& Sutherland, J.W. (2008). An exploration of measures of social sustainability and their application to supply chain decisions. Journal of Cleaner Production, 16(15), 16881698.

IATA, (2013). IATA Fact Sheet: Fuel. Retrieved Aug 28, 2013 from http://www.iata.org/pressroom/facts_figures/fact_sheets/pages/fuel.aspx.

ICS, (2013). International Chamber of Commerce-Comparison of CO2 emissions by different modes of transportation. Retrieved 18 Dec 2013 from http://www.ics-shipping.org/shippingfacts/environmental-performance/comparison-of-co2-emissions-by-different-modes-of-transport.

IEA, (2010). Key World Energy Statistics-2010. IEA. Retrieved Mar 20, 2012 from http://www.tsl.uu.se/uhdsg/Data/IEA_Key_Stats/IEA2010.pdf.

IEA, (2011). IEA. Retrieved May 15, 2012 from http://www.iea.org.

Ilgin, M.A., \& Gupta, S.M. (2010). Environmentally conscious manufacturing and product recovery (ECMPRO): A review of the state of the art. Journal of Environmental Management, 91(3), 563-591.

IMO, (2013). Introduction to IMO-The International Maritime Organization. Retrieved Aug 16, 2013 from http://www.imo.org/About/Pages/Default.aspx.

InflationData, (2013). Historical oil prices: InflationData.com Retrieved Aug 10, 2013 from http://inflationdata.com/Inflation/Inflation_Rate/Historical_Oil_Prices_Table.asp.

ITC, (2012). ITC. Retrieved May 15, 2012 from http://www.intracen.org.

Iveco (2013). Iveco Electric: New Daily Electric the future of urban transportation. Retrieved Aug 12, 2013, from http://web.iveco.com/uk/products/pages/daily_electric_features_and_benefits.aspx.

Jaber M.Y., Glock C.H., \& El Saadany A.M.A. (2013). Supply chain coordination with emissions reduction incentives. International journal of production research, 51(1), 69-82.

Jaber, M.Y., \& Zolfaghari, S. (2008). Quantitative Models for Centralised Supply Chain Coordination. Supply Chain, Vedran Kordic (Ed.), ISBN: 978-3-902613-22-6, InTech.

Jacobs, P. (1985). A sustainable society through sustainable development: Towards a regional development strategy for northern Quebec. Landscape Planning, 12(3), 267-283.

Jaehn, F., \& Letmathe, P., 2010. The emissions trading paradox. European Journal of Operational Research, 202(1), 248-254.

Jeihani, M., \& Sibdari, S. (2010). The impact of gas price trends on vehicle type choice. Journal of Economics and Economic Education Research, 11(2), 1-11. 


\section{References}

JOC (2013). Top 100 Importers in 2012. JOC. Retrieved Jul 11, 2013 from http://www.joc.com/international-trade-news/trade-data/united-states-trade-data/top-100importers-2012_20130524.html.

Jones, T.C., \& Riley, D.W. (1985). Using inventory for competitive advantage through supply chain management. International Journal of Physical Distribution and Materials Management, 15(5), 16-26.

Kahai, S. K., \& Sara, T. S. (2011). Off-shoring and outsourcing. The Journal of Applied Business Research, 27(1), 113-121.

Kakumanu, P., \& Portanova, A. (2006). Outsourcing: Its Benefits, Drawbacks and Other Related Issues. Journal of American Academy of Business, Cambridge, 9(2), 1.

Khosla, A., Prakash, S., \& Revi, A. (1986). A transcultural view of sustainable development. The landscape of design. Landscape and Urban Planning, 13(C), 401-410.

Kim, I., \& Min, H. (2011). Measuring supply chain efficiency from a green perspective. Management Research Review, 34(11), 1169-1189.

Kim, S-T, Lee, S-Y. (2012). Stakeholder pressure and the adoption of environmental logistics practices. The International Journal of Logistics Management, 23(2), 238-258.

Kinkel, S. (2012). Trends in production relocation and backshoring activities: changing patterns in the course of the global economic crisis. International Journal of Operations \& Production Management, 32(6), 696.

Ko, H.J., \& Evans, G.W. (2007). A genetic algorithm-based heuristic for the dynamic integrated forward/reverse logistics network for 3PLs. Computers and Operations Research, 34(2), 346366.

Koh, S.C.L., Birkin, F., Lewis, L., \& Cashman, A. (2007). Current issues of sustainable production, eco-supply chains and eco-logistics for sustainable development. International Journal of Global Environmental Issues, 7(1), 88-101.

Koroneos, C., Spachos, T., \& Moussiopoulos N. (2003). Exergy analysis of renewable energy sources. Renewable Energy, 28(2), 295-310.

Kula, E., \& Gunalay, Y. (2012). Carbon sequestration, optimum forest rotation and their environmental impact. Environmental Impact Assessment Review, 37, 18-22.

Lamas, M.I., \& Rodríguez, C.G. (2012). Emissions from marine engines and NOx reduction methods. Journal of Maritime Research, 9(1), 77-82.

Lane J. (2011). $\mathrm{CO}_{2}$ emissions and GDP. International Journal of Social Economics, 38(11), 911-918. 


\section{References}

Lee, T., Chang, Y., \& Lee, P.T.W. (2013). Economy-wide impact analysis of a carbon tax on international container shipping. Transportation Research Part A: Policy and Practice, 58, 87102.

Lin, B., \& Li, X. (2011). The effect of carbon tax on per capita $\mathrm{CO}_{2}$ emissions. Energy Policy, 39(9), 5137-5146.

Lin, C., \& Chang, Y. (2009). The analysis of an extended average cost inventory model for reverse logistic planning. Journal of the Chinese Institute of Industrial Engineers, 26(3), 157-164.

Louca, S., \& Kokkinaki, A. (2011). Closed-loop supply chains in ICT: Best practices and challenges in Cyprus. Journal of Green Engineering, 1(2), 165-177.

Lowry, K., \& Carpenter, R.A. (1985). Institutionalizing sustainable development: Experiences in five countries. Environmental Impact Assessment Review, 5(3), 239-254.

Lu, Z., \& Bostel, N. (2007). A facility location model for logistics systems including reverse flows: The case of remanufacturing activities. Computers and Operations Research, 34(2), 299323.

Lummus, R.R., Krumwiede, D.W., \& Vokurka, R.J. (2001). The relationship of logistics to supply chain management: Developing a common industry definition. Industrial Management \& Data Systems, 101(8), 426-432.

Mallah S., \& Bansal N.K. (2012). Carbon tax and energy resource in Indian power sector. International Journal of Global Energy Issues, 35(5), 343-370.

Maruyama W.H. (2011). Climate Change and the WTO: Cap and Trade versus Carbon Tax? Journal of World Trade, 45(4), 679-726.

Mentzer, J. T., DeWitt, W., Keebler, J.S., Min, S., Nix, N.W., Smith, C.D., \& Zacharia, Z.G. (2001). Defining supply chain management. Journal of Business Logistics, 22(2), 1-25.

Ministry of Environment, Finland, 2012. Finland's environmental administration environment.fi. Retrieved Jan 14, 2013 from http://www.environment.fi/default.asp?contentid=405927\&lan=EN.

Mollenkopf, D., Stolze, H., Tate, W.L., \& Ueltschy, M. (2010). Green, lean, and global supply chains. International Journal of Physical Distribution \& Logistics Management, 40(1-2), 14-41.

Notteboom, T.E., \& Vernimmen, B. (2009). The effect of high fuel costs on liner service configuration in container shipping. Journal of Transport Geography, 17(5), 325-337.

OECD, (2013a). OECD Glossary of Statistical Terms - Offshoring Definition. Retrieved Nov 22, 2013 from http://stats.oecd.org/glossary/detail.asp?ID=6271.

OECD, (2013b). Statistics. Retrieved May 14, 2013 from http://www.oecd-ilibrary.org/statistics. 
Olugu, E.U., Wong, K.Y., \& Shaharoun, A.M. (2011). Development of key performance measures for the automobile green supply chain. Resources, Conservation and Recycling, 55(6), 567-579.

Ontario Ministry of the Environment, (2013). Ministry of the Environment / Ministère de l'Environnement. Retrieved Jan 17, 2013, from

http://www.ene.gov.on.ca/environment/en/category/climate_change/STDPROD_078899.html\#tr ade.

Pan, S., Ballot, E., \& Fontane, F. (2013). The reduction of greenhouse gas emissions from freight transport by pooling supply chains. International Journal of Production Economics, 143(1), 8694.

Peters, G.P., 2008. From production-based to consumption-based national emission inventories. Ecological Economics, 65(1), 13-23.

Petroleum Times. (1951). New oil jetty is largest in Thames Estuary. Petroleum Times, 55(1399), 216.

Piecyk, M.I., \& McKinnon, A.C. (2010). Forecasting the carbon footprint of road freight transport in 2020. International Journal of Production Economics, 128(1), 31-42.

Reyes, O., \& Gilbertson, T. (2010). Carbon trading: how it works and why it fails: carbon trading is not the answer to tackling climate change. Soundings, 45, 89.

Rodrigue, J-P., Comtois, C., \& Slack, B. (2013). The Geography of Transport Systems, Chapter 3, Transportation Modes: An Overview. Third Edition, New York: Routledge. ISBN: 978-0-41582254-1

Rogers, D.S., \& Tibben-Lembke, R.S. (1998). Going backwards: reverse logistics trends and practices. Reverse Logistics Executive Council (RLEC), Pittsburgh.

Rosic, H., \& Jammernegg, W. (2013). The economic and environmental performance of dual sourcing: A newsvendor approach. International Journal of Production Economics, 143(1), 109119.

Russell, R.M., \& Krajewski, L.J. (1991). Optimal purchase and transport cost lot sizing for a single item. Decision Science, 22(4), 940-952.

Sahin, B., Yilmaz, H., Ust, Y., Guneri, A.F. \& Gulsun, B. (2009). An approach for analysing transportation costs and a case study. European Journal of Operational Research, 193(1), 1-11.

Salema, M.I.G., Barbosa-Povoa, A.P., \& Novais, A.Q. (2007). An optimization model for the design of a capacitated multi-product reverse logistics network with uncertainty. European Journal of Operational Research, 179(3), 1063-1077.

Sarkis, J., Zhu, Q., \& Lai, K. (2011). An organizational theoretic review of green supply chain management literature. International Journal of Production Economics, 130(1), 1-15. 


\section{References}

Seuring, S., \& Müller, M. (2008a). From a literature review to a conceptual framework for sustainable supply chain management. Journal of Cleaner Production, 16(15), 1699-1710.

Seuring, S., \& Müller, M. (2008b). Core issues in sustainable supply chain management-a Delphi study. Business Strategy and the Environment, 17(8), 455-466.

Solar impulse, (2013). Solar Impulse - around the world in a solar airplane. Retrieved May 21, 2013 from http://www.solarimpulse.com/en/.

Srivastava, S.K. (2007). Green supply-chain management: A state-of-the-art literature review. International Journal of Management Reviews, 9(1), 53-80.

Stevens, G.C. (1989). Integrating the supply chain. International Journal of Physical Distribution \& Logistics Management, 19(8), 3-8.

Suhaimi, M.A., Hussin, H. \& Mustaffa, M. (2007). Information systems outsourcing: Motivations and the implementation strategy in a Malaysian bank. Business Process Management Journal, 13(5), 644-661.

Susomrith, P., \& Brown, A. (2013). Motivations for HR outsourcing in Australia. The International Journal of Human Resource Management, 24(4), 704.

Sweden Gov., (2014). Energy- and $\mathrm{CO}_{2}$-Taxation. Government office of Sweden. Retrieved Apr 7, 2014 from http://www.government.se/sb/d/16022/a/190032.

Swenseth, S.R., \& Godfrey, M.R. (2002). Incorporating transportation costs into inventory replenishment decisions. International Journal of Production Economics, 77(2), 113-130.

Taticchi, P., Tonelli, F., \& Pasqualino, R. (2013). Performance measurement of sustainable supply chains: A literature review and a research agenda. The International Journal of Productivity and Performance Management, 62(8), 782-804.

The Economist (2013). The Economist Newspaper. Retrieved Dec 5, 2013. From http://www.economist.com/blogs/economist-explains/2013/05/economist-explains-14.

Ubeda, S., Arcelus, F.J., \& Faulin, J. (2011). Green logistics at Eroski: A case study. International Journal of Production Economics, 131(1), 44-51.

Ulku, M. A. (2012). Dare to care: Shipment consolidation reduces not only costs, but also environmental damage. International Journal of Production Economics, 139(2), 438-446.

UN, (2014). The Intergovernmental Panel on Climate Change. Retrieved Apr 10, 2014 from http://www.un.org/climatechange/blog/category/ipcc/.

UNCTD (2012). Review of Maritime Transport, United Nations publication, New York, USA.

UNFCCC (2013a). Issues - bunker fuels. UNFCCC. Retrieved Jul 13, 2013 from http://unfccc.int/methods/emissions_from_intl_transport/items/1057.php. 
UNFCCC (2013b). GHG Emission Profiles. Retrieved Jul 16, 2013 from

http://unfccc.int/ghg_data/ghg_data_unfccc/ghg_profiles/items/3954.php.

University of Warwick (2013). Formula 3 Racing Car Powered by Chocolate and Steered by Carrots. Retrieved May 16, 2013 from

http://www2.warwick.ac.uk/newsandevents/pressreleases/racing_car.

US Census (2014). Foreign Trade: Data. Retrieved Jan 10, 2014 from http://www.census.gov/foreign-trade/Press-Release/ft920_index.html.

USDoT (2013). US Department of Transportation-Data and Statistics. Retrieved Dec 17, 2013 from

http://www.marad.dot.gov/library_landing_page/data_and_statistics/Data_and_Statistics.htm.

Vaaland, T.I., \& Owusu, R.A. (2012). What is a Responsible Supply Chain? International Journal of Business and Management, 7(4), 154.

Van der Zwaan, B., \& Rabl, A. (2004). The learning potential of photovoltaics: implications for Energy Policy. Energy Policy, 32, 1545-1554.

Varadarajan, R. (2009) Outsourcing: Think more expansively. Journal of Business Research, 62(11), 1165-1172.

Vlachos, D., Georgiadis, P., \& Iakovou, E. (2007). A system dynamics model for dynamic capacity planning of remanufacturing in closed-loop supply chains. Computers and Operations Research,34(2), 367-394.

Vöhringer, F., Grether, J., \& Mathys, N.A. (2013). Trade and Climate Policies: Do Emissions from International Transport Matter? The World Economy, 36(3), 280-302.

Volvo (2013). Volvo FE Hybrid. Retrieved Mar 21, 2013 from

http://www.volvotrucks.com/trucks/global/en-gb/trucks/new-trucks/Pages/volvo-fe-hybrid.aspx.

Wahab, M.I.M., Mamun, S.M.H., \& Ongkunaruk, P. (2011). EOQ models for a coordinated twolevel international supply chain considering imperfect items and environmental impact.

International Journal of Production Economics, 134(1), 151-158.

Wal-Mart (2006). Annual Reports. Walmart Corporate. Retrieved Jul 11, 2013 from http://stock.walmart.com/annual-reports.

Wal-Mart (2013). Walmart Announces New Commitments to Dramatically Increase Energy Efficiency and Renewables. Walmart Corporate. Retrieved Nov 25, 2013 from http://news.walmart.com/news-archive/2013/04/15/walmart-announces-new-commitments-todramatically-increase-energy-efficiency-renewables.

Wang, S., Meng, Q., \& Bell, M.G.H. (2013). Liner ship route capacity utilization estimation with a bounded polyhedral container shipment demand pattern, Transportation Research Part B:

Methodological, 47, 57-76. 


\section{References}

Wang, X., Li, J.F., \& Zhang, Y.X. (2012). A case for introducing an explicit carbon price into China's export tax. Climate Policy, 12(4), 410-423.

WCED (1987). Report of the World Commission on Environment and Development: Our Common Future. United Nations.

Wei, C., Ni, J., \& Sheng, M. (2011). China's energy inefficiency: A cross-country comparison. The Social Science Journal, 48(3), 478-488.

Westing, A.H. (1986). International cooperation for sustainable development and peace. Environmental Conservation, 13(2), 97-99.

Wittneben, B.B.F. (2009). Exxon is right: Let us re-examine our choice for a cap-and-trade system over a carbon tax. Energy Policy, 37(6), 2462-2464.

World Bank, The, (2013). The World Bank DataBank, World Development Indicators. Retrieved Jul 30, 2013 from http://databank.worldbank.org/data/views/reports/tableview.aspx.

World Shipping Council, (2013a). Facts About Serving US Export Commerce. Retrieved Dec 5, 2013 from

http://www.worldshipping.org/Facts_About_Serving_U_S_Export_Commerce__Feb_2010_2-.pdf.

World Shipping Council, (2013b). History of Containerization. Retrieved Dec 3, 2013 from http://www.worldshipping.org/about-the-industry/history-of-containerization.

World Shipping Council, (2013c). Containers. Retrieved Dec 5, 2013 from http://www.worldshipping.org/about-the-industry/containers.

World Shipping Council, (2013d). Top 50 World Container Ports. Retrieved Dec 17, 2013 from http://www.worldshipping.org/about-the-industry/global-trade/top-50-world-container-ports.

WTO (World Trade Organization, The), (2013). International Trade Statistics 2012. WTO. Retrieved Jul 21, 2013, from http://www.wto.org/english/res_e/statis_e/its2012_e/its12_toc_e.htm.

Wu, W-M. (2012). Capacity utilization and its determinants for a container shipping line: theory and evidence. Applied Economics, 44(27), 3491-3502.

Wu, Z., \& Pagell, M. (2011). Balancing priorities: Decision-making in sustainable supply chain management. Journal of Operations Management, 29(6), 577-590.

WWF (World Wide Fund For Nature) (2014). WWF Global-Marine problems:Shipping.

Retrieved May 3, 2014 from

http://wwf.panda.org/about_our_earth/blue_planet/problems/shipping/

Zanoni, S., \& Zavanella, L. (2009). Energy and inventories. Inventory management: NonClassical Views, Jaber, M. Y. (Ed.), (pp. 43-74), ISBN: 978-1-4200-7998-2 CRC Press. 


\section{References}

Zhang, C., Beck, M.B., \& Chen, J. (2013). Gauging the impact of global trade on China's local environmental burden. Journal of Cleaner Production, 54, 270-281.

Zhao, Q. Wnag, S., Lai, K.K., \& Xia, G. (2004). Model and algorithm of an inventory problem with the consideration of transportation cost. Computer \& Industrial Engineering, 46(2), 389397.

Zhu, Q., Sarkis, J., \& Lai, K.H. (2007). Green supply chain management: pressures, practices and performance within the Chinese automobile industry. Journal of Cleaner Production, 15(1112), 1041-1052.

Zhu, Q., Sarkis, J., \& Lai, K.H. (2008). Confirmation of a measurement model for green supply chain management practices implementation. International Journal of Production Economics, 111(2), 261-273. 


\section{ACRONYMS}

\begin{tabular}{|c|c|}
\hline Acronym & Description \\
\hline $\mathrm{Bn}$ & Billions \\
\hline $\mathrm{CNG}$ & Compressed Natural Gas \\
\hline $\mathrm{CO}_{2}$ & Carbon dioxide \\
\hline CSCSC & Canadian Supply Chain Sector Council \\
\hline CSR & Corporate social responsibility \\
\hline DWT & Dead weight tonnage \\
\hline EOQ & Economic order quantity \\
\hline ETS & Emissions Trading Schemes \\
\hline GDP & Gross Domestic Product \\
\hline GHG & Greenhouse gases \\
\hline GSCM & Green supply chain management \\
\hline IMO & The International Maritime Organization \\
\hline JELS & Joint economic lot-size \\
\hline JELSP & Joint economic lot-size problem \\
\hline MMT & Millions metric tons \\
\hline NEI & National emissions inventories \\
\hline NOx & A generic term for mono-nitrogen oxides $\mathrm{NO}$ and $\mathrm{NO}_{2}$ \\
\hline OECD & The Organization for Economic Co-operation and Development \\
\hline RPPP & Relative purchasing power parity \\
\hline $\mathrm{SCM}$ & Supply chain management \\
\hline SITC & Standard international trade classification \\
\hline SSCM & Sustainable supply chain management \\
\hline TBL & Triple bottom line \\
\hline TEU & Twenty-foot Equivalent Unit \\
\hline UN & United Nations \\
\hline UNFCCC & United Nations Framework Convention on Climate Change \\
\hline WTO & World Trade Organization \\
\hline
\end{tabular}

